

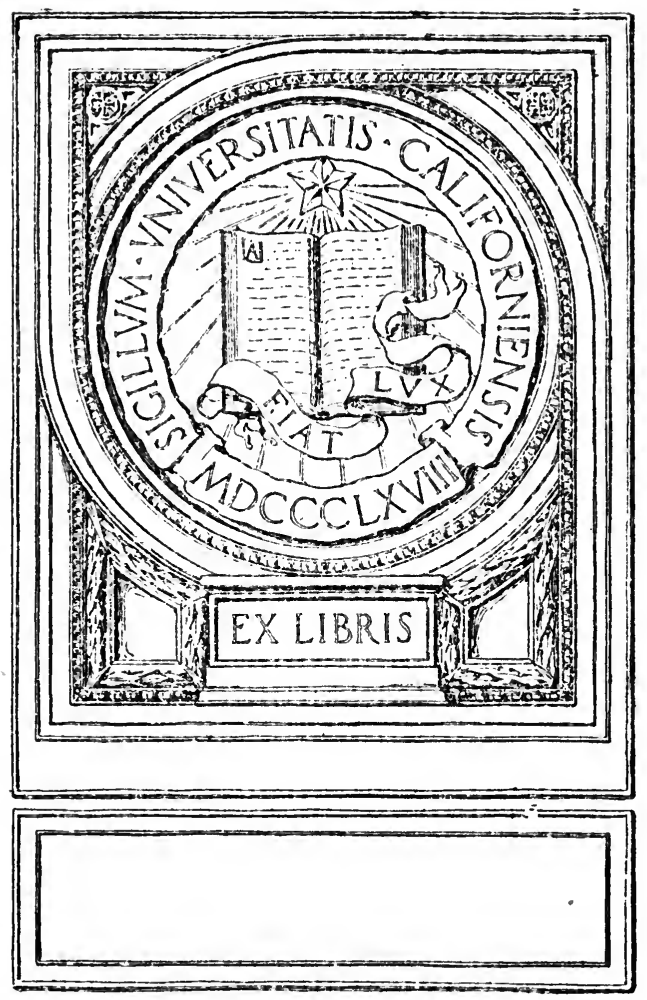




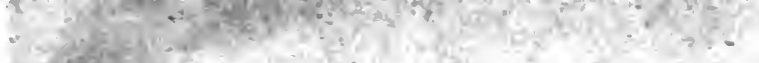

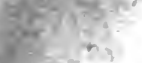

$$
\text { Es }
$$

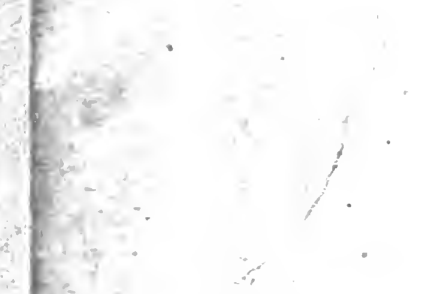

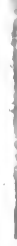

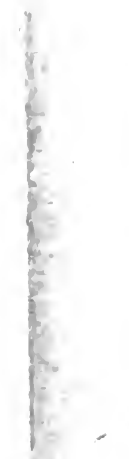


Digitized by the Internet Archive - in 2007 with funding from Microsoft Corporation 
THE FUNDAMENTAL PRINCIPLES OF LEARNING AND STUDY 


$$
\int_{1} I_{A}
$$




\title{
THE FUNDAMENTAL PRINCIPLES OF LEARNING AND STUDY
}

\author{
By \\ A. S. EDWARDS \\ Professor of Psychology \\ University of Georgia
}

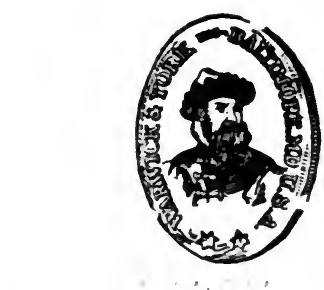

BALTIMORE

WARWICK \& YORK, Inc.

1920 
Copyright, 1920

By WARWICK \& YORK, Inc.

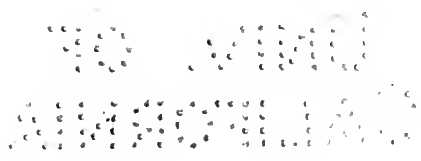


TO MY MOTHER

437589 



\section{THE FUNDAMENTAL PRINCIPLES OF LEARNING AND STUDY}

\section{Preface}

The present volume is a rewriting of manuscript which the writer has used for some time as part of his lectures to students in educational psychology. The aim is especially to show how the results of general psychology and experimental psychology and of allied sciences can be put into use by the teacher. and the student in the problems of learning and of study. In the chapters on Making the Appeal to the Student, and Attention and Sustained Effort, examples have been given from the writer's own studies and observations for the purpose of illustrating psychological principles involved and to suggest to teachers ways that have proved successful in the actual everyday work of the teacher.

The writer thinks that The Habit Theory has not received its due in educational practice and perhaps not in educational thought. It is a principle which runs through the whole work of education and the adoption of it as the fundamental working principle of the teacher's work should help to bring the definiteness that is needed. If habits, including habitudes, dispositions and attitudes, are not all the results that education can show, we can see what is left out after we do our duty to the first and fundamental things.

The general scheme of the book can be indicated by the following statement of some of the main thoughts: 1) The nature of education and of the educational process from the point of view of permanent results in the individual. 2) The necessity for permanent results of some kind and the nature of these results. 3) The process of learning, of making acquisitions which can be made more or less permanent and suggestions for the right direction of this learning process. 4) A discussion of how to make the best progress in learning. 5) The getting of not only specific but general improvement. 6) The factors that make for permanent results. 7.) Modes of appeal for the purpose of arousing and directing the desired activities. 8) The development through lower to higher stages of attention, activity, and effort. 9) The development of the emotional and moral nature for permanent results in moral character. 10) Physical and physiological conditions that are 
involved in learning and study. 11) The problem of how to study, teaching to study, and of putting supervised study into the school. 12) The need for definite ends of education and the possibility of using the principles and facts presented herein to help towards greater definiteness of aim, of procedure and of obtaining recognizable and measurable end results so that the work of education shall approach in definiteness the achievement of other big business enterprises.

The directions for students appearing in chapter 16 are practically unchanged from the early writing nearly three years ago.

References at the ends of chapters indicate books and articles that seem to the author to be most useful to the teacher if he wishes to choose from a large number of possible references. Others may be equally good, but a selected bibliography seems to be most valuable.

It is my pleasure and duty to acknowledge the helpful criticisms and suggestions of Dean L. D. Coffman, Professor N. Wilde, Professor H. H. Woodrow, Professor J. Peterson, and Mr. J. R. Kantor, of The University of Minnesota and of Professor H. W. Odun, of The University of Georgia.

\section{A. S. EDW $\Lambda$ RI)S.}

The Psychological Laboratory.

Peabody School of Education.

University of Georgia. 


\section{TABLE OF CONTENTS}

Chapter 1.

\section{FUNDAMENTAL PRINCIPLES OF EDUCATION.}

Pages 11-21

Purpose and point of view of writer. Habit a convenient term. Habit but not automatism. Habit fixes but it also releases. No justification for education which does not make permanent results. Education compares in importance with heredity. Importance of the habit theory. Habit in various fields of thought. Habit at bottom a matter of physics. Ideals and standards. Three great principles of education. The greatest needs of education.

\section{Chapter 2. \\ NEUROLOGY AND THE BASIS OF EDUCATION.}

Pages 22-36

The fundamental nature and importance of habit: Quotation from Dr. Carpenter. The modifications in the individual which result in habits make up his education. The work of the teacher. Sully on habit. Comprehensiveness of the habit theory as shown by Prof. Angell's Psychology. Habit is fundamental for the most complete kinds of thinking. Habit and originality. Habit and plasticity. Habit and the fixity of response. The danger of too much fixity. No necessary danger of losing plasticity through education. Flexibility depends partly on a variety of habits and a habit of choosing from among then. Variety of response a peculiarly human thing. Education and initiative. The varying strengths of habits. Types of habit: habit and habitude.

\section{Chapter 3.}

\section{THE FUNDAMENTAL WORK OF EDUCATION.}

Pages $37-50$

Habit is the basis of progress in learning. Progress to higher stages of efficiency. Progress and modifying the old habits. Education and the development of permanent desires and in- 
terests. The advantages of the habit theory: Fundamental nature and comprehensiveness of the theory. It gives definiteness to the work of the teacher. It gives the basis for scientific treatment and measurement. It reduces all education to the same terms. It emphasizes the psychological factors necessary to learning. The knowledge of habit formation reveals the manifold nature of the teacher's work. Other aims of education are included and defined. Disadvantage of the term habit. Judgments, ideas and habits. Ideals, the guiding influence of education. Ideals and achievement. The case of Dr. Brashear. Ideals as permanent motives in life. The controlling principle of education. Determination of the curriculum on the basis of activities which result in habits. Kinds of habits to be formed. Education as the formation and modification of habits under the guidance of ideals and the control of standards.

\section{Chapter 4.}

\section{LEARNING AND HABIT FORMATION.}

Pages $5 \mathrm{I}-62$

Life and habit formation. The need for habits. The effects of habits. The strong guiding influence of habit. Principles of habit formation: Learning correctly. Accuracy first, speed later. Helps to habit formation include:-Strong and decided initiative. Continuity of practice. Use of every opportunity. Caring enough and determination. A clear plan. The realization of value. Success and the feeling of success; mastery and the feeling of mastery. Suggestion. Publishing intentions. Penalties. Putting self on honor. Thoroughness. Hindrances to habit formation: Not caring enough. Laziness. Lack of incentive. Other habits. Difficulty and complexity. Unpleasantness. The pressure of time and other things. The tendency to feel without acting. The incomplete learning of other habits. Breaking old habits: Never permit the old habit to function. Remove the conditions and suggestions for the old habit. Develop a substitute habit. Penalties. A new ideal coupled with strong emotion. New demands and responsibilities. "Keep the faculty of effort alive." The habit of making new habits. 


\section{Chapter 5.}

\section{ACQUISITION WHICH INVOLVES STUDY.}

Pages $63-75$

The acquisition of knowledge. Association in all kinds of learning. Acquisition through the senses: observational learning. Factors that determine our perceptions: The object itself. The contents of consciousness. Mental habits. Physiological processes. Attention. Thoroughness. Observation with definite expectation ideas. "Apperception." Observation for complete analysis. Total impression. Learning by trial and error. Imitation. Note-taking. Acquisition by reasoning. Selection and organization. Essence of reasoning. The problem for the student. Helps to habits of correct thinking. The value of ideas. Age and learning. The value of early acquisitions. Jost's law. Some kind of habits are formed early. Subjects to be taught at different ages. Other conclusions in relation to age and learning. Social factors involved.

\section{Chapter 6.}

\section{WAYS OF THINKING AND PITFALLS FOR THE STUDENT.}

Pages $76-85$

Common tendencies: advantages and disadvantages. Predisposition, or prejudice. Empathy. Learning by trial and error. Imitation. Partial, hasty observation and faulty conclusions. Careful rather than fast work. The tendency to get general impressions. Coincidences considered as matter of cause and effect. Jumping to conclusions on the basis of too few facts. Reasoning by analogy. Reasoning from "what ought to be" to supposed facts. The conversion of arguments. Originality without preparation. Affirming of the whole what is true of the part. Affirming of a part what is true of the whole. Reasoning from incorrect premises. Proving one thing and assuming another. Appeal to the feelings instead of to the intellect. Throwing overboard a conclusion or belief because the arguments found for it are bad. Language difficulties. The great achievement for the student. 


\section{Chapter 7. \\ PROGRESS AND IMPROVABILITY.}

Pages 86-96

The universality of improvement. Habit and the law of short-circuiting. Regularity and persistence. Drill. Use versus drill. Definiteness of practice. Lower and higher order habits develop together. The order of learning. Correct practice. The critical attitude and ability to distinguish the correct from the incorrect. Thoughtful practice. Improvement of methods. Improvement in observational learning. Feelings of satisfaction and of dissatisfaction. The feelings an unsafe guide. Physiological conditions. The principle of completeness of response. Improvement in subnormals.

\section{Chapter 8.}

\section{ARRESTS IN LEARNING AND THE LIMIT OF IMPROVABILITY.}

Pages 97-106

Are plateaus necessary in human learning? The curve of learning. Causes of plateaus: The nature of the learner. Defective training. Growing complexity and critical stages. Little experience in higher habits. Improper use of time and effort; poor methods. The illusion of progress. Avoiding and overcoming plateaus: Observation of principles already mentioned. Forcing one's self. The limit of improvability.

\section{Chapter 9.}

THE TRANSFER OF ACQUISITIONS: GENERAL

\section{IMPROVEMENT.}

Pages ro7-1 г6

Most improvement is specific. Some transfers may take place. Factors that complicate the discussion. The nature and amount of transfer. Quotation from Ladd and Woodworth. The conditions of transfer. Quotations from Bagley, Judd and Pearson. Transfers and the choice of subjects. Choice should also be a choice of teachers. Studies should call out our best efforts. The value of intensive study. 
Chapter 10.

\section{MEMORIES AND THE PERMANENCE OF ACQUISITION.}

Pages II 7-I 3 I

The modern conception of memory. Memory as a kind of habit. Not memory but many memories. The conditions of memory: Better methods of learning. Many associations. Vividness, frequency of repetitions, duration, recency and primacy. Accumulations of repetitions: Meumann. Jost's law. The "warming up" period. Fatigue. The "hardening" period. The value of comparatively short periods. Immediate and permanent retention. Cramming. Memory and general intelligence. The rate of learning. Regularity of application. Distribution of practice.

\section{Chapter 11.}

\section{MEMORIES AND THE PERMANENCE OF ACQUISITION.} (Concluded).

Pages $\mathrm{I}_{32} 2-\mathrm{I} 42$

The nature of material. Topical study and topical organization. Light from later chapters. The whole versus the part method. The mediating or emphasizing method: a modification of the whole method. Size of units. Order of learning. Size of units and the length of assignments. Silent learning versus learning aloud. The attitude of the student. Artificial systems and devices: Mnemonics. Mnemonic devices. Forgetting. The curve of forgetting. Reviews. The value of reviews in learning small amounts of material. Permanence of acquisition and the kind of learning.

\section{Chapter 12.}

\section{MAKING THE APPEAL TO THE STUDENT.}

Pages I4 $43^{-1} 57$

The release of energy. The teacher's work is to arouse and to direct. The means of appeal: the native and acquired dispositions. Case studies of successful appeals: A tactful recruest. Arousal of the group spirit. One's own problem. The feeling of usefulness. Being a knight. School money, bank books, and ownership. Appeal to pride in one's own possessions. Winning pupils through tact. play and a friendly attitude. Army organization, and reward of a holiday. The arousal and development of interest. The force of sugges- 
tion. The law of affective expansion. The law of affective transfer. Association and the development of interest. Interest and attitude. Realization of use or value. The feeling. of need. Interest through special topics. Interest and the assignment of lessons. Utilizing manual activities. Use of the dramatic tendency. Sublimation. Action and feeling. Centering interest in the pupil's activity. Motivation through the activity of the pupil. "A passion for your subject." The development from interest to effort.

\section{Chapter 13.}

\section{ATTENTION AND SUSTAINED EFFORT.}

Pages I.58-I74.

From interest to effort. The need for attention. Kinds or stages of attention: primary attention. The conditions of primary attention. Vividness or intensity of stimulus. Change of stimulus. Novelty. Familiarity. The concrete. The definite and concrete. Secondary or "voluntary" attention. Derived primary or habitual attention. The conditions of secondary and derived attention. The arousal of sustained attention. The driving power of pain, fear and anger. Appeal made through the removal of privileges. Appeal to an habitual tendency. The passing of secondary into derived primary attention. The best attention is had with slight distraction. Hindrances to good attention: The feeling of fatigue versus fatigue. Exciting emotions. Not knowing what to do or how to go ahead. Lack of technique and of instruments. Bad suggestions and failure to try. Self government and sustained effort. Self government aided by school paper. A teacher's personal interest, trust, and right direction of a boy's activities. Sharing in activities. Pride and interest in one's. own achievement. Appeal to sympathy and the sense of responsibility. A position of responsibility. Improvement from within. The direction of attention. Control of action through control of attention. The direction of native tendencies. The value of purpose. Ideals.

\section{Chapter 14.}

\section{FEELING HABITS AND MORAL EDUCATION.}

Pages I75-I 83 .

The feelings and permanence of acquisition. Feelings and action. The feelings dependent upon action. Associations. 
The development of interests. Making interests permanent. Other emotional tendencies. Imitation. Moral education. Will in moral training. The type of moral habits. Moral education in our schools.

\section{Chapter 15. \\ PHYSICAL AND PHYSIOLOGICAL CONDITIONS.}

Pages I84-I95

Dependence of mind on body. Special defects. Food. Air. Temperature. Humidity. Atmospheric conditions and mental work. Regularity and efficiency. Change of work. Fatigue. Sleep. Short naps. Health and social activities.

\section{Chapter 16.}

\section{THE DIRECTING OF LEARNING AND STUDY.}

Pages I96-210

Methods of teaching versus methods of study. Results of supervised study. Moral value of home study habits. The pupil's failure in the application of advice for method of study. The teacher's inability to advise. Detailed suggestions to give students in connection with improved study. The teacher's responsibility. Pupil's study card. Suggestions for the individual student. The final result.

\section{Chapter 17.}

\section{SUPERVISED STUDY AND THE SCHOOL CURRICULUM.}

Pages 2II-22I

Methods for putting supervised study into the curriculum outlined. The use of the regular teacher. Use of a special teacher. Both methods valuable. Separate times for instruction in study during the school session. Special times appointed by the principal. The division of every period, part for supervised study. The double period. Study conferences. Extra study periods. Directing study in the general study hall. Essential factors in the administration of study supervision. An experiment in supervised study in the schools of Athens. General suggestions for study. Special suggestions and directions for the study of special subjects: How to study reading. How to study history. How to study science. How to study mathematics. English composition. Manual training and domestic science. Some results of the experiment. 
Chapter 18.

\section{DEFINITENESS IN AIM AND IN METHOD.}

'Pages 222-23'

Quotations from Snedden and Judd. Social Values. The binding force of tradition. The case of Latin. The question of English. Results of an experiment by Professor Mead. A lesson from the French schools: quotation from Professor Brown. Other facts in relation to English. Some conclusions. The theory of specific versus formal discipline. A quotation from Professor Snedden. A quotation from Professor Thorndike. The practical conclusion.

SELECTED BIBLIOGRAPHY.

Page 232

BIBLIOGRAPHY OF REFERENCES USED IN TEXT.

Page 232

INDEX.

Page 237 


\section{Chapter 1.}

\section{INTRODUCTION. \\ FUNDAMENTAL PRINCIPLES OF EDUCATION.}

Purpose and point of view of the writer. It is the purpose of the writer to deal with the problem of education from the point of view of economy in learning and study. The student should be interested because his problem is to know how to learn and to study most effectively. The teacher should be interested because all teaching must be true to the laws of learning and of study and should not conflict with them. If teaching does conflict with the laws of learning it is relatively ineffective. Fundamental to knowing how to teach is knowing how to help the student to learn.

Education comes about through the learning process. The results of education are more or less permament dispositions or tendencies of some kind. We may, then, define education tentatively as the making, modifying, and remaking of more or less permanent dispositions or tendencies. It will be shown later how these permanent tendencies make for fixity and stability on the one hand, and, on the other, for flexibility, originality, initiative, and may require conscious choice and moral reflection.

Habit a convenient term. In order to conveniently express these more or less permanent dispositions or tendencies, memories, habitudes, habits, interests and the like which are the result of education we shall use the word "habit." This word is used commonly in a narrower and in a broader way. In the narrower sense it refers to the more or less mechanical tendency to act as we have acted before. But it is used commonly in a broader sense. Thus habit is defined as being "the tendency to think, feel and do as we have thought, felt or done before." In the broadest sense we find writers speaking of "habits of thought," "habits of liberality," "habits of devotion," "habits of attention," "moral habits," and we hear of people habitually liking or disliking this or that. Habit thus includes attitudes and may be used as a general term for all more or less permanent tendencies of mind and body. 
Habit but not automatism. Habit is thus used in this book, according to common usage, to refer in the broadest kind of way to the permanent acquisition of the individual. It is not to be interpreted as meaning a bringing about of automatism. It includes this, as in the best formed acts of skill, but it includes much more. Making an individual a narrow mechanical kind of person could never be a satisfactory or adequate work of education. Man is not made to be an automaton. In fact, with normal people and any right kind of education there is no danger of making one an automaton. The fact is that fixity and plasticity exist together in the organism. The increase of fixity does not do away with the plasticity, though it modifies it, and brings not rigidity but elasticity. (62).

Habit fixes but it also releases. The higher centers of the brain are released by habit to deal with the new and problematic, to make further modifications which may result in habit, and to permit greater and greater freedom in higher and still higher mental problems. The absurdity of the idea that habits rob the individual of further modifiability is shown by countless facts in our everyday observation. Men are all the time shifting from one thing to another, from one view to another, from one attitude to another. They are different individuals in different years and even, sometimes, in different months of the same year. Deep set habits of a life time may be changed by disappointment in love, in business, by great good fortune, by deep emotional experiences. The facts suggest that more and not less permanence would be better and render the individual and society more stable and efficient.

No justification for education which does not make permanent results. Furthermore, there would be no excuse for education if the results of education were not in some way permanent. If tendencies to think, feel, and do, could not be more or less well fixed in the organism, the efforts of teachers might as well stop. Just what these permanent tendencies shall be must be determined by society in terms of its needs, right desires and ideals. And the aims may be expressed in broad generalizations, such as, adaptation, social efficiency, or character. But we attain these things by acquiring the habits and by later modifying these habits and forming new ones to bring better adaptation, greater efficiency, the higher development of character. Social organization depends on custom and custom depends on habit. Evolution appears to 
provide for just this bringing about of fixity and for the subsequent breaking up of the fixity for the purpose of further progress. Witness the change from plasticity to fixity from infancy to old age, and the production of plasticity again by means of the new generation. Witness in the course of history the development of forms in social usage and the breaking up of these forms or their modification for further progress.

The forming, modifying and remaking of habits, habitudes, dispositions, tendencies, etc., under the guidance of ideals set up by society, seems to be the fundamental work of education. The theory is not new. Witness the work of Radestock on "Habit and Education." (83). Many will accept this theory; others will be disturbed and object. It is worth noting that of the many people the writer has asked, none has been able to suggest an exception to the statement that all the results of education are habits of some kind. But remember that habit as defined by the author means more than is commonly meant by that term in its narrow mechanical signification.

Only results in the individuabyealt with in this book. Let it be fully understood at this point that the writer is not dealing with the results of education in society; nor with the ultimate results of education in the institutions of society. Here indeed, we may find other things than habits as the outcome of education. The only results of education considered under this theory of habit and, for the most part throughout this volume, are the results in the individual. This point is of the greatest importance and must not be lost sight of.

Second, and of equal importance, it must be understood and remembered that the writer has in mind the educational process in the individual. The futility and uselessness of attempting to give a simple definition of such complex things as education in its many phases, is fully apparent to the writer. There is no attempt to deal with education in all of its varied aspects. The attempt,- and it cannot, perhaps, be too much emphasized, or held too clearly in the mind of the reader,-is to deal in the most fundamental and definite way possible with the educational processes, the means and methods of directing them, and the results of these educational processes in the individual.

The importance of this educational process cannot be overestimated. All that an individual is or can be, is the outcome of two things, physical heredity on the one hand, and educa- 
tion, or social heredity, on the other. Educational influences form, modify, change, bring about the most desirable development of that which is given in heredity. This process of education in the individual, not to speak of the education in the larger sense of its various aspects, ranks with the few great things in life, $i . e$., the process of getting food and drink, that of getting shelter and clothing, and of obtainıng social intercourse with other human beings. If life is to go on normally, we need all of these things. But, also, if living is to improve from generation to generation we are absolutely dependent upon education.

Education compares in importance to heredity. A certain age old discussion, and the fact that it appears to be as far from settlement as ever, gives evidence of the value of education. I refer to the argument as to which is more important, heredity or environment, nature or nurture. Than being necessarily thus ranked with heredity in importance in the minds of men, there could hardly be greater evidence of the value of education, nay, more, of its necessity. To recall the debt of civilization to those who kept learning alive during the dark ages, or to refer to the efforts of civilized countries to keep open their schools even during the ravages of desolating war, can add but little weight to the overwhelming evidence for the importance of and need for education already cited. Just as surely as the doing away with the results of physical heredity, if it were possible, would be the doing away with the race, so the doing away with the results of education would be the doing away with the achievements of the race,--civilization, efficiency, culture, and what not.

But we hear objections to and adverse criticisms of education. Yes, and again, just as the objections to and adverse criticisms of heredity are in reality only against bad heredity; so are the adverse criticisms of education in reality only against bad or mis-directed education. If we need good heredity, so do we need good education. Or better still, if we work for the best heredity, so should we work for the best education.

Still another fact may be brought forward to indicate the importance of education. Turn to the anthropologist, if you please and realize, that in looking back through the history of the race, he finds it impossible to discover evidence that the physical endowment of the modern man is any better than the physical endowment of the most primitive man of whom 
we have knowledge. To what, then, is his advancement due? To the results of the educational process, $i$. $e$., to the results, in other words, of social heredity. Or grant, if you will, the very doubtful proposition that acquired characteristics can be inherited, that the modifications of the body cells can also modify the germ cells of the present and therefore of succeeding generations, how are we told that the niodifications of the germ cells can be brought about? Only by thorough modification of the body cells through many generations. Here again the necessary resort to education.

Importance of the Habit Theory. Habit formation, modification and remaking as the basis of education have not been sufficiently stressed as principles in the actual work of education. And if the Habit Theory is inadequate, it still seems that inestimable advantage could be gained by beginning with it, and carrying it as far as possible. Before the work on reflexes was done, no one probably dreamed of the immense light it would throw upon more complex processes. And if educators would not only accept in theory the principle of habit, but also shape their work in accordance with it, it is not unlikely that we would find a solution for many, if not for most of our so-called higher and more complex problems of education.

Habit a universal principle. It is not inappropriate to indicate that this principle of habit, or the tendency for repetition, is fundamental for phenomena other than those found in the human and animal organism.

The logician tells us that "Induction is only possible on the assumption that things not only are together but belong together. .... the universal nature of a thing cannot be discovered in the form of some essence or substance that remains permanent and unchanging. .... it must be defined through the constancy of behavior shown in its changing relations to its environment." (19).

But even more, the finding of things happening again as they have happened before under the same conditions is at the very bottom of our thinking and a necessary basis of all reasoning. According to Pearson, "Anything, be it noted, that tends to weaken our confidence in the uniform order of phenomena, in what we have termed the routine of perceptions, tends also to stultify our reasoning faculty by destroying the sole basis of our knowledge." (76).

Jevons writes that "It must be the ground of all reasoning 
and inference that what is true of one thing will be true of its equivalent, and that under carefully ascertained conditions, Nature repeats herself." (45). "We must always rise to something which is general or same in the cases (of induction), and assuming that sameness to be extended to new cases we learn their nature. Hearing a clock tick five thousand times without exception or variation, we adopt the very probable hypothesis that there is some invariably active machine which produces those uniform sounds, and which will, in the absence of change, go on producing them." (46).

On what else can prediction in any science be based than on the assumption that what nature has done before under certain conditions, will be done again under those conditions? "Every law of nature is the statement of a certain uniformity observed to exist among phenomena, and since the laws of nature are invariably obeyed, it seems to follow that the course of nature itself is uniform, so that we can safely judge of the future by the present. This inference is supported by some of the results of physical astronomy." (47).

Habit and the social sciences. Or let us turn to history. We are all accustomed to the phrase that "history repeats itself." The orders and speeches of Napoleon to his troops are seemingly repeated in the present speeches and messages of the Kaiser to his troops. The French denunciation of the English one hundred years ago appears today in the German denunciation of the English. The treaty of Utrecht and the reapportioning of Europe among the powers, (1713-14), finds its counterpart in the Congress of Vienna and another reapportioning of Europe, (1815). We may ask, will this analog of habit appear the same as before? The present war completes part of the repetition of events. Will the reapportioning of Europe again recur?

Biology furnishes analogs. Spencer writes: "A species of plant that has been transformed from one soil or climate to another, frequently undergoes what botanists call 'a change of habit.'

In the field of social psychology McDougall tells us, "In short, the formation of habits by the individuals of each generation is an essential condition of the perpetuation of custom, and custom is the principle condition of all social organization." (63). Ross, in his Social Psychology, also shows the working of this fundamental law.

(87). 
Sumner in his excellent work in social science takes us again to habit. In the preface he says: "The thesis which is expounded in these chapters (chs. 1 and 2) is: that the folkways are habits of the individual and customs of the society which arise from efforts to satisfy needs," etc. (93).

In his Laws of Imitation, Tarde (106), writes: "Repetition exists, then, for the sake of variation." "Science, as I have said, deals only with quantities and growths, or in more general terms, with the resemblances and repetitions of phenomena. ..... Every advance of knowledge tends to strengthen the conviction that all resemblance is due to repetition." "In the distant future all social phenomena will be reducible to mathematical formula." ...." ... every civilization is fated to ..... begin its endless cycle over again." "Everything repeats itself, and nothing persists."..."Tradition and custom, the conservative forms of imitation, have been fixing and perpetuating its new acquisitions and consolidating its increments in the heart of every class of people that has been raised up through the example of higher classes or of more civilized neighbors."

Ellwood, summarizing the studies of the classicists in social theory, says that, "Law in the social sciences, then, rests upon the fact of habit.... A social law is a statement of the habitual way in which individuals, or groups of individuals, interact." (26).

In the realm of philosophy we find Taylor telling us that "We should ... have to think of the 'laws' or 'uniformities' in physical nature as corresponding to the habitual modes of reaction of the sentient beings. .... Habit and spontaneity would mutually imply each other in nature at large." (107).

Habit at bottom a matter of physics. Early in his great chapter on "Habit" James tells us, "that we may without hesitation lay down as our first proposition the following, that the phenomena of habit in living beings are due to the plasticity of the organic materials of which their bodies are composed.

But the philosophy of habit is thus, in the first instance, a chapter in physics rather than in physiology or psychology. That it is at bottom a physical principle is admitted by all recent writers on the subject. They call attention to analogues of acquired habits exhibited by dead matter. Thus, M. Leon Dumont, whose essay on habit is perhaps the most philosophical account yet published, writes: 'Every one knows how a garment, after having been worn a certain time, clings to the 
shape of the body better than when it was new; there has been a change in the tissue, and this change is a new habit of cohesion. A lock works better after being used some time; at the outset more force was required to overcome certain roughnesses in the mechanism. The overcoming of their resistence is a phenomenon of habituation. It costs less trouble to fold a paper when it has been folded already. This saving of trouble is due to the essential nature of habit, which brings it about that, to reproduce the effect, a less amount of the outward cause is required. The sounds of a violin improve by use in the hands of an able artist, because the fibres of the wood at last contract habits of vibration conformed to harmonic relations. This is what gives such inestimable value to instruments that have belonged to great masters. Water, in flowing, hollows out for itself a channel, which grows broader and deeper; and, after having ceased to flow, it resumes, when it flows again, the path traced by itself before. Just so, the impressions of outer objects fashion for themselves in the nervous system more and more appropriate paths, and these vital phenomena recur under similar excitements from without, when they have been interrupted a certain time.'

Not in the nervous system alone. A scar anywhere is a locus minoris resistentiae, more liable to be abraded, inflamed, to suffer pain and cold, than are the neighboring parts. A sprained ankle; a dislocated arm, are in danger of being sprained or dislocated again; joints that have once been attacked by rheumatism or gout, mucous membranes that have been the seat of catarrh, are with each fresh recurrence more prone to a relapse, until often the morbid state chronically substitutes itself for the sound one. And if we ascend to the nervous system, we find how many so-called functional diseases seem to keep themselves going simply because they happen to have once begun." (33). (See also 117).

This is a long quotation. But probably nowhere and at no time has the fundamental and comprehensive nature of habit been better stated. Two other principles of education must also be considered.

Ideals and standards. The making, modifying, and remaking of habits should be done under the guidance of ideals set up by society. What ideals shall be set up is a problem of the philosophy of education and does not primarily concern us in this book. At bottom it is an ethical problem: what 
should be the sum total of habits of the educated person, the intellectual, emotional, and motor habits?

Also the making, renraking, and modifying of habits should be determined as much as possible at each stage of education by standards determined by educators. For each mental age there must be certain standards which students shall be expected to reach in each subject or activity. We have thus three great principles of education. We might, of course, emphasize needs. But it is assumed that the needs of the individual and of society are cared for in the ideals.

The three great principles of education. The fundamental working principle of education is thus seen to be the making, modifying, and remaking of Habit. The guiding principle of education is striving towards Ideals. The controlling principle of education is attaining Standards. The ideals may be those of neatness, loyalty, accuracy, clear thinking, perfect memories, appreciation of the best in literature, art and science, the best kind of critical judgment in a chosen field of thought, accurate spelling of all words, perfect rendition of a picce of music, etc. The strivings toward these should reach certain standards determined by educators. In terms of these principles we can give a more complete definition of education. Education is the making, modifying, and remaking of habits under the guidance of ideals and the control of standards.

It is not inappropriate to say that inasmuch as the making and modifying of habits is the modifying primarily of the nervous system, there is nothing more fundamental or valuable for the teacher than a knowledge of the nature and working of the nervous system. In all fields the best progress has always been made by starting at the bottom and working up. In education the way is not to begin with philosophy and work down, but to begin with the fundamental processes of the nervous system, with the neuron, and work up.

The means of Education. All the inherited tendencies of the organism are the means of education. The extent of education depends upon the capacities that physical heredity gives. Thus the fullest knowledge of these is indispensible to the teacher. All the methods that the teacher can use are methods to take advantage of these native tendencies, to develop them, to make the most of them.

These methods of dealing with the individual for the purpose of modifying him, that is, of educating him in the most 
economical way, are the things with which the teacher must be most familiar in the actual teaching. Never before has the demand for the best method been so insistent as it is today. The past has been chiefly interested in the methods of teaching; the present is specially interested in the methods of studying. The writer has tried to present to the teacher the results of psychological study with the emphasis upon the learning by the pupil. Only in so far as the methods of learning are known can the best methods of teaching be discovered. For, ultimately, the ways in which learning goes on must determine the methods of the teacher.

The educative process is then essentially that of making and modifying the individual's tendencies to think, to feel and to act. As long as the educative process goes on, there is a continual remaking of the individual. The process of remaking the individual so that he approaches the ideals of his people, is the process by virtue of which he comes to acquire those ideals as his own.

The greatest needs of education. The greatest needs of education are those of clearness, definiteness and concreteness. The lack of these things has been the worst kind of a handicap. Vagueness has been declared to be the greatest vice of education. Variety of aim, and of method, and indefiniteness of end product which may be observed and measured, have for too long characterized educational procedure. Measurement of educational products has begun and it is of the greatest value. We need some principles by means of which we can understand and interpret the work of education, and which we can use as working principles for the direction and control of the educational processes and for the measurement of the end products. It is the purpose of the next two chapters to show the teacher how three great principles enter into the work of education, to explain the nature of the great basic principle of education, and thus to lay the foundation for all understanding and practice of directing the process of education.

\section{QUESTIONS AND SUGGESTIONS FOR STUDY.}

1. Compare the principles of education emphasized in this chapter with others with which you are familiar.

2. Try to state in your own words why you think the author has chosen to emphasize the principles indicated. 
3. Can you think of any work of the school, which is worthy of being continued, which does not result in some permanent changes in the pupil?

4. Does helping the children to harmless enjoyment constitute an exception? If there should be permanent results here what are they?

5. What does the term habit mean for the author and how is it commonly used?

6. What facts can you state as to the importance of education?

7. Show how the principle of habit appears in various fields of thought.

8. What are the functions of ideals and of standards in education?

9. Why are clearness and definiteness so much needed in education? 


\section{Chapter 2. \\ NEUROLOGY AND THE BASIS OF EDUCATION.}

Purpose of the chapter. In the present chapter it is the purpose of the writer to help the teacher to a more thorough understanding of the nature of habit in the broadest sense of that term, and of how habit formation and modification are the fundamental concerns of the teacher because they are the fundamental processes in education. For this purpose numerous quotations have been chosen, partly to introduce the reader to some of the most authoritative statements and studies of the subject of habit, and partly, to show how fundamental, adequate, and comprehensive the habit theory is, as indicated by men who have written at different times and with different interests. Quotations that appear in this chapter give us conclusions of men who have written from the points of view of neurology, of pure psychology, of educational psychology and pedagogy.

This chapter should help us to see how whatever one thinks, feels, or does, tends to become, in the form of habit, a very part of his being. If we can understand fully the getting of results in education, $i$. e., skills, memories, understanding, interests and appreciation, tendencies to act in accordance with certain ideals, and all the rest, we can see how the work and methods of education become definite. If, as Professor Angell says, the processes which bring order out of threatened chaos in the human organism leave it a group of habits, so perhaps, education may be brought to the best, clearest, most definite working efficiency by thorough conformance to the laws of habit.

The fundamental nature and importance of habit. Nowhere, perhaps, has the fundamental nature and the importance of habit been better shown than by Dr. Carpenter. "It is a matter of universal experience," he writes, "that every kind of training for special aptitudes is both far more effective, and leaves a more permanent impress, when exerted on the growing organism than when brought to bear on the adult. The effect of such training is shown in the tendency of the organ to 'grow to' the mode in which it is habitually exercised; as is 
evidenced by the increased size and power of particular sets of muscles, and the extraordinary flexibility of joints, which are acquired by such as have early exercised in gymnastic performances.... There is no part of the organism of man in which the reconstructive activity is so great, during the whole period of life, as it is in the ganglionic substance of the brain. This is indicated by the enormous supply of blood which it receives..... It is, moreover, a fact of great significance that the nerve-substance is specially distinguished by its reparative power.... the study of psychology has evolved no more certain result than that there are uniformities of mental action which are so entirely conformable to those of bodily action as to indicate their intimate relation to a 'mechanism of thought and feeling, acting under the like conditions with that of sense and motion. The psychical principle of association, indeed, and the physiological principles of nutrition, simply express the former in terms of mind, the latter in terms of brain-the universally admitted fact that any sequence of mental action which has been frequently repeated tends to perpetuate itself; so that we find ourselves automatically prompted to think, feel or do what we have been before accustomed to think, feel, or do, under like circumstances, without any consciously formed purpose, or anticipation of results. For there is no reason to regard the cerebrum as an exception to the general principle that, while each part of the organism tends to form itself in accordance with the mode in which it is habitually exercised, this tendency will be especially strong with the nervous apparatus, in virtue of that incessant regeneration which is the very condition of its functional activity. It scarcely, indeed, admits of loubt that every state of ideational consciousness which is either very strong or is habitually repeated leaves an organic impression on the cercbrum; in virtue of which that same state may be reproduced at any future time, in respondence to a suggestion fitted to excite it.... The 'strength of early association' is a fact so universally recognized that the expression of it has become proverbial; and this precisely accords with the physiological principle that, during the period of growth and development, the formative activity of the brain will be most amenable to directive influences. It is in this way that what is early 'learned by heart' becomes branded in (as it were) upon the cerebrum; so that its 'traces' are never lost, even though the conscious memory of it may have completely faded out. For, 
when the organic modification has been once fixed in the growing brain, it becomes a part of the normal fabric, and is regularly maintained by nutritive substitution; so that it may endure to the end of life, like the scar of a wound." (Also 34).

These modifications which result in habits make up one's education. These facts are not only fundamentally true and vitally important, but also give the basis for the much needed definiteness and specificness to the problem of and procedure in education. This it can do by defining the habits to be formed, thousands of habits of spelling, of arithmetic, of French, of German, of mechanical acts and skill, etc. It would thus have end products, $i$. $e$., behavior which results from habits formed, which could be measured. This, furthermore, is exactly what is measured by the educational examinations and tests at the present time.

Taking certain habits as the ends to be attained, the teacher could have a clear and definite idea of his work and could be able to look for the particular means of attaining these ends and know when he has attained them.

Comprehensiveness of the principle of habit. While this conception of education is fundamental it is also comprehensive. The growth of our perception is a matter of habit formation; perception does not actually take place until one comes to associate certain meanings with certain sense impressions and this soon is habit; memory is a kind of habit, (65). depending upon associations which tend to recur again as they earlier appeared. Likes and dislikes are habits, and if we could not get our pupils to habitually like and prefer certain more worthy things and actions, and to habitually dislike and refuse other things and actions which are unworthy, we might well despair of ever raising them to any higher moral, aesthetic, or other levels whose attainment depends upon the higher feelings and sentiments.

The formation of so many thousands of habits as the aim of education is only a more clearly defined way of saying that the aim of education is the development of character. For character, when it is analyzed, is found to be the sum total of one's habits of thinking, feeling, and doing. If the teacher attempts to follow the extremely vague and indefinite direction: Develop the characters of your pupils, there is no possible way in which he can go about doing it except by directing the development of habits. 
Prof. Titchener tells us that "the habit imposed by education becomes second nature. This, indeed, is the chief problem of education. In psychological language, the teacher must find out the child's natural mental constitution, noticing the good and bad features of it, and must seek by influence of all kinds to accentuate the good and minimise the bad. In biological language, he must find out the child's natural nervous tendencies, and strive-by favoring the formation of good habitsto keep the right channels open for the flow of mental processes and dam up those that lead mind astray. Natural constitution and natural tendency must be partly reinforced and partly checked by acquired constitution and acquired tendency." (116).

The work of the teacher. "All our life," wrote James, "so far as it has definite form, is but a mass of habits,-practical, emotional, and intellectual,--systematically organized for our weal or woe, and bearing us irressistibly toward our destiny, whatever the latter may be.... Ninety-nine hundredths or, possibly, nine hundred and ninety-nine thousandths of our activity is purely automatic and habitual, from our rising in the morning to our lying down each night..... the teacher's prime concern should be to ingrain into the pupils that assortment of habits that shall be most useful to him throughout life. Education is for behavior and habits are the stuff of which behavior consists." (42).

It is then the concern of the teacher to understand what habits should be formed, to learn how they can most economically and nost thoroughly be developed, and to train himself in the technique which is necessary for directing the development of new habits and the modifications of old ones, $-i$. $e$., the language, arithmetic, science, aesthetic, motor, attentive, and other kinds of habits. And not only habits which appear in external behavior, but also those habits which are internal and may never be apparent from ordinary observation, which may, for example, result in inhibition, in refusal to do the unkind, the immoral, or other undesirable act $e$. g., habits of decision.

Sully on Habit. Writing on habit, Prof. Sully tells us that: "The dependence of mental development on cerebral changes is illustrated in a peculiar way in the phenomena of habit. By the term habit is meant the transfornation of once fully conscious mental processes into semi-conscious or automatic actions, as in the practised actions of walking, writing, and so 
forth. This result depends, it is evident, on the perfect co-ordination of certain central elements. As a result of such perfect "organization" of psychical actions nervous energy is liberated for the building up of new formations. (96).

Development and habit. Mental development implies not merely an advance from lower to higher psychical forms, but a growing rapidity and facility in all recurring or repeated processes. This result, already touched on in connection with organic development, is an extension of the psycho-physical attribute, retentiveness. We carry out accustomed acts of perception, as in recognising a person, customary trains of ideas, as in learning a series of historical events, and habitual actions, as in swimming or skating, more and more rapidly, and with less and less strain of attention, just because of the organization of the traces of previous like actions. So far as this organization comes in, the conscious element grows weaker, and tends to lapse. To this extent habit would seem to imply no psychical but only nervous development.

This dropping out of the conscious factor as the consequence of repeated exercise and of habit is, however, only one part of the result. The tendency of repeated psycho-physical processes to become automatic and unconscious sets free the activity of attention for further processes of psychical acquisition and growth. Indeed, it is only by this economising of attention or consciousness in the case of habitual processes that the more complicated psychical processes become possible. Thus it is by learning to recognise first words, and then groups of words, swiftly and automatically, that we are able to carry out the difficult, complex intellectual processes of reading."

Two meanings of habit. "Habit, as we shall see, has a narrower and a wider meaning. When it refers to the rigid fixing of ideas or actions in one definite order it is a force that opposes development. Habitual action or grouping of ideas means action or grouping which is altered with difficulty. This is seen in the case of the uneducated mind, which is narrow and rigid, just because it has formed certain fixed modes of associating ideas through which it cannot break. But taken in a larger sense, as including all the effect of repetition of psychical processes, habit is an integral factor in the processes of development itself; for it is only by retaining the traces of our past activity that we can render this activity more perfect." (97). 
"We are best fitted to cope with our life-surroundings when we are able on the one hand to carry out all recurring uniform modes of responsive action easily, simply and automatically, and at the same time to bring to bear a highly evolved reflective consciousness on new, difficult, and complex problems of life." (98).

Comprehensiveness of the habit theory. For those who are used to thinking of habit in a narrow sense there will undoubtedly be objection to making habit the all embracing thing which the writer is attempting to do. But if he will go through the pages of a psychology, such as that of Prof. Angell, he will see how inevitably habit appears as the result of the modified nervous system. The following quotations help to indicate this inevitable and comprehensive result, that is, habit, and if there is any result of education which does not fall under this head, it will appear to be an exception to the rule.

Writing on habit, Prof. Angell says: "The whole course of mental development could truly enough be described as made up of this process of acquiring habits, which once imbedded in the tissues of the nervous system become the permanent possession of the individual, ready, when need arises, to step in and deal with the necessities of any particular situation. .... Neural habit.... is not only the great emancipator of consciousness from the necessities of endless control over the same trivial round of acts, it is the great tool by which that feature of mind which we call the will executes its behests and renders our mental decisions and choices effective in the world of action. Without habits, consciousness could never get beyond the borders of the inevitable daily routine. With habit, however, it is able to pass from victory to victory, leaving behind in captivity the special coordinations it needs." (3).

The formation of habits. "It shall be our next business to trace in outline the process by which consciousness and the brain bring order out of ....threatened chaos and leave the organism a group of habits to which additions are continually made and by means of which the organism becomes increasingly master of the situation. This account will be only a sketch, however, for all the rest of our study will be devoted to filling in the details. In the chapters upon volition we shall return specifically to these very points." (4).

Passing over these pages which give the details mentioned. but to the most important (5) of which the writer gives page 
references, if the reader cares to look them up, we come to Angell's concluding statements: "When we bring all our considerations together it becomes obvious that the proposition from which we set out early in our work is true in a very wide and deep sense. Mind we have found to be, indeed, an engine for accomplishing the most remarkable adjustments of the organism to its life conditions. We have seen how the various features of cognitive and affective consciousness contribute each its quota to the general efficiency of the reactions which the organism is able to make upon its surroundings, physical and social.... we have discovered volition concerned with impulses, with pleasure and pain, with emotion, with ideas, with sensations, with memory, with reasoning, and with every form and type of mental operation. We have observed the evolving control beginning with the mere mastery of movements, passing from this to more and more remote ends, for the attainment of which the previously mastered movements now available as habitual coordinations are employed, until finally we find the mind setting up for itself the ideas which we call ideals, and by means of these shaping the whole course of a lifetime."

Habit is fundamental for the most complete kind of thinking. The teacher should realize how thoroughly necessary habit is to the higher forms of thought, reasoning, original thinking, and the like. Any kind of thinking whatever appears to be dependent upon just this elementary law of habit. "I shall try to show, in the pages which immediately follow," writes James, "that there is no other elementary causal law of association than the law of neural habit. All the materials of our thought are due to the way in which one elementary process of the cerebral hemispheres tends to excite whatever other elementary process it may have excited at some former time. The number of elementary processes at work, however, and the nature of those which at any time are fully effective in rousing the others, determine the character of the total brainaction, and, as a consequence of this, they determine the object thought of at the time. According as this resultant object is one thing or another, we call it a product of association by contiguity or of association by similarity, or contrast, or whatever other sorts we may have recognized as ultimate. Its production, however, is, in each one of these cases, to be explained by a merely quantitative variation in the elementary brainprocesses momentarily at work under the law of habit, so that 
psychic contiguity, similarity, etc., are derivatives of a single profounder fact." (35) ...."From the guessing of newspaper enigmas to the plotting of the policy of an empire there is no other process than this. We trust to the laws of cerebral nature to present us spontaneously with the appropriate idea." (36).

"The way to a deeper understanding of the order of our ideas lies in the direction of cerebral physiology. The elementary process of revival can be nothing but the law of habit." ".... But even though there be a mental spontaneity, it can certainly not create ideas or summon them ex abrupto. Its power is limited to selecting amongst those which the associative machinery has already introduced or tends to introduce." (37).

Formation of new habits. In another place he writes, "I have been accused, when talking of the subject of habit, of making old habits appear so strong that the acquiring of new ones, and particularly anything like a sudden reform or conversion, would be made impossible by my doctrine (the doctrine, namely, that "Education is for behavior, and habits are the stuff of which behavior consists"). Of course this would suffice to condemn the latter; for sudden conversions, however infrequent they may be, unquestionably do occur. But there is no incompatibility between the general laws I have laid down and the most startling sudden alterations in the way of character. New habits can be launched, I have expressly said, on condition of there being new stimuli and new excitements. Now life abounds in these, and sometimes they are such critical and revolutionary experiences that they change a man's whole scale of value and system of ideas. In such cases, the old order of his habits will be ruptured; and, if the new motives are lasting, new habits will be formed, and build up in him a new or regenerate "nature.", (43).

Habit and originality. Nevertheless from one quarter we hear that the originality of the educated man has been spoiled by the college. From another quarter we are told that there is no one so set in his ways, so inflexible in his thinking as the uneducated. The fact is that the ways of the educated and the uneducated may become fixed, and either may fail in ability to be original, or what is worse, to accept the worthwhile originality of others.

What kinds of habits are necessary to keep one from this rut of stereotypy? And is it after all habit that is to blame 
for the inability to look at things from more than one point of view, for always thinking exactly the same thing and doing exactly the same thing in the similar situations of life? The difficulty is not in having these habits, but in not having other habits as well, other habits from which one may choose and thus respond in different ways as the particular needs of the situation and the times demand.

This may be shown by the following considerations. Let us take on the one hand, the man who has thought according to one point of view, and in terms of one theory all his life. His habits of thinking are fixed and his actions are always in accordance with this one fixed mode of thinking. On the other hand, take the man who has thought out the same problems from different points of view, $i$. $e$., who has formed several habits of thought where the other man had one. He may, therefore, act not merely in some one fixed way, but in one situation at one time one of these habits of thought may gain the ascendency and determine the action, at another time another of the habits of thought may win out and determine the response.

Habit and plasticity. Sully tells us, "It is evident from our account of habit that it is essentially a process of fixation, a restriction of movement to definite lines. Habitual actions, just because they become sub-conscious and largely non-voluntary, are rendered stable and unalterable. Habit thus presents one aspect which is opposed to all that we understand by development or progress. Itself the product of development, it tends in its turn to obstruct to some extent further development. We see this in the difficulty the tyro at the oars encounters in turning his boat, rowing with the one arm and backing water with the other; and in the common failure of stout resolve to break through noxious habits.

While, however, in its narrower and more rigid form, habit diminishes the plasticity of the neuro-muscular apparatus, it would be an error to suppose that it is wholly an obstacle to progress. This would overlook the range of the principle, its influence in cases where action falls far short of the automatic stage, and also misunderstand the nature of motor development. What we call new movements are never wholly new, and, as pointed out above, the perfect mastery of particular movements always helps us to the mastery of others. Thus the movements of equilibration and locomotion in skating are, as every learner knows, greatly furthered by previously 
acquired and habitual movements. The learning here consists in a few and comparatively slight modifications of old combinations in particular directions; and though the modifications may be difficult through the obstructive force of the previous coordinations, they are a far less difficult operation than would be the learning of the whole group of movements de novo."

(99).

The danger of too much fixity. The question of the danger of too much fixity, the killing of originality, and the like, may always arise to point out a possible bad effect of education, that is, of the formation and modification of habits. Occasionally an article appears in which the writer has endeavored to show that our original men are men who never had the advantage or disadvantage of a college education; their originality was not taken away from them by an education which fixed their thoughts in the ruts of academic thinking, in stereotyped ways of looking at things. Suppose that for the majority of people education does bring about a good deal of fixity, of following in the thoughts and ways of the teachers, this may not be so bad considering the value of most of this much vaunted originality. The writer hazards the statement that for every list of men who have produced valuable original things without having had formal school training, equally imposing lists could be made of men who have produced things of originality and of as great or greater value, who have had this school training. If a careful comparison were made of the products of the originality of men with and without school and college educations, it is not at all unlikely that the men of the greater amount of education would be found to have produced per capita more things of originality and of lasting value than have those without this education. The originality of the expert, of the man with the best knowledge of the best in his line, is, in other words, likely to be the most valuable, and to be just as frequently found. As has already been said, the instability of the individual in everyday life, in vocations, etc., suggests that perhaps more and not less fixity would be well. A recent writer tells us that the average length of time a man holds a position in the United States is less than a year.

No necessary danger of losing plasticity through education. The danger of losing plasticity that is sometimes expressed is not founded upon the facts of experience. We do not find that the man who has practised and formed many habits has 
become thereby unable to make new habits or to modify his old habits. The most highly educated people are not found to be unable to accept new ideas. True, we can find plenty of cases in which people appear unable to change. We find plenty who are 'set in their way.' But we can find also many who are able to change and who do change even in advanced years of life. It is in the advanced years that we may look for the fixity that does not change. And this fact of age is the one that we must look to if we would find that which leaves increasingly less and less plasticity. In other words it is senility and not the number of habits that means the loss of plasticity.

Even the reflexes have not lost all plasticity but are in some cases at least modifiable. Angell writes "that certain of them are unquestionably open to modification, either through the direct control of the mind, as when one succeeds in suppressing a tendency to wink, or through the indirect effect of general organic conditions."

As one can demonstrate by experiment, the winking reflex can be practically eliminated by practice. Have someone place a glass immediately in front of the eye and hit the glass continually with a felt hammer. The winking finally disappears.

Flexibility depends partly on a variety of habits. . Besides the fact that plasticity is still present until advanced years, flexibility depends partly on having a variety of habits for situations in which a variety of responses may be desired. And, from these habits, one should have the habit of choosing. This choice may take the form of choosing partly from one habit and partly from another. Moreover, the impulse may guide one to modify some old habit a little or a good deal, and the original comes out of such an operation if it occurs at all. Remember again how James pointed out that from the simplest thinking to the most complex, we are dependent upon the associations and what they can suggest. Education can train to habits of looking at the same thing from different points of view, and of reacting to the same thing in different ways. It may, in other words, by developing a variety of tendencies to react, lay the foundation which avoids the inflexibility, and which helps,- - not merely permits,-but helps to bring about a variety of possible responses.

Both fixity and flexibility are desirable, in some things the one, in some things the other to a larger degree. Spelling, 
multiplication, addition, and many like things call for fixity of response. The choice of methods of solving problems, the taking of new points of view, the accepting of new ideas, demand thought about such things in different ways, $i$. $e$., habits of thinking and of acting in different ways.

Variety of response a peculiarly human trait. We come to a most significant thing in connection with the human being when we deal with the more and more varied modes of response in a given situation. By nature man has the possibility of more ways of responding to situations than the lower animals. Through education he may find more than he could otherwise know. He may, in other words, through the chosen experiences brought about by his teachers discover responses of which he had never thought and of which he might not be able of hinself to think. He may have as a result of his education very many tendencies from which to choose instead of only a few or of only one; or, he may hesitate in great moral matters, where, before, he acted on some primitive impulse and habit arising from the activity of that primitive impulse. To hesitate before we do the immoral act may mean that we are saved; that we make the moral decision after all and act accordingly.. So, out of education may come that higher result, the development of ideas of better action, from which one chooses according to the particular situation in which he is placed. This is a peculiarly human thing, that an impulse can shoot through a new brain path; that of many possible tendencies, one of many, instead of one only, may function.

The varying strengths of habits. Using habit as we have broadly defined it, that is, as more or less permanent dispositions or tendencies, we find tendencies of various strengths. Language supplies us with terms which express some of these degrees, as for example, inclination, desire, bent, bias, leaning, attitude, disposition, predisposition, mood, passion, craving, automatisms. Habits of all degrees of strength exist. We may, perhaps, for practical purposes distinguish five degrees: 1) There are the strongest habits which we may call automatic or reflex. These are habits that tend to act invariably on the appropriate stimulus. They include tendencies that were inborn and have been often repeated, and tendencies that were acquired early in life which have also had much repetition. Things learned later in life may approach this degree of automatism, but rarely if ever reach it. Habits formed in a strict military school during tour years and repeated daily through- 
out that period might furnish examples of this order. These are quite fully second nature, so to speak. 2) Well established habits of adult life, such as professional habits, ways of doing things, ways of looking at things, affective responses of the artist, and the like. 3) The fairly well formed habits of life, such as the things that are pretty well learned in school and college, things that we recall but not perfectly, activities that we can perform, but which need considerable practice before they are prompt and sure. 4) The dispositions that may or may not act upon the proper occasion, that depend upon recency of practice and mood, and the number of obstacles or inhibitions that arise to hinder them. 5) The weakest tendencies which have relatively little effect on the individual, and which tend to die out in a very short time and leave but the faintest trace. The faintest impression probably leaves some. effect upon the nervous system, although it may be so little that for practical purposes it can be ignored.

The teacher should be very much interested in the matter of the strengths of various habits. Some are to be brought to the greatest strength and others do not need to be so completely learned. For those which are to be brought to the highest degree of strength, there must be the most frequent repetition, unbroken continuity, correctness of response, and other helpful factors; while for things that are not to be so completely learned and mastered, efforts can be less strenuous.

Education and initiative. Education which fails to arouse the pupil to try new methods, to work out new results, to act in a different and more appropriate way in the varying situations of life would fail in that all important thing which we call-initiative. There is education which spoils initiative; there is also education which arouses one to take initiative. There is education which makes one more resourceful, and which helps one to have the courage to try the new, to step out of the beaten road and to make a path that has not yet been tried and proven safe. Education must, among other things, develop the habit of taking the initiative.

The basis for this initiative has already been intimated and it lies in the tendencies already formed in the nervous system. We found a few pages back that only the habitual associative tendencies could give us the ideas from which to choose in the most complicated kind of thinking. This with some feeling, impulse, courage, is the raw material of initiative. The possibility of taking the initiative, of doing the new thing, lies in 
having a variety of things suggested by our associative processes; and the likelihood that we shall do this, lies in the habit of choosing from among them, of combining in a new way, of trying to make the impulse shoot through the new path.

Education, in other words, must train us to various possibilities of response; along with these we must have formed the habit of thinking, reasoning, choosing, sclecting, and then acting, and not of merely responding in a mechanical, reflex sort of way in either new or old situations. The continual formation and modification of habits should help this rather than hinder it. They should predispose the individual so that he may tend to select in new and modified ways.

Types of habits, habit and habtiude. We commonly think of habits as specific, and so hundreds and thousands of them are, such as the specific responses of the individual in any skilled act. But we must also admit what James has called "general forms of discharge, that scem to be grooved out by habit in the brain," such as the tendency of our emotions to evaporate, and of the attention to wander. Colvin has used the term "generalized habit," for those habits "which are common to a number of different stimuli." Other writers use the terms "habitude" and "habitual attitude."

Although we shall use the term habit, as our definition permits, to include this type of habitual tendency, it is most important that we distinguish habitude from habit in the narrower sense. And this to which I refer is not a kind of habit whose development is correlated with a dropping out of consciousness. The development of habitudes, on the other hand, may actually demand definite conscious reflection where previously there was none. Sully thus makes the distinction: In speaking of moral habitudes, he tells us how "The prevailing motive, for example, punctuality in fulfilling engagements, now passes into the form of a fixed inclination or active disposition. Or, to express the result another way, we may say that conduct is brought more fully under the sway of a general rule or maxim. This result is what is known as a moral habitude... The word habitude is here used to mark it off from 'habit' in the narrow sense of mechanical response. In following out a general maxim we never act mechanically as when we repeat a particular kind of action..... our actions may be organised into a certain number of persistent norms or types of conduct, as thrift, temperance, fulfilment of prom- 
ise and the like, they are not so uniform in their actual, concrete combinations as to allow of our particular actions becoming in the complete sense habitual. It may of ten require a good deal of reflexion before we can say what is the honest or the just course of action." (100). We may therefore say that while we commonly think of habits which lead to action, we have also habits which lead to thought.

Habit in the narrow sense could never be the satisfactory end of education as Colvin well says, and further, as he tells us, we must seek in education "the disposition to learn new facts and acquire new habits."

As mentioned above, we shall for convenience use the term habit to include habitude, attitude, disposition, etc., and to indicate any strength or type of habit at all.

\section{QUESTIONS AND SUGGESTIONS FOR STUDY.}

1. How does a study of the nervous system help us to understand the work of education?

2. Show how habits, in the broadest sense of that term, make up the sum total of the results of education in the individual. Can you mention any exceptions?

3. How is thinking dependent upon habit?

4. What is the relation of habit to a valuable kind of originality?

5. How great is the danger of losing plasticity through the formation of habits?

6. Do we need greater or less stability in our present social and industrial life? Cite examples to show the truth of your conclusion.

7. If fixity and flexibility are both desirable can we have both at the same time in the individual? Why do you think we can or cannot?

8. Make lists of desirable habits of different degrees of strength.

9. Explain how some habits lead to a dropping out of consciousness and some require more conscious reflection.

\section{REFERENCES.}

B. R. Andrews. Habit. Am. J. Psychol. 14, 1903. Pp. 121-149.

W. James. Talks to Teachers on Psychology. 1904, Ch. 8.

W. JAMEs. Psychology, Briefer Course. Ch. 10. Or Principles of Psychology. Vol. 1, Ch. 4. 


\section{ChAPTER 3. \\ THE FUNDAMENTAL WORK OF EDUCATION.}

Habit is fundamental. In the preceding chapter we have shown how the formation, modification, and remaking of habits are the fundamental things that take place in the process of education in the individual. Whatever permanent changes occur, habits of some kind and of some degree of strength are the result. It is the duty of educators to see that the habits are desirable ones. It was also shown that the reduction of the results of education to habit was fully comprehensive and adequate. It is the purpose of the writer in the present chapter to show how the principle of habit formation and modification is the true principle underlying all advancement in learning, and how this principle, taken as a practical working theory, has certain advantages which teachers and students cannot afford to overlook.

Habit is the basis of progress in education. In the first place, and, perhaps, most important, habit is the basis of all progress in education. As Professor Titchener tells us "Looking at life in the large, we may say that the period of training or education is a period of secondary attention, and that the following period of mastery and achievement is a period of derived primary attention. Looking at experience more in detail, we see that education itself consists, psychologically, in an alternation of the two attentions; habit is made the basis of further acquisition, and acquisition, gained with effort, passes in its turn into habit; the cycle returns, so long as the nervous system remains plastic." (113).

In another place in the same book the author emphasizes the value of practice whose results are habits. The passage is too good to leave unquoted and its significance too great to overlook. "In psychological experiments," he writes, "the practised observer has a threefold superiority over the unpractised: his attitude to the stimuli, in successive observations, is more nearly uniform; his attention is sustained at a higher level; and his discrimination is more refined. This means that the focal mental processes are few in number; that they are extremely vivid; and that they are protected by 
strong inhibitory forces, against intrusion from the outside. ..... Habit is, in general, the outcome of practice; if practice shows us a nervous set or disposition in the making, habit is the set taken, the disposition established; the plastic organ has hardened in some special way. Like practice, habit in its early stages requires attention; but it is to be noticed that a habit may be formed, not only by the repetition that practice brings, but also by any single stimulus that violently impresses the nervous system; the plastic mechanism may be thrown, by a sudden wrench, into a new and permanent arrangement; just as we may give a permanent bend to a fencing foil by a single violent lunge. We have already seen, in our discussion of the development of attention (pp. 98-99), that habits already formed are the basis of new acquisition; and we may remark in passing that the moral and practical importance of habit has often been written upon and can hardly be overestimated." (114).

Progress to higher stages of efficiency. Progress, if we look at the matter in the large, means breaking up one's present efficiency in order to raise him to a higher stage of efficiency. More in detail, this means the modifying of old habits, of thinking, of feeling, and of acting, as well as the making of new ones. It means the improvement of methods. It includes the raising of ideals and stimulating one to striving harder for the attaining of results in the direction of these ideals. Work must proceed on a higher level.

Progress and modifying the old habits. The fact that old habits can be modified, that they are not unalterable, that they need not leave us unchangeable in our responses, is almost too well known in everyone's experience and observation to need mention. I know, for example, of a man who practised law until he was over fifty years of age and was then called to be head of a large university. According to his own statement, the first year called for the making of many new habits and the modifying of old habits so that the new work could go on in the same habitual way in which the law work had gone. But the changes were made and the new work was done later in the same easy habitual way as the law work had been done. We can all, no doubt, cite many examples of this kind of thing. A shift from one kind of position requires a great many new habits and the modifying of many old habits,--but, and here is the essential point, - the change can and does come. The old habits do not leave us merely fixed and hardened. The 
habits which are already made are the foundations for the necessary changes, without which the adaptation to the new kind of work would be even more difficult.

A quotation from the study of typewriting will show how this change goes on in the process of learning. Professor Book, in his excellent monograph on The Psychology of Skill, writes as follows: "Besides determining the special habits of every kind and order involved in the mastery of typewriting and showing concretely, by a minute history of the learning process, how these habits were developed and perfected as successively organized and recombined into associations and habits that bring the learner always more directly and economically to his goal, this study has shown the important role played in the learning by effort and hygiene.

"Two facts stand out above all the rest: 1) All special habits and associations involved in the mastery of typewriting must be carefully perfected. 2) They must then as rapidly as possible be outgrown and give way to higher and more direct habits of writing. Bryan and Harter were right when they said: "We believe that by no device is it possible to gain freedom in using the higher-order habits until the lower have been so well mastered that attention is not diverted by them.' They suggested a truth of still greater importance when they added: 'It is, nevertheless wise at all times to practise with the highest units possible, and thus learn all the units in their proper setting.' The older elementary habits tend naturally and strongly to persist and must be left behind as rapidly as possible to prevent arrest. To try to crowd ahead before the elementary habits are sufficiently mastered to make safe the taking of a forward step, or to fail to perfect the elemental associations which must be combined to form the higher and more direct methods of writing, is fatal to progress or interest." (10).

Other points appear in the above quotation, but of interest in this connection are the facts that the fundamental things are habits, and that progress depends upon them. These habits can and must change, just as surely as they are necessary as foundation habits.

Education and the development of permanent desires and interests. It cannot, perhaps, be too much emphasized that a part, and an essential part of the work of education is to develop permanent desires and interests. Not only to read good literature but to have a permanent interest in good literature. 
Not only to be neat or accurate or careful when required, but to develop the desire to be neat, accurate, and careful. And not only to have the idea of these things, and the permanent desire to attain them, but to try to do so, in order that the desired educational result, $i$. $e_{\text {., }}$ the permanent tendency to think, feel, and do these things, may be accomplished, so far as possible. These, also, are fundamental to progress. What would one accomplish without a passion for his work? This very lack of passion for work is the cause of much mediocre performance.

Fundamental nature and comprehensiveness of the habit theory. If we look back over the facts brought out in the first chapter we will see that the theory has the advantage of bringing us to the fundamental elements of the learning process. Such a procedure cannot do other than help us to a better understanding of education. One of the most common, and also, perhaps, one of the wisest pieces of advice given to beginners in whatever field it may be, is to start at the bottom and work up. Beginning with a study of the original inherited disposition, the native tendencies, and learning how to make them into the desirable thought, feeling and volitional dispositions is doing just this thing in the field of education.

As to the comprehensiveness of the principle it is not a small thing for the teacher to realize that all results of the learning process come only in conformance to the laws of habit formation. Wherever economy is to be had it is to be had only when there is conformance to these laws. Disregard of them and opposition to them cause unnecessary waste for both the student and the teacher.

It gives definiteness to the work of the teacher. No one thing more than definiteness is needed in the school. And nothing more than the thorough application of the habit principle to all phases of education will help to this great end. The great aims of education whatever they are can be interpreted in terms of habits. The methods of the teacher, the technique necessary for successful teaching, can be definitely worked out for the work of forming and modifying original nature so as to make the desirable permanent dispositions. In fact the more general statements of the aim and work of education can be dealt with in the school in no other way. To develop character, social efficiency, to prepare for enjoyment of life; to make one ready for one's vocation or profession can be done, but it cannot be done in general or in the abstract. 
These results are big complex things and must be dealt with by dealing with the elements that constitute them. The elements are thousands of habits. The habits are habits of thought, of feeling and of action. These the teacher can deal with definitely and can prepare himself to deal with. Thinking, feeling, and doing this, and this and this, and in this way, and that way and the other way, is specifically and definitely what the teacher can deal with. And he can do it with the assurance that this thinking and feeling and doing will determine the general outcome.

Habits result in character. There is nothing more true than that the definite bits of work and application that the teacher gets the student to do become the very texture of his life. Note what James says in this connection and note also that he speaks not merely of that which concerns skill or more mechanical habitual things but of the most complex thought processes.

"As we become permanent drunkards by so many separate drinks," he writes, "so we become saints in the moral, and authorities and experts in the practical and scientific spheres, by so many separate acts and hours of work. Let no youth have any anxiety about the upshot of his education, whatever the line of it may be. If he keep faithfully busy each hour of the working day, he may safely leave the final result to itself. He can with perfect certainty count on waking up some fine morning, to find himself one of the competent ones of his generation, in whatever pursuit he may have singled out. Silently, between all the details of his business, the power of judging in all that class of matter will have built itself up within him as a possession that will never pass away. Young people should know this truth in advance. The ignorance of it has probably engendered more discouragement and faintheartedness in youths embarking on arduous careers than all other causes put together."

And it may be said also that for the teacher, much of his work has been indefinite, and without sufficient knowledge and understanding of aim and method and results. With a proper understanding of these elements with which he is dealing he should be better able to attain that which is the greatest need in education today, namely, definiteness of aim and procedure, and in the getting of end results that can be measured. The general aims are thus analyzed into definite working aims. 
It gives the basis for scientific treatment and measurement. This treatment of the results of education also gives the elements that can be dealt with in a scientific manner. All that can be measured and all that is being measured by educational tests is behavior, and habits are the stuff of which behavior is made. It may be that some of the higher moral and aesthetic attitudes cannot be measured, or at least, that they cannot be measured in the same way that intellectual and motor habits of many kinds can. Difficulty with some of the more elusive results is no reason to fail with the quantitative treatment of the results that can be measured.

Looking over the results of some of the school surveys that have been made one may see how of ten this quantitative treatment has helped to point out the places where particular qualitative defects appear in the work of certain teachers. The quantitative work, does not, then, in any way, take the place of, or displace qualitative work. It supplements it and it is the direct scientific way of getting at the places where quality of work is poor. The teacher will find that such a study of all the work of teachers in a school will be much more just to each one than the old method of making personal judgments.

It reduces all education to the same terms. Whatever of value comes from a fundamental principle and reducing of large and various activities to the same terms appears in the reducing of the results of education to habits. There is here a unifying principle. The teacher should be helped to see the far reaching significance of the fundamental laws of habit for all his work. There should come a much greater simplification of many complex matters and more clarity in the understanding of them. The interpretation of all education in terms of habit should help the teacher to avoid many of the violations of the laws of habit that are all too common in the schools of today.

Psychological factors necessary to habit formation. The emphasis of these factors is more significant than may at first appear. We cannot merely look at end results. We cannot merely think of stimuli and responses. Successful direction of habit formation requires a knowledge of the conscious factors, the intellectual and emotional factors that enter in practice. The presence of ideals, knowledge of successes and failures, intention to remember, attitude of the learner, determination, knowledge of what to do and how to do it, etc., all are 
important in the economy of learning. Later pages will show how these and kindred factors are all important.

Manifold nature of the teacher's work. A further advantage of this habit theory of education, emphasizing as it does, the various kinds of habits to be formed, lies in its pointing out clearly the manifold nature of the teacher's work. If the teaching is merely informational, instructional, it is inadequate, as this type of teaching deals only or at least for the most part, with the habits of thought. There must also be the inspirational, the arousing, the stimulating, for the purpose of developing the feeling habits, and habitudes. And, finally, there must be such instructing and arousing as will result in the motor conclusion, the tendency to act appropriately in the various situations for which education succeeds in preparing the individual.

Other aims of education included and refined. This view of education also includes and makes definite the various aims of education with which we are familiar. Adaptation, social efficiency, the formation of character, etc. These aims are to be attained through the formation of the appropriate habits. Adaptation comes only through the forming and modifying of habits. Whatever efficiency one has is the result of practice, and the outcome of practice is nothing more nor less than habit.

The principle is true for the highest results at which education can aim. Sully long ago emphasized the place of habit in moral character, and we can perhaps, do no better than to quote a few sentences from his pages concerning moral character and the education of the will. "The height of moral character," he writes, "attained in any case is thus determined by the fixity and the commanding influence of the virtuous disposition, which again is measurable in terms of the facility, or absence of conscious effort, of the controlling process." (101).

This he writes under the caption of "Character as organized Habit." On the education of the will, he writes, "As we have seen in dealing with the several forms of self-control, and more especially with the phenomena of moral effort, the special direction of attention to an idea serves to modify its feeling-value, and so its motive force. Education of will, in the sense of developing one's character, turns on this fact. If only a desire to be better exists we can ourselves contribute towards the improvement by furthering from time to time the rein- 
statement of the appropriate motives so as to fix them as dominant forces. (102).

Disadvantages of the term habit. The term habit in too many minds suggests only the narrow mechanical action of the individual. The term habit does include those activities which have been made habitual to the highest degree, activities which are often called automatic. But habit rightly understood means just what the term is used to mean, from the automatic activities in the motor realm to the professional attitudes and moral habitudes. Bagley speaks of "a new habit of psychological observation," and of "specific habits of cleanliness, industry, and mental application." Andrews, in an excellent article in The American Journal of Psychology defines habit and gives as his first illustration the "attitude of 'loyalty to Alma Mater.' The habit, strictly speaking, he writes, "is the similar form as regards feeling which consciousness repeatedly takes." In a later place he quotes the following from James: "It is not simply particular lines of discharge, but general forms of discharge that are grooved out by habit in the brain." 'The disadvantage in terms exists, however, though many quotations of this kind might be made to show that common usage of the term includes this broader meaning.

Judgments, ideas and habits. The teacher finds one of the most important and most difficult parts of his work is that of getting the student to think, to form correct judgments, to deal with ideas instead of mere words. It may be that if the school gave more material for thought and more of live incentive and brought more of the kind of appeal to thought and the kind of reward for thinking that life normally affords when people outside of school actually think, it would not be so disappointing a matter. The writer has seen the school room made lively with keen critical thinking and has seen teachers whose pupils could not have failed to catch some of the stimulus to more careful and correct thinking. Such stimulus and practice cannot fail to make desirable tendencies or habits in the field of thought.

The tendency to have certain ideas or forms of thought are not, of course, the ideas or thoughts. Habits of thought are the tendencies to think more or less as one has thought before, and we have already shown how even the most complex thinking depends at bottom on the laws of habit. Helping the student to think and reason is dealt with in a later chapter. 
The whole emphasis of the book is toward the realization that if the thinking, the having of ideas, as well as of all other experiences of the learner is to be of value, there must be some permanent dispositions as a result.

Ideals, the guiding influence of education. We have already suggested that ideals are the things which should be the great guides for the accomplishment of results in education. Education we defined as the making, modifying, and remaking of more or less permanent dispositions, tendencies, habitudes, or, to use a single term, habits, under the guidance of ideals. As habit is the fundamental principle of education, so the determining of these habits in the directions of ideals is the guiding principle. The history of education is the history of how educators have tried to make ideals function in the lives of people and to bring about permanent educational possessions in terms of ideals. The importance of ideals can hardly be overestimated and the necessity for the best ideals surely cannot.

The following true story is a suggestion of what ideals mean in life. What they mean for the individual they mean for society. What they mean for society they mean for the whole world. Let the reader look to history and decide for himself how far the ideals of people or of individuals might be taken as true indication of what they shall be and do.

Ideals and achievement. "Success," said the master instrument maker of the world, "is having an ideal and living up to it as closely as one can." Last November, some of the leading men of the country gathered to celebrate the seventy-fifth birthday of the man who made the statement quoted above. "Uncle John" Brashear for twenty-one years worked for ten hours a day in the South Side Mills of Pittsburgh. After supper, in a little shop built by himself and wife with their own hands, he made astronomical instruments which are considered the best that man has produced. His first lens took three years to finish. The second lens took two years more and broke before it was finished. Dismayed at first, a word from his wife gave him new courage, and together they set out to make a larger and better lens than either of the others. After twenty-one years in the rolling mill he was free to give all of his time to the interest of his life, which was to make the best instruments possible by which people could study the stars.

The most difficult problems in instrument making have been given him. When Professor Michelson needed optical sur- 
faces that nowhere showed an error as great as one-millionth of an inch he asked Brashear to make them, and he made them. When the Canadian Government decided to have the largest telescope in the world they turned to Brashear. In return for a kindness which Professor Tyndall did him, the instrument maker sent him two planes and a ruled grating on which he had scratched lines so fine that they were sixty to the breadth of a human hair.

Dr. Brashear says: "If there is anything in my life uncommon it is because from the time I was a boy, no matter what I had to do, I tried to do it a little better than it had ever been done before." But Charles S. Schwab writes: "It seems to me that of all men of fame and achievement I have known, he is the most wonderful, ..... I have known him at times to get so interested in the struggle for perfection that he would turn out an instrument which in the making cost several times its selling price."

Ideals as permanent motives in life. What greater work can the teacher do than to develop ideals which shall function powerfully as motives? Note the essential factors which appear in the above example. On the one hand was the habitual thinking of perfection, on the other the permanent desire to make things a little better than they had ever been made before. Added to this was the constant effort to attain this perfection. So education must most vitally concern itself with ideals. It must do so by developing a tendency to think the ideal something, neatness, perfection, or what not, to feel for this thing and to have the habitual desire for it, and, also, to stimulate one to act in connection with this ideal so that the disposition to strive towards it becomes the habit of life.

The controlling principle of education. If the ideals of perfection and completeness in achievement, for example, in observation, memorization, in attainment of most valuable interests and sentiments, and in the mastery of skill and execution, - the standards in attainment in each and every bit of learning should be those which are reasonably and psychologically possible. The striving towards the ideals should reach certain standards at certain stages of education; thus standards should be the controlling principle of education.

So the ideal may remain ever so high and unattainable,-if they are attainable they are not high enough;- - but the standards must be determined by the physical and mental consti- 
tution of the student. For each individual let us say: We will try to educate him to his best, not some one else's best.

Curriculum based on activities which result in habits. Professor Meriam, among others, has brought to our notice lately the very important fact that grade school pupils may be prepared for high school as well, and in some cases better, without ordinary teaching of arithmetic, reading, writing and spelling. The students in The University Elementary School of the University of Missouri, pursue four "studies." They are, 1) Observation of nature and industrial activities, 2) Playing games of present interest, 3) Handwork: making things of immediate usefulness, 4) Enjoyment of stories, pictures, music.

"Reading, writing, arithmetic and other such 'common branches' are not taught as such at all. The content of such branches is used only as needed in one or more of the four studies constituting the curriculum of this school. This does not mean that pupils in this school do not learn to 'read, write or cipher.' It does mean, however, that proficiency in these common school studies is made subordinate, as a purpose, to proficiency in 'Observation,' 'Play,' 'Handwork,' and 'Enjoyment of Stories.' Thus it might be rightly claimed that the work of this school should be measured, not in terms of school subjects, but in terms of the out-of-school activities of the pupils.” (64).

The point is that activities that children will be required to do can be chosen and the habits involved in these activities developed. The resulting proficiency can be measured. If the habits to be formed can be chosen the teacher has a definite work to do. And the performance of the pupil in the expression of these habits is as definite an end product to measure as is possible in human beings.

In other schools the same emphasis on activity and the direction of activity instead of on content and information has been made. Notable among them are The Andover Play School. (48), The California Play Demonstration School. (31), and The Worcester Girls' Trade School, (83). Jones in his excellent monograph on "Training in Education" gives an outline of the principle features of these systems, (49), and savs: "Activity liberates reflexes involved in instincts, thus making possible the formation of Habits, of learning and forgetting through the operation of the factors and laws discussed previously. As pointed out and emphasized by almost every 
great educator and implied in the great systems of education, activity is the real basis of education." (50),

Kinds of habits to be formed. Finally we may indicate in general summary some of the most important kinds of habits that are to be formed. They are given under the heads of intellectual, emotional and motor. This classification helps to show from one point of view, the different kinds of work the teacher has to do as already mentioned.

I. Intellectual.

1. Habits of observing carefully and accurately.

2. Habits of clear and accurate association and recall; memorial habits, or memories.

3. Habits of forming new concepts and of refining and correcting old ones.

4. Habits of making clear, accurate, logical judgments.

5. Habits of thinking over, meditating upon, rehearsing, and thinking out old ideas and conclusions, from new points of view, for productive thought, $i$. $e$., originality.

6. Habits of good attention.

II. Emotional.

1. Permanent interests, in science, literature, art, government, etc., as for example, a passion for science.

2. Emotional attitudes, desires, and the like, which may develop into such things as, logical sentiments or desire for truth, ethical sentiments or desire for the highest good, aesthetic sentiments or desire for the beautiful, religious sentiments. Dislikes on the other hand, for things that are unworthy, immoral, etc. Under this head we may include "habitudes."

III. Motor habits.

1. Habits of quick and appropriate action following upon the appropriate stimulus, or upon deliberation and decision.

2. Habits of decision.

3. Particular habits of skill or technique, as those of writing, handling apparatus, using tools, etc.

Generalized habits and the habit of generalizing and applying. Habits are both specific and general. The habits mentioned above must be acquired in connection with certain activities and result in the easier, more economical doing of the things learned. But habits may be generalized or general; that is, they may act from the arousal of different stimuli than 
those which originally aroused them, or they may act under the dominance of different emotional states. There may also be the habit of applying what is learned, of trying to make it help in other fields than that in which the habit was acquired. These may include the results of education which are called "transfers of training," and it is possible that all transfers may be reduced to the transfer of habits, under favorable conditions, e. g., presence of ideals, realizations of value, desire and attempt to make applications, etc. In other words, transfer of training, which refers to improvement in one activity which is correlated with improvement in another or other activities, may at bottom be habits learned in one situation which are set into action by stimuli different from those which originally started the habit.

Education as habit under the guidance of ideals and the control of standards. Education, reduces, then, to the formation of habits including habitudes and the modifications of those already formed. It means the remaking of the individual. This process goes on under the guidance of ideals and the control of standards. Society must determine what these ideals shall be. Educators must determine the standards. The pressure upon the learner to acquire the necessary education, $i . e$., the necessary habits, may come from without himself, or the ideals may be accepted and a motive force arise within him to drive him on to attainment. Both of these things occur: society, in the persons of parent and teacher, and the demands of others, and ideals attained in the course of development in the individual all play their part.

The native tendencies are the means of bringing about actions or responses. Acquisitions take place in various ways. Progress in this acquisition and the permanence of this acquisition follow. Various physiological and physical conditions enter to help or to hinder the development. Training in one thing may improve other activities. And finally suggestions and rules for the direction of the learner in the most economic acquisition may be given. These things will be treated in the following chapters.

\section{QUESTIONS AND SUGGESTIONS FOR STUDY.}

1. Show how habit is basic for education and for progress in learning.

2. How far are habits already formed modifiable? 
3. Is it necessary to form habits and then modify them in learning? Illustrate.

4. Discuss the advantages of interpreting education in terms of the principle of habit?

5. How may this be disadvantageous, especially, so far as the use of the term "habit" is concerned?

6. From what you have learned in the last two chapters discuss the meaning and truth of the following statement."An acquired habit, from the physiological point of view, is nothing but a new pathway of discharge formed in the brain, by which certain incoming currents ever after tend to escape ....the association of ideas, perception, memory, reasoning, the education of the will, etc., etc., can best be understood as results of the formation de novo of just such pathways of discharge." W. James.

7. What is the teacher's work in terms of habit formation?

8. Find illustrations to show the effect of ideals in individusls and in groups.

9. To what extent have educators in various ages consciously concerned themselves with ideals?

10. State and discuss what you think should be the controlling principle of education.

\section{REFERENCES.}

Andrews, B. R. Habit. Am. J. Psychol. 14, 1903, Pp. 121-149.

James, W. Psychology, Briefer Courses. Ch. 10. Or, Principles of Psychology, Vol. 1, Ch. 4. Also, Talks to Teachers on Psychology, 1904, Ch. 8.

RADESTOCK, P. Habit and Education. D. C. Heath and Co., 1902, P. 117. 
Chapter 4.

\section{LEARNING AND HABIT FORMATION.}

Life and habit formation. Life goes on mostly through habit; and any progress beyond the slow laborious doing of things as one does when learning how to do them, depends, if we except reflex and instinct, absolutely upon habit. Moreover this learning as we have already shown, depends on previous acquisitions which have become habits. If we think of the nervous system this means that the higher centers are concerned with the new, the problematic, the difficult, that which has not yet been mastered. As soon as this learning becomes sufficiently habitual, the lower centers take up the activities, as far as they can, bring about the performances, and at the same time relieve the higher centers. The higher centers can now concern themselves with the next new problem. It is not to be understood that only the lower centers act according to this law of habit. The higher centers, the brain, also must be considered as taking the 'sets' which practice gives them. Progress in learning shows the presence of activity with attention at first, changing into activity which is habitual; again attention appears, but to something new, what has been learned sufficiently well being carried on by habit. In this way all progress is made in skill, in memorizing, in mastering all of the reactions to our world.

We have said that the results of education are nothing more than habits of some kind, $i$. $e$., more or less permanent dispositions, tendencies, interests, habitudes and the like. The important thing is that the habits be good rather than bad habits; that they be helpful rather than harmful: that the nervous system be trained to react as we want it to act.

The need for habits. The need for habits is coextensive with the need for education. Progress is dependent upon acquisition which has become habitual. Efficiency, mastery, competency in anything whatsoever, exist only insofar as they are made possible by the necessary groups of well formed and well organized habits. The need for and the value of habits mav be shown by a statement of the results of habit formation.

The effects of habit. The effects of habit may be summed 
up as follows: it brings perfection and accuracy of action, lessens fatigue and strain, insures an increasing degree of promptness and certainty of response, and gradually eliminates things to which one must give attention. The scope of one's response is thus greatly enlarged, and the time in which one can successfully and comfortably carry on activities which have been made habitual is very much lengthened. Judgments and actions are better and quicker; and one can respond to more and more complex situations.

Habits tend, within limits, to make people do the same things in the same way; stick to the same trade or profession; like the same kind of music; turn to the old familiar authors, want the old coat and wear the new clothes in the old way; think things are right because they have done them for years, or wrong because they have never done them; fall back on the old interpretations; cling to the old beliefs; in short, be and feel and do the same things in the same way. It gives a stability to the individual and to society.

Habits of the broadest kind, or "habitudes," it must be remembered, have a different result. They tend to make people respond in terms of ideals, motives, maxims, and the like, and require judgment, and conscious reflection. Here one is made more rather than less conscious.

Strong guiding influence of habit. Little do we realize, perhaps, the fact that habit once made determines what we shall do even in cases in which our conscious processes would indicate some other behavior. No better statement of this matter can be found than that of Prof. Titchener, who writes: "Now the important point in the present connection is this: that the side which finally proves to be the stronger, in the struggle of secondary attention, need not necessarily be the consciously stronger. The conflict between working and going to the fire may lead to a victory for work. in spite of the fact that consiousness is more fully occupied by fire-ideas than it is by work-ideas. The nervous system, in virtue of its own bias or leaning, has brought up further reinforcements on the side of work, and these reinforcements have directed or guided consciousness although they are not themselves represented in consciousness."

"The guiding influence of nervous bias is not a matter of inference, still less a matter of speculation; it can be demonstraded in the psychological laboratory. Suppose that we are measuring the time required to reply to a spoken word by an- 
other word of the same class or kind: to associate dog to cat, table to chair, and so on. The experimenter prepares a long list of words: cat, chair, and so forth. Then he explains to the observer the precise nature of the experiment: I shall call out certain words, he says, and you are to reply, as quickly as you can, with words of the same class; if I say horse, you will mention some other animal, and if I say pen, you will mention something else that has to do with writing. The observer understands, and the experiment begins. Suppose, further, that the experiments have been continued for some days. The experimenter has no need to repeat his explanation at every sitting; the observer takes it for granted that he is still to reply with a coordinate word. And suppose, finally, that some day, after a week's work, the experimenter interrupts the series, and asks: Are you thinking about what I told you to do? The observer, fearing that he has made some error, and feeling very repentent, will say: No, to tell the truth I had absolutely forgotten all about it; it had gone altogether out of my mind; have I done anything wrong? He had not done anything wrong; but his answer shows that a certain tendency, impressed upon his nervous system by the experimenter's original explanation, has been effective to direct the course of his ideas long after its conscious correlate has disappeared. And what happens here, in the laboratory, happens every day of our lives in the wider experience outside the laboratory." (118).

Importance of early training. For the determination of our future life, our future thinking, liking, disliking, ability to do and ways of doing, nothing so much as the understanding of habit, makes one realize the importance of doing early what one desires to do later. Competency, efficiency, mastery, are the results of continual and regular practice. The point is that regular application brings inevitable results in whatever field it may be: in the making of judgments in the fields of law, or science, or business; in acquiring appreciation in the field of art, or of music, or of literature: in drawing, or in playing a musical instrument, or in anything else of which one can think.

These habits of feeling, of thinking and of acting are the things we fall back on in the emergencies of life, and they are what carry us through successfully if we come through successfully at all. Even the original thinking in the novel situations, depend, as already shown, upon the habits of thought. Or, to put it differently, for example, we rightly expect that the 
difficult problems will be solved better and more surely, not by one who has newly entered the field of thought in which the problem occurs, but by one who has worked in this field, who has solved problems and become familiar with all this kind of facts, who, in other words, has formed his habits of thinking in this field and whose judgments are, in proportion to his mastery of the field, liable to be sure and right.

Knowing this, one knows, not the royal road, but what might perhaps be called the real stairway to efficiency or better to mastery of his chosen field or portion thereof. The analogy of the stairway is significant. It should suggest two facts, first, that there are habits dependent on others made earlier, and second, and partly for this reason, that habits should be fully made. Many habits are made easily, some with a single performance if they are simple and easy and pleasant, or if the experience is very vivid; but it is obvious that there are many desirable habits which are complex and not so pleasant and which do not make themselves, so to speak. The hit or miss method of learning, imitation of which one is conscious, or imitation of which one is not conscious, are sufficient for many of the former kind of habits; but for the more difficult ones there are many conditions of which the teacher and the student should be conscious, manv helps to the formation of habits of which they should be able to take advantage; many hindrances which they should be able either to avoid or to render less effective.

\section{PRINCIPLES OF HABIT FORMATION.}

1. Learning correctly. That "we learn to do by doing" is true. That we learn to do incorrectly by doing incorrectly is part of this truth. Above everything else, the student must follow another precept: "learn to do by doing correctly." Repeat but repeat only correct actions. The selection of the correct response is essential. Anything that is once learned is never entirely unlearned; that is to say, anything once made a part of the nervous system is never entirely wiped out. Anyone can pick out many incorrect habits that are a part of him. The spelling of a certain word was learned incorrectly; the finger learned to hit the wrong key on the typewriter; the wrong form of speech or the incorrect pronunciation crept in and became habitual; then there was the attempt to unlearn and relearn. Who does not keenly realize the difficulty? Unlearning and relearning harder than the original learning! Yes, but more than that, the original learning is never entirely un- 
learned. The new habit may be learned. The old habit may be submerged a good part of the time, or may grow weaker from disuse. But when one is in a hurry, or is striving the hardest for a perfect performance, out comes the old incorrect response. We hit the wrong key on the typewriter, or make the same grammatical error. With an understanding of the facts of habit, the conclusion is obvious: learn correctly the first time, never let anything incorrect become habitual. Never practise unless you practise correctly and thoroughly; bad practice is worse than no practice; the pianist, the singer, the billiard player, the expert in any line comes to learn this sooner or later.

2. Accuracy first, speed later. As a corollary of what has just been said it follows that accuracy should be worked for first and that speed should be left till later. Without doubt this is a principle which should govern all kinds of learning. The fastest way to progress is to go slowly at first. Speed will come. And the demand and pressure of circumstances can generally be expected to accomplish this. I have frequently stated this general principle to teachers and have had nothing but concurrence in the matter from them.

3. Strong and decided initiative. (41). As has been of ten said, in the forming of a habit, we should launch ourselves with as strong and decided an initiative as possible. The start is very important. Success helps to further success. Failure may dishearten.

4. Continuity of practice. "Continuity of training," James says, "is the great means of making the nervous system act infallibly right." Never to permit an exception till the habit is fully formed is the rule. Exceptions undo much that has been done. They even start another habit; the habit of making exceptions. The more difficult the habit, the more important that an exception does not occur; because this makes it easier to fall into the way of letting them occur.

5. U'se of every opportunity. The same author adds the following maxim: "Seize the very first opportunity to act on every resolution you make, and on every emotional prompting you may experience in the direction of the habits you aspire to gain. It is not in the moment of their forming, but in the moment of their producing motor effects, that resolves and aspirations communicate the new 'set' to the brain.'

6. Caring enough and determination. If a person only cares enough, he is likely to succeed in forming the habit he 
sets out to make. What we care enough for we generally find time for, and find a way to do. It is just the not caring enough that is as likely as anything to be the weak place. Closely related to this is determination; let one be determined, his mind be fully made up, as the phrase goes, and he has one of the best helps. Internally one needs this whole hearted giving of one's self to the task of habit making if the habit be difficult and unpleasant. Caring enough, a deep thorough-going desire for the habit, determination, high resolve, and then throwing one's self into the doing,-these are invaluable internal aids.

7. A clear plan. One is more likely to do a thing if he knows exactly what to do and how to do it. If the method of doing, the way to start in, the order of sequence, or what not, are still in question, it takes more effort to hold to the thing. A clear plan eliminates many difficulties, and hesitations, and decisions to put off until another time.

8. Realization of value. Another internal help is the realization of the value of the habit, if it be once formed. Knowing what one can accomplish with this skill; what can be attained with that combination of habits; how certain acquisitions can be applied in bettering one's position, or salary, makes one of the strongest incentives. As an illustration of this, note the change in attitude and efforts of students when they come to find that certain subjects will be of practical value to them, $e$. $g$., professional students, who are getting the things which mean entering into and succeeding in their professions.

9. Success and the feeling of success; mastery and the feeling of mastery. One needs to succeed, to master something, and to learn the difference it makes in the whole mental life and attitude of the individual. One is a different person when he has mastered something and has the feeling of success and, better, the feeling of mastery. Move slowly and surely totowards success and towards mastering your desired habits, and every bit of success and the feeling of all earlier successes will help you.

10. Suggestion. Suggestion helps in various ways. You may have the suggestion of people. People who are accomplishing things, who are doing what you want to do, who are enthusiastic, and who keep you in the general atmosphere of doing and succeeding, are by all means valuable to one who is trying to form difficult habits. 
Suggestion also helps when it lies in objects, and places, and the like. The library, the gymnasium, the study room, the laboratory, all are suggestions, and where work is being done and studying is going on, it is easier to work or to study as the case may be.

11. Publishing intentions. Telling a friend or a few good friends that you are going to form a certain habit may bring the strongest pressure to bear. If the friends are of the right kind they will see that you are reminded of your resolution; if you fail you will be joked about it; whatever happens, you will either succeed or fail, not only in your own knowledge, but in the eyes of your friends. This has been found to help where everything else has failed.

12. Penalties. If one can enforce a penalty or get someone else to enforce a penalty for him. he may find that he has a very helpful incentive. But the penalty must be a real one. Putting a dime in a box for each failure and having in the background of mind the idea that when you get enough you will spend it for a box of candy or a theatre is not a penalty. There must be an actual felt loss to yourself. If you pay for every failure, the money in the end must be lost to you entirely. Perhaps the best kind of a penalty is the removal of some privilege. It presses hard on one to find himself deprived of something which he really desires and to which he is accustomed.

13. Putting one's self on honor. If it seems necessary, putting one's self on honor, will often help. But one should never do this unless he endeavors in every possible way to succeed. Failing when one has appealed to this kind of a last resort is a serious affair.

14. Thoroughness. Habits should be completely formed. Habits are the bases of later acquisitions and for that reason if for no other they should be fully made. A partially formed habit fails to bring the results that habits are known to bring, and which we have mentioned above. Neither is there the permanence that goes with the fully made habit. Perhaps the largest part of the difficulty with most of our learning lies in the fact that previous acquisitions have not been sufficiently well learned. The promptness and accuracy which some people show in learning new things, in solving new problems, in applying old knowledge, lies very largely, if not almost wholly, except for native capacity, in the fact that the earlier acquisitions were thoroughly made. Getting over the ground, 
getting through, is not making the most valuable and permanent progress.

\section{HINDRANCES TO HABIT FORMATION.}

1. Not caring enough. Some of the things that we have called helps to habit formation may be lacking, and a lack of the sincere desire is one of the most serious handicaps. Many things in this life are not done simply because we do not care. If the stimulating suggestion only happened along, or we fell upon the right biographical sketch, or had one of the "calico wives" that make "broadcloth husbands!" Perhaps we would not settle down comfortably and say, "What's the use?"

2. Laziness. Human beings, like inanimate objects, are subject to the law of inertia. Laziness may be merely a matter of habit. Again failure to rise and make necessary efforts may be simply that the incentives, the things that stir one up are lacking.

3. Lack of incentive. This lack of incentive may well be emphasized. A word from a friend, a suggestion from a newspaper, or a journal, a smile of reproach may be all that is necessary to arouse one to the most strenuous efforts. If the incentive does not come and if one is not too lazy, he may find the former with a little effort and be a winner instead of a loser.

4. Other habits. Old habits are the basis upon which new acquisitions are made. But it is also true that some old habits interfere with the formation of some new habits. Where the new act opposes the habitual acts, the old tendencies make the acquisition difficult. This is all the more true where one has to break an old habit or substitute a new for an old one.

5. Difficulty and complexity. The habit itself may be difficult. Progress in the formation of habits leads one to more and more complex and difficult problems. The advance that one makes renders it easier to do what has already been made habitual, but succeeding steps are naturally harder and discouragement may creep in.

6. Unpleasantness. When a thing is to be done, it is likely that the best thing one can do is to forget one's feelings and think of the thing to be done. Old things are pleasant and new things are likely to be unpleasant if they require effort. We have, at least, to cope with that biological tendency that leads us to avoid the unpleasant.

7. The pressure of time and other things. We fail to take 
up the formation of many new habits because we have too many other things to do. It is the old story: I haven't time; I'm too busy; I can't get time now to do half the things I want to do. Time is short when we are doing things. When we are really busy we have not time for half of the worth while things. It is a question of choosing; but if we really care enough, and if the new habit is sufficiently valuable, the probability is that at least most of us can find time.

8. The tendency to feel without acting. One of the most insidious evils of life lies in this habit of feeling, of having a fine impulse or sentiment, and then letting the tendency fritter off without coming to any motor consequence. Instead of forming the desirable habits of acting in accordance with our fine feelings, we actually form habits of merely enjoying the thrill and then, likely enough, of looking for the next thrill. James tells us that "Every time a resolve or a fine glow of feeling evaporates without bearing practical fruit is worse than a chance lost; it works so as positively to hinder future resolutions and emotions from taking the normal path of discharge. There is no more contemptible type of human character than that of the nerveless sentimentalist and dreamer, who spends his life in a weltering sea of sensibility and emotion, but who never does a manly concrete deed.

The habit of excessive novel-reading and theatre-going will produce true monsters in this line. The weeping of a Russian lady over the fictitious personages in the play, while her coachman is freezing to death on his seat outside, is the sort of thing that everywhere happens on a less glaring scale. Even the habit of excessive indulgence in music, for those who are neither performers themselves nor musically gifted enough to take it in a purely intellectual way, has probably a relaxing effect upon the character. One becomes filled with emotions which habitually pass without prompting to any deed, and so the inertly sentimental condition is kept up. The remedy would be, never to suffer one's self to have an emotion at a concert, without expressing it afterward in some active way. Let the expression be the least thing in the world-speaking genially to one's aunt, or giving up one's seat in a horse-car, if nothing more heroic offers-but let it not fail to take place." (38).

9. The incomplete learning of other habits. Although treated in another place, it is appropriate here to mention the fact that incomplete learning of foundation habits interferes 
with future learning. Whereas one's attention should be free to deal with the new habit that is to be formed, this incomplete learning necessitates giving attention to direct the old actions. This is a serious interference and is to be obviated by complete learning of one thing before going on to the next.

BREAKING OLD HABITS.

1. Never permit the old habit to function. If possible, and if the consequences are not too severe on the individual, the best thing is to discontinue the old habit at once and completely. This may be extremely difficult and one may need all the determination, and purpose, and desire for the death of the old habit that is possible. 'Tapering off' is a makeshift which may be necessary. But after all it is probably only in very extreme cases that it is necessary. It has the disadvantage of continuing the habit, of exercising it, even though it be only light exercise.

2. Remove the conditions and suggestions for the old habit. To assist one in leaving off the old habit, all the things that suggest it should be avoided. It is easier to stay away from a feast than to go and not partake. If necessary remove yourself from the environment and the people which invite or even make you think of the old habit. The force of suggestion can hardly be too much emphasized. One may break an old habit with comparative ease by going to a new environment and among different people. And one may fall into the old habit again immediately on frequenting the old haunts.

3. Develop a substitute habit. Train yourself to a substitute habit so that whenever you think of the old habit, the new one takes its place. In the development of the new habit one can make use of many suggestions given for the formation of new habits.

4. Penalties. As already shown, penalties, if they be real, are helps to the formation of habits; they are also helps to breaking habits. Let one suffer some unpleasant consequence of every lapse into the old habit and he will have a powerful influence to its discontinuance.

5. A new ideal coupled with strong emotion. Religious conversions give us some of the best illustrations of the breaking of old habits under the guidance of a new ideal and aided by the strong emotional reaction that may accompany it. Finding a new center of energy as it has been termed, a new 
strong motive to action and to a new kind of life, may bring the desired result. Religion of ten accomplishes this.

6. New demands and responsibilities. New demands and responsibilities also afford the motive power, so to speak, for breaking old habits and forming new ones. A new and better position, the presence of imitative children, the need for greater efficiency, the influence of a new group of busines or social acquaintances, all help if they can be had.

"Keep the faculty of effort alive." "As a final practical maxim, relative to these habits of will," writes James, in his immortal chapter on Habit, "we may, then, offer something like this: Keep the faculty of effort alive in you by a little gratuitous exercise every day. That is, be systematically ascetic or heroic in little unnecessary points, do every day or two something for no other reason than that you would rather not do it, so that when the hour of dire need draws nigh, it may find you not unnerved and untrained to stand the test. Asceticism of this sort is like the insurance which a man pays on his house and goods. The tax does him no good at the time, and possibly may never bring him a return. But if the fire does come, his having paid it will be his salvation from ruin. So with the man who has daily inured himself to habits of concentrated attention, energetic volition, and self-denial in unnecessary things. He will stand like a tower when everything rocks around him, and when his softer fellow-mortals are winnowed like chaff in the blast."

The habit of making new habits. One of the best ways in which to keep in the way of making progress beyond the old methods, the old ways of thinking, feeling and acting is to form the habit of making new habits. There is something stimulating and invigorating about the making of a new habit. There is no need for more than one settled kind of response in many of the situations of life, perhaps, in most of the situations. But several kinds of response for situations that require new adaptations, offer just the possibility of keeping pliable and avoiding narrowness. The most valuable tendency of several may thus be chosen according to the circumstances.

\section{QUESTIONS AND SUGGESTIONS FOR STUDY.}

1. Show the needs for habits in the individual.

2. What are the effects of habit formation? Do all habits 
have the same effect as regards the presence and absence of consciousness?

3. Discuss the desirability of getting accuracy before attempting speed.

4. Think of some desirable habit you might make and make a list of the factors you could use best to help in the formation of the habit.

5. What are the greatest obstacles to habit formation?

6. Discuss the best methods of breaking a bad habit.

7. How may habits make for a contemptible character?

8. How may habits be the greatest safeguards against temptation.

\section{REFERENCES.}

Book, W. F. The Psychology of Skill, with Special Reference to its Acquisition in Typewriting. Univ. of Montana Pub. in Psychol., Bull. No. 53, Psychol. Series No. 1, 1908.

JuDD, C. H. The Psychology of High School Subjects. Ginn and Co., 1915. Ch. 12.

JAMES, W. Psychology, Briefer Course. Ch. 10. Or Principles of Psychology. Vol. 1, Ch. 4.

Rowe, S. H. Habit Formation and the Science of Teaching. Longmans, Green and Co., 1916. 


\section{Chapter 5. \\ ACQUISITION WHICH INVOLVES STUDY.}

The acquisition of knowledge. Lower organisms come into life and seem to adapt themselves with comparative ease to their environment. They do adapt themselves with less difficulty than the higher organisms. This is true, partly, because their inherited tendencies suffice to a very large degree to adapt them, and partly, because they have no such complex environment to which to become adapted as have the higher organisms. It is, however, not until we come to the highest form of life, namely, man, that we find the learning process must go on for a good many years before the individual is prepared to do what human beings consider really effective living. And it is only in the years beyond babyhood and earliest childhood that the conscious, self directed learning, called study goes on. The young child can learn but he cannot study.

When he does come to study, in the home, in the school room, on the playground, or later in professional life, certain mental processes are necessary and fundamental. Of these processes we may mention as perhaps the most important, the ones that enter. into the acquisition of knowledge through the senses, the making of judgments, the getting of clear conceptions, and memorizing or making permanent, or, at least, comparatively permanent the acquisitions.

The ${ }^{\circ}$ larger activities just mentioned are made possible in different ways. The gathering of facts may be by means of observation, by reading, by conversation, or by recall of facts formerly learned and by reasoning. Clear ideas may be had through sufficiently careful and prolonged observation, or by turning over in mind ideas recalled or thought out. The desired judgments can be made only through careful reasoning with relevant ideas.

In acquisition selection is always going on. One selects certain factors rather than others in the study of external things; one selects some ideas rather than others in reasoning. There is always a grouping of thoughts; ideas are grouped with other ideas already present; indeed, either for understanding or for remembering, there must be some grouping or associating of 
ideas. There is always some degree of impressing, of making the tendency to remember. Other processes might be mentioned. In the present chapter we shall deal in turn with the acquisition of knowledge through the senses, and the acquisition of knowledge through reasoning. We may in fact classify all kinds of learning under these two heads for practical reasons. We might, of course, have another division of associative learning. But again let it be said and emphasized that association goes on in all kinds of learning and we prefer to deal with it in this way.

Acquisition through the senses: observational learning. Four factors which determine our perceptions can be mentioned. These are the objects themselves, the contents of consciousness, mental habits, and physiological conditions.

1. The external object. The physical object obviously enough is one determinant of perception. The stimulus arouses the sense organ. But the sensory processes alone are not sufficient. The first sights, sounds, feelings and the like, of the infant are not the same as the sights, sounds and feelings of the adult. We are reasonably sure that there are no "perceptions" in the first experiences of the infant. The impressions at first have no meaning. The object is not seen as: the particular object which it is.

2. The contents of consciousness. A particularly instructive case which illustrates the second factor is that of a man who was born blind and received his sight by an operation when an adult. He gazed at objects which were familiar to him through touch, but was unable to recognize them until he felt of them. Not until past experience, in the form of imagery if you please, supplemented his sense impressions, could he "perceive" through the sense of sight. In the same way, knowledge that one has, determines whether or not one can read a page of Latin or of any other language. Knowledge of an object makes it possible to observe more details of the object.

3. Mental habits. Mental habits also have a great deal to do with our perceptions. A good illustration of this is afforded by the clock in the Court House tower in Minneapolis. I fell into the habit of asking my students what kind of numerals there are on the face of this clock. Most of them answered Roman, a few said Arabic, and a few that there are no numerals on the face of this particular clock. The latter few were correct; there are none. But many people have 'seen" 
them and I am sure that I 'saw' them once or twice before I discovered that I had a good example of illusion to use for my classes in begimning psychology. On.the face of this clock twelve single bars are used in place of numerals; but people tend to 'see' what they are in the habit of seeing.

4. Physiological processes. The correcting of physical defects of school children has impressed those at all conversant with the facts that the physiological processes of the body and especially those of the nervous system are exceedingly important. In fact, when we state the exact truth, we are obliged to say that mental activity, of whatever kind, is absolutely dependent upon the underlying physiological activities. Mental defects correlate with brain defects. The removal of defects of eye and ear and of adenoids is followed by improvement in school work. More will be said on this subject in the chapter on Physical and Physiological Conditions. Suffice it to say here that observational learning as well as any other kind of learning depends directly upon good neural activity.

Attention. One of the results of attention is better intellectual work. The better the attention, the better the intellectual activity. Attention means mental clearness. Genius, we are told, is only a "protracted attention." And it is this getting ideas clear and having them clear for a sufficiently long time that is one of the essentials in learning and especially in study.

Attention to the object, the page, the speaker, is of prime importance in this kind of learning; attention which is definitely directed to the things which are to be remembered. This attention needs to be, not spasmodic and wandering, but sustained.

Thoroughness. The completeness of observational learning, Meumann tells us, aids the memory. Where things are left out, where there are lost links, so to speak, memory fails to find the connections which should be present. Thoroughness is essential, but just what thoroughness means in a given case is a matter of judgment. Only by fulfilling the requirements of a task is one sufficiently thorough, but thoroughness in finishing a woodshed is different from thoroughness in finishing parlor decorations. A student may not be sufficiently thorough even if he does all the exercises in a given lesson; he may be much more thorough if he does half of the exercises and masters the principles involved. But it must be remembered that it is the doing over and over again that makes an acquisition wholly ours. Again a student may not be suf- 
ficiently thorough even though he memorizes all the facts in a chapter; he may be more thorough if he chooses only the important facts and understands them.

There is a quotation in Porter's famous old book entitled, "The Elements of Intellectual Science" that is worthy of the consideration of anyone who would become a real student: "The late Sir Thomas Folwell Burton advised his sons in the following golden words: 'What you know, know thoroughly.' ..... There are few instances in modern times of a rise equal to that of Sir Edward Sugden..... I ventured to ask him, What was the secret of his success; his answer was: 'I resolved, when beginning to read law, to make everything I acquired perfectly my own, and never to go to a second thing until I had entirely accomplished the first. Many of my competitors read as much in a day as I read in a week; but at the end of twelve months, my knowledge was as fresh as on the day it was acquired, while theirs had glided away from their recollection."'

Observation with definite expectation. Observational study may go on under either one of two conditions : first, with definite expectation of the things that are to be noted; second, under the problem of making a complete observation of everything under consideration. The results of the observations with and without definite expectation are sure to be different in most cases. With the expectation present a person finds what he is seeking more quickly; he is surer of it when he sees it; and he has a more comfortable feeling in being able to say, this is not it and that is not it, and finally, this is it and I know it; this looks exactly like the picture in the book, or it is exactly what the teacher described.

But beware!. The clear imagination of the thing to be observed is all too likely to make one see it as he imagines it rather than as it is, or possibly to think he sees it even if it is not present. Students find what they are looking for whether it is there or not. In the laboratory they find structures whether the microscope reveals them or not. Or they see something else and mistake it for the thing which is clearly imagined in their own minds. The fact was reported to me recently that for a number of years instructors in a certain subject had "seen" a certain structure which had been reported to exist in a certain kind of plant. The existence of this structure was believed for several years and was found by many students. A more intensive study of the same plant 
later proved that no such structure existed. The triumph of suggestion over perception. The student who knows definitely what he is looking for, must then, make his observation as true to the facts as possible to avoid the influence of misleading suggestions.

"Apperception." As commonly used, apperception probably means nothing more than perception, except that it may serve to emphasize the meaning side of the perception. It is true that a person must interpret in terms of the knowledge that he has; that is the only possible way. The more he knows when he reads a book or hears a lecture, the more he can understand and remember. The student generally has too few ideas under which to classify the new facts; one important work of an education is to develop more and more heads under which to classify new facts. In this way classifying can be more accurate. Getting mentally fossilized is mostly a matter of being unable to develop new ideas with which to understand and to classify. Taking one point of view may lead one to over look others. And one should remember that it is safe to look at problems from more than one point of view.

Observation for complete analysis. In the second place, observation may be made for complete analysis. A problem may be set: to analyze as completely as possible this plant, or that tissue in anatony, or the reaction in the test tube, that is, to note whatever there is to note. Here the student loses the limiting effect of definite expectation, and he needs to limit the attention by the problem, noting only the things that are pertinent to his problem. If he is to note everything possible, to make an exhaustive analysis, the limitation of the attention is not so vital; but here one should at least be systematic and observe first one kind of fact and then another, for example, facts in relation to form, then to color, then to texture, etc., or in whatever order the material and problem demand. Points of view should be present to the student from his general information, and others should present themselves as the study proceeds. The results of such study are to be verified by repeated observation and by comparison with the results of others. It may also be remarked that besides the details to be noted, one should not forget to note the impression of the thing as a whole, that is, the general or total impression.

Learning by trial and error. What is commonly known as the trial and error method of learning offers a means of pro- 
ducing results that the student can observe and from which he can select those results and methods that are suitable for his purpose. It should be remembered that the trial and error method may waste much time, but for simple things it may give a solution quickly and save time required for reasoning. If the method is used systematically, as by the inventor, it may give results that could be had in no other way. This is the method by which Edison is said to have discovered the filiment for the incandescent lamp. One kind of material was used after the other and cast aside until finally the acceptable material was found. The value of a theory obtained by reasoning, the usefulness of a new piece of apparatus, can be known only through trying and observing the results of the trials.

Imitation. Imitation has its limitations; it permits one to progress no farther than the model, and the value of results is directly dependent upon the correctness of the model. Above all, one should realize how much is learned through unconscious imitation, that is, imitation of which the imitator is unconscious: the acquiring of a language, of the accent, of the feeling for a language, pronunciation, manner of acting and of talking, all are or may be learned largely by imitation of which the learner is hardly conscious and all too likely not at all critical. Some of the things that go the deepest and are the hardest to eradicate are learned by this method. This fact alone makes it imperative that one have for teachers those whom one can imitate to advantage. The need for a fine personality in the teacher comes from the tendency towards unconscious imitation on the part of the student.

Note-taking. Learning through the senses is likely to involve taking notes. Taking notes is a difficult art. Reviewing poor notes for an examination is the cause of some if not of many failures. A few suggestions are pertinent.

Just as all study should be topical, so all note-taking should be topical. The first thing is to know the general subject or problem; next to get the first main head. then the sub-heads under this with illustrations for each point if possible; next the second main head with the sub-heads and illustrations; next the third main head, and so on.

Note specific facts and the exceptions to the facts; both are valuable. Be sure to put down self explanatory headings, not mere headings that suggest that there were facts of some kind given. Get the facts. Do not fall into the bad habit of mere- 
ly getting general impressions. If an address is for the purpose of inspiring, be inspired if you can; this is not the kind of talk of which to take notes.

For accuracy use the words of the speaker; for speed in getting things written, learn to put into your own words and to abbreviate. Use shorthand expressions and learn the words that can be omitted without loss of meaning. Be brief; the fewer notes you take, the more likely you will be to choose the more important things or at least to have a chance to train yourself to do this, and, what is also very important, you can attend to the thoughts expressed and not be so liable to put down one thought and lose two. Taking complete statements means a loss of time and is of very questionable advantage in the long run. Occasionally a full statement, or a.definition, should be taken. As a rule you can find a sufficient number of full statements in the text-books. Remember anyway that the speaker gives more than you are to get into your notes or than you need to remember. Get the important things with examples to make them clear.

Improvement in the art comes through practice. The writing itself should become largely mechanical. Train yourself to give the maximum of attention to the thought and to the selection of what you shall write and a minimum of attention to the writing itself.

Acquisition by Reasoning. In reasoning the emphasis is on the selection of ideas, meanings, consequences. The picking out and ordering of material, facts, ideas, according to meaning, is the fundamental and essential thing to both understanding and remembering. The student, the public speaker, anyone, indeed, with a reasonably good memory, finds it possible to memorize unorganized material; but that which is organized can be mastered much more quickly. If the material that one studies is not presented with a sufficient degree of organization, the student will do best to organize it for himself, both for ease of understanding and for subsequent ability to recall it.

Study of this kind follows one of two directions, either the thinking through the thoughts of another as found in his written discourse or speech, or in the relatively independent reasoning carried on by the use of ideas present in one's own memory. The two situations are, so far as the nature of the problems of study go, very largely the same with one exception; in the latter case the student is dependent upon the richness 
and readiness of his own mind to furnish the ideas with which to reason.

Selection and organization. Taking selection and organization of material as the most vital things to be accomplished in study of this kind, how shall we proceed? It is found, as might be expected, that attention to meaning is best. The realization of the general problem, of the point at issue, of the purpose or aim should be sought first; then the leading thoughts and the subsidiary thoughts for each leading thought. Every concrete example that is given or that can be found is a help in getting the ideas clear, in knowing not vaguely but exactly what is meant. Concrete examples, thinking in terms of definite objects, etc., are valuable especially if the matter is descriptive. Attention to temporal relations is important if the matter is narrative; and the logical relations help wherever they can be found in any kind of material. Concrete examples are always valuable, and the ability to give a concrete example is a good test of clearness of thought. Experience seems to show that a mastery of material is aided very greatly by outlining and then mastering the outline. The outline emphasizes the important thoughts, and shows relations between them; making the outline directs attention upon one point after another, assuring the student of attention to each point which goes into his outline. Putting the thoughts into one's own words may help also.

Essence of reasoning. The essence of all reasoning lies in the choosing or rejecting, the affirming or denying of any ideas or rather series of ideas that are present in succeeding moments in mind. One such affirmation or negation is a judgment; a series of such judgments constitutes reasoning. The raw material of the reasoning is the ideas of which something is to be affirmed or denied. The highest type of reasoning, socalled, requires that the former ideas be attributes of some larger complex, or of some phase of a situation, some partly hidden quality perhaps; and being able to affirm or to deny the consequences of these.

The problem for the student. The problem for the student, when he is to do something more than merely follow the course of reasoning of someone else, is to reason correctly for himself. What helps to this do we find? The study of logic may help or it may not; it depends on how it is taught and how it is studied. But if it or anything else demands certain practice, especially, in the way of correct thinking, or if the 
student demands it of himself he may expect to come into the habit of correct reasoning.

Helps to the habits of correct thinking. Following through good reasoning of others is a valuable aid. This is made possible both by the written and spoken words of another. It is obvious that one should choose only books in which the thinking is correct, clear, and helpful, not books which are vague and confused. Reasoning with others and finding one's mistakes in the criticisms of others and in the inability to make one's arguments go clearly and strikingly home to the other party in the discussion; studying one's own language and developing one's vocabulary, these are essential. Advance in thought and language will be found to go along together.

Another help lies in the checking of the results of reasoning by trials or by experiment. In other words, learn to verify. This is done in the business and professional world and should be practised by the student. A sufficient fund of knowledge on which to do the reasoning is necessary; observation, recall in memory, all the results of past thinking are foundations for reasoning. Practice in picking out the essential attribute or phase of a situation, or fact that in this particular case leads to the right conclusion, and knowledge of right and wrong ways of thinking, common errors in thinking and how to avoid them, all help.

The value of ideas. Ideas, it is seen, are useful in several ways: they permit a wider range of possible judgments and therefore of possible modes of action; they permit the affirmation or the denial of a reasoned conclusion, which means perhaps great economy. So far as action goes, this means that memory can present what observation cannot in the way of suggesting the right performance; a course of action may be rehearsed mentally and judged to be satisfactory or unsatisfactory without the need of actually trying out and losing time. Ideas may suggest several things and the best tried first thus bringing a saving of time and effort.

Age and learning. In the molern tendency to think that all types of learning are about equally important at all ages, we may fall into the way of thinking that age, after all, is not so very important as a factor in acquisition. Recent experiments tend to show that students in the elementary school carry on reflective thinking in the same general manner as do high school pupils. All of which may be true, but if it is true, it does not in any way go to show that a greater amount of re- 
fective thinking for younger pupils is a step in the direction of economy.

The more important question in relation to age, is not just what should come early, but that acquisitions that are to be made, be made as early as possible. It seems that we can do no better than to go back to James' statement: "The greatest thing, then, in all education, is to make our nervous system our ally instead of our enemy. It is to fund and capitalize our acquisitions, and live at ease upon the interest of the fund. For this we must make automatic and habitual, as early as possible, as many useful actions as we can, and guard against the growing into ways that are likely to be disadvantageous to us, as we should guard against the plague."

The truth is that the earlier we make acquisitions the more they become a part of us. The better the habits the better foundation we have for all later acquisitions. And, furthermore, the better we have guarded against poorer and less economical learning.

Jost's law. Jost's law states that "Of two associations which are of equal strength but of different ages, the older receives the greater intensification from a new repetition." Surely economy appears to lie in early acquisition. This does not mean to imply that health of the young child should in any way be endangered. Health is the first and most important thing for the young.

Let us add the fact that some kind of habits are formed anyway by the child in his earliest years and the educational problem resolves itself not into how early shall education begin but into the problem of determining what those early habits shall be. After all, then, it is merely a choice of what habits shall be formed in the earliest years. It is to be hoped that the education will be directed and only the best habits be formed. We say, of course, and then forget the matter, that children know more than we give them credit for. Yes, they do, and they are forming habits of thinking, feeling and doing, which we undertake altogether too late many times to deal with.

Subjects to be taught at different ages. To come back to the less important problem, which is, however, of considerable importance. How much should age determine the content of what is taught? The common view, which has been current for a long time, is that up to the age of about eight or nine, the student is preeminently fitted to do memory work and not 
very well able to do work that involves much reasoning. After this age he is especially fitted to study things that involve reasoning. As Parker puts it: "It is commonly maintained that the age from six to fourteen is the best age for learning a language and for acquiring motor skill, and that adolescence is the golden age for reasoning." The newer conception is expressed by the same author as follows: "In opposition to this general point of view this chapter maintains that all types of learning are important at all ages." (73).

Out of the conflict of facts and opinions it is probably too early to draw many conclusions. But it is certain that some reflective thinking is beyond the grasp of children; and further that some reflective thinking that they can do can not be dealt with economically till a later age.

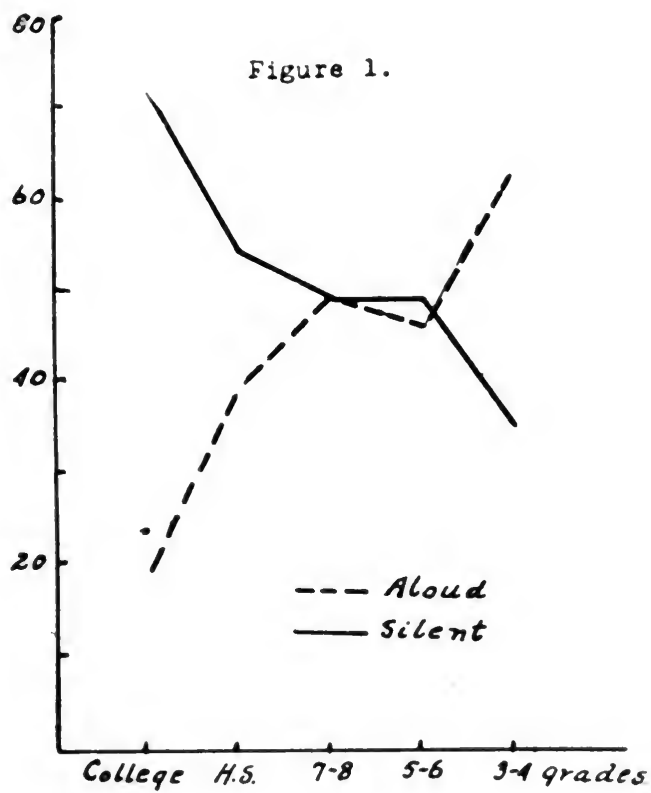

Fig. I. Percent of uhservers who did tetter work in reading silently and aloud. Pintner and Gilliland). J. Ed. Psychol., 7:1916, 2 Io. 
The question is not what they can do, merely, but what can they do most economically? And this is, probably, for the most part to be determined.

Other conclusions. It seems possible at this time to state a few other conclusions relative to age. Younger children lack a wide range of information for use as the basis for reasoning. Children before adolescence have fewer and in many cases no ideals, and lack in determination, purpose, and "mental grasp." They are more bothered and distracted by their feelings. There is greater fatigue for the same amount of work and shorter study periods are necessary. Silent reading is faster than oral reading after about the fourth grade. See Fig. 1. Arithmetic is learned much more quickly after about ten years of age. The study of grammar shows relatively poor results with children, and much better results with adults.

What subjects should be taught at certain ages is also complicated by social problems which are very important. The question has been raised especially in connection with the teaching of foreign languages to young people. Many children will never use foreign languages and many parents have objected to teaching them until it is known that children will need them. When it is found that a child will need a certain language, it is argued, then is time enough to teach him that language.

\section{QUESTIONS AND SUGGESTIONS FOR STUDY.}

1. What are the main kinds of learning? Why do you distinguish these?

2. Classify the kinds of learning in as many different ways as you can. What new facts can you learn from making different classifications?

3. What reason can you give for not considering associative learning as a separate kind of learning?

4. In learning through the senses what are the most important conditions of learning?

5. What errors are most likely to occur in this kind of learning?

6. In what ways can you improve your methods of taking notes?

7. How is learning by reasoning different from observational learning? 
8. What have been the greatest helps to you in learning how to reason? How can you improve your reasoning in ways that you have not tried?

9. Will practice in correct reasoning help you in other fields besides the fields in which the practice occurs? (See chapter on The Transfer of Acquisitions: General Training).

10. How far should age determine what should be taught and studied? How far should other factors determine this?

\section{REFERENCES.}

Bagley, W. C. The Educative Process. The Macmillan Co., 1906. Ch. 12.

Colvin, S. S. The Learning Process. The Macmillan Co., 1911. Pp. 259-329.

DEWEY, John. How We Think. D. C. Heath and Co., 1910.

James, $W$. The Principles of Psycholog!y. H. Holt and Co., Vol. 1: 459-482; Vol. 2: 323-360.

PARKER, S. C. Methods of Teaching in High Schools. Ginn and Co., 1915. Ch. 13.

Pillsbury, W. B. The Psychology of Reasoning. D. Appleton and Co., 1910.

SwaIn, G. F. How to Study. McGraw-Hill Book Co,s Inc., 1917. 
Chapter 6.

WAYS OF THINKING AND PITFALLS FOR THE STUDENT.

Common tendencies in intellectual activity. The economy of study demands that the student's thinking be accurate. It is of value then, to note the common natural tendencies in the world of thought; some of them are very likely to lead one astray. They are all valuable in their places and when used correctly. So easily does one fall into the pitfalls of incorrect thinking that students often become skeptical of reasoning altogether. History reveals blunder after blunder in the reasoning of men. It reveals also the travail through which man passed to find correct solutions for his problems. A review of the intellectual efforts of man permits us to note the advantages and disadvantages of his modes of thinking. Some of these are the subject matter of this chapter. Perhaps the most valuable service such a chapter can render is to point out the dangerous bypaths into which one is continually liable to be led, many of which he may never notice if his attention is not called to them.

Predisposition or prejudice. It must be remembered that all of our thinking is subject to our particular prejudice or bias. Try as hard as we will it is practically impossible to free ourselves from all prejudice. Our points of view have been largely determined by our home training. The likes and dislikes, the hopes and beliefs of our dear ones have become a part of us. So our political creed is largely a matter of prejudice with most of us rather than conclusions cooly and carefully thought out. Our hopes and our ambitions color our thinking. How many of us have believed that a doctrine was right because a dear friend accepted it! How much more the evidence for our side of an argument weighs with us, even though the evidence for the other side is better! We 'preperceive', as James puts it, because we already have the image of the thing in mind. That is to say, we see things before they have appeared for observation. More than that we see things that cannot by any possibility appear for observation. Remember the structure 'seen' by the botanists in the plant which was afterwards proved to contain no such structure. We hear 
much about "party bias" and find even in advanced students evidence of the fact that disputes arise on account of the prejudice of people. A man, for example, hears what he wants to hear in a lecture and afterwards in discussion with the lecturer shows that he has interpreted the statements of the lecture not at all in accordance with the intention of the lecturer but according to his own prejudice.

Some predispositions have their advantages; know just what you are looking for, and if it is there, you will find and recognize it more easily. Espouse a cause, and you can the more easily find the arguments to justify it. Get into sympathy with an enemy, and you can more easily see and understand his situation and the reasons for his actions.

To realize the presence and the effects of predispositions is a means and should be a help towards guarding against our being misled. Granted that we cannot be without prejudice of some kind; we can learn to predispose ourselves to know exactly and clearly instead of to know just this or just that and to justify what we have thought or believed, or want to think or to believe.

Empathy. Man tends to humanize his surroundings, and the tendency harks back to the childhood of the race. For early man, all that moved and changed was supposed to have thoughts and feelings like his own. As a heritage of the childhood thinking of the race we have such expressions as "the angry storm,' 'the gentle breeze', 'the fury of the clements,' and 'the smiling sky.' Thus we are prone to think of the pillars that hold up ponderous weights in a humanizing kind of way. We see a pillar, as Titchener puts it, "plant itself doggedly under a too heavy pressure,-precisely as a man might do." But we go on to read reasoning into the mind of the animal, and morality into the mind of the human infant. How do we know that the motive of a certain writer was the same as we would have had.

The tendency to interpret in terms of our own mental processes thus leads us to very questionable conclusions not only in the empathizing of inanimate things but in the particular conclusions in regard to the human being itself. To reason our own personality into things has its basis in the fact that we are dependent upon our own thoughts for the interpretations of things external to ourselves. But it is obvious that the tendency needs to be checked by objective facts. 
Partial, hasty observations and false conclusions. A common, and all too common, tendency is to observe only partially, to notice some outstanding features of the thing observed, of the page read, to get a hasty total impression and afterwards, likely enough, to supplement this from imagination. A short time ago a student made a statement which was obviously the result of unconsciously putting together two halves of two different sentences. The ideas expressed in the two sentences had been missed and another incorrect one substituted.

The often quoted case of Agassiz and the fish furnishes an example of that kind of study which should offset the hurrying, superficial work of the majority of our students. The student you remember thought he had finished his observational study of the fish in a few hours. Agassiz taught him that he could see new things for several days. To be able to perceive is an achievement.

Learning by trial and error. The trial and error method may most quickly show how a simple piece of apparatus works; in searching for the best material for the filament for the incandescent light that method may be the only way, and the inventor accordingly chooses it, because it offers material for observational learning and reasoning. But in complex and especially in dangerous problems the method may be very slow or hazardous; a little thinking may remove both the waste of time and the danger; the use of reason may permit one to rehearse former performances and reject many useless trials; by thinking one may select the best way to be tried first; thus instead of shaking the clock to make it go, one may look for the simple thing which may set everything right so that it will not soon stop again. But reasoning seems to be unpleasant for most people, and they fall into the easier habits of the trial and error method or into the habit of imitating wherever they can.

Imitation. Imitation gives us a very large part of our habits. We unconsciously imitate the language of those around us; we consciously imitate the methods of the expert workman. There are the advantages of directness, and concreteness, and a clear idea of the thing to be done and how to do it, economy of time and high incentive if the model is sufficiently good. But the poor model and the mistaken action mislead the imitator; how much easier and more expedient to copy the poor model in the shop, the poor system in the office, the time worn methods of the mechanic than to think a little and to have something better. 
The student whether he be in college or in business, should choose the best model, and should add some reasoning also. The successful man must have not only sight, but insight; and not only insight but foresight. It is by seeing into, and through and beyond; by dreaming out what may be and making those dreams come true that one transforms a job into a position, and is himself transformed from a $\$ 1000.00$ man into a $\$ 5000$.00 man.

Careful rather than fast work. We need to advise students to do careful, accurate, work rather than to do fast work. The demands of life will bring the student to work fast. Speed, after all, is one of the late things to acquire. The stenographer works first for accuracy and can later force himself for speed. All our knowledge of habit formation, so far as it bears on this subject, emphasizes the need of accuracy first. Speed can and will come later; and later is the only time it can come without interfering with the quality of the work. Rapid reading and skimming are work for the very advanced student, or reviewer, not for everyone.

The tendency to get general impressions. When Professor Hiram Corson, the famous teacher of English literature at Cornell University, advised his students to read the plays of Shakespeare, going rapidly over one each evening until he had read them all, he had in mind, as he once told me, a very valuable point. That was that it was highly educative to get bird's eye views, general impressions, to see in a large view, things in their relations, somewhat as one might get their general impressions of a city by going over it in an air ship or riding through all its principal streets in an automobile. Grant that this is valuable and it is. Grant that it is well worth while to get general impressions, to see the significance of many facts, to be able to see the principles, or fundamental truths, which may be derived from detailed facts. The sciences demand the knowledge of detailed facts, and the student should realize that if he sometimes studies for general impressions alone, at many other times he must be very attentive to details for the purpose of having detailed knowledge. It is easy to fall into the habit of getting general impressions; it is not so easy to bring one's self to the hard work of mastering details.

Coincidences considered as matters of cause and effect. One of the most common and misleading tendencies is that of regarding coincidences, things that occur together in time, as 
having happened as cause and effect. It having been observed that accidents have befallen those who began a journey on Friday, the belief has arisen that the accident happened as an effect of the starting on Friday. One may ridicule, but such superstitions are so deeply set in many people that it is considered by some business men a bad proposition to have a room numbered 13 in a hotel. If one analyzes like cases one finds that a few facts have been observed and many others overlooked. People have started on Friday and had no accidents. Others have started on other days of the week and met with accidents. The illustration is typical, and the tendency involved is universal: events, which are mere coincidences, are supposed to have happened with some cause and effect relationship.

Jumping to conclusions on the basis of too few facts. Our practical every day living leads us to make many inferences very quickly and with brief observations that we do not need to stop and verify. The advantage is obvious; it saves time and in a large percent of cases satisfies the requirements of the situation. But this is just the tendency that frequently leads us astray. The student of sociology may spend a few hours in an institution and from his observations come to conclusions which are wholly at variance with the facts. Many of those who as students have worked their way across the Atlantic have found that a few hours observation which a passenger can enjoy even under the best circumstances, give in many ways an inadequate idea of many of the workings of the ships. Not so long ago people concluded that a liquid would rise in an inverted tube from which the air had been withdrawn, because 'nature abhorred a vacuum.'

One may conclude that a certain method of study is the best because of the excellent results obtained, e. g. memorizing by parts. Further facts may show that another method is better. Memorizing by wholes rather than by parts has thus proved to be better. The student who makes observations in the laboratory needs to realize that what he observes, far from indicating a scientific law, may be an exception to the rule. The fact is that a few observations may be very misleading; many detailed observations alone give safety to conclusions and then they should be verified by the observations of other students.

Reasoning by analogy. As misleading, and probably as common, as any method of reasoning, is analogy, reasoning by 
similarities or by resemblances. We reason that the school system of Gary is very good and that since it is so good for Gary it would be good for our city. The likelihood is that it would not be good for any other city than Gary, although some features might and probably could be very well adapted to other cities. The classical example of analogy which is best known is that of Newton reasoning from the fall of the apple to the theory of gravitation which he afterwards verified by other methods. But it should be remembered that he did verify by other methods. And it should not be forgotten that for one analogy that has led scientists to the truth, there have been many that have led them astray.

The first thing to realize is that analogy never proves anything; at best it can only suggest possible truths, and reasoning of some other kind is necessary to bring the proof. Only on the degree of similarity and the importance of the similarities found can truths be even indicated. Vague resemblances and fancied similarities are forever leading the reasoner astray and proving nothing.

The economist reasons that since government ownership has proved good for some other country it would in like manner be good for us. But what is good for one people would not necessarily do for another people. Farmers have reasoned that if fertilizer is good for one crop it is good for another. But the fertilizer that is good for corn is not in like manner good for oats. I have an acquaintance who reasoned that since the daily cold plunge was excellent for her husband it would also be good for her. The result of her first plunge was a severe illness from which she did not recover for two weeks. A good many people who see life in terms of efficiency,- there are many students among the number,-are reasoning that they can work the long hours and sleep the few that some great people are said to have worked and slept. Some discover the danger; others go on to the breakdown.

Reasoning from what 'ought to be' to supposed facts. Reasoning from the idea that a thing ought to be thus and so, is a dangerous kind of procedure. The fact is that we frequently do not find what we think ought to be. The law on this subject ought to be so and so, but very likely it is not. Or perhaps we find the statement of the law and decide that the interpretation ought to be thus and so, and to our dismay find out later that it is very different. Perhaps a thing should be a certain way, but that does not alter the facts of the case. The oft re- 
peated remark of one of my old teachers of mathematics is not without its significance: we should "ascertain by finding out."

The conversion of arguments. A less common tendency is that of converting arguments. Students learn in psychology that for every psychical process there is a corresponding process in the nervous system. It is not uncommon for them to erroneously conclude that for every process in the nervous system there is a corresponding psychical process. This is not true. The error of conversion of arguments is obvious, if from the statement, all college professors are adults, we concede that all adults are college professors. In physics we learn that equal volumes of gases having the same temperature and pressure have the same number of molecules; but to convert this and say that volumes having the same number of molecules have the same temperature and pressure, is wrong.

Originality without preparation. There is also a tendency to attempt to be original on the basis of too few ideas, of too little knowledge in the field where the originality is attempted. To be original is one thing; to produce something that is both original and valuable is another. For the latter, one needs first to know all one can in the field of his efforts; to have many memories of the best in this field; to have some critical judgment in these matters. Then he may reasonably hope to be original in a valuable sort of way.

Affirming of the whole what is true of a part. Like the blind men who told about the elephant after each of them had felt of a part of the animal, we are continually reasoning from a part of the whole. One man said that the elephant was like his trunk; another said he was like his tail; another who had felt of a leg said he was like a tree. We reason that an organization is like some of the members we know. Commonly enough people denounce a club, or a church, or all churches, on account of the few rascals, or hypocrites that they know to be members. Many people evidently judge a college community by the noisy, loafing few who are generally conspicuous.

Affirming of a part what is true of the whole. Commonly also we reason from a whole to the part. An organization is taken as sufficient to vouch for its members. If a man belongs to that organization, we say, he must be all right. Most people are on their guard against this particular mistake. But most people do exactly the same kind of thing when they accept every statement of a man or a book because of the establish- 
ished reputation of the individual or of the book as a whole. This is indeed an error against which the student must constantly guard. A text book may be the best that can be had but the excellence of the book cannot be so great that every statement is to be accepted.

Reasoning from incorrect premises. Auch of the trickery used by those who would mislead the unwary consists in trying to get the victim to accept something incorrect at the outset, in the first statement, before he realizes that it is time to be on his guard. A small error at the begining of an argument is sufficient to lead to the wildest conclusions. A good illustration of this is the course of reasoning, familiar to many of us, by means of which we prove by faultess logic, that an obtuse angle is equal to a right angle. All that is needed for this is the incorrect start. And the error is, by the way, not very easy to detect.

Proving one thing and assuming proof of another. If a belief is very dear to us it is not at all uncommon to reason to the possibility of the belief and then to assume the probability. However, a thing may be possible but far from probable. It is possible that the world will come to an end in a few years but it is not probable. The student may prove that government ownership is good for one country and assume that he has proved it for his own country. One may prove objections against a movement and assume that the movement itself has been proved undesirable. But there may be more or better arguments in favor of it.

Appeal to the feelings instead of to the intellect. Everyone is well acquainted with this form of influencing people. In the court room, pictures of the sorrowing, needy wife at home, of the children who need the protection and care of the father, or the presentation of a child to the jury, are used to work upon the feelings. The clever writer may be able to make you feel that a thing is so; but to feel may lead you from the correct thinking. The slogan appeals largely to our feelings and carries conviction, especially with the crowd. When facts give out, when the lawyer can not prove his case against his opponent, the appeal mav be to the feelings by way of slander.

Rejecting a conclusion because of some bad arguments. It seems to be a common tendency to throw things overboard in a wholesale fashion when one begins, instead of selecting the good and retaining it and rejecting the rest. "Nothing," wrote Paulsen, "is more dangerous to a good cause than false argu- 
ments." I know, as most of us do if we look around a little, a number of people, who have lost their faith because their beliefs were dependent upon bad arguments. When the arguments went, the beliefs went with them. Paulsen gives the case of Darwin who lost his belief in Christianity because the poor arguments which had been taught him in early life had to go by the board. The thing that the student should learn, of course, is that arguments may be bad and have to go, but that the belief, or cause, or what not, may be good, and that there may be good arguments if they can only be found.

Language difficulties. One of the great difficulties in education is in the use of words. Words are easily used not to express ideas but in place of ideas. One child returned home from school and told her mother that she had learned a new word. What was it? "Gozinta." What did it mean? That she did not know, but the teacher had said: "Two gozinta eight four times." This indefiniteness of ideas in connection with language is the cause of most of the differences between disputants in ordinary arguments; the definition of terms and a few distinctions may show them that they have no real difference of opinion.

Words are used in more than one sense, and ambiguity arises; words are employed as slogans and election cries to arouse the feelings and at the same time to hoodwink the intellect. Our natural psychological tendencies, if we are not alert and discriminating, put us at the mercy of these things, not only when used by others but also when used by ourselves. A good piece of advice from which every student might profit, is : "Avoid being at the mercy of your words." Students are often unable to answer a question unless it is stated in the exact words of the book. They are at the mercy of words.

The great achievement for the student. The great achievement for the student is to be clear and accurate and to understand. To be lost in logical quibbles is small, and to put undue emphasis on technicalities hardly gives evidence of sincerity and desire for the exact truth. To think accurately and to get into the habit of thinking accurately is far different from the mere getting of conclusions or answers. In order to think clearly and accurately, the student must learn how to think and how to avoid errors in thinking. He must realize the natural tendencies and know when they are leading him aright and when they are misleading him. He must put himself resolutely to the effort of doing the hard work of real 
thinking. And it is well and comforting for him to remember that there are few things in which keener or more lasting pleasure can be found than that which is to be found in good intellectual work.

\section{QUESTIONS AND SUGGESTIONS FOR STUDY.}

1. Distinguish between psychological tendencies of thought and logical errors that may result from them.

2. What errors may occur from too much haste?

3 . What would you consider as the most common logical pitfalls for the student?

4. How may predisposition or prejudice affect reasoning and even perception?

5. Pick out as many mistakes as you can that you think you have been making in your studying.

6. What are some of the advantages of learning by, A) the trial and error method, B) by imitation? Name some disadvantages for each method.

7. Are there times or studies that make the attempt to get general impressions more valuable than learning so many detailed facts? When or for what studies is this true?

8. Recall instances in which pupils have answered in terms of words instead of ideas. What can you do to help students to get back of words to the ideas? What does it mean to be at the mercy of words?

REFERENCES.

Creighron, J. E. An Introductory Logic. The Macmillan Co., 1910. Espec. Chs. 12, 13, 18, 20, 22 and 25.

SIDGwick, A. Fallacies. Int. Scien. Series. D. Appleton and Co., 1895. 


\section{Chapter 7. \\ PROGRESS AND IMPROVABILITY.}

The universality of improvement. With the exception of a very few cases, it can safely be said that there is no intellectual or motor activity which does not improve with practice. Where small improvement is noted it is likely either that the requirements of life have already brought about a large share of the possible improvement in the given case, or, that the conditions for improvement are in some way lacking. Normally one can rightly expect, if he take advantage of the conditions of improvement, and, of course, if he have the capacity to start with, that very great improvement can be made in anything which he is willing to practice regularly and persistently. The fact stands out from experiments and the experiences of experts that the improvement can be much greater than most people ever attain.

How easy to go a little way while the novelty continues and the difficulties are comparatively few and quickly overcome. How sure, on the other hand, is the expertness, the proficiency, even the mastery of practically anything, if one has the stuff within him and is aroused to make continuous application to the chosen work. To do and to do again, to fail if necessary and to come back with the resilience of a Damascus blade, to keep everlastingly at it, is the first and most fundamental condition of improvement.

Habit and the law of 'short-circuiting.' In the process of learning the new activity which is to be learned requires the activity of the higher centers of the nervous system. The learner must be attentive. There is necessary a relatively high degree of attention to each action. Immediately, however, the law of 'short-circuiting' is found to be working, and that which is, at first, highly conscious, begins to be carried on by the lower centers. That is, the activity which necessitated the use of the cerebrum to a very high degree in the learning, comes to require a relatively small activity of the cerebrum and the function is carried on more and more by the 'automatic' action of the lower centers of the nervous system. In other words, when we improve in a function, the lower cen- 
ters increasingly assume the direction of the activities involved and leave the higher centers relatively free for the next new learning. The cerebrum also comes to act habitually and to do with ease and promptness that which was at first slow and difficult. Efficiency, mastery, progress in any line of endeavor involves the development of many well formed habits so that these activities, so to speak, 'go off' of themselves when the right situation presents itself. All acquisitions, remember, become habits, and these habits are the bases for all further acquisitions.

Progress lies then fundamentally in the development of desirable habits, and goes on according to certain laws, many of which we can at the present time state with a good deal of definiteness. What are the conditions of improvement in learning?

Regularity and persistence. It has been said twenty minutes a day for a year would give an average individual the fundamentals of practically any science which he would study with this regularity. Remember James' statement in his chapter on habit, the most frequently read and quoted chapter of psychology ever written. "Let no youth have any anxiety about the upshot of his education, whatever the line of it may be. If he keeps faithfully busy each hour of the working day, he may safely leave the final result to itself. He can with perfect certainty count on waking up some fine morning, to find himself one of the competent ones of his generation, in whatever pursuit he may have singled out. Silently, between all the details of his business, the power of judging in all that class of matter will have built itself up within him as a possession that will never pass away."

This persistence is not easy. Man is inherently lazy. He needs the conditions, the suggestions, motives, incentives, those things which bring about the sustained attention and the permanent interests. Teachers note that pupils do about as well as they are obliged to do. We often see authors settling down comfortabiy after they have produced books which bring them satisfactorv incomes. And the fact is that we know very little about the highest degrees of improvement because it is so difficult to get people to practise sufficiently long.

Drill. The value of drill is clearly shown by Dallenbach. (20). In his experiment, twenty-nine 2 nd grade public school pupils, of both sexes, were given daily for 17 weeks a ten minute exercise in rapid observation and reproduction of various 
visual materials, letters, digits, words, geometrical figures, etc.

The results of the experiment show that the effect of drill was clearly persistent even after 41 weeks of no practice. Further, a special test by means of Binet's card of objects, showed that the practiced children were superior to their unpracticed schoolmates when tested in recall and description some 50 weeks later. (See figure 2.)

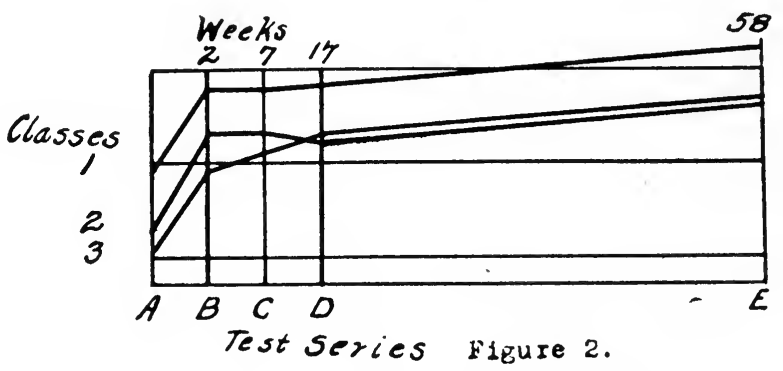

Fig. 2. Effect of practice on visual apprehensions (Dallenbach).

Phillips (79) reports that a drill group in arithmetic made a much better gain than the non-drill group, being 12 per cent. better in fundamentals, 50 per cent. better in reasoning tests, and 31 per cent. better in the combined tests.

Brown (12) summarizes results of some of his experiments as follows: "Five minute drill periods upon the fundamental number facts, preceding the daily lesson in arithmetic, were found to be beneficial in the sixth, seventh and eighth grades.

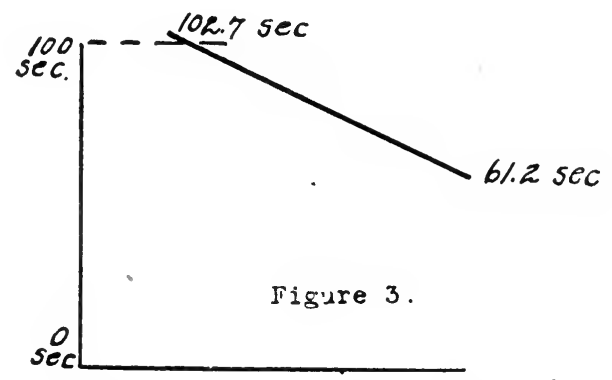

Fig. 3. Reduction in time in adding 17 to 50 2-place numbers as affected by practice. Average results of one group during i 7 trials after having had 35 preliminary trials. (Hollingsworth, 3ia). 


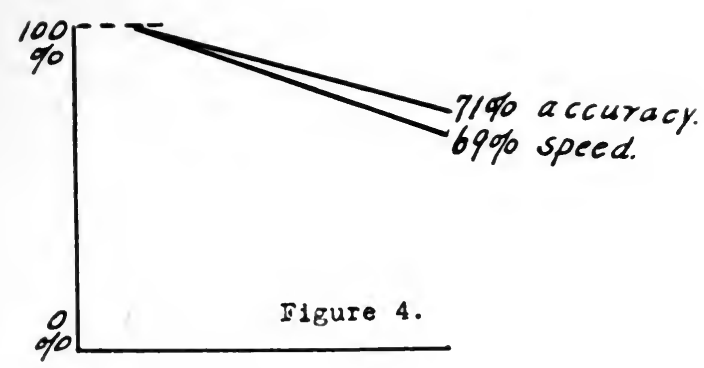

Fig. 4. Median reduction in time made by practice of 19 university students, who daily added for a week 48 columns of ten numbers. Total time of practice for each individual about one hour. ('Thorndike, I12a).

Benefit was not limited to improved mastery of the number habits, but included increased efficiency in arithmetical reasoning."

Results of practice in addition are shown also in the accompanying figures. (Figs. 3 and 4).

Use versus drill in memorizing. Kirkpatrick has given the results of a study in which he dealt with three methods and their value for the acquisition of arithmetic combinations in the multiplication of numbers. The problem was to learn the products of 7 multiplied by the prime numbers from 17 to 53 . Various groups of students, including both children and adults were studied, three methods being used. The methods were, (1) to memorize and then use the knowledge, (2), to practise with the help of a key, and (3) to compute the products from former knowledge. He reports the value of the methods as follows: "It seems that memorizing apart from use is the poorest method of all, drill in using somewhat better, (if there is not so much effort to attain speed that there is little incidental learning), while the method of using previous knowledge as a guide in practice is the best of the three.... The results indicate that in many lines of teaching there has been a tremendous waste of time, energy and interest in first memorizing, then later practising, the use of what has been learned." (53).

It is likely that these results found in arithmetic would be largely the same in other fields, although we must always be very careful about generalizing from one field to another. We may probably say that working things out for one's self is su- 
perior to memorizing or learning by use of a key or set of rules. There is reason to believe that the following methods from 1 to 4 indicate increasingly better ways of learning.

1. Memorizing and then using. Poorest.

2. Learning by use of a key or set of rules. Better, but not most economical.

3 . Learning by using former knowledge to work out results. Better than methods 1 or 2 .

4. Learning by using former knowledge to work out results plus the intention or purpose of memorizing. Probably the best of all. The value of intention to learn has been shown in another place.

Definiteness of practice. The greatest improvement appears to come from the most definite practice. This means that improvement is best and fastest when one practises directly the thing to be done and not something else, not something very like it, not a combination of things, but definitely and specifically the thing to be improved.' In other words, if one desires to improve his ability to remember prose, he should practise memorizing prose; if one desires to improve in remembering poetry he should practise memorizing poetry; if it be in anatomy, study anatomy; if it be reasoning in philosophy and logic, study philosophy and logic; if it be reasoning in law, study law; if it is stenography, study stenography, and further, if it is to write business letters, study and practise writing business letters; if it is writing scientific matter, practise that; one does not practise in a canoe if he is in training to win a boat race, nor does he practise swimming to gain improvenent in the high jump.

The whole point is that the mind works much more specifically than most people imagine; and one cannot train in one thing and have equal improvement in another; the fact is that he may have no improvement in the other activity, or further that there may be actual interference. (See chapter on Transfer of Acquisitions). The injunction, practise the thing you would improve in, does not mean, however, to attempt the higher habits before the lower habits are formed; that is, one does not attempt to play the pipe organ, nor to sing in opera at the outset; the principle indicated is that one should go as directly as possible to definite specific training in the habits desired. On the negative side one should avoid forming irrelevant habits; habits which have to be modified later or perhaps unlearned, so far as they can be unlearned. 
Louver and higher order habits develop together. Experiments have shown that lower and higher order habits develop together. For example, in learning a language the grasp of larger units comes along with the attempt to grasp smaller units. The telegrapher finds words coming along with letters, and, later, sentences coming with words. The context helps in learning to deal with parts. This fact indicates a psychological basis for beginning a foreign language with sentences instead of with words, or letters. It is perhaps too early to generalize fully, but it may be said that the direct method, which follows this procedure, is proving to be very econom:ical of time and effort, and it may prove to be the most economical method with pupils of some if not of all ages. The great difficulty at present is to get teachers who can teach by this method.

The order of learning. The suggestion has been made that The order of learning is important. Work done on text books during the last twenty-five or more years, gives evidence of the value of learning in at least a good order. It is a question as to whether there is a best order for any material; there is no question among teachers that a good order of presenting topics of or requiring habits to be formed is exceedingly valuable. The best direction of action and the best order of things depend generally on the text or the teacher; these requirements for the best progress, even if there were no others, are sufficient to make it fully worth while to have the best teacher and the best text. Especially should the best teacher be had at the beginning so that the best foundation be laid; a poor teacher cannot do so much damage later; it is obvious also that a good teacher can carry one to a higher stage of mastery than a poorer teacher; so one should have the best teacher again for the most advanced work.

Correct practice. One very fundamental and essential condition for economical progress, or perhaps, for any progress at all, is correct practice. Skilled players who are going into a tournament, tell us that it is better not to practise at all just before the game than to practice carelessly. Whatever one practises, one tends to do again in the same way. The old maxim. 'learn to do by doing.' must change to the maxim which is true to the laws of habit and which does not overlook those laws, namely 'learn to do by doing correctly.'

The critical attitude. In experiments where the subjects know their scores, their successes and failures, they make the 
best progress. The elimination of much waste lies in the picking out of the correct responses and repeating them, and the picking out of incorrect responses and eliminating them. Without this the student fails to make the improvement he should. Nor could he expect to make very much improvement unless he can make the necessary distinctions between what should be continued and what discontinued. Here again appears the value of the teacher and of the best possible teacher, the teacher who permits only the correct actions and eliminates the incorrect responses. This does not mean that the student should not try for himself and make no mistakes. It does mean that after the student has made mistakes, they should be corrected and only the correct tendencies be allowed to develop into habits.

When Fritz Kreisler emphasized the value of thoughtful practice he struck one of the keynotes of improvement. Not only should one be persistent and practice correctly, etc., but he must do more than mere mechanical repitition. The latter drills into the nervous system, it makes for habit, but is nowhere so valuable as careful, thoughtful efforts.

Improvement of methods. Prof essor James brought to our attention the fact that the secret of a good deal of improvement in memory lay in the improvement of methods. He refers to the experience of Mr. Thurlow Weed, who improved his ability to recall the events of the day by recounting them to his wife every evening.

On this matter Professor James writes: "I do not doubt that Mr. Weed's practical command of his past experiences was much greater after fifty years of this heroic drill than it would have been without it. Expecting to give his account in the evening, he attended better to each incident of the day, named and conceived it differently, set his mind upon it, and in the evening went over it again. He did more thinking, about it, and it stayed with him in consequence. But I venture to affirm pretty confidently, (although I know how foolish it of ten is to deny a fact on the strength of a theory), that the same matter casually attended to and not thought about, would have stuck in his memory no better at the end than at the beginning of his years of heroic self-discipline. He had acquired a better method of noting and recording his experiences, but his physiological retentiveness was probably not a bit improved. All improvement of memory consists, then, in the improvement of one's habitual methods of recording facts." (39). 
Recent experimentation has shown the truth of James statement in relation to improvement of method. Nor can this be too much emphasized. A fundamental fact in the problem of improvement is that if one wants to improve in anything, he should improve his methods. There is no question as to the great generality of this principle. The only question is as to the extent of its applicability.

The following study very well illustrates and emphasizes the importance of methods.

Improvement in observational learning. The careful study of Dr. Foster on the effect of practice upon visualizing throws light upon the ways in which learning of this kind may improve. During 10 weeks three adult observers practiced on pictures, nonsense syllables, drawings, poetry, and objects. Dr. Foster writes: "Ability to reproduce increased with practice, although the increase was rapid at first and slow later. The greatest gain of final over initial ability was 44 per cent.; the least, 6 per cent.

The chief reasons for the practice-improvements were:

1. Confidence and 'doing one's best' replaced discouragement and 'giving up.'

2. Familiarity with material lessened the difficulty.

3. The observers learned where and how to distribute attention effectively.

4. More efficient methods of work were adopted. Tricks of counting, naming, grouping, etc., were discovered and used.

5. Regular and definite procedure replaced hap-hazard, unorganized procedure.

In no case did practice increase the ability or even the tendency to visualize. The best reproducer of visual impressions was the poorest visualizer, and relied almost wholly upon verbal cues for recall.

Our results show that the ability gained is very specific." (28). (See also 17).

The feelings of satisfaction and of dissatisfaction. Let one be satisfied with one's efforts and progress is likely to stop. To be dissatisfied is one of the best indicators of better effort for improvement. Conscientious effort brings in better results in learning. As we have said before the feeling attitude, the realization of need for accomplishment, desire for the best results, caring enough, etc., are real aids to progress. Or to be more accurate they are the psychical aspects of the dispositions which result in better work. 
Can we work better when we are in the mood for it? Shall we wait until we feel like work in order to get the best results? We often do work better when we feel like it, but it is found that scores may be better on days when the subjects of experiments do not feel fit. Or a subject may feel very fit and actually do poor work. There are many who say that they cannot do good intellectual work unless they are in the mood for it. We all know that valuable thoughts come to us when we are thinking of something else. We know the right idea may flash across our minds when we least expect it. Experiments seem to show, however, that in the long run, we are likely to do more and better work if we apply ourselves independently of our feelings. It certainly appears that the habit of depending upon moods may be formed and much valuable time may be lost by giving way to them.

Physiological conditions. Good physiological conditions evidently make for better intellectual work. Some discussions of this point seem to err by making the judgment of individuals as to whether or not they felt fit the criterion of the physiological conditions. There are many cases where known illness correlated with poor work. School children have been found to improve after the removal of physical defects. Proper feeding improves study. The importance of the subject makes it worthy of discussion in a separate chapter. Here it is sufficient to emphasize the fact, that while progress may not be interfered with by not feeling well, it is interfered with considerably by not being well.

The principle of completeness of response. Professor Peterson has called attention to a very important point which is undoubtedly too much overlooked in attempts to understand and explain improvement in learning. "There is no question that many of our attempted neural explanations involving one arc, or at best a few neural arcs, are altogether too simple adequately to explain in such physical terms as we desire how one act can survive over the other more or less random acts because of its greater success in meeting the needs of the organism.... In a complex condition such as we actually find in the nervous and muscular systems, where various more or less related acts are involved in each reaction, some of these acts may be of an inhibitory nature to others under certain curcumstances, while occasionally under other conditions all may tend rather positively to aid or strengthen one another. These mutually inhibiting or reinforcing effects would be determined 
not only by the nature and complexity of the stimulus but also by the inherited and acquired disposition-neural connections, bodily structure, etc. - of the organism".....

"In the case of the maze problem the animal on entering a cul de sac,- - or any other path, in fact-responds more or less incompletely, because all the subordinate activities involved cannot take place at once. If the animal's progress is soon checked in a blind alley the animal is not seriously nonplused. Certain elements of the general response are tending to drain into other alleys that may recently have been passed, thus partially dividing the animal's activity. These elements now prevail when the others are checked. Let us suppose that the correct path, $\mathrm{A}$, has just been passed when the animal suddenly comes to the end of the cul de sac, B. The tendencies to respond to $\mathrm{A}$ are still surviving and now direct the impeded activity into this, the successful, path. If, on the other hand, the correct path had been chosen the first time the distracting impulses toward $\mathrm{B}$ would have become fainter and fainter as the animal proceeded into $\mathrm{A}$, and would have finally faded away. The principle is not different when the complexity of the situation is increased. When the food is finally reached all the remaining delayed reactions, the tendencies, still persisting, to go into other alleys recently passed, are relaxed-the act as a whole is complete." (78).

This principle, which is also called the overlapping of responses, is worthy of the emphasis which Professor Peterson puts upon it. We are undoubtedly helped to a large extent by artificial simplifications in psychology; we are brought back to the real situation by statements like the above which emphasize the great complexity of affairs.

Improvement in subnormals. A study by Professor Woodrow, recently published, (121), suggests that subnormals can improve as rapidly and as well as normals in activities which are not beyond the mental grasp of the subnormals. Both normal and subnormal children, all about nine years old mentally, were trained by means of a form sorting test. In his manuscript, Professor Woodrow concludes as follows: "To sum up, in the present experiment, feebleminded children were found to show the same amount of improvement and to improve in accordance with essentially the same practice curve as normal children of the same mental age and same initial ability. While in both the feebleminded and normal groups there existed great individual variation, it was impos- 
sible to discover any effects of practice which were significantly different for the two groups." Also, "The conclusion is definitely indicated, that feebleminded children improve with practice the same as normal children of like mental age." As noted by the writer the normal children might have been expected to outstrip the subnormal children if the practice had continued for a very long period. Subnormal children do not change mentally as do the normal from one age to another.

\section{QUESTIONS AND SUGGESTIONS FOR STUDY.}

1. Pick out several things in which you have made a good deal of improvement. For each of these what percent of possible improvement do you think you have made?

2 . What obstacles have laid in the way of your improvement in things that you have attempted?

3. Compare the value of mechanical drill with that of thoughtful practice.

4. What is the value of improvement of methods in comparison with any other aids to progress of which you can think?

5. How does use play a part in progress in learning? Illustrate from school work and from other lines of activity.

6. How much should one permit one's self to be affected by moods?

7. How much difference do not feeling well and not being well make in progress? Which is more important, to be well or to feel well, and why?

8. Mention some other factors that are involved in improvement.

\section{REFERENCES.}

E. L. Thorndike. Educational Psychology. Vol. 2, The Psycholog! of Learning. 1913. Espec. chs. 6 to 8 inclusive.

Also see references at the end of chapter 8. 


\section{Chapter 8. \\ ARRESTS IN LEARNING AND THE LIMITS OF IMPROVABILITY.}

Are plateaus necessary in human learning? It is maintained on good authority that there are no plateaus in animal learning. It is also believed by some psychologists that plateaus are not necessary in human learning. But other psychologists believe that they are in the natural order of events. Plateaus, it may be said, are arrests in learning; one learns but comes to a time when he either does not, or apparently does not, make any progress. It may be that he takes a 'slump' and the work is actually poorer than previous work. The apparent arrest, may, as many believe, be only apparent; progress may actually be going on somewhere among the neurons.

On the one hand we have the fact that progress after a plateau is very likely to be rapid. It may be inferred from this that there was no actual stop in progress but that the progress could not be observed. It simply did not appear in objective results.

On the other hand nature seems to advance by fits and starts. Plants grow more at one time of the year than at another. In the growing child increase of weight appears more at one time and increase in height more at another. The fact stands that in most learning, whether in laboratory experiments or in our schools, individuals show advance at times and at other times fail to show advance. The practical conclusions for us at present is that plateaus exist and that we have not been able to wholly eliminate them, especially under school and college conditions. We have therefore the problem of understanding the conditions or causes of plateaus and the methods for making them as few as possible, of postponing their appearance, and of overcoming them when they do appcar. (54 and 109).

The curve of learning. If we can represent in a kind of ideal way the progress of learning of different kinds, it can be done only by dropping out all the variations and differences 
that appear in the different kinds of learning and giving a sort of approximate curve such as the one shown in Fig. 5.

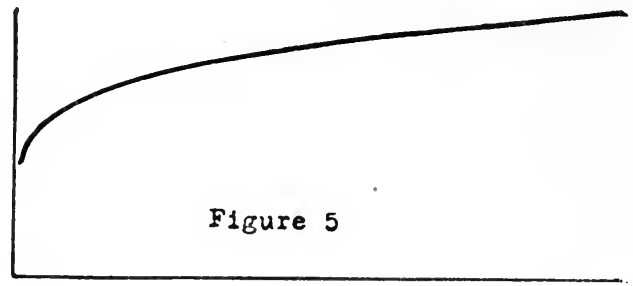

Fig. 5. Approximate curve to represent a general average of facts in con-nection with progress of learning. (Thorndike, 109, p. 255).

The actual progress in learning, showing fluctuations, can be shown by curves which represent the progress of individuals in learning of different kinds. The presence of plateaus

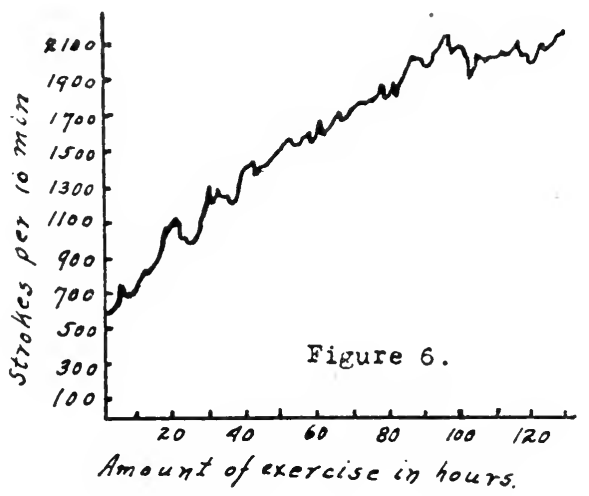

Fig. 6. Improvement in typewriting by the touch method. Suljject Y. (Busk IO, p. 2I). 


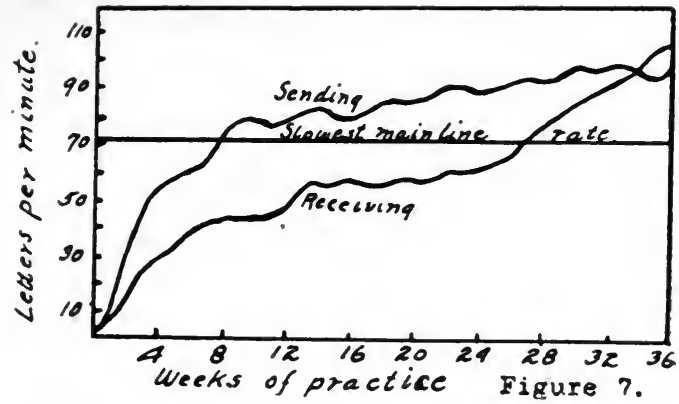

Fig. 7. Improvement in telegraphy. E. L. B. (Bryan and Harter, I3a).

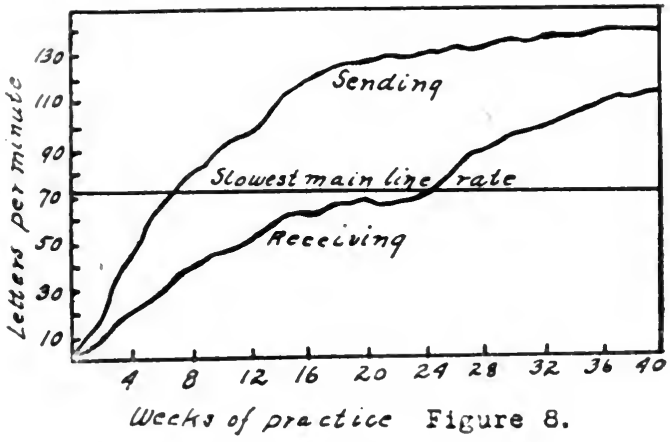

Fig. 8. Improvenent in tclegraphy. W. J. R. (Bryan and Hartcr, 13al).

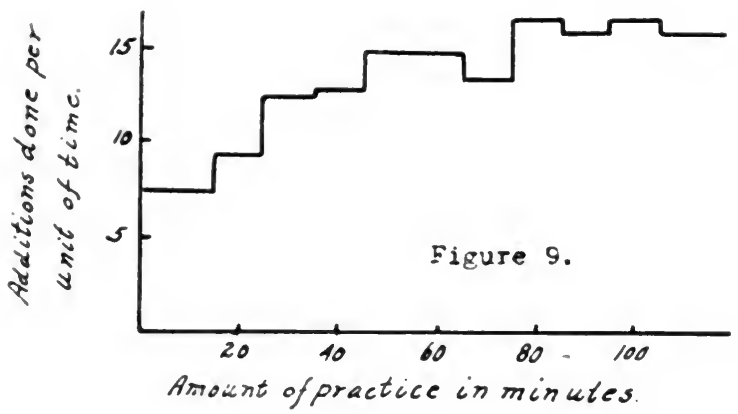

Fig. 9. Average curve of improvement of school children in column anlili. tion. (Thorndike, I09, p. 254). 
is indicated in these curves, as is also the presence of slumps. See Figs. 6, 7, 8 and 9.

Progress at different stages of learning. It appears from an examination of the curves shown in the text that learning, so far as these curves go, is fast at first and later slows down. This is, in fact, what appears from most of the studies of learning. It is not safe to generalize from one kind of learning to another and while the above facts may be true for most learning, still we do not yet know this and we must take into account such studies as those of Professor Swift in which learning is found to be slow at first and then faster.

In the study of Tossing and Catching Balls and in one On Learning Short-hand, Swift finds that the initial progress is slow and then very fast. As he puts it: ".... the learner seems to make no advance for a time and then springs to a higher level, perhaps only to fall back a little but, at all events, not to go higher until he has strengthened his position here."

Also he writes: "I have found no evidence for one or two special periods of delay in progress in which preparation is made for a higher order of habits .... automitization is going on throughout the process."

In discussing the rapid rise found at the beginning of other studies of learning than his own he writes: "This immediate rapid rise at the beginning seems to be true only of these things that have symbols or other devices for handling and presenting ideas, and it is probable that after this first spurt, the length of which would vary with different sorts of material, the general form of the curve for learning is concave until the physiological limit is approached. Telegraphing involves fewer symbols, and the distraction of deciding on sounds and abbreviations, that mark the learning of the Pernin shorthand system, would not so greatly disturb the beginner, and so, having less thinking and deciding to do at the start, the learner in telegraphy would probably go on improving without great set backs longer than the short-hand writer."

(95).

The effect of the learner becoming able to get the context appeared soon after the reading of the short-hand notes began. Occasional spurts occurred as a result. Later many spurts were noted and attributed to this cause. Swift thinks that early rapid rise in the learning of short-hand does not occur because of the lack of associations also and after many associations have had time to form they bring about the rapid 
progress. Some concave curves are probably due to a faulty method of plotting.

Progress and individual differences. Progress of individuals in the ordinary classes in our schools is made more difficult because of the individual differences of the different pupils. A very few of the pupils are able to go very rapidly. Most of the pupils can go only at a medium rate. A number will be found who can keep up with the medium rate students only with great difficulty, and with special attention, or who cannot keep up at all.

The best rate of progress for one pupil is not the best rate for another. It is doubtless true that for any given student it is right for him to go ahead at his own best rate. With small classes or with individuals it would be reasonably possible for the teacher to see that this was accomplished. If for no other reason, the possibility of better progress for all, would demand the best possible classification of pupils into the various classes.

Sorting of pupils: "Opportunity classes." In many schools there are slower and faster classes of pupils who are doing the same work. This is of ten convenient and helpful. Where a school system is large enough it is advantageous if not ethically the duty of the school authorities, for the children to be classified according to ability. Two percent. of a school population can be picked out as especially bright and capable of fast progress. A larger percent are unable to do the average work of the average student. For the sake of the teachers and for the best progress of the individual pupils experience indicates that there should be special classes. There are many kinds of makeshifts for the purpose of letting the brilliant student get along faster and for getting the poor student up to grade but the special classes are the real solution.

Such classes could be called opportunity classes. The pupils do not need to be tagged "supernormals" or "subnormals." In fact it is almost necessary that they do not be called such. There is too much feeling aroused in the minds of both pupil and parent. But opportunity classes might be formed for both the bright and dull students. The bright students could go faster and do their better quality and quantity of work. For the less bright pupils there could be a modified curriculum. They could be called upon to do the kind of work they can do and at which they can succeed and all be greatly benefitted. 
It is not the purpose of the writer to discuss at length the problem of special classes. But it is a matter which cannot be overlooked and one which teachers must more and more come to consider, where ever their school systems are large enough to permit of such a solution of individual differences. Going at the right pace for the great majority of pupils is going too fast for the dull ones. And it is not at the present day sufficient to give the old solution: teach the dullest in the class and the rest will get the lesson. We must administer our schools so that all students, so far as is possible, will make the best progress that is possible for them. It is not, by the way the function of the bright pupil to stimulate the dull pupil. He is there to learn and not to be bored to his educational death by the pace required for the latter. It is the teacher's place to do the stimulating.

Causes of plateaus. Plateaus are variously explained by different writers. We do not yet fully understand plateaus and their causes. It is possible to state many conditions which are directly correlated with plateaus. These should give us a fair basis for dealing with the problem involved. Future study must supply information as to what conditions are most important for particular subjects.

The nature of the learner. The feeling attitude is likely to change as one goes on in a subject; the novelty wears off, and the first enthusiasm dies down; interest and effort are all too likely to wane. Add to this the laziness of human nature, faintheartedness, distrust of one's own ability, anxiety, and the feelings of discouragement and we have the secrets of a good many of the failures to get very far with anything. Distractions at such a time can easily disturb and one may be wooed to a pleasanter task. Something else novel and easy makes the stronger appeal. Strong emotions, especially those that last for a long time, indicate conditions in the individual that are likely to interfere with progress. Adolescent changes are examples of this. As already indicated physiological conditions are important and bad bodily conditions interfere with progress.

Defective training. Poor preparation is a cause of plateaus. Things are not sufficiently well learned; habits not fully formed interfere with the advanced work, with the formation of higher habits. Where habits are not fully formed and one attempts to take the next step in advance, the attention is constantly distracted from the new to the old activities. This is 
a serious cause of trouble and may result in disturbing both stages of the activity, the one which is not fully made into habit, the other which should have undistracted attention so that it can be properly learned and reduced to habit.

Growing complexity and critical stages. It is obvious that work gets more complex and difficult as one proceeds; there are fewer improvements to make, and these few are harder to make; the advanced work requires the perfecting of habits which takes a long time. We are fairly well acquainted with the critical stages that appear in certain kinds of learning, for example, in typewriting, and in telegraphing. Two such critical stages are commonly distinguished. There is the plateau which separates the first easy learning from the stage in which some little or perhaps fair proficiency is gained; the second plateau precedes the ascent from drudgery to a considerable degree of proficiency. Teachers often know just about the place in the student's progress in which to look for these plateaus and may give valuable aid and encouragement at such a time. The fact also appears that most people, students and teachers alike, have altogether too little experience with higher habits. IVe are just beginning to learn about the factors entering into the highest degrees of skill.

Improper use of time and effort; poor methods. Plateaus are brought on by the improper use of time and effort. James long ago told us that improvement in memorizing lay largely in improvement of methods used. Several of our recent studies show that much of the lack of progress is due to poor methods. We are told that methods should never be left to chance. They should be carefully worked out and then inproved as progress in the study shows that it is possible to improve them. Failure to make use of a proper distribution of time, so that intervals, and Jost's law, can help the learner, mean slower progress, if they do not actually bring about plateaus.

The illusion of progress. In intellectual work one needs to be warned against the illusion of great progress which is likely to come with going over a large amount of material in a short time: the result in the long run is very often little actual gain and, especially, a relatively small degree of permanent retention. It was not vanity or conceit, but this fact which led a great scholar to remark that if he read as much as most of his colleagues did, he would know as little as they.

The illusion of progress in a young child may occasionally be helpful in getting him to try to do his best. Children who 
have been given praise or good marks that they had not really earned have been known to live up to the praise, or the marks immediately afterwards. This suggests one of the factors that make for economic progress, namely, thoroughness of learning. The quotation already made from Porter is apt. The phenomenal success of the lawyer was on account of his reading, not so much as his colleagues, but on account of his making it thoroughly his. Thorough learning, completely formed habits, do more for the avoidance of plateaus than one ordinarily realizes.

Observation of principles already mentioned. Many principles have already been mentioned whose observance make for avoidance of plateaus; regularity of practice and adherence to correct practice; definiteness of practice; practice of the thing to be learned and not something else; the avoidance of irrelevant habits; the right use of time and effort; the best number and frequency of practice periods and intervals. and the like. Learning in a good order; distinguishing the correct from the incorrect responses and eliminating the latter; satisfaction only with the correct actions and results. Improvement of methods, and the continual use of the best methods,methods should never be left to chance; mastery of fundamentals before going to something dependent upon them. The best physical conditions; avoidance of getting mentally stale; independence of moods, rest and recreation when needed; forcing when one tries to get on the highest levels of performance.

Forcing one's self. The fact appears from experiments and from the experiences of those who have attained the highest degrees of skill that the only way in which to get to these very high stages is to force one's self. Forcing is not to be recommended if one is ill, or too nervous, or if he needs quiet, rest, and recreation to get him out of a rut or to remedy his having become stale. But granted a good healthy condition, to attain the highest stages of proficiency, only one thing will serve, namely, forcing. The learner must put forth his very best efforts, without forgetting, however, that short periods of this great effort are undoubtedly best, and that the best methods. must be used.

Colvin, in The Learning Process, very well summarizes the facts in connection with this matter of effort. He writes: "The value of putting forth a maximal effort to gain a permanent improvement has been emphasized, particularly by Bry- 
an and Harter, who say: 'One conclusion seems to stand out from all these facts more clearly than anything else, namely, that in learning to interpret the telegraphic language, it is the intense effort that educates.' Swift, while agreeing with this conclusion in general, adds the caution that spurts cannot be relied on to accomplish this result. The effort must be sustained, not sporadic and haphazard. Book emphasizes the fact that a balance must be preserved between accuracy and speed. The imperfectly formed habits must be mastered before substantial progress can be made. They should be acquired as rapidly as possible, but not so rapidly that speed shall be gained at the expense of accuracy, 'The desire to hurry on must be nicely balanced with due caution.',

The effort to get to the highest efficiency may need to continue not only months but years. In the higher stages of expertness a little improvement of ten means that a man is many times more valuable in his line of work; this little improvement in the advanced stages may mean that a man is worth several thousand dollars more than formerly in his business.

The limit of improvability. There is a point above which there are only diminishing returns for one who tries to reach a higher degree of expertness, and this point one must decide very largely for himself; some can go farther than others with profitable returns for the investment of time and energy; others reach their limits of profitable returns earlier. The demands of different individuals also make it advisable for each to determine the degree of expertness in any particular line he needs for his own best service. Let it be said again, however, that most of us can improve far beyond our expectation if we only go about it rightly and keep persistently at it. In the problems and experiences of the expert one finds much that is closed to the student who goes only the little way that most people go; on the highest levels of endeavor one can find the keenest intellectual pleasure and the best and most lasting satisfaction.

\section{QUESTIONS AND SUGGESTIONS FOR STUDY.}

1. What is meant by plateaus and what is their probable nature?

2. Can you mention studies in which you have noticed the presence of plateaus? in which learning has gone without plateaus? 
3. What are the characteristics of the curve of learning?

4. How far is it safe to generalize from one kind of learning to another kind?

5. In what kinds of learning may we possibly expect no plateaus?

6. Indicate several cases in which plateaus should be treated by different methods.

7. What should be done in order to avoid plateaus so far as possible?

8. What educational benefits within the individual may come to one who makes himself a master of something?

\section{REFERENCES.}

E. J. Swift. Studies in The Psychology and Physiolog!y of Learning. Am. J. Psychol. 14: 1903, 201 ff.

Thorndike, E. L. Educational Psychology, Vol. 2, Psychology of Learning. Teachers College, Columbia University, 1913. Chs. 6, 7 , 8 and 9. Also Educational Psychology, Briefer Course, 1915, Chs. 14, 15,16 and 17.

Whipple, G. M. Manual of Mental and Physical Tests. Warwick and York, 2nd Ed., 1914, Pt. 1122 f., 136, 143, 219 f., 228, 234, 254 ff., 273 f., 286 fr., 295,304 f., 315,321 f. Pt. $2405,431,452,470$ f., 482, 491-494, 508-512, $550 \mathrm{ff} ., 580,596,601,659$. 


\section{Chapter 9 \\ THE TRANSFER OF ACQUISITIONS: GENERAL IMPROVEMENTS.}

Most improvement is specific. We have said that if a student wishes to improve in anything, the best results come by practice in that one thing and not in something else. If he wishes to improve in memory for prose he should memorize prose; if in anatomy he should memorize anatomy; if in reasoning in logic and philosophy he should study logic and philosophy; if in reasoning in practical affairs he should study practical affairs. One can state the same thing negatively by saying that improvement in one subject does not give equal improvement in other subjects. This is in direct contradiction to the old view, that one could study certain disciplinary subjects and thus train the mind so that it would be equally able to do any kind of mental work. This is the doctrine of formal discipline, as it was called, and no one who has read the results of experiments on the matter can longer maintain its truth in this extreme form.

Some transfers may take place. Neither can one who knows the facts deny that there may be some improvement in activities other than those used; some general improvement so to speak; or, as it is generally termed nowadays, transfers of training from one field to another. Experiment has shown that improvement in one field may mean improvement to some extent in other fields. And, to go deeper into the problem, experiment has shown some of the factors which when learned transfer to another subject and the causes of these transfers. There may be transfer to help, that is, to cause improvement in another subject, or to hinder, that is to actually interfere with other performances in other subjects or lines of work. In brief, there is no training in anything which will make one equally able to do any other kind of work; there may be some improvement from one subject to another; there may be interference from one subject to another; experiments show us further something of the nature of transfer and the causes or conditions of the transfer. 
We are interested, then, in considering the nature and amount of improvement which may cross from one field to another; and the way in which we can make sure of the transfers where they are possible. But first we must be sure to eliminate certain things which might seem to indicate general improvement or transfer of training but which must really be explained on other grounds.

Factors that complicate the discussion. We must be sure that what we attribute to study of some subject is not simply the result of the growth and normal development of the student; that is to say, an individual may do better in all subjects, not because he has put special attention on mathematics, or Greek, but simply because he is a year older. In the next place we must remember that men are not necessarily successful because they have studied hard subjects. It is likely that they had it in them to be successful whatever they studied, and being good students, having good stuff in them, was partially the cause of their choosing the hard subjects, and not the study of the hard subjects the cause of their success. It is undoubtedly true, of course, that the proper study of hard subjects was a valuable part of their training.

Finally, one should not confuse the spread of training with the transfer of training. The improvement of one hand after the other hand is used is not due to transfer; when one hand is trained the use of the other is modified, if for no other reason, because the brain centers connected with the hands are modified and are better able to direct either hand; also, both hands may be somewhat active when one is being trained; or, again, the training of one eye which results in improvement of the other eye, most likely involves the use of both eyes in the training. Such things must be distinguished from the transfer of training.

The extent of transfer. If now we consider the extent of improvement from one field to another, we have evidence from experiment to give us partial answer. Improvement has appeared, for example, in several ways. Judging the size of certain areas brought about improvement in judging the size of larger areas of the same shape and areas of different shape; improvement transferred was from 30 per cent. to 52 per cent. as great as the improvement in the judgments of the areas practised. Practice in estimating weights brought improvement in estimating heavier weights 39 per cent. as great as the improvement with the weights used in practice. But the 
improvement in judging parts of speech that was 21 per cent. in reduction of time and 70 per cent. in reduction of omissions, gave a transfer to the judgments of other parts of speech in reduction of time of only 3 per cent. and an actual increase in omissions of more than 100 per cent. Here, then, we find training in one performance interfering with action in another performance. Other studies show that an improvement in one activity may bring about from 20 per cent. to 80 per cent. as much improvement in other activities.

But they show also considerable interference. Increase of speed frequently' brings about decrease in accuracy. Practice in writing digits for letters has helped in writing symbols for digits, but has interfered with writing digits for symbols, and the longer the drill was spread out in time the greater was the interference. Practice in memorizing some kinds of material has frequently helped memorizing other kinds of material, but, for example, drill in memorizing prose has hindered subsequent memorizing of nonsense syllables. Experiment and experience also show other interferences, for example, learning to cross out certain letters may bring about interferences in crossing out other letters; learning to finger one kind of musical instrument makes a temporary interference with learning to finger some other kinds of instruments. Some experiments also point to the probable fact that the more expert one is in a certain thing the greater interference may be found in changing to other operations which involve the habits that are developed to the point of expertness.

In thinking of the transfers and the per cent of transfer that has just been mentioned, we must remember that these results were obtained under conditions which favored the transfer. Other experiments can be cited which show no evidence of any transfer whatsocver. We must therefore not assume that as many transfers or as large a percent of transfer ordinarily takes place in the course of the education of the students in our schools and colleges. All the evidence we have indicates that in the latter situation, transfers are less frequent and smaller in amount.

The nature of transfer. We are also specially interested in knowing what it is that transfers; no small part of an education lies in acquiring those habits, or whatever they may be, which will help not only in the subject in whose study they are learned but also in other situations of life. (See also ch. 14). 
It is obvious that one cannot study a subject very thoroughly without in some way changing his point of view or his attitude. One is a different individual in so far as one has had added experiences; the nervous system is modified; the outlook of the person cannot be just the same as before, when one has studied a subject where careful and critical thinking has been demanded. A person is likely to be less inclined to accept statements unthinkingly; he may grow into the habit of asking the question, Is that true? or, in what way can I apply this fact to my work? Or a student may go into the laboratory and tend to react quickly and impulsively and to produce careless work with many details overlooked; but the demands of the course, if it be well taught, make the student more careful; he may now get into the habit of doing much better work; of being dissatisfied with careless work; of desiring to do and being pleased only with the better quality of work. So the experiences of life, influence of others, lectures, interviews, things read, may dispose one to act differently; to be more accurate, to be more sympathetic, to be more honest, or more neat, or more punctual. In short, one may learn from one situation or study that which will change his attitude, his disposition, so that he will respond differently thereafter in many situations of life.

Again, it is found that one may learn methods of doing things and transfer their use to other situations; methods of study may apply to all kinds of, study; methods of handling apparatus, of memorizing, of grouping facts or of outlining material may be of wide application. Indeed the improvement found in many experimental studies is found to be due very largely if not almost wholly to better methods. These methods may apply to many other lines of work than that in which they are learned.

The knowledge of facts may also transfer from the subject in which they are learned; they may be recalled and used in situations widely different; they may form the bases of judgments; and they may of course change the attitude and thus the response of the learner.

Factors in transfer. Without attempting to classify we may mention the following transfers which have been reported by students of the problem: Improved methods, improved habits of attention and will; moral qualities such as diligence, perseverance, and intensity of application; method of orientation, that is to say, special training gives us ability to respond more 
favorably in a new situation; better discrimination in the same field, for example, of colors, or of judging length of lines; facile adaptation of attention and control of mental imagery; adjustment to apparatus and to general conditions; special methods, general methods; habits of analyzing each new situation, or of trying to induce variations instead of repeating an unsuccessful reaction time after time; confident and selfreliant attitude toward a new situation; habit of keeping up active attention during the course of practice, and of looking for improved methods and higher units, instead of settling down to a mediocre performance.

We are told that: "Transfer is readiest in the realm of ideas: and the more definitely a method of work, either special or general, has been conceived and formulated, the wider is the field of its probably usefulness. It may be remarked in passing that all these admittedly possible forms of so-called transference when taken together, amount to a tolerably complete summary of the most essential factors in what is popularly included in the training, or culture of the mind." (55). It is worthy of note also to recall the early conclusion of Woodworth and Thorndike: "The mind works in great detail, adapting itself, of necessity, to the particular material with which it has to deal; and, therefore, that training in one performance could only help another when the two had elementary factors in common." The study has only begun, and we must wait patiently to know more about what is transferable and from what subjects, and especially by what methods, the greatest number and the most important transfers can be had.

Transfers, though possible, may not take place. It must be remembered that while transfers are of ten possible, they may not take place. In fact, we cannot expect them to take place unless certain conditions of transfer are present. Two students may study the same thing, one getting a transfer or transfers to other situations, the other getting no transfer; or the same student may at one time study so as to get transfers, and at another time he may study so that he will fail to get any transfer.

The conditions of transfer. We may now ask what conditions are necessary in order to secure transfers where they are possible. This question can be answered, at least partially, from the results of experimental studies. Certain conditions have been found to bring about transfer, whereas, the transfer failed to take place when these conditions were absent. Bagley 
found, for example, that a child might be taught to be neat in writing papers for one subject but that he would not thereby learn to be neat in other subjects; later investigations showed that when the child was roused to have the ideal of neatness, the habit transferred in many cases to papers in other subjects. The presence of the ideal of the habit to be transferred is, then, one of the conditions of transfer. Being definitely conscious of the thing to be transferred and making the attempt to transfer it, that is, trying to apply it to some other situation makes the transfer more likely. (9).

Judd tells us that "Transfer depends on the power of generalization. The first and most striking fact which is to be drawn from school experience is that one and the same subject matter may be employed with one and the same student with wholly different effects, according to the mode of presentation. If the lesson is presented in one fashion it will produce a very large transfer; whereas if it is presented in an entirely different fashion it will be utterly barren of results for other phases of mental life.... A teacher can teach birds and plants in such a way as to arouse a minimum of ideas in the student's mind.... On the other hand, the same subject matter may be taken by a different teacher, and under other methods can be made vital for the student's whole thinking. James cites the example of his own experience with a smoking studentlamp. He discovered by accident that the lamp would not smoke if he put something under the chimney so as to increase the air current, but he did not realize that what he had done was only one particular example of the general principle that combustion is favored by a large supply of oxygen. The general principle and its useful application belong to a sphere of thinking and experience which the untrained layman has not yet mastered." (51).

In this connection it is fitting to recall the interesting footnote which Karl Pearson thought it worth while to add to the discussion of scientific method in his Grammar of Science. "Personally," he writes, "I have no recollection of at least 90 per cent. of the facts that were taught me at school, but the notions of method which I derived from my instructor in Greek grammar (the contents of which I have long since forgotten) remain in my mind as the really valuable part of my school equipment for life."

Transfers actually taking place in our schools. The writer has made an attempt to discover transfers and the causes of 
transfers that are actually taking place in education. The observers were to record things that had been learned in one study or situation which they found active, either to help or to hinder, in other studies and situations. Six observers worked systematically and reports were also had from several college classes. Many of the things mentioned were too indefinite to be of much value. But there was considerable concurrence in certain respects. And the value of these reports lies largely in the fact of corroboration by different observers who reported independently of one another.

Those conditions recurring in the reports of both systematic observers and students in my classes include the following : Realization of advantage or usefulness or importance of the thing that transferred. Feeling of need or actual demand for application. Desire to use, or to apply, desire for results, interest, desire to improve. A few observers mentioned for many transfers, the continuance of a well formed habit or of the use of a method that had become thoroughly habitual. Some observers recognized that a combination of some of these conditions had been the cause of the transfers. In a number of cases these observers also mention the method of instruction of their teacher as being the cause of the transfer. The teacher, in other words, had aroused in them the desire to apply what they learned, had shown them the advantage of so doing and had shown them how to make the application.

We must undoubtedly conclude that there are various conditions of transfer; others that we have not yet discovered may be found; whether or not they can all be reduced to a single type is a question and it is, perhaps, too early to attempt to decide this matter.

Maxims for bringing about transfers. If we were to state maxims for getting transfers and for directing our cducation so that the greatest amount of desirable transfer could be had, the following might be stated: Choose those subjects in which there is the largest number of things common to many situations in life. Choose the best teacher, and sometimes choose the teacher instead of the subject. Form the habits and learn the methods that can be used helpfully in many situations. Be conscious of the "notion" of idea of method and form the habit of applying what is learned. Have the ideal of the thing to be transferred. Try to generalize. Realize the value or advantage of making transfers. Cultivate valuable attitudes and points of view. 
Mentioning these things as we have emphasizes the fact that transfers depend upon the student, and upon the ways of doing things, as well as upon the teacher. The teacher should also remember that he must help the student to do the things mentioned above. Standards should be set according to the point of progress of the student, ideals should be made conscious in the student, and no teacher should accept inferior work.

Transfers and the choice of subjects. From the psychological point of view the student has at least two main problems in the choice of subjects so far as he has any choice. On the one hand, he should have a specific training for something; a training which shall make it possible for him to do something and to do it well. On the other hand he has the problem of general education, as it is called, of learning those things, and of becoming acquainted with those fields which will make him a possessor of the common heritage of his people, which will give him that common knowledge and insight into the activities and institutions of the people with whom he will live. When he may choose, then, he should choose those subjects which give him the information and insight and acquaintance with things that are required of the educated person, making the choice such that he will study subjects which have the largest number of elements in common with future living, and which will demand of him the formation of those habits which will be the most useful later; and wherein he will learn the best ideas of method, and the highest ideals, and be aroused to the desire to apply what he has learned. It is, therefore, as we have already said, not merely a choice of subject matter, but also a choice of teachers, since one teacher may teach so that many transfers result and another teacher fail altogether in this respect.

A subject supposedly of high disciplinary value may be taught so as to be of less disciplinary value than any other well taught subject. That is to say, the demands that are put upon the student, the way in which he studies, are perhaps, of more importance than the subject itself. Certain subjects are or may be of more disciplinary value than others, because they offer better opportunities for, or demand better use of, the student's intellectual activities. But again, the subjects that are not supposed to be of high disciplinary value may be studied so as to be of great disciplinary value. Remember that the most valuable thing is the right use of the mind, the 
formation of the right habits of study, the gaining of the right ideas of method and habits of method, attaining the highest ideals and the desire to apply. It should be added that the student should study subjects hard enough to call out his best efforts, subjects which appeal to him as worthy of his powers.

The value of intensive study. The sufficiently intensive study of some one thing may broaden a student in a way of which he never dreamed. Tennyson suggested that if we knew enough about the flower in the crannied wall, we would know what God and man are. All knowledge may be likened to a ball and all parts of this knowledge may be likened to lines which lead from the surface to the center; these lines are interconnected. If we should go deep enough on any one of these lines we would approach this center; and if we should be thorough as we go along we should work out on many intersecting lines. We would thus travel far towards the center of knowledge and at the same time learn much of the related subjects. In other words, thorough intensive study may at the same time be broad.

\section{QUESTIONS AND SUGGESTIONS FOR STUDY.}

1. Distinguish between the old statement of The Dogma of Formal Discipline and the present day statement of The Transfer of Training.

2. Why is the old extreme view impossible to accept?

3. What kinds of general improvement may take place?

4. To what may improvement be due besides transfers of training?

5. What improvements have you ever made in one field and thereby made improvement in other fields?

6. Diseuss the value of taking one subject for improvement in general. Be sure to deal with both the positive and negative aspects of the problem.

7. If a person wanted to make certain kinds of improvement, what advice would you give him in regard to making that improvement most economically?

8. Discuss the value of general improvement even though it be small in amount.

9. Is it advisable to take a subject in school purely for its disciplinary value?

10. On what general principles should one choose subjects in school or college? 
11. Where general improvement is possible how would you make sure of getting it?

\section{REFERENCES.}

Bagley, W. C. The Educative Process. The Macmillan Co., 1906, Ch. 13.

Colvin, S. S. The Learning Process. The Macmillan Co., 1911. Chs. 14,15 and 16.

Coover, J. E. Formal Discipline from the Standpoint of Experimental Psychology. Psychol. Rev. Mon. Series., Vol. 20, No. 3, Jan. 1916. Whole No. 87., Pp. viii, 307.

HEck, W. H. Mental Discipline and Educational Values. 2nd Ed., 1911. 
Chapter 10.

MEMORIES AND THE PERMANENCE OF ACQUISITION.

The modern conception of memory. The modern conception of memory leads us to think of it as a form of habit; (66), the recall of facts in memory is brought about in much the same manner as all habitual response. In other words, the making of memories makes at the same time dispositions in the nervous system, opens certain paths of discharge, and the more practice, the more easily and certainly will these paths, these dispositions, act or function again as they functioned before if only the right stimulus comes along.

Memory is commonly thought of as being a "storehouse" of ideas. But, if we wish to hold to that gross notion, we must remember two facts; first, that memories change by subtraction, dropping out of details; a memory is not as full or accurate a few days or weeks after the learning as at first; and, second, that memories change by addition; addition from later experiences, perceptions and other memories, and also from the creative imagination. The psychology of testimony gives us ample illustration of both kinds of change. The "storehouse" idea is, then, misleading. Memorizing is practice for recall; learning a skillful act is also practice for recall; the first being recall of nervous activities which reinstate with greater or less accuracy the ideas desired; the second being the recall of nervous activities which bring about the desired actions.

Another fact is that the term memory itself is likely to be misleading. We have many memories, or many kinds of memories, and that is a fundamental fact that should be kept in mind. Psychology has not far to look for proof of the existence of many memories. "The successful business man may have good memories for many kinds of things, but he frequently has a good memory for his line of work and miserably poor memories for other things; students who have memorized a great deal of one kind of material, do not find a corresponding improvement of ability in memorizing other kinds of material; pathological cases show loss of one kind of memory while the other memories remain unchanged. Wve have, then, not memory, but many memories. 
The conditions of memory. The secrets of good memories have been partly revealed in the preceding chapters. For the way to get the best results in memory is to have the right conditions for study and study according to the best methods. As Watt puts it, "Do not try to improve your memory. Try to learn better."

All the conditions which we can name for attention and for observation are also conditions of memory and help to determine what and how well we shall remember. Attention is a prime condition of memory. The factors that determine attention, are, then, determinants of memory so far as they function. (See chapters on Making the Appeal to the Student, and Attention and Sustained Effort.)

In like manner all the factors that make for the right feelings make also for memory: the arousal of instinctive tendencies, curiosity, emulation, etc., the suggestion that brings the right set or mood, the control of bodily conditions and action, acquiring pleasing or valuable knowledge, having a purpose, a determination, and especially an intention to remember.

Association is the grouping of impressions, and the primary law, so called, of association is that conscious processes are likely to recur with those conscious processes with which they earlier appeared; given, that is to say, any conscious process, as it appears, any or all processes that were earlier associated with it are likely to appear. But it must be remembered that they may have been together under any one of many different circumstances,- with attention or with inattention, clearly or vaguely, for a long time or for the briefest moment, on only one occasion or at a number of times. These other factors, besides the mere being together, are also factors that determine our memories. Mere association would not necessarily make for retention. Ability to recall depends upon the conditions under which the associations are made.

These conditions indicate what are called the secondary laws of association of which the following are the most important: (some have already been mentioned but are included in the following list) attention, feelings, emotional impressiveness, 'will,' want or need, feeling of social pressure, frequency of repetition, duration of the stimulus, vividness, recency, primacy, age, regularity, number of previous connections, order of learning, rate of learning, distribution of time, nature of material, divisions of material, length of material, logical connection, rhythm, warming up period, hardening 
period, fatigue, physiological conditions, habits, individual differences, number of senses involved,-all are given as determinants of memory.

Vividness, frequency of repetition, duration, recency, and primacy. Attention and feeling disposition are prime conditions of good memory; so are the factors of vividness, frequency of repetition, duration, recency and primacy of impression. It needs no argument or example to prove that vividness of impression means greater likelihood of retention; emotional impressiveness, pleasantness or unpleasantness, the whole feeling reaction, may be important solely for the vividness of impression which accompanies it. It is a question how many of the other factors mentioned could not be reduced to a matter of vividness. We shall discuss them separately.

Frequency of repetition. The law most commonly recognized and most frequently relied upon is that of frequency of repetition; it is pretty certain that if a thing is repeated a sufficient number of times it will leave some impression. What is said later about the presence of the intention to remember, indicates the limitation of this law however. Drill work in the schools which was once very popular became less so as teachers began to emphasize the need of the pupil's understanding every thing he learned. But experiments have shown that while the understanding is very important, the repetition is also important, and drill is rightly becoming fashionable again. Again, let us say, understanding is an immense aid in memorizing. But it has not proved to take the place of frequency of repetition.

The duration of any impression naturally has much the same effect in deepening an impression. Thoughts aroused by a hasty skimming of the daily paper, the hundred and one ideas that flit through the mind in the course of the day, are generally doomed to an early oblivion. But the ideas that are held until they are once clear, the thoughts that are turned over in the mind, are impressed and associated with other thoughts, and are proportionately more likely to be remembered.

An accumulation of repetitions. Meumann has made a careful summary of facts in connection with an accumulation of repetitions and we cannot do better than quote his conclusions: "What is the effect," he asks, "of an accumulation of repetitions of any given material? Let us assume that a material which, so far as its amount is concerned, can be 
learned perfectly well at a single sitting is learned until it can be repeated once from memory. What now is the effect of additional repetition?..... According to the experiments of Ebbinghaus the extra repetitions gradually become less and less effective so that, for instance, a disproportionately large number of repetitions must be employed in order not only to attain the first recitation from memory, but to imprint the material so indelibly upon memory that it can be repeated without error at the end of twenty-four hours, or can be retained permanently. This observation was, in general, confirmed by Weber and by Knors; but these investigators also show that a process of learning which has been continued only to the point where a first recitation from memory is just barely possible does not by any means guarantee a complete mastery or a permanent retention. Many additional repetitions are still necessary before a lasting retention is attained. It is clearly evident that immediate reproduction is a potent factor even in this process of 'first correct recitation'".

Continuing, Meumann writes: "Certain important rules for the practice of teaching may be derived from the foregoing.

1. The mere act of learning a material until it can barely be reproduced never secures a permanent retention in the case of nonsense material of considerable bulk, even up to ten or twelve syllables; in the case of significant material it very seldom secures a permanent retention. From this it follows:

2. That for everything which is to be retained permanently, a subsequent 'freshening' by means of additional repetitions is indispensible. It follows, too,

3. That we should not be content to regard the ability barely to recite it from memory as an indication that a material has been memorized. Really permanent retention or complete mastery demands many more repetitions for its achievement. IVe see here how important the factor of mechanical learning is for genuine memorial function. That which is to become an imperishable possession of memory,not as a part of one's systematized body of knowledge, but only as a datum of concrete cognition,- - can be acquired only at the cost of many repetitions.

4. If we wish, at a single sitting, to learn a material so perfectly that it will be retained permanently we must devote an excessive number of repetitions to it; and even then the result, so far as permanent retention is concerned, will remain in doubt." (67). 
Primacy and recency. "First impressions are lasting;" and other things being equal the most recent experience makes the deepest impression. We remember the first story in the old school reader, and carry away most clearly the ideas expressed by the last speaker. Other factors modify the working of these, of course. Other laws of memory are working at the same time. For example, the first impression is likely to determine the feeling disposition. But the most recent impressions, on the other hand, have the advantage of being left without interference by succeeding impressions. Both laws, primacy and recency, are exceedingly important. Each may be disturbed by the other, or by still other laws.

The teacher may of course take advantage of several laws in the presentation of material. That material which he specially wishes to be remembered he may present at the outset, thus taking advantage of primacy, he may refer to it several times during the presentation, thus having repetition, and in conclusion he may bring this material together in a summary so as to take advantage of the law of recency.

Distribution of repetitions. The time element enters into the learning in other ways than those already indicated. Jost's law, as already indicated, states that "Of two associations which are of equal strength but of different ages, the older receives the greater intensification from a new repetition." That is to say, the older memory can be relearned more quickly if it has faded.

The practical significance of this law is, for example, if one has to memorize material that will take approximately six hours, he should divide the time, and thus give an opportunity to make associations at different periods, which means the opportunity of refreshing older impressions. The same law indicates one of the reasons for having children learn many valuable things early in life, the earlier the better.

Besides the advantage of having older associations to strengthen by this division of study periods, there is another in the activity that continues during the intervals between study. Improvement is often found at the beginning of study periods which points to the making of progress during the intervals; the nature of the activities that bring about this progress is not definitely known. Perhaps the learning processes actually continue after one stops the studying. Perhaps, and what is more likely, partly formed bad habits tend to drop out, to be weakened or lost during the intervals of practice. 
In this way inhibitions or interferences are eliminated.

Reviews and the division of time. Reviews are important for preparation for advanced work, they are important when one is preparing for an examination that covers a term's or a year's work. One of my advanced students who has taught history for a number of years found that the surest way to get her pupils through the state examinations was to organize the work so that the most important things recurred systematically and were thus reviewed several times during the course. This teacher tells me that the suggestion came from another instructor and proved so successful that, whereas, her pupils formerly often failed in the state examinations, she now succeeded in preparing as many as forty pupils and with not a single failure in the examinations.

In preparation for advanced work, probably the best method for the student is to go through the previous notes or text or both and mark the things that need to be reviewed. Then the student should concentrate on these things until they are thoroughly learned.

Experimental study of the value of reviews for a short assignment. In a preliminary study the author has made experiments with sixth, seventh and eighth grade, high, and normal school students, to discover the relative value of $61 / 2$ vs. 4 plus $2 \frac{1}{2}$ minutes study of a page of difficult history, a page of easier history, and a page of introduction to the metric system. Fourteen classes were tested. Each class was divided into a review and a non-review group. The review groups studied a page of history mimeographed, for 4 minutes, then wrote that they could remember for exactly 12 minutes. Later they reviewed for $21 / 2$ minutes. The non-review groups studied for $61 / 2$ minutes at one time and then wrote for exactly 12 minutes. In some experiments the non-review groups studied at the same time that the review groups studied. In some experiments they studied when the review groups had their review. In this way the factor of recency was checked up. Both groups were later given an examination at the same time. The groups were divided on the basis of scholarship according to school grades. Fourteen experiments were made with fourteen different classes. In all there were 730 cases. Experiment 1 was done with a page of history that was too difficult. Experiments 2-9 were done with an easier page of history. Experiments 10-14 were on the metric system. In experiments 1-3 the review groups had the advantage of re- 
cency. In all other experiments the review groups reviewed at the same time the non-review groups studied so that neither groups had the advantage of recency.

"The average superiority of the review groups in the first three experiments where the review groups had the advantage of recency is 93 per cent. The average superiority in the other experiments is 67 per cent, and if we eliminate experiment 12 , it is just less than 30 per cent. The extreme result in the twelfth experiment is due to the fact of several failures and near failures in the non-review group." (24). (See Fig. 10). The experiments without exception show that the division of time so as to allow a short review period is valuable. It is generally known that the division of time for large amounts of material is very important. As suggested in the article just quoted, it may be that the value of reviews is directly proportional to the difficulty of the learning.

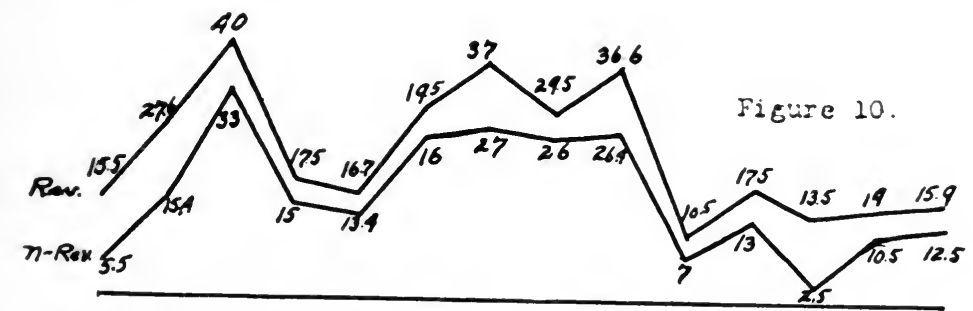

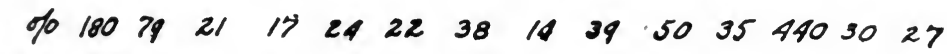 Tests: $1 \begin{array}{llllllllllllll} & 2 & 3 & 5 & 5 & 7 & 8 & 9 & 10 & 1 / & 12 & 13 & 14\end{array}$}

Fig. Io. The lower curve represents the non-review, the upper curve the review groups. Superiority of review groups in percents in experiments I to I4 is as follows, respectively: $180,79,21,17,24,22,38,14,39,50,35,440,30,27$.

The "warming up" period. The division of time involves other factors: the "warming up" period, the "hardening" period, and fatigue. The nervous system works very much like a machine. If one watches a lathe as the turner begins work in the morning, one notices that after the belt is thrown on the lathe starts, gathers speed, and is soon going merrily. After a moment or two the observer notices a continuing increase of speed; the machine is getting "warmed up" and for the first few minutes does not attain its greatest speed. So with the nervous system and mental activity: the first few 
minutes do not give the best results, and a study period should be long enough to allow taking advantage of the warming period.

Fatigue. At the other end of the study period there is the factor of fatigue. This, as has been said, is to be distinguished from weariness or the feeling of fatigue. This feeling is not an index of actual fatigue; the feeling may come prematurely on account of lazy habits of stopping long before one is really tired, or, if frequently disregarded when one is working long hours, perhaps with insufficient sleep, the feeling may fail to appear and be a warning against overwork. Experiment shows that the time during which the same quantity and quality of work can be sustained can be lengthened greatly over what is commonly believed. Eight, ten and twelve hours have been tried successfully, for example, in multiplication work.

This does not prove, however, that very long hours of study are the most economical and best in the long run for study or for health. The fact is that fatigue lowers the quality and lessens the quantity of work and is to be avoided. The fact is, also, that work for fairly long periods is less harmful than has been supposed, and that a good deal of the injury attributed to work and study is the result of poor bodily conditions, insufficient fresh air, sleep, exercise, proper food, and the presence of abnormal emotional states. In fact, one way to improve the memory is to improve the physical conditions.

The "hardening" period. It has further been found that one can take advantage of what has been termed the "hardening" period. This is the period immediately following a study period. If, during a few minutes directly after study, one lets his mind dwell on the subject of study, permits no distractions, no other thoughts to come, does not turn his attention to some other topic, the things learned will have a chance to sink in, so to speak; interference with the ideas will be avoided; the associations just made will not be broken up. Three or four minutes may very profitably be used as a hardening period.

The value of comparatively short periods. Experiment has shown us more in regard to the division of time. Economy requires avoidance of fatigue, elimination of the over long study period; economy may also be gained under some circumstances, at least, by the use of very short periods. In memorizing non-sense syllables, Ebbinghaus found that for later relearning, thirty-eight repetitions distributed over three 


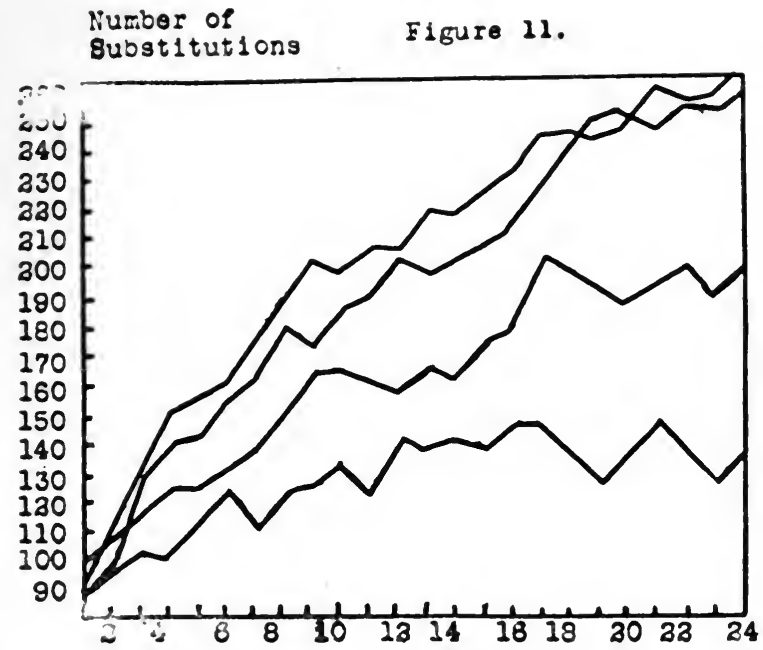

Fig. II. Relative value of 10, 20, to and 120 minute periods. Substitution Test. (Starch, 92a). The curves, from highest to lowest, respectively, represent results of the $10,20,40$ and 120 minute periods, the results being checked twenty-four times, and at five-minute intervals.

days were better than sixty-eight repetitions in one sitting. Jost, using non-sense syllables and making experiments with three divisions of time found two repetitions a day for twelve days best, four repetitions a day for six days, next best, and eight repetitions a day for three days poorest. Starch requiring the association of letters with numbers and the transposing of grouped numbers into prose, reports ten and twenty minute periods of practically the same value, the former slightly better. A forty minute period considerably poorer than either and a two hour period poorest. (See Fig. 11.)

Dearborn (21), with the same kind of material and problem, found that one ten minute period was better than two five minute periods per day. Pyle (80) has experimented with adults in the learning of alphabet characters. He found that 30 minutes a day gave better results than 15,45 , or 60 minutes. He concludes that the second practice on the same day is not as valuable as the first, and that after a few practices, further practice on the same day is useless. In learning to run the typewriter the results were somewhat different. In the acquisition of skill in this experiment Pyle found that concen- 
trated practice,-about 5 practices the first day,-was economical. Later on the distributed practice again proved to be most economical.

(81).

It is generally dangerous to draw conclusions from one kind of material to another. But it appears that for many kinds of material, at least, fairly short periods are not only economical, but far better than longer periods. Experience and experiment seem to show that for the working out of ideas, solving problems, writing essays, and the like, longer periods may not only be better but that they may be absolutely necessary.

Immediate and permanent retention. Many associations. The factors that make for immediate retention for a first accurate recitation, for example, great concentration of effort for a short time, many repetitions during one sitting, do not make in the same way for permanent retention. While a thing may be learned for immediate recall by great effort and vividness of impression, psychologists have no two opinions in regard to the need for many associations with the thing to be remembered if it is to be long retained. That is to say the material to be remembered for a long time must be assimilated, it must find its place in the thinking of the student. It must be gone over again and again, and this means time, and better yet, distributed time; time divided into different periods as has just been shown.

It is just this going over day after day, this using at frequent intervals that makes permanent and sure the recall of facts by the teacher, the business man, the doctor, the man in any line of work. Constant use means frequent repetition and many associations and as a result permanent acquisitions. If one realizess the thousands of impressions made through the eye and ear and the other senses in the course of only one hour, it will be seen that it is extremely valuable that the individual soon forget most of the impressions that are made only once. For the course of his thoughts would otherwise be continually disturbed with worthless memories constantly usurping the place of useful information and relevant thinking. It is again extremely valuable that the things gone over again and again are the things that become permanent for these are the things useful in every day life.

Cramming. Cramming, it will now be seen, becomes a matter of making impressions which will last only a short time, for the failure to go over again and again, to review at different periods, means a lack of associations, a lack of as- 
similation, and hence, a lack of permanency. Cramming therefore fails for retention that is to last any great length of time. But cramming, on the other hand, is not to be condemned for other purposes. Some material is valuable only for a short time; furthermore some professions demand the ability to cram; the lawyer, the public speaker, the business man, the actor, all are required to learn a fairly large number of facts at short notice; very often this knowledge need not be remembered for a long time. The ability to cram is, therefore, a valuable asset; this the student soon learns,- to his delight, if he is able to do it well and wishes to pass an examination,- - to his sorrow, if he hopes to retain the information after the examination.

The student, then, must choose: either to depend on cramming, and to find that, outside the good or bad results of the examination, all that he has left is the ability to cram: or to take more time, to review at different times, to form the necessary associations and have a surprising amount of information when he gets through. Cramming is after all neither good nor bad, but like almost everything else, it is good for some purposes and inadequate for others; the ability to cram is likely to be a valuable asset to anyone. It is possible to learn to cram for more permanent retention. The determination to remember permanently; thinking over the material as much as possible and early and frequent reviews make for permanent retention.

It is worth noting that inability to recall immediately indicates poor observation, imperfect impressions, and the student who finds this kind of difficulty needs practice in observation. Inability to recall after a lapse of time indicates a defect in memory, and the student here needs practice in memorizing the kind of material which he wishes to remember.

Memory is no sure index of general intelligence; people of low intelligence often show astonishing memories, and can sometimes repeat accurately without hesitation more than one has patience to hear. On the other hand memory is fundamental to reasoning. inasmuch as memory furnishes the material for reasoning; neither is great learning an index of ability to use that knowledge, and we often find the great student unable to use his knowledge, whereas the man with a few facts and ability to put them into operation, to make the applications, steps in and achieves the success.

The rate of learning. The old statement that quick learners 
are correspondingly quick to forget has been denied; and evidence has been brought forward to show that students who learn fastest also remember the best; we are told that fast learners are at no disadvantage. It seems most probable that two types of learners have been observed: one in which learning is fast and retention superior; another in which the learning is fast and retention inferior. There is no room for doubt that there are fast and slow learners; in the face of evidence. available during the last few years it must be believed that many fast learners remember as well as, or better than, slow learners.

The problem for any individual student is to find his own best rate; and excepting those who skim over their books with a superficial rapidity, it is for most people true that their rate of study could and should be a little faster than it generally is. A little extra pressure, desire to beat the other fellow, something that gets us more solidly to work, frequently helps us to a speedier learning of a lesson which generally is learned lazily and not so well. The only way to find one's own best rate of study is to try out different rates and choose the rate that gives the best results.

But it is to be understood that the rate of learning at the beginning of a task is not the rate which is best later when some progress has been made. Understanding requires a slower rate at first; accuracy is the essential in the beginning, for the understanding of logical material, memorizing, the learning of a skillful act, or what not. The work should go slowly enough for accuracy; speed can and should come later. The later study can be faster and should be; if as slow as at first, interest may lag and effort wane.

Meumann considers the rate of learning "the most universal and fundamental condition of memorial activity work because the tempo of learning determines the time during which not only the single syllable remains in consciousness and is imprinted upon consciousness, but also the rapidity with which the associations between the several syllables are formed." Learning at a very fast rate is bad; learning at a very slow rate is bad; there is a loss either way, and the student if he is to do his best work with the best economy must find his own best rate of study, first for the material he is studying, second, for the stage of progress he has already made with this material, and third, for the problem he has before him, whether to understand, to memorize, or to learn a skillful act. 
Auditory learning is faster than visual learning; if one learns through the eye, one must then expect to go a bit slower, but there is the satisfaction of knowing that the visual learning is more accurate.

Regularity of application. The continual dropping of water wears away stones; regular application to a subject will remove mountains. It is not too much to say that twenty minutes a day for a year would be sufficient for a fair student to learn the fundamentals of a science. This means regularity, and it is the regular application day after day, week after week, month after month that counts. The spasmodic effort just before an examination serves, perhaps, for the inmediate occasion, but for that only. The superhuman effort for a short time overtaxes the system, and gives only indifferent results with a very disproportionate expenditure of time and energy.

The regular, systematic, accomplishment is the true way to success; this is the insuring of habits, and habits, if well formed, are as sure as anything that a man can rely upon. It is because of this regularity more than anything else that men awake suddenly to the realization of competency in their field. It is this which brings mastery; and when it comes one knows that he has command of that which has thus been practiced regularly; it is a part of him, and remains a part of him as long as his nervous system contiues to work normally.

Frequency of practice. Is it most economical to practice for a certain length of period once a day, once every other day, twice a week, or several times a day? Granted the value of regularity, what is the best distribution of periods? The problem is very important especially in connection with the determination of the curriculum for schools and colleges. Very commonly we find students studying according to either one of two plans: the five times a week plan, or the alternate day plan.

The study of Murphy (71) perhaps sums up the larger part of our experimental information on the subject. We have spoken elsewhere of the value of distribution of periods. Of this there is no doubt. We have only begun to get answer to the question of the best distribution.

Murphy tells us: "In regard to periods of work up to a limit of twenty or thirty minutes, the conclusion has been reached that one practice periorl per day gives better results than any other larger number per day. Lashley (in an unpublished 
study) found in archery practice that the group which made five shots per day showed greater improvement for the same number of shots than those who made twenty shots or forty shots per day.

As yet no conclusion has been reached in regard to the value of alternate days' practice compared with daily practice. Pyle, from his experiments in transcribing reading matter into new characters, concluded that daily practice is better than practice on alternate days. He had, however, only six subjects in the test, and even to this conclusion, he adds that after the initial stages alternate days may be better.

Professor Leuba and Miss Hyde of Bryn Mawr have added some information to this question in their tests on "Hand Movements." Their test was to find out the progress in skill in writing English prose in German script. Four divisions were made of their subjects: One group working twice per day, one daily, one on alternate days, and another every third day"....there is seen "very little difference between the alternate and daily practice groups, but in comparing them with other groups a decided showing is found in favor of the daily and alternate day groups. One defect in this comparison is the short length of the curve. The indications are that with further practice the alternate group would compare yet more favorably ..... at the end of the tenth trial the group working on alternate days was superior."

Professor Murphy gives the result of his own experiments in javelin throwing. Three groups of Normal School girls using the left hand, practised throwing the javelin; one group throwing five times a week, another three times a week, the third once a week. Some attention was also given to twice a day practice. Professor Murphy states in conclusion that, "From a study of the results of the above experiment, and from a careful study of the attitude of those throwing the javelin, we conclude that learning periods can be distributed by giving alternate days practice, and even weekly practice, without any loss in learning. We believe this to be a conservative statement not only for practice periods involving skill or hand manipulation but also for so-called mental work. We believe we are justified in stating that better work, for the amount of time expended, can be done in our schools through a distribution of three times per week than through a distribution of five times per week."

While there is apparently considerable economy in relative- 
ly longer intervals between practice periods, it is perhaps wise to await further study and to be especially careful about generalizing from one kind of learning to another.

\section{QUESTIONS AND SUGGESTIONS FOR STUDY.}

1. Explain how the old view of "memory" is supplanted by the modern view of "momories:" Give reasons for this change of view.

2. How may the "storehouse" idea of memory be misleading? In what sense may it be correct?

3. "The nervous modification which we have here named 'impression' is, clearly, the first term in the series of nervous changes which condition the process of learning." Discuss this statement and show how much that we have said in earlier chapters is significant for the permanence of retention.

4. "The conditions of impression are also the conditions of association." Can we conclude from this fact that we should try to make the conditions of learning as nearly as possible the same as the conditions that will be present when we want to recall?

5 . Make a list of the factors that you consider most valuable in the school room for the purpose of helping students to retain what they study.

6. Show how you could make use of several of these factors in presenting something to a class. Choose the subject and the factors you would use and show how you would use them.

7. State Jost's law and show its significance for memorizing.

8. What can you say as to the value of reviews? Are they valuable for short as well as for voluminous inaterial?

9. Discuss the relative values of different lengths of time for the learning of lessons.

10. For what is cramming good? For what is it bad? Explain.

11. What can you say as to the frequency of study? Should subjects be studied twice a day, once a day, every other day, or every three days?

\section{REFERENCES.}

Ebrixghaus, H. Memory. Tr. by Ruger, 1913, Teachers College, Columbia University.

Meumann, E. The Psycholog! of Learning. Tr. by Baird. D. Appleton and Co., 1910.

ThoRndike, E. L. Educational Psychology. Vol. 2. The Psychology of Learning. Teachers College, Columbia University, 1913, Ch. 10. Also Briefer Course, 1915, Ch. 17.

WATt, $\mathrm{H}, \mathbf{J}$. The Economy and Training of the Memory. Longmans, Green and Co., 1910. 


\section{Chapter 11. \\ MEMORIES AND THE PERMANENCE OF ACQUISITION. (CONCLUDED)}

The nature of material. The nature of material and its organization or lack of organization make an immense difference in learning and in retaining. Organization is immensely valuable both for mastery and for subsequent recall. A speaker finds it easy to remember his address if he has organized it logically; the audience finds that such a talk can be reported with comparative ease; but let it' be put together in a disorderly way and both speaker and hearers find proportionate difficulty in remembering even the main ideas. The teacher who can lecture hour after hour with comparatively little dependence on notes owes his readiness of recall very largely to the fact that the ideas have been organized. When one has this organization of a science in mind, whatever he studies finds its appropriate place in his system of thought, and is so much the more likely to be remembered.

It follows for the student, then, that if the material which he studies is not properly organized, he should organize it for himself. It is conceivable that the organization of material could be done by a few very good students without written notes; but this method is bound to fail in many details if not with many of the main thoughts; this is especially true of things learned through lecture. If one can listen to a lecture, understand it, and afterwards find what he is unable to remember in a textbook sufficiently well organized, it is probably the best way to do. But the essential thing is to have the material organized and to have it so that it can be reviewed. Once going over a thing is not sufficient.

Topical study. Topical study and topical organization are undoubtedly the best; know first the general subject, next the first main thought and the subheads under it with illustrations; then the next main thought and the subheads and illustrations under each, and so on. The subheads may be arguments for or against, examples, explanations, applications, or whatever 
else belongs with that main thought. We think by topics, we use, answer questions, solve problems, index our knowledge by topics; and for all these purposes and in practically all circumstances the topical method of study and of organization is best.

Light from later chapters. It is obvious that some material can be mastered as one goes along and that other material is so difficult that one.finds it either very hard or impossible to master in this way. For skillful acts, habits need to be made thoroughly before higher habits, that is, habits dependent upon the fundamental habits, can be made economically. On the other hand, common experience shows that what is not understood or well remembered may be cleared up and easily fixed in memory when later paragraphs are read, or after later chapters are studied: later statements throw light on earlier ones.

It is a common experience for students to find on review for examination that many parts of a course which were not at all clear earlier become perfectly clear through the review, and furthermore, the different facts find their proper place, appear in the true perspective in the student's mind. To go ahead and get light and then to review is, with much meaningful material, of ten the thing to do. This suggests naturally enough the problem of learning by the whole or part or by some other method, and the further problem of the size or amount of the units to be learned at any one time.

The whole versus the part method. Experiments give us considerable evidence in connection with the first question. The most common way to learn a poem or a speech is to learn a part, then another part, and so forth, until the entire poem or speech is learned. The results of experiments show that in comparison with the method of learning by going from beginning to end and repeating the process till the learning is complete, learning by parts is wasteful of time and energy. Learning by wholes is more economical than learning by parts. The possible exception to this rule is found with nonsense syllables which have been used in experiments; there is little or none of this kind of memorizing in real life however, and furthermore, there is reason to believe that a modification of the whole method is best even with this kind of material.

Meumann has reported the results of his own experiments and of the experiments of others. The results, in which there is general agreement, are as follows: "For adults and children 
it is more advantageous and it is psychologically and pedagogically more appropriate to learn every sort of material as a whole than to break it up into parts:"- "If, for example, an observer remembers thirty percent of a poem which he learned three months ago by the whole procedure, he would be found to have forgotten almost the whole of it during the same interval if he had learned it by the part procedure. Indeed, it sometimes happened, it is true, that stanzas which had been learned by the whole procedure required more repetitions on relearning than stanzas learned by the part procedure; but, even in those cases, the former stanzas were remembered essentially better than the latter. Hence, the whole method again proves to be more advantageous in so far as retention for longer periods of time is concerned."

Again he writes: "I have discovered that the whole procedure is advantageous not only in the laboratory but in practice, for teachers of my acquaintance have submitted it to a thorough test in their schools. Let the children see how wholly different is their concentration of attention when they learn by means of the whole method or by one of the mediating methods, and how, in employing the part method as they ordinarily do, they waste an extravagant number or repetitions on the first few lines of a stanza of poetry and neglect the other lines." (68). The conclusions stated above were based on studies of memorizing non-sense syllables and poetry.

Miss Lakenan compared the whole and part methods in connection with both prose and poetry. She writes: "For memorizing poetry, the whole method is, in general, more economical than the part method. In cases where the part method was of advantage for the first learning, the percentage retained after a number of months was greater for material learned by the whole method than for that learned by the part method; prose is more readily learned and better retained by means of the whole method than by the part; for both poetry and prose there is an increase in effectiveness of the whole method with increase in the length of the selection to be learned, up to 36 lines of poetry and 300 words of prose, which were the limits of the experiments.... most children tested found the whole method of advantage for the first learning." (56).

Reasons offered in explanation of the advantage of the whole method are numerous: better distribution of attention and effort; realization of meaning of the whole; consequent better interest and sustained effort; avoidance of transition 
from one section to another and the final putting them all together; having parts in right order and position from the beginning, and thus learning cues for succeeding parts from the outset; aid given by total impression.

Modification of the whole method. What Meumann calls the "mediating" method is a modification of the whole method. For example, a language vocabulary exercise is to be learned; the student goes through it from start to finish as required by the whole method; but he notes or marks the hard places and as he goes over the exercise in the following repetitions he allows the mind to dwell longer on the hard parts. This obviously combines the further factor of duration of impression. The term "mediating" is not sufficiently descriptive of the method designated: the expression, emphasizing whole method, is at least more definite and might perhaps be most useful.

Another modification of method is in the combination of the whole and part methods; this allows for individual differences. It has been used most successfully with school children. The material is first studied by the whole method; then the hard parts are studied by the part method; finally the entire matter is gone over by the whole method again. This also permits greater attention and the expenditure of more time and energy on the hard parts and proves to be most successful and economical in many situations.

Size of units. As to the size of units, the amount of material to be studied by the whole method or by any other method, only partial answer has been given by psychological experiments. The results seem to differ with practised and unpractised observers. Ebbinghaus found that with unpractised observers larger amounts of material required a disproportionately large number of repetitions. With practised observers an increase in the amount to learn does not require a proportionate increase in the number of repetitions needed for learning. The conclusion seems to be that for unpractised observers or learners, shorter units, and for better trained students longer units, are best.

Meumann states on the basis of work done in his laboratory that "the task assigned for a single period must be as great as the capacity of the learner permits." (69). In defense of this he reports the following facts: syllables may be learned with a certain number of repetitions, as for example, 8 in 5.2 repetitions; 12 in 10.4 ; 16 in 17 ; 18 in 21.5 ; 24 in 30 ; 36 in 32.5 repetitions. 
Miss Lakenan reports: "In learning prose by the whole method, fewer repetitions are required for learning a 300 word selection than for learning a 100 or 200 word selection, while in learning prose by the part method there is a slight increase in the number of repetitions required with increase in the length of selection to be learned. In memorizing poetry, 36 lines require fewer repetitions for learning than do 18 lines, when the whole method is used. When the part method is used, there is an increase in the number of repetitions required for learning with increase in the length of the selections to be learned, with one exception,-36 lines require fewer repetitions than do 27 lines." (57).

Henmon found similarly with meaningful material that an increase in amount of material did not require a proportional increase in the number of repetitions. It is probable, therefore, that economy is to be found in taking a fairly long task rather than a shorter one; just how long, psychologists are not ready to say; further experiments must be made; and when they are made, individual differences will probably make it very much an individual problem still; better students will find it economical to take longer amounts while poorer students will find it advisable to take smaller amounts to study at one time. Experience tells part of this, as, for example, the division of a play into acts is found to be the best.

In this connection Meumann writes: "The slow increase in number of repetitions with increase in amount of material reveals the presence of a fact of will, and also perhaps of an attitude or adjustment, which may be described by the statement that the expenditure of energy is regulated automatically to conform with the magnitude of the achievement which is demanded of the learner. It is a matter of every-day observation that our task progresses more readily when we make it part of a larger task than when we set about it independently. Our awareness of the fact that the task is large leads us. unconsciously and involuntarily to a keener and more effective concentration of our energies. I have found this phenomenon to occur in learning, in the work-curve, and even in ergographic experiments, so that I am led to suppose that it may be a universal law of will."

Size of units and the length of assignments. The topical method of study and of assigning lessons permits of a solution to this problem. A topic or several topics are assigned. All students must learn a certain minimum about each topic. The 
better students are credited for all they learn in addition. Credit is also given for quality of work. Obviously the procedure requires a careful organization of the course. But no teacher should attempt to teach a course if it has not been well organized.

Order of learning. Order of learning is akin to organization of material. The order of studying facts in a subject in a course in school or college, gives the basis for the organization of all the facts learned; on the basis of such order of learning and organization the material is most easily learned and best remembered. In physics, for example, it is likely that the fundamental matters of time, space and mass should be studied first; then the phenomena arising from the combination of two of these; then the phenomena arising from the combination of all three; and, finally, the more complex phenomena which can be properly understood on the basis of these facts. This ordering of materials, the presentation of facts in the best sequence, is the problem of the teacher and of the author of the text-book; but the student should expect to find such presentation from the teacher and from the textbook.

Silent learning versus learning aloud. Is it more economic to study silently or aloud? Dumville and Lewis (23) report that they found the silent method better for groups of children who learned poetry by the "entire" method. The groups using the silent method not only did better in reproduction but the individuals, evidently without exception liked the silent method better.

Pintner and Gilliland (82) report that groups which they studied showed better results when using the silent method. (See figure 1). Mead (61) reports that fifteen out of seventeen classes did better in reading by the silent method. Seventy percent of the children, aged 9.2 to 16 years, taken separately did better by this method.

Explanations offered indicate that the silent method is considered to allow better exercise of individual differences in such things as rate of learning, span of apprehension, difference in understanding words, kinds of associations, type of imagery, and that there is less distraction and better attention when this method is used.

We have yet to learn if a combination of the two methods would not give the best results. Dumville and Lewis think that the combination of a little concerted learning and the rest 
and by far the most of silent learning would in common practice in schools give the best results.

The attitude of the student. When all is said the fact remains that all progress in learning depends on the activity of the student; and it depends on the text or the teacher only so far as the text or the teacher arouses this activity of the student. Ultimately all education depends on the activity of the learner, and the school or college can only arouse and help to direct this activity and make it economic. The teacher can offer the stimulus, the incentive. The attitude, the condition of the student, the way he goes to work, determine what he shall learn. In the field of memory the old illustration is pertinent. A baggageman delivered a trunk to the wrong address while drunk and was unable to recall the place where he had left the trunk until he was again drunk. The point is that the conditions of learning are also the conditions of recall. The student should realize then that he should put himself in the same attitude when studying in which he will find himself when trying to recall; this means among other things, something of the aggressive attitude.

Artificial systems and devices:Mnemonics. The majority of students, teachers, business and professional men find that the logical organization and the continual use of their subject matter are not only sufficient for remembering their material but that these means are the most satisfactory; on the other hand, men with excellent memories find aid in the use of artificial systems or devices, in mnemonic systems or mnemonic devices. The railway postal clerk who has to memorize all the post-offices in three states, looks in vain for logical connection with such incorrigible material and rightly seeks aid in mnemonics.

We have, in the first place, to recognize the fact that people for the most part do not make their memories serve them as they might; case after case could be cited of people who complained of poor memories, but found that a little demand in the way of practice revealed good or excellent memories. In the second place, people commonly hold to the notion that they can practise on one kind of material and as a result be better able to remember other kinds of material; failing in this they feel the need of an artificial cure-all. And, in the third place, the flight to an artificial system is a flight to a means of interpolating into the material to be learned the logical or other associations which the student should find within nearly 
all kinds of material itself. The justification of a mnemonic, therefore, so far as it can be justified at all, lies in its interpolating some kind of helpful association where there is none in the material itself.

Disadvantages of mnemonics. This bringing in of some kind of association into discrete, incorrigible material is the advantage of mnemonics, and constitutes, so far as the author can see, its only defense. And the disadvantages are many. The logic that is used is often bad logic; one uses poor logic enough without training in its use; the system is of little use unless it is fully mastered and continually used; this is likely to mean overuse, that is, use where it should not be resorted to, and therefore, a tendency away from relying on hative memory and making it serve one as it should. It is obvious, too, that reliance on an artificial system may postpone or even eliminate the discovery of logical relations within the material to be learned which the student should find if he is to have any mastery of his subject.

Furthermore any recall through the medium of mnemonics is slower because of the additional associations involved, and is correct only if the system has been used correctly. The mind has all this time of course the burden of the additional auxiliary ideas demanded by the system. The enthusiast is likely to overuse such a system at first; later to become dissatisfied with it and to find it more a burden than a help.

At best mnemonics is only an aid to memory and should never be substituted for ordinary memorizing; it should never be used except to supplement, and then only for material which cannot be dealt with in a better way. Its true use is, then, with very difficult discrete material and only as an occasional supplementary aid. The little mnemonic devices arranged by teachers perform this office.

Habit or logic in language. Rules for correct pronunciation and for the correct use of language are a sort of logical method of dealing with language; and the teacher should learn once for all that knowledge of rules does not make much difference with the actual performance. A person speaks and writes correctly because he has heard and read and been called upon to use correct language. The direct method of teaching languages recognizes this fact. Experimental pedagogy has shown us how little the knowledge of rules has to do with the correct use of language; (85) and experience tells us that children can learn several languages if people around them 
use those languages. It is fairly safe to say that no one but a teacher and he very seldom thinks of a rule or makes any application of a rule in the use of language. "Grammar," according to the recent report of the U.S. Bureau of Education, (32), "receives altogether too much time and is taught too intensively and too analytically."

Forgetting. The facts of forgetting are very complex and confusing. Few generalizations can be made that apply to different kinds of material. The rate of forgetting and its extent differ as the material as well as the conditions of learning differ. It may be safe to say, however, that forgetting is at first very rapid and that this decreases as time goes on. In some kinds of learning at least one retains or is able to reproduce more at the end of twenty-four than at the end of eight hours after learning.

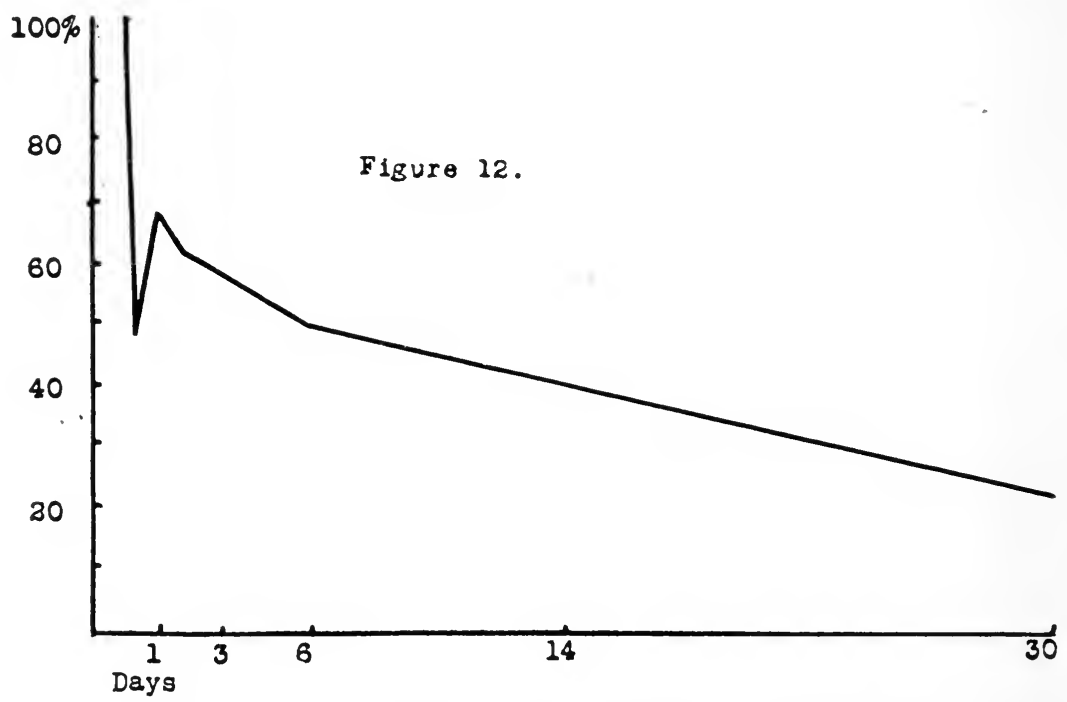

Fig. I2. The rate of forgetting non-sense syllables. Results from a study of 27 observers. The curve is drawn from results given by Radossawljewitsch. See table in E. Meumann. The Psychology of Learning, 333.

The study of Radossawljewitsch is probably as representative as any for the rate of forgetting non-sense syllables. These were learned by 27 observers until they could reproduce them twice without error. The average results are as follows: 2.5 per cent were forgotten in 5 minutes; 11.4 per cent in 20 minutes; 29.3 per cent in 60 minutes; 52.6 per cent in 8 hours; 32.2 
per cent in 1 day; 39.1 per cent in 2 days; 50.7 per cent in 6 days; 59 per cent in 14 days; 62.2 per cent in 21 days; 79.8 per cent in 30 days; 97.2 per cent in 120 days. This is made clearei by the accompanying curve (Figure 12).

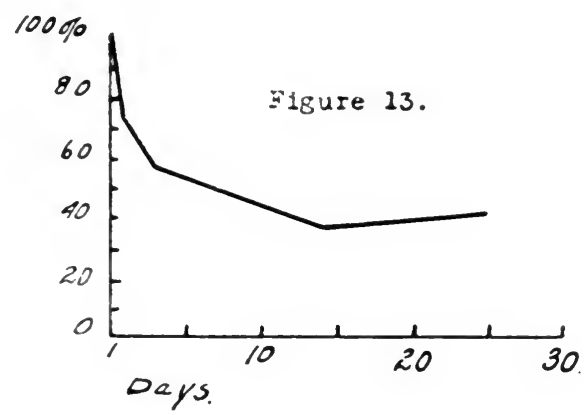

Fig. 13. "The approximate curve of forgetting for poctry learned to the point of two successful reproductions. Drawn from data of Radossawljewitsch. (Thorndike)."

The forgetting of poetry seems to follow another curve, and this is represented in the second figure which again shows the faster forgetting at first and slower later. (Figure 13).

Permanence and the kind of learning. Some of our acquisitions are without doubt much more permanent than others. Some are no doubt more likely to be permanent because of the nature of the learning or of the nature of the thing learned, or for both reasons. Thorndike makes the following statement in The Psychology of Learning: "It is perhaps the case that functions whose improvement consists in responding more surely and more quickly by some movements of the muscles to some sense presentations with which the former are to be bound with few intermediaries, retain their improvement better than functions where the surety and speed of bonds from one internally initiated event in the brain to another are the main facts to be improved. Skating, dancing, swimming, typewriting in an advanced stage, on the one hand, and the recital of poems, or nonsense series, knowledge of chemistry or geology, the ability to translate English into German, and typewriting at the beginning, on the other, illustrate and suggest this contrast.

"It is possible that the secondary or so-called higher connections in the nervous system which correspond to the asso- 
ciation of 'ideas' are fundamentally less retentive of modification produced in them by learning than are the more primary and direct neural bonds which correspond to the association of senory situation and motor response. Knowledge may be by the nature of man's neurones less retainable than skill. Roughly, as a matter of general observation, it seems to be." (110).

\section{QUESTIONS AND SUGGESTIONS FOR STUDY.}

1. Explain why the organization of material is very important.

2. Many students say that they could never study by the whole method. What facts are there to indicate that they should study by the whole method?

3. How would you modify the whole method for group study?

4. "The task assigned for a single period must be as great as the capacity of the learner permits." What is the reason for this and why is too short a task an evil?

5. Choose several subjects and thinking of the age of the students, how large units would you have to be studied by the whole method?

6. What two kinds of reading must children learn? Which is more important and more used in adult life?

7. What has the attitude of the student to do with learning? Cite some examples.

8. Distinguish between mnemonic systems and mnemonic devices and indicate the probable value of each.

9. What general laws of forgetting can you mention and what can the teacher do to help pupils with the problem of forgetting?

10. Make three lists of five subjects each which shall show, 1) subjects in which there must be the most effort to bring about permanent retention, 2) subjects requiring the least effort, and 3 ) subjects requiring intermediate amounts of effort. Can you find any general principle involved?

REFERENCES.

Ebringhaus, H. Memory, Tr. by Ruger, 1913. Teachers College Columbia University.

Meumann, E. The Psychology of Learning. Tr. by Baird. D. Appleton and Co., 1910.

Thorndike, E. L. Educational Psychology, Vol. 2. The Psychology of Learning. Teachers College, Columbia University, 1913. Ch. 10. Briefer Course, 1915. Ch. 17.

WATT, H. J. The Economy and Training of the Memory. Longman's Green and Co., 1910. 


\section{Chapter 12}

\section{MAKING THE APPEAL TO THE STUDENT.}

The release of energy. (One of the most conspicuous characteristics of the living organism is that it responds to stimuli in a vastly different way than do inanimate objects. A billiard ball responds, if the term be permitted in this case, in direct proportion to the amount of stimulus. The response of a living organism, and especially of the human organism, is likely to be out of all proportion to the strength of the stimulus. The response is more nearly similar to the action of gunpowder, or of a coiled spring when the energy is suddenly released. The analogy is inadequate. The response of the organism may be varied and the extent of the reaction impossible to calculate beforehand. But the analogy holds in one respect. The response of the organism is determined both by the stimulus and by the inherent tendencies to respond. Instinctive and acquired dispositions, which are many and varied, are necessary to account for the many and extensive responses of the organism. Also, and especially in the human being, the problem is complicated by the inhibitions which may limit or entirely hinder any response at all.

The present and following chapters (chapters 12 and 13) will deal with the means of arousing the desirable activities on the part of the student. In the present chapter we shall emphasize the instinctive and emotional side of the matter. In the following chapter we shall emphasize the matter of attention and sustained effort.

The teacher's work is to arouse and to direct. (If these inherent tendencies in the student were absent the process of education would never even get started.) No difficult case in my own teaching experience ever aroused so deep an interest in me as one in which these feelings and tendencies seemed to be as nearly missing as they could be in a human being. The young man in question had no apparent interest in anything. He made no progress in his studying. In fact, so far as I knew, he did little more than to take an attitude of study at rare intervals. I asked him if he did not want to keep up with his class; he said that he did not care. I inquired if he 
did not care what his teachers thought about his work; he said that it did not matter. Did he not care what the fellows thought; it made no difference what they thought. Was he not interested in any study or work; no, not at all. My own interest in him and in his work seemed to arouse none in him. Nothing mattered. There seemed to be nothing to appeal to.

One day I invited him to spend the afternoon with me. I took him to lunch and then through a part of the University which he had not seen, and we finished the day by seeing part of a base-ball game. From that time he was interested and eager to do anything I asked. The authorities had just ordered him to a school for delinquents because he had trouble with all his teachers; but he obtained permission to come and work for me part of each week. The secret was that he had been punished, pounded, maltreated at home and at school until he was callous to all appeals that had formerly been made. Now he did care and he worked well, as well, indeed, as any of my pupils. The point is: he began to care. The tendencies within us that make us care and rouse us to do are the all important, yes, the absolute essentials to achievement.

The means of appeal: Native and acquired dispositions. The material with which the teacher has to work so far as the student is concerned are his native and acquired dispositions. The individual has at the beginning of life, and acquires later many intellectual, emotional, and bodily tendencies to activity. The task of the teacher is to arouse the ones desired and to direct the activity into desirable channels. This is the rule but occasionally it is right to repress some activities. Such repression can generally best be done by the arousal and direction of another activity.

No complete list of the tendencies which a teacher has to work with has been made. And for the most part thorough analysis and understanding of the native tendencies are still to come. The tendencies themselves form the means to the transformation of the individual into that which he should be. The ends to be attained are the more or less permanent dispositions. Without attempt at classification or of completeness, we give the following list of tendencies with which the teacher should be familiar. For such knowledge the teacher should have a course in Child Study. It may not be too much impressed upon the teacher that he is dealing with activity and life, not with inactivity and death. 
What the tendencies are:

\section{Reflexes}

Tendencies to more comFear plex movements

\section{Imitation \\ Fighting}

Rivalry

Acquiring and collecting

Protecting instinct

Hunting

Scorn

Self assertion

Submission

Bashfulness

Bullying

Tendency to follow

Tendency to lead

Curiosity

Love

Anger

Tendency to enjoy

Avoidance of pain

Play
Manipulation

Love of approval

Desire to be with others

To be comfortable or annoyed

Sex instinct

Parental instinct

Repulsion

Credulity

Suggestibility

Tendency to try things out

Tendency to let things be

Empathy

Tendency to run from

Wonder

Elation

Pity

Surprise

Fascination

Joy

Sorrow

Respect

Reverence

Let it be remembered that this is no attempt to indicate the original nature of man, but to suggest the tendencies with which the teacher has to deal. Some of those named above are not native but acquired, e. g., the tendency to imitate. Neither does the list indicate those elements which are irreducible to simpler tendencies. Play, for example, is complex. The teacher in actual work is not concerned with the final analysis of these things, but must work with simpler and more complex dispositions as opportunity permits and need demands.

Results of an attempt to classify in order of importance. It is of great value for the teacher to realize so far as possible the relative value of appeals to different tendencies. It is clear that this is so when one realizes that the activities aroused tend to become permanent, conforming as they must to the laws of habit. It is true that the teacher should know all the kinds of appeal that are available and follow the general principle of making the highest type of appeal possible in any given case. An attempt at classification has been made by some of my students who have had experience in teaching. The following list shows the order from most to least import- 
ant as agreed upon by the class after studying their separate reports and discussing them in class. Another group might find little agreement with this order, but would find it of value to consider the order given and to compare it with some other order that they judge better, and to think out the reasons for their preferences.

1. Desire to learn and tendency to give attention.

2. Curiosity and the tendencies to be interested and to use effort.

3. Play.

4. Imitation. Tendencies to unconscious and consciously directed imitation, and in connection with ideals.

5. Emulation; also, in connection with fear of scorn and of criticism.

6. Secondary race preserving tendencies: hoarding, exploring, ownership, manipulating, collecting, and the like.

7. Altruistic: communication and cooperation; gaining attention of others for their good; kindness, and the like. To be master of or submissive to.

8. Tendencies to physical adjustment: to give attention, to inhibit distractions, to make motor coordinations.

9. Primary race preserving tendencies: sex, gregariousness, reverence, jealousy, anger, bodily fear, sorrow, and the like.

The selfish instincts. Professor E. J. Swift, in his "Youth and the Race," (94), shows the way in which students have been aroused to devote themselves to earnest effort. Emulation, competition, ownership, and other native tendencies were aroused in such a way that enthusiastic study took the place of lack of interest and lawlessness. One point which he brings out is worthy of special consideration. It is that of the realization of an activity being "mine" and for "my" good. Many examples are given to show how a pupil will take a new and deep interest in an activity which he comes to think of as not the teacher's work but of being "my work." Latin instead of being an uninteresting subject came to be a language in which to debate. Other subjects in which teachers worked in vain to keep up an interest came to be subjects in which the students vied with each other to be the best informed. It was their activity and not the teacher's. Even truants were aroused to solve the truancy problems in several schools and succeeded where the principals had failed. 
Case studies of successful appeals. The writer has collected cases of successful appeal by teachers and social workers. Many of these he has found in his visits to the school room. Some of them he has learned of in conversation with the teachers. For some of them he is indebted to the reports of former students in educational psychology, who report their own experiences, or who have brought to his attention successful cases of other workers. These cases illustrate concretely and vividly the application of psychological laws, and, it is hoped, may offer valuable suggestions to teachers who have not solved this particular kind of problem.

A tactful request. The following incident occurred in a country school. The scholars were of many different ages and sizes. The teacher was a young lady. One of the largest boys had been causing a good deal of trouble; finally he threw a large ball of paper across the room. The teacher who was accustomed to keep order told him to pick it up. This he refused to do. The teacher asked him several times, but he absolutely refused. The teacher asked him finally in the following way: "All I can do is to ask you to pick it up. You are much larger and stronger than I am, so you see I cannot make you do it." At this the boy changed his attitude, picked up the paper, and came to treat the teacher more courteously.

The group spirit: the pupil's own problem. The people living near a certain school play ground called an indignation meeting following the breaking of a window during a ball game. The play ground had been disorderly and the neighbors had had considerable trouble at various times. Contrary to the plan of these people, the boys were permitted to attend the meeting. Before the supervisor of play grounds they were permitted to present their case. They admitted their wrong doings, and presented a plea for the use of the ground as before. They were finally granted the use of the ground to see what they could do to make it what it should be.

After the parents had departed the boys stayed and took up the matter of discipline. They condemned smoking and swearing on the play ground and planned several reforms. It now being their problem they went to work to see that the ground was used so as to be unobjectionable and some of their own number were appointed to see that the plans were carried out. A great deal of improvement in the discipline was observed. 
The feeling of usefulness. In a sixth grade of a certain Minneapolis school, one boy was very obstinate and a great disturber of the school. The teacher had repeatedly kept him after school and tried different methods to get him to do better. All efforts had failed and they were very much at odds with each other. One noon she asked him to stay a few minutes. When she went to his desk she found him drawing a coffee pot and other similar objects. She asked him why he drew such things and he told her that his mother worked, so that when he reached home he had to prepare lunch for the other children and they were uppermost in his mind. She talked with him a few minutes and told him that she thought he could be of a good deal of help to her, that she would depend upon him to assist her with the diagrams, and drawings which she had to make. Beginning with that afternoon his conduct changed and he never afterwards gave any trouble. He showed interest in the work of the school and seemed to feel that he was of real use to the teacher and to the whole school.

Being a knight. A boy in a local kindergarten came from a wealthy home and had no idea of obedience. He seemed to want to do whatever he thought he should not do. If the teacher told another child not to do a certain thing he at once did it. The teacher conceived the idea of having the boy take the role of a knight. What a knight should be was explained to him. A knight would be courteous, etc. Of course, a knight would not do certain things, for example, he would not knock down smaller boys, or pull girls' hair. 'The ideal appealed to the boy and he decided to be a knight. In this way he grew to be one of the best behaved boys in the kindergarten.

School money, bankbooks, and ownership. "At a small school in California which I attended some years ago," writes a former student, "a number of devices were used to direct the energy and interests of the students into useful paths. In the first place, all of the boys and girls in the school were rewarded for their efforts by toy money. They were paid for washing the blackboards, for doing copy work for the teacher, for receiving the best marks in spelling or arithmetic for one week, and the like. There were also fines for misconduct. Each one in the school had his private account book. Monthly these books were handed in for inspection. Incidentally, many of us learned some useful hints about keeping accounts. The system aroused the instincts of play, rivalry and ambition. Each child felt the pride of ownership in money he himself 
had earned by hard work. The children did not become miserly, but were generous with their money. In the same school, there was a monthly paper published by the students. Also, each one had his little garden plot in the school yard. In all these things, the children felt the pride of ownership and its responsibility. By appealing to the selfish instincts, the teacher gave the stimulus to rapid progress."

Appeal to pride in one's own possessions. The following case represents the experience of one of my students. She writes: "When I was a child I took no interest inside the house and did not seem to be at all domestically inclined. My father had a play house built and all the children of the neighborhood enjoyed it. I took great pride in keeping my play house clean and straight, and it was almost impossible to keep me away from the place. I must have taken more interest in the play house because I felt that I owned it. This shows a pride in one's own possessions not felt in another's."

Winning pupils through tact, play and a friendly attitude. The following quotation from the statement given me by a young and inexperienced teacher shows the possibilities that lie in the right treatment of a difficult case.

"I had signed my contract to teach a rural school in the eastern part of - county, Minn. The district had offered what was considered an unusually high salary and that fact alone was sufficient to prove that 'there was something wrong somewhere.' Hardly had I reached my boarding house before I was told of the awful ordeal ahead of me. No teacher in the last four years had been able to finish the term of her contract because of Willie. I learned that Willie was a boy of eleven, whom no one had been able to discipline. Even his parents could not do anything with him. Many tales were told of his obstinacy and absolute disregard of authority .... Here was I, confronted by the problem, and only an inexperienced girl of seventeen. What was my surprise, on unlocking the school house door the next morning, to be confronted within by a sickly looking, stunted figure of a boy with a face which, despite the evident satisfaction of having 'put one over on the new teacher,' was wizened and somewhat pitiful if one stopped to analyze it. He had evidently crawled in through the window and seemed to be quite taken aback when I did not immediately reprimand him for having done so....

When I began to try to carry on a conversation with him, he started to bounce a baseball against the blackboard. It 
was not yet 7:15 and after not noticing (apparently) what he was doing for some time and having arranged for the opening of school, I suggested to Willie, for it was none other than he, that we go out on the hill and play, catch. I never have seen a more surprised boy. He seemed unable to understand me and did not take me seriously until I led the way. I had had considerable experience in playing catch, so was not at all doubtful about my ability, which so surprised Willie that he almost forgot, by the time the other pupils arrived, that he was playing with the new teacher whom he had come early to tease into reprimanding him..... Several children arrived early, so I suggested that we play baseball, which suggestion was readilly adopted.

By school time my ability to play and my attitude of 'being one of them in their play' had won the admiration, not only of Willie, whom I feared to meet, but of all the pupils, so that when we came into the school room every one went to the assigned seat and to work without the least disturbance. Not once during my stay of nine months did I have trouble with Willie and he begged his father, who was on the school board, to get me to come back. To this day, Willie is a loyal friend and his cards of greeting come regularly. His parents tell me that he learned more in those nine months than in all his previous school work.....

My measure of success was due to what at that time was an accident, but a lucky one for me, for it was one which resulted from my directing their innate tendency to play, and through that channel, I was able to direct not only Willie, but all the pupils into an attitude of mind which fostered study when it was time to study...."

Army organization and reward of a holiday. A fifth grade teacher had experienced a great deal of trouble on account of noise and confusion in the school room and was getting discouraged over the general problem of discipline. To solve the problem she appointed those who were making the most trouble as captains,-one for each row. It was the duty of each captain to collect all papers and to maintain order in his particular row. Each child was under the jurisdiction of the captain of his row. And every soldier was to cooperate with his captain in an endeavor to make his army, $i$. $e$., the pupils in his row, maintain better order than was maintained in any other army. 
As a reward for the best disciplined army the teacher gave a half-holiday. Since the troublesome scholars are usually the most desirous of a holiday, this plan worked well and the teacher found a very effective method of keeping order with little effort on her part.

The arousal and development of interest. One feeling, namely interest, deserves special mention. It goes with a disposition particularly valuable for study. The means of arousing interest are various. Through some of the following means it is generally possible to arouse it if it be lacking and to increase it where there is very little.

Interest and the force of suggestion. There are many kinds of suggestion. People, actions, things, places, all are suggestions to something good or bad. In the first place, a desirable environment for study incites one to the work. Where the work is going on; where others are interested and enthusiastic; where the subject is being discussed; where the books or material are present and ready for use; and where distracting things are not too many or too insistent, the student finds that interest is likely to come, or if already present, to develop. When one has magazines coming to his door, and books on his table, they are suggestions to read. One is more likely to find himself reading them regularly than if the suggestion were lacking and he had to go to the library for them. People who suggest study are to be chosen and those who suggest laziness are to be avoided. Biography is very stimulating and one can hardly find any reading that offers more stimulating suggestion to effort than biography affords.

The law of affective expansion. The gaining of some pleasant knowledge about a subject is of ten a means of arousing interest in the whole subject. No better way of starting botany can be found than by going with an interesting botanist through the woods and listening to him tell about this plant and that flower. One of my students reports to me that in high school he cared little or not at all about literature until one day a teacher read to the class one of Poe's stories. After that he was not satisfied until he had read more of Poe. From Poe he went to Cooper and then to other writers. A visit to a municipal water works, has in my knowledge, led many students to an interest in the problems found there but has expanded to other problems of civics. One of my students reports the following expansion of interest in the field of history. "Interest in chivalry was aroused and this turned to interest 
in feudalism and from that led on to the crusades, and later to the rise of Italian cities, all of which transferred to the whole field of medieval history."

Association and the development of interest. Another method of getting interest is to associate something pleasant with the activity. Rewards often act in this way. The pleasantness of the reward is associated with the study itself. The pleasantness of a trip with the geology that is learned. The delightful textbook may associate pleasantness with the subject itself. The sarcasm of a teacher too often couples the unpleasantness with the subject which is being taught. The interest which may be aroused by a moving picture is an illustration of this use of association.

Interest and attitude. Another way to arouse interest is to take an attitude in connection with the matter. Take up a point in relation to your subject and defend it; or take a theory or what not and show its weakness or its value: It has been found that taking some such attitude may in the long run make the whole subject interesting.

Realization of use or value. Things are commonly interesting when we find a use to which we can put them. Courses are much more likely to be chosen if students find that they can make application of the material taught. One may develop an interest in a subject by discovering some way in which the knowledge may throw light on some of his problems; it may throw light on facts in some other field. It may be by coming to a realization of the significance of the subject in one's future career.

One may also find a deep and abiding interest in a subject if one can see its relation to some larger work, the way it may help in achieving some larger purpose in life. Domestic science is often interesting because it is thought to be valuable in preparing the student for home making. So may other subjects be interesting if one only realize that studying them puts him into possession of the intellectual heritage of his people and makes him acquainted with the things that are common knowledge of educated people. Certain it is that domestic science, and manual training, and like subjects have given many students a new interest in all the school subjects and have helped solve problems of interest and truancy alike.

The feeling of need. It is a commonplace of psychology that people give attention to those things that satisfy desires or needs. This fact is taken advantage of in the school in dif- 
ferent ways. The writer discovered this principle being used systematically by some of the teachers in The Dunwoody Institute in Minneapolis. The boys were taken, for example, to the shop. Here certain work was planned. But to do this work it would be necessary to solve some mathematical problem. The boys were eager to begin the work on this particular piece but were told that they would have to be able to work out the mathematical problem for themselves. This they could learn to do in the class in mathematics upstairs and they found the mathematics teacher ready to lay aside other pressing matters and satisfy their desire to know how to do this problem. The members of this class showed unmistakable interest and good attention and all the mathematics teacher had to do was to explain the matter. Here, also, one finds a pretty example of correlation.

On inquiry the teacher said that a very large number of the problems in mathematics could be made to come up in the shop and be thus answered in the class room. Where they could not, the problem was presented in the class room in such a way that the pupils recognized that they would need this work in the shop or elsewhere before long.

Interest through special topics. In some of the schools which the writer has visited, he has found teachers assigning special topics to pupils. A problem would arise in the course of a recitation and, the pupils being unable to solve it, the teacher would ask one of the pupils if he would look up the matter and report it at the next recitation. Or a lesson would be assigned and the teacher would single out several topics of special significance and ask as many pupils to be prepared to talk on them next time, each pupil being given one of the topics. This plan seems to give very good results. The children have been interested not only in their own reports but in the reports of other students and this interest has been accompanied by increased interest in the regular assignments.

Interest and the assignment of lessons. Making the assignment for the next lesson is a very important part of the teacher's work. It is to be hoped that the old method of telling the pupils to "take the next chapter," or "take the next eight pages" will soon disappear from practice as it has from theory. There is nothing interesting about such an assignment. It does not arouse to a study attitude. It has, perhaps, no advantage at all except that it saves the teacher the time of preparing the assignment. And the assignment should be pre- 
pared just as surely as the teaching itself should be prepared. The giving of the assignment is, in fact, a part of the teaching.

Let us suppose that the "next chapter" is on capillary attraction. What kind of a real assignment can be made? The writer suggests something like the following: It has been said that when one end of a small hollow glass tube open at both ends is put into water, the water will rise in the tube. If you lower one end of such a tube into the water, the water will rise inside the tube higher than the level of the water outside the tube? Will it always do this? I want you to find out whether or not this is true, and if it is sometimes true, when it is true? You can find help in solving this on pages so and so in your text book.

Such an assignment has at least some advantages. It is more interesting than the assignment first mentioned. It may arouse the pupil to try for himself to find out the truth of the matter. It suggests experiment and the teacher may add further suggestion for experimentation when he gives the assignment. It is definite and not so likely to be forgotten as the other assignment.

Utilizing manual activities. A boy in a local school was reported to be the worst that the truant officer had to deal with. Finally the boy was sent to a detention home for boys. It seemed as though no one could succeed in any way with the case. He stayed at the detention home for a few days and then ray away. He was later found and sent back to the home. Finally a man interested himself in the matter. Through his influence, the boy was admitted to one of the city schools again and allowed to take manual training. This was a special concession as he was below the age at which boys were permitted to take this subject. He became greatly interested, found an outlet for his desire to do things, and in a short time became one of the most efficient and trusted boys in the school.

Use of the dramatic tendency. The failure of one teacher to interest her pupils in geography was remedied in the following way. She had a 6 th grade class and her pupils showed almost no interest in the subject. They seemed to do as little work in connection with the subject as possible and could tell hardly anything about the work from day to day. Miss told her class one day that they might act out things where they found it possible. The children devised, with the help of the teacher, ways and means of acting out some of the activities of different peoples. They even got costumes for some 
occasions and brought in some objects to illustrate the lives and occupations of those whom they were studying. Interest was kindled. The children studied, either to put on something of their own or to see if those who did put it on did it right. This method gave opportunity for originality and ingenuity on the part of the pupils in working up their presentations. Geography in this school became one of the most interesting subjects instead of the least interesting as it had been.

Sublimation. The energy aroused in connection with some of the strong emotions which may be misdirected, can very well be directed into higher channels so to speak, that is, it may be sublimated. During my student days I had a typewriter which did not do good work. It was not until I found a man rooming in the same house whose machine did better work than mine that I became somewhat indignant. This was partly due to the fact that I had paid a little more for my machine than he had for his. The result was that I was determined that my typewriter should work as well or better than his and two hours spent in taking it apart and putting it together again achieved my purpose. The point is that my indignation was turned to good account. The boy who likes to fight and who feels like fighting may be taught to direct his energy to overcoming problems or to protecting weaker companions from the school bully, instead of becoming a bully himself. Jealousy may be valuable if it is jealousy for one's reputation. These native tendencies may, with the proper suggestion, be turned to good account and the study attitude aroused and interest be developed in study.

Action and feeling. Independent of any theory of emotion, the fact is that feelings and attitudes may be aroused by acting as though one had them. To be cheerful let one act cheerfullv. To be attentive let one go through the motions of attending. Repeating the words of the instructor, writing notes, talking about the subject, or asking questions, have been found to help students. This action is likely to result in an interest before one realizes it.

Centering interest in the pupil's activity. One of my students reports the following from her experience: "The boys in my Sunday School come to class every Sunday and sit and squirm around without ever listening to anything they are told. Last Sunday I turned the whole lesson over to them. It was review and was conducted in the following manner. One boy started a Bible story and when he had told some of it called on another boy. This boy continued and called on someone else. 
When one story was finished they started another and kept that going. I did not have to say much of anything and they seemed much more attentive and interested than they ever had before. They even got interested enough to ask the others to please call on them."

Motivation through the activity of the pupil. A friend of mine, a very successful teacher, makes a great deal of use of the pupil's activity. The class visited the local water plant recently to get ideas in connection with civics. The trip raised many questions about the city government. The interest aroused by this trip was sufficient to keep the class discussing pertinent problems for several days and led them to look up various subjects in their books to find answers to their questions.

In teaching English this teacher sends his class to look at something which is to be described and they then come in and write. The class I visited had recently gone to a room which was used for teaching wireless telegraphy and then had written a description of the room. Preparation for writing narratives was made by having pupils ride in an auto, or on a car, or witness something which was going on in the busy part of the city; they then gave an account of what they had seen.

These methods of arousing interest succeeded. And they had not only the immediate success needed for the writing and for the next day's discussion, but in many cases, if not in most cases, did that far more valuable thing. They aroused permanent interests and sustained efforts in these subjects. They were not dead or semi-remote things existing only in text books. They were living realities discovered by the pupils who had been physically and mentally active in relation to them.

"In almost any subject;", wrote James, "your passion for your subject will save you. If you only care enough for a result, you will almost certainly attain it." Then follows the warning: "Only you must not wish at the same time a hundred other incompatible things just as strongly."

The development from interest to effort. If it is permissible to try to hold attention at first by appeal to the native tendencies and interest, it is not permissible to stop at that. No education is complete. But any education which fails to include the use of effort as well as the use of interest has failed signally in one of the essentials. The world calls for those who can work for long periods on things that are of ten not interesting, on things that are arduous and unpleasant. And it calls more 
and more for men who can work, not for the immediate satisfying of desires, but for ideals.

We must then look at our problem of bringing about educative activity from the point of view of effort. In doing this we shall look at the other side, so to speak, of mind. We have been looking at the feeling side. In discussing Attention and Sustained Effort, we shall look for the most part on the other side, for interest and attention are but obverse and reverse of the same thing; when we look at the intellectual aspect we find attention; when we look at the feeling side we find interest.

\section{QUESTIONS AND SUGGESTIONS FOR STUDY.}

1. Show how the actions of an individual are the result of an interaction between the stimulus and the tendencies to react.

2. Show how the teacher's work is to arouse and direct the activities he desires.

3. Why is unnecessary repression wrong?

4. Comment on some of the things in and conditions of the present day school that make for inactivity and suppression instead of making for activity and direction of activity.

5. What is meant by making the appeal to the student? To what is the appeal made, specifically and definitely?

6. Compare the motivation of school work with the motivation of work done outside of the school. Can you see any way or ways in which the motivation of school work can be made more like that of every-day life where men are aroused to do long and arduous tasks?

7. Try to study out for yourself what kinds of appeal you think you could most successfully make.

8. How would kinds of appeal differ because of the age and the mentality of the person appealed to?

9. How far is it permissible to make school work merely pleasant and play? Can the play appeal be overdone?

\section{REFERENCES.}

JAMEs, IV. Talks to Teachers. Henry Holt, 1904, Chs. 6, 7, and 10. KinkPtrick, E. A. Fundamentals of Child Study. The Macmillan Co.. 1913, Chs. on instincts.

TANNer, A. E. The Child. Rand. McNally \& Co., 1917.

Thonndke, E. L. Educational Psycholngy, Vol. 1. The Original Nature of Man. 1913. Teachers College. Columbia University. Also Educational Psycholog!n. Briefer Course, 1915. Part 1.

H. G. Winsox and G. M. Wisos. Motivation of School Work, 1916, Houghton, Mimin Co. 


\section{Chapter 13 \\ ATTENTION AND SUSTAINED EFFORT.}

From interest to effort. The preceding chapter has dealt with the arousing of activity which is, for the most part, pleasant, easy, interesting, and free from that which we may call effort on the part of the student. We have just said, if education may begin with that which is thus pleasant and interesting, it does not follow that all education may be of this softer kind. Such an education has not prepared the student for the difficult, unpleasant, arduous tasks of adult life. Those who understand psychology and the demands of life, can I think, have no question as to the need for this training that requires the student to do some things which require effort.

In the present chapter we shall try to show how the doing of the unpleasant, the arduous, that which requires effort on the part of the learner, may and often does, grow naturally out of the pleasant and interesting activities. Some of the things already said and some of the examples already given show this. Here we are especially interested in effort; and shall deal with the subject so as to show how we may begin with a simple, primary kind of attention, how we may at a higher stage of education bring about a secondary or voluntary attention, and how this higher kind of attention may grow into a derived primary, or habitual, attention, which is more stable and sustained than the first kind, and which may be accompanied with the pleasantness and interest of the first kind.

The need for attention. Without attention no study! The better the attention, the better all intellectual work, observation, memory, reasoning, or whatever it may be. Inattention has been placed at the top of a list of faults, and crimes of school children. Many of us have still clear in memory, much clearer than the things we were supposed to learn, the request of the teacher for our "undivided attention." Students have often asked me how they could get better habits of concentration, this being their greatest difficulty. Nothing, perhaps, disturbs the student more than this tendency of the mind to wander. All that we have said in the last chapter may apply here but we are now to look at the matter definitely from the point of view of attention. 
Kinds or stages of attention. Before attempting to suggest methods that have been found to be practically valuable in bringing about good attention it will be worth while to note the kinds or stages of attention. The student of psychology is familiar with terms "voluntary," "involuntary," and "nonvoluntary" in connection with attention. The classification of attention which seems most useful for our purpose is that of Titchener. He uses the terms "primary," "secondary," and "derived primary." (115).

Primary attention. Primary, or as it is sometimes called, passive attention, is the kind that is determined by the things going on about us. A loud noise, a bright object, a change in the sound of the automobile engine, brings this kind of attention. This attention is attracted first to one thing and then to another; it is held to one thing only if there is not relatively greater distraction. It is the kind of attention that we find in lower animals, and in people as they walk along the street and are led to notice objects in the shop windows. One learns in this stage of attention. And one learns many valuable things. But the learning is dependent upon the appeal to the mind by external things. Anything may distract and the learning be interrupted. In animals and young children, we find, for the most part, only this kind of attention, and they therefore fail in one of the things essential to study.

The conditions of primary attention. If the teacher could control the mind so as to have this attention to the subjects of study whenever and as long as he wished, the task of teaching would be as easy as the most hopeful would wish. But the passing auto truck, the sounds in the corridor, the memory of last night's dance, the expectation of the picnic next Saturday, the subject for debate, the mistake that lost us the game, the tendency to think about something in the shop, run the keenest competition to the attractions offered by the teacher.

The conditions that the teacher can use are already taking the student along some line of thought. There is never a time when a person is not attentive to something if he be awake. The problem is to determine the conditions so that attention will be directed to the subject of study. These conditions are vividness or intensity, novelty, suddenness, continued repetition, familiarity, movement, cessation of stimulus, change of stimulus, and leaving aside the technicalities of scientific psychology, interest. 
Vividness or intensity of the stimulus. It is obvious that the teacher may make the sound of the voice very forceful and not without good results on many occasions. The very earnestness and forcefulness of many speakers often reach their hearers when no other quality is present that would command attention. I know one professor who is of ten called upon to give commencement addresses and nothing more than his very earnestness holds his audience in close attention. But I also remember another professor whose lectures I attended and whose intensity missed the mark. He was in the habit of raising his voice, pounding upon the desk and reaching a closed fist out over the desk where he shook it at the class. My attention was attracted to be sure. I sat on the front seat and had the full benefit. But my attention more than once was attracted to the actions themselves and to the wondering if his white cuff would not some day fall off in my lap and I have the pleasure of returning it to him.

Change of stimulus. Lowering the voice is often very effective. I have of ten brought a class of boys to quiet by starting to talk in a voice so low that they could not hear and found that they would stop their noise and ask one another to be quiet so as to hear what I had to say. I recall a very impressive bit of advice given me by a teacher in a very low voice; so low, in fact, that I had to strain a little to hear. I recall also hearing the same teacher make a public address which was a dismal failure. The whole reason being that the voice was too low and the effort to attend was altogether too great. The changing of the intensity of the stimulus is then not without its disadvantages, though it may sometimes be utilized successfully.

Novelty. The discussion of novelty will bring us to see as we must how interest is involved in very much of our attention. The new attracts attention and it is likely also to be interesting, at least, for a short time. Many ways have been successfully tried to keep attention through novelty. New questions, written instead of oral recitation, debate on the subject, pupils questioning, new illustrations, new order, summaries, a new record to make, applications to a new problem at home, in business, or in the school,- - these and many others have proved useful. One of my students reports that when other things had failed to keep attention and interest in addition, one teacher aroused almost tireless effort in the adding of columns of figures by using a new incentive. Those who 
added all the columns of figures without making any mistakes were "given bank positions." Imaginary salaries were also offered. Accuracy and speed were soon at a premium. The interest kept up for a long time.

Familiarity. Everyone realizes that the familiar object, or idea, or sound is naturally pleasing. As we read the evening paper the eye falls on the familiar words and we are pleased to look through the articles on familiar topics, that is, of course, if we have not already had too much of them. Those who are acquainted with children are continually impressed with the fact that children ask again and again for the stories they have heard until an adult would expect that they had grown tiresome. It is true that the new is interesting only when it is related in some way with something which is familiar. That which arouses the old associations, the old tendencies, is necessary to give interest and to hold attention.

The concrete. It must be remembered that these factors that determine attention are found best in concrete situations. One of the instructors in physics whom I know finds the concrete holds the attention to things not intrinsically interesting. What is an erg of work? The student is not aroused to enthusiasm by the question. This instructor brings out the matter so as to hold attention throughout. He takes one milligram weight on which gravity acts with the force of approximately one dyne. He then with seeming effort raises it by means of a pair of tweezers, elevates it to the upper surface of a block one centimeter high and then informs his class that he has done one erg of work by causing a force of one dyne to be exerted through a distance of one centimeter.

The definite and concrete. In a class of children most of whom were below the average in mathematical ability, as shown by school grades the writer found the following method very successful in arousing interest and also clear ideas of the problem to be solved. The lesson was to teach how to determine the circumference if the diameter were given. The teacher took a piece of wood, one inch square and about twelve inches long. With a pair of dividers he described a circle whose circumference was tangent with each of the four sides of the square end of the stick.

The teacher then gave the class the dimensions of the piece of wood. He then asked how long a string it would take to just go around the stick. Next, how long a string would it take if the stick were put into a lathe and turned down so that 
it would be round and just the size of the circle which he had drawn on the end? Not quite four inches but more than three. Well, exactly how long must it be? The teacher had very successfully aroused the desire of the pupils to know how to solve the problem.

Contrast this method with the common method of attempting to teach problems in mathematics with no such concrete, definite presentation to the pupils. Once trying the new is sufficient to demonstrate to the teacher its superiority.

Secondary or voluntary attention. We have said that primary attention is not likely to be sustained. The tendency to study that the teacher is trying to arouse and keep going is all the time being interfered with by the tendency of the student to respond to all those other stimuli of which we have spoken. We say that the mind tends to wander. Most of our education goes on, not in this primary attention, but in secondary attention. In other words study is hard work. It requires effort. There must be a conflict of impulses and, if the work is to go as it should, the impulse to "stick to it," to go in the line of greater resistance, must win. Suppose, then, that the student can think his problem through to the end even though other things arouse impulses to shift his attention to them. He compels himself to write his essay instead of thinking of a dance or a football game. He follows the lecture, or outlines the chapter notwithstanding the desire to do something else. $\mathrm{He}$ is working in the stage of secondary, or as it is sometimes called, voluntary attention.

Derived primary or habitual attention. At any time now the conflict may cease; there may no longer be any effort to attend. The subject, may, so to speak, hold the student. The sound of voices nearby, the noises of the street, the call to dinner even, may go unnoticed. The student is now working in the stage of derived or, it may be called, habitual attention. This is a stable, sustained, untroubled attention, in which disturbances are no longer distractions. This is the attention commonly found in the inventor, or the research worker.

The conditions of secondary and derived attention. The native tendencies. We have already spoken of the tendencies that may be aroused and of the feelings that indicate favorable conditions for study. The desire to improve, curiosity, emulation, pride in one's accomplishments, desire for the approval of successful people, dissatisfaction at one's own shortcomings are likely to mean greater efforts. Obviously. if a person is 
sufficiently interested, if he have a passion for the work, the attention will almost surely be sustained. It is necessary only that the right suggestion, the right appeal of people or things, or events arouse the desired disposition for study:

The arousal of sustained attention. Determination, purpose, realization of the value of the results of study, the expectation of advantage to be gained, are closely related to the best kind of attention. I am indebted to Dean Coffman for the story of a boy who was aroused to this kind of effort by that more vigorous method than is now supposed to be fashionable. The boy had been sentenced to one of our state penitentaries and began his record in the institution by breaking the machine at which he was put to work. The overseer repaired the machine and informed the boy that he would be sent to the superintendent if he broke the machine again. Very shortly the boy broke the machine again and was sent to the superintendent. The latter informed him that he should go back to work and added that in case the machine was again broken he would thrash him. The boy fulfilled the requirements for the thrashing, received it and spent the night pacing his cell. The guards reported that he had not slept at all during the night.

The next day his conduct changed. He went to work and from that day worked faithfully. He also began to read and study and took the best books he could find from the library. His term in the penitentiary was shortened and the day he was released he called on the superintendent. Do you remember, he asked, the day you thrashed me for breaking a machine? Yes. Well, you did not know what I was thinking. No. I was thinking that I would be the best citizen that was possible or the greatest criminal that the world had ever seen. And I decided to be the greatest criminal. I also decided that in order to be the greatest criminal the world had ever known I must be well educated and know the things that other people knew, so I took the best books I could find. But as I read those books they made me think it over again and again and finally I concluded that I was wrong. Now I am going out to be the best citizen that I can be.

The point in which I am interested here is that through strong measures the boy was brought to the determination to study and that long continued effort resulted. I have used corporal punishment myself and never without good results; sustained effort and good or excellent work followed. But 
one must use judgment and no rule can determine when one should use strength or when one might better take a boy for an afternoon's trip as my first case illustrated. Needless to say corporal punishment should be used only in the last resort. It should never degenerate into the brutality which was the just cause for its being thrown into disrepute.

We would be blind, indeed, if we overlooked the fact that human beings are moved as much or more by their pains as by the beckonings of pleasure. Pleasure and pain have been called the great educators of the world. Fear (30) and anger (29), if rightly directed, may be counted upon as great educative forces.

The demand for study is not a siren call and the pains and discomforts that are necessary to move men to work are appropriate for the same reason as regards study, for study is work.

Appeal made through the removal of privileges. A few years ago one of our Minneapolis judges told of a delinquent whom he had sent to the reformatory. The boy seemed to be utterly hardened. No appeal reached him. Nothing would bring him to a desire to obey the authorities. Later they began to remove privileges, one after another, to see if they could find anything that would touch a tender spot. Finally they refused to let him see his mother. This was the thing for which he really cared and he soon promised and performed faithfully all the authorities desired.

Appeal to an habitual tendency. The appeal to an habitual tendency often brings the desired result. A principal of one of the Minnesota high schools told me of a boy who absolutely refused to work for a certain teacher. He told the principal that she was "down on him," she was unjust to him; would not give him a chance; he did not intend to do any work for her and did not care if he failed in the subject. The principal had noticed that he was always courteous to ladies. He at once appealed to the boy to consider her not as a teacher but as a lady and to realize that even if she were unjust it would be well for him to think not of teacher and pupil, but of gentleman and lady and to take the initiative. This appealed to the boy and a reconciliation was effected.

The passing of secondary attention into derived primary attention. The derived primary, which is an absorbed, sustained, attention is the best kind for study. It comes about when the conflict of impulses ceases; when the ideas present, 
the determination, the purpose, win out over the distractions and there is no longer the effort to attend. This happens when the conditions of secondary attention are strong enough to hold attention relatively independent of distraction. Any of the factors that arouse interest and hold attention may do this; they must do it so that the disposition to continue remains. On the nervous side we have, in this highest stage of attention, permanent dispositions to work or study or to attend along certain lines.

The best attention is had with slight distraction. Not only in every day work but in the laboratory it is found that the best attention is had when some slight distraction is present. It is this disturbance that seems to be necessary to arouse one to real effort. The overcoming of some difficulty means more earnest endeavor. It may be that the student will do well to practise studying where there is considerable noise; not that the distraction helps the study but that the ability to study in any kind of a situation is worth developing into a habit. The ability of students to study in the old fashioned country school, or even in many schools now where there is a recitation going on, is well worth remembering. One might say then, that for the best attention, one should have slight distraction; but for developing the habit of concentration one should practise studying in any and every kind of a situation in which one finds oneself.

Hindrances to good attention: The feeling of fatigue, vs. fatigue. Professor Thorndike summarizes a study of mental fatigue as follows: "Six subjects worked continuously from three to eight hours on the mental manipulation of one threeplace number by another. Ten subjects worked from four to twelve hours with pauses for meals. All subjects did from a half-hour's to an hour's work on a following day. Only three out of the sixteen subjects did as well at the end of work as after rest. The greatest fatigue effect came after a work period of about five hours, the smallest (except in the three negative cases) after a work period of almost nine hours. The subjects who were most efficient and worked most rapidly showed a smaller loss through fatigue than did the less efficient workers. Inspection of the records shows that the results are probably a compound of a gradually decreasing practice effect with a gradually increasing fatigue effect. There seems to be "little correlation between the fact of fatigue and 
the feeling of fatigue." (112). An excellent study of fatigue has been made by Offner (72).

It is well to understand the distinction between fatigue and the feeling of fatigue. Weariness, or the feeling of fatigue, is generally followed by a wandering of the attention and a general relaxation of effort. Recent studies of fatigue, as the above quotation indicates, prove that the feeling of fatigue can be pushed back for an astonishingly long time and that excellent work can continue much longer than we commonly suppose. Laziness and habit probably account for the unnecessarily early onset of weariness which is popularly confused with fatigue itself. Fatigue, let it be remembered, is actual inefficiency or lack of ability for further work, and it is not to be thought of as synonomous with the feeling of fatigue; nor is the latter to be considered a safe indication of real fatigue.

When the feeling of fatigue caused, perhaps, as it often is, by nothing more than a dislike for the work in hand, wears off, one may go on for hours and do as well as, or better than, he did before the onset of the feeling. Less attention to feelings would be better for most of us; nevertheless, denial of fatigue and disregard of weariness after a reasonable period of study, is extreme and hazardous; a tendency in that direction today, seems to indicate a misinterpretation of the results of fatigue experiments and a dangerous attitude so far as health is concerned.

Emotional and intellectual factors. Needless to say exciting emotions disturb study. Adolescent changes are correlated with some retardation in school work. So far as possible these disturbing factors should be eliminated and, where this is impossible, they should be reduced to a minimum.

Study is also disturbed by other factors of a different nature. Students are often troubled by not knowing just what to do next; or by failing to have clearly in mind just how to proceed. This is well illustrated by an incident that happened in one of our Minneapolis schools a short time ago. The teacher had taught a lesson in arithmetic and then told the class to do all the examples on a certain page but to omit the first. One boy failed to get started and finally the teacher went over to him and asked just what the trouble was. At last he admitted: "I don't know how to omit the first." The case may be rare but the kind of difficulty is typical of many instances where the mind wanders. 
Lack of technique and of instruments. Getting started, finding instruments, pencil, pen, or what not, divert attention and according to Breslich (11) ten to fifteen minutes are of ten wasted by high school students getting down to work. The difficulties in the actual doing continually tend to break up sustained effort. Again and again one can observe in the laboratory a student who has not the technique, and who fails or does work clumsily and then turns to watch someone else.

Bad suggestions and failure to try. If good suggestions are valuable to help the student get into a study attitude and to study with sustained effort, it is also of importance that suggestions to listlessness and ease be eliminated so far as possible. Many people fail to do things merely because they fail to try. And they may fail to try simply because of the lack of incentive and the presence of suggestions to ease and comfort. One should not hesitate to get away from the wrong suggestions be they places or persons, to seek the stimulating environment and then to try. To move the lips, to take up the pen, to begin to say the lesson to oneself, if nothing more to make believe one is studying, may be all that is necessary to bring on a study fit. (44).

Self government and sustained effort. Responsibility and the feeling that it is $m y$ work are important factors in conduct. In a small high school, of about 60 or 70 students, there had been a great deal of trouble and very poor discipline. The school work had necessarily suffered very much. The difficulty was due partly to the activities of a "gang", and partly to the fact that the teachers had failed to "reach" or make the right appeal to the students.

Finally a young man who believed in self government was made superintendent. He told the young people that he expected them to govern themselves. At first chaos reigned. Soon the leaders of the gang called a meeting of the entire student body. A self governing association was formed. Today it is one of the best governed high schools.

As one of the students said: These people who had never been interested in school activities, because they thought the teachers were running them, formed clubs. One, a literary club which has given some enjoyable entertainments, was the cause of a fine victrola being placed in the assembly room. Another literary club has established a school paper which is published once a month. The students have entire charge of these things and because they feel that they control the enter- 
prises and are responsible, they take great interest in making everything the best possible.

Self government aided by a school paper. An eighth grade class in one of the public schools of St. Paul publishes a school magazine every month. The pupils formerly had it typewritten. Now the father of one of the boys has it printed for the class. A large portion of the class are on the staff. They have some worth while poetry, a few original essays, school news, personals, and jokes as well as editorials.

Through the columns the children try to enforce self government. They comment on the fact that they have "found two boys who cannot be trusted out of Miss ___'s sight." "Lost, some time from study, because a member of the class acted up." They state that they want "brighter boots and smoother hair at nine A. M." They also want "Less home study for over Saturday, Sunday, and other holidays." They want their room to be "as nearly a perfect room as we can make it." One item said that "A certain person should worry more about his character. Most of us would be ashamed if the reading teacher had to speak to us."

There are also comments on good work done, such as, "We have all noticed how well the boards look after- has washed them." Mention of those who have done good work frequently appears in the editorial column.

The children do very well in getting out this little magazine. They take great delight in all the work and do not object to writing essays or to any task which may be theirs to help in getting the material ready. They encourage the best actions in the school and plainly show their disapproval of bad acts."

A teacher's personal interest, trust, and right direction of a boy's activities. John was a bright active boy in the eighth grade. He liked to "cut up," and although not malicious was a great disturbance. He was very stubborn and both teachers and parents failed to get him to conduct himself as he should. He often did not realize the wrongs he did. He learned that threats that were made were not carried out, and he became openly defiant and distrustful.

Finally he got to high school and entered a week late. His new teacher found out what he wanted and made out his program. She also made arrangements to meet him to help him make up the work he had lost. At the times she met him in this way she learned what John wanted to be when he got older. He wanted to be a doctor, and she advised him about 
his course, told him about the course at the university and how hard it was and how hard he would have to study to get through it. She also impressed him with the necessity of learning to study while in high school in order that he might be able to do the work when he entered the university. She paid little attention to his pranks and drew his attention to the things he should do and could do. Her sincere interest in his desires and ambitions and her confidence in him coupled with her doing exactly what she said she would, won his respect and confidence in her. His attitude changed for the better and he became an earnest student.

Sharing in activities. Throughout high school a certain class was noted for its many class "scraps." It seemed impossible for the class to plan anything without some group making trouble. If one group had charge, other members of the class would criticise the arrangements. Groups formed so that members of one group were continually at odds with members of other groups. During the senior year a girl was elected president of the class who solved the difficulty by giving each individual some part in arrangements for the class activities. The first class affair was a party given by the class for the faculty. The president chose as chairman of the committees the girls who had made trouble; each chairman elected his or her own committee. By dividing the work sufficiently all of the members of the class had some share and as a result no trouble arose and the best party of the four years took place.

Pride and interest in one's own achievement. One teacher was very much interested in teaching nature. In order to get the class interested she divided the class into sections and gave each section a plot of ground for a garden. Each section was to try to have the prettiest garden and to do it without help. Interest in the gardens was great and competition keen as each group wanted to have the best garden. Each child seemed to have the interest and pride of ownership and of achievement.

Appeal to sympathy and the sense of responsibility. During a study of classroom methods by one of my students, the following example of successful appeal to an unruly class was discovered. I give it nearly in the words of the report. One of the teachers of a grade school in a small town was having her first experience with an unruly class, mostly boys. She tried every means of correction of which she could think but had failed. Her pupils knew she was inexperienced so were 
"trying her out," and from their point of view, were succeeding admirably. One afternoon, tired and discouraged, she decided to resort to a last measure. When the pupils assembled after recess she told them that she felt so ill that probably she could not be there the next day, but that they were to come and to try to get a few exercises done by themselves. Also, if they had time and wanted to, they were to make a map which she explained to them. She stated that it would please her if they would be as quiet as possible and try not to disturb the other rooms. With this she dismissed the class early and went home leaving the children with the feeling that they would be responsible for their own actions.

When she returned, the exercises were written and placed on her desk. Most of the children had finished maps. Favorable reports came from the other teachers who had been asked not to interfere unless the room got too noisy. During the day she had several inquiries concerning her health, and one or two of the most "desperate" boys even said that they were sorry that they had caused her trouble. After that the room seemed a different place. Each student felt that he was responsible for any disturbance of the class and there was little trouble from that time.

A position of responsibility. A certain young man had been at the St. Cloud Reformatory in Minnesota for several years. He was twenty-two years of age. On three occasions he had broken his parole. Each time he had been caught and returned to the institution. Finally the superintendent thought he saw possibilities of another kind in him and made him manager of the dining room in the reformatory. A change was soon apparent. The boy saw to it that things went on as they should in the dining room and his own conduct changed greatly. So well did he succeed that he was given his dismissal from the institution a year later.

Improvement from within. A fundamental principle which appears in many studies is illustrated in the following case. This principle is one that is not at all new, but is held altogether too much in theory alone. Not what some outsider does for a group, but what the group does for itself, is the important thing. What the group decides, what it works for, it values and is ready to defend.

In one of the schools of Minneapolis where most of the children were Scandanavian, there happened to be a little Italian boy. The children fell into the habit of teasing him. 
He was especially sensitive about his inability to speak English very well. The teasing continued until the children had worked him up to the point of chasing them with an open knife which he threatened to use on them. After an actual attempt to stab one of the boys a teacher called the children together and told them that she thought they should take up the matter, have a court and jury and decide what should be done.

A judge and jury were chosen from among the offending boys. The matter of justice was placed in the hands of the jury. The tormenters told their story and the Italian boy told his. The jury decided that the American citizens had placed the foreign boy in a very disadvantageous position inasmuch as he knew the English language but little. They decided that they had not given him a square deal and the verdict was, in their own words, "Give the dago a chance." A short time afterwards the Italian boy, who had been accepted as one of the crowd, was making rapid progress in adapting to the new group. The boys had solved their problem and the friction disappeared.

The direction of attention. What shall be noticed, remembered, understood, and the accuracy and faithfulness of memory depend upon the things that are attended to. There is the question of the attitude of the student and of the presence or absence of goal ideas. Goal ideas may be either useful or harmful. If one wishes to make an exhaustive study of an object, a reaction in chemistry or the anatomy of a tissue, definite ideas of what he is to see may too much limit the attention and cause important things to be overlooked; again, the know!edge of what should appear aids in the actual finding of what is expected. But again, and it cannot be too much emphasized, the observer may see or think he sees things which are not there if he only has sufficiently strong expectation of them.

Briefly, economy is gained in the discovery of things if one has definite ideas of what he is looking for, which means that the field of exploration is limited and attention is relieved of much which is beside the mark. But one should never limit the attention by expectation to such an extent that he cannot observe the entirely new, that which has not been imagined or expected, but which, however, may be very valuable.

Control of action through control of attention. A social worker found a group of boys who were trying to tie a tin can 
on a dog's tail. "Boys," he said, "I can show you how to tie a knot that won't come untied." The boys gathered around him. The knot was demonstrated. "I can show you the best kind of a knot for tying a horse so that he cannot get away." The boys became very much interested and the dog made good his escape. Pieces of rope and string were produced and the boys began to learn how to tie different kinds of knots. The dog was forgotten and they found a new interest in learning how to do something worth while.

The directing of native tendencies. An excellent illustration of the result of good leadership and the utilizing of native tendencies was reported to me as follows: "In Litchfield, Minn., there was at one time a crowd of boys, from fifteen to eighteen years of age, who, though not bad, were a cause of many great annoyances to the town. They were not really bad, but extremely mischievious. There came to the town a new Methodist minister. Though not particularly successful as a preacher, he liked boys and knew how to manage them. In a short time he had organized these boys into an athletic association, organized in the first place, merely for play and games, but rapidly it became a club for organized athletics. The Y. M. A. C., or Young Men's Athletic Club, as it was called began to talk over the town affairs, social work and politics, as they heard the older men talk. When state elections came they were as interested in the outcome as were their fathers. As soon as they were well organized, the minister stepped out of the executive staff and allowed the boys to govern themselves entirely, coming to him only for advice as they wished it.

As their interest in the club grew, their interest in the town's welfare grew, and they became a potent factor in maintaining order in Litchfield. An ordinance had been passed that no storekeeper could have sign boards or advertisements of any kind out on the side walks cluttering up the streets. Whenever the boys saw any such advertisements, they reported the storekeepers to the town authorities. At home they had heard their mothers talk of the uncleanliness of having fruit, etc., on open stands in front of fruit stores. The boys took the matter in hand and fairly boycotted one Greek who insisted on keeping fruit uncovered. They carried their protests to such an extent that the authorities finally took it up and issued an ordinance prohibiting food to be displayed on uncovered stands. 
The loyalty of the boys to one another and the harmony and zest with which they worked under their sixteen year old president was a marvel to the inhabitants. Although they joked at a club for such young boys, they soon found themselves and their town greatly benefitted by the work of the organization."

The value of a purpose. Meumann, in his book, The Psychology of Learning, says that having a purpose seems to make for better and easier accomplishment. From the laboratory to everyday life the ability to connect a smaller work with some larger purpose makes it easier to do and seems to bring better results. So much is this so that he concludes that there is here a universal law of mind.

A boy may fail in school, but if he has a purpose, may make a great success in life; or your honor student, lacking a purpose and determination, may go down in failure in later years. Purpose and determination turn failure into success, and the world is a place in which men wrest victory from defeat. It is often noted as students go on into high school and into college that, as they acquire a purpose, their work shows a corresponding improvement. Why is it that many students, as they begin their professional work show the ability to do a quality of work that they have never before shown? Partly because of higher requirements. But it is safe to assert that, for a very larger number, the improvement is due to the developing of a definite aim, purpose, determination. A recent research gives results of recall with and without determination to recall; and shows that the presence of determination to recall may improve the actual recall by as much as 147 per cent. (70).

\section{QUESTIONS AND SUGGESTIONS FOR STUDY.}

1. If education may begin with the pleasant and interesting and easy, why should it not end with these? Show fully and carefully what more is necessary and why.

2. How does the psychology of attention show the "higher results" that should be obtained through education?

3 . Explain the need of attention for all learning of whatsoever kind.

4. Give examples to show how you would get each of the three kinds or stages of attention. 
5. How far does the control of attention settle the problem of discipline and of better school work?

6. Compare the results of teaching in the abstract and in the concrete. Take examples from your own experience.

7. Is it right to say, in teaching always begin with the concrete and end with the abstract?

8. Do you think that the school provides sufficiently for training students to do long and arduous tasks? Discuss this.

9. Discuss the problem of interest in connection with school work. How can the teacher obtain it? How can he teach the student to obtain it?

10. Cite some examples in your experience where sustained effort was brought about, 1) by arousing interest, 2) by coercion.

11. Explain the value of getting continued attention and effort of a group by helping it to make changes from within the group rather than because of coercion from without.

12. How far can one control attention and thereby action by arousing ideas and purposes?

REFERENCES.

Bagley, W. C. Classroom Management. The Macmillan Co. 1907, Chs. 9, 10, 11 and 12 .

JAMES, W. The Energies of Men. Psychol. Rev., Vol. 16, 1907, 1, ff. SwiFT, E. J. Youth and the Race. Ch. Scribners, 1912. 


\section{Chapter 14.}

\section{FEELING HABITS AND MORAL EDUCATION.}

Habit extends to feeling. The instability that we commonly note in the life of the feelings may of ten lead us to doubt whether or not there is anything permanent in connection with our feelings. We are pleased with one thing one day and displeased with it the next. Something has satisfied us for weeks, but all of a sudden we decide that we are tired of it.

On the other hand, we find ourselves saying that old friends are best. We turn back to the old accustomed authors and delight in the music with which we are familiar. In the emergencies of life we fall back upon the old customs and the old beliefs. In fact, when we depend upon what we consider the stability of a man's character we depend upon what we believe or know to be his habitual way of acting in terms of certain sentiments of right and justice, etc. When we plan entertainments for our friends we plan in terms of what we know they like and are interested in.

In the education of our children we are certainly hoping that we shall succeed in getting them to like and be satisfied only with certain worthy and acceptable things and actions; and that they shall dislike and be dissatisfied with certain other unworthy and unacceptable things and actions. We hope that noble desires will become permanent, and ignoble desires will die out. Perhaps nowhere do our feeling habits appear more strikingly ingrained than in some such case as the way in which we like a certain chair, or place to read or study, or certain of our old haunts; or in what we term cravings, such as the craving for strong drink or tobacco, or the symphony if we have been accustomed to it and are deprived of it for a year or two.

In the extremity we fly to the old beliefs. Through life we have the same old illogical fears that were implanted in childhood. One child gets into the habit of flying into a rage if things cross him; it may be the severest struggle of adult life to control this habit and not fly into a rage. Another child is taught to be good natured and smile when he desires anything from his parents. It becomes the habit of his life. The child 
cares little for the classical music or literature but he hears it at home and at school. He may tire of it. Repetition may make him weary of it. But there is implanted in him an appetite, perhaps, a craving for it, which is a permanent acquisition.

The opposing tendencies. Here we seem to have a contradiction; repetition blunts feelings but it also develops permanent desires, appetites, cravings, and the like. Sully has told us in this connection: "Our permanent surroundings and manner of life tend to grow indifferent, that is, to lose all or most of their affective concomitants. This applies at once to our pleasures and to our pains. Thus we get used, that is, comparatively indifferent, to surroundings, companions, lines of activity, which, when they were new, were highly enjoyable, or, on the other hand, particularly agreeable." But, also, Sully writes: "The process of organic adjustment or accommodation just referred to is less simple than we have supposed. Exercise tends to strengthen an organ, and is one main condition of organic growth. One important result of this is that stimuli, which were at first fatiguing and so painful, may with repeated application become pleasurable. Thus an amount of muscle-work or brain-work, which is at first unpleasant, may with increase of functional power become enjoyable. Another effect tending to disguise the general decay of feeling is due to its increasing complication as experience advances and associations form themselves. In this way our friends, our books, and so forth, though losing some of their pristine charm, become endeared by associations. The action of association leads on to the influence of Habit in the domain of feeling. What remains with us, what we habitually see, and habitually do, while it loses its keen pleasurableness, generates through habit an attachment or clinging of mind which betrays itself whenever it is removed. Jennie Deans, feeling strange and lost in her London surroundings, and longing to get back to her familiar scenes, is an example of this effect. Every sudden rupture in our experience, as the loss of a familiar friend, shows the same force of custom in producing an attachment of mind. Here, then, we have an effect precisely the reverse of blunting. The older and more fixed the habit, the harder is it to bear the sundering of the bond. Habit is thus a fertile source of negative pains, or the pains of craving, a source which grows more prolific as life adrances." (103). Thus we see as Sully says in summary, "the principle of habit, 
which, though it tends, as we have seen to dull feeling, tends also indirectly to fix and further it by strengthening the disposition to the appropriate motor reaction. A child who is allowed to fall again and again into the mental and bodily attitude of anger contracts a stronger organic disposition to react in this way, a fact clearly seen in the greater rapidity of the outburst, and in the diminished strength of the stimulus requisite for calling it forth." (104).

Permanence in connection with the feelings. The habitual in the world of feeling is indicated also in the following quotation from Professor Titchener: "The name of passion is also given to any abiding interest, to any mode of strong emotive response that is specific and lasting. We say that a man has a passion for success, for science, for gambling; and we mean that a situation which shows any sort of reference to these things will appeal to him, dominatingly and one-sidedly, through that reference." (119). Whatever we shall call these permanent or relatively permanent acquisitions in the world of feeling, we mean just these things that are called permanent interests, or cravings, or passions or sentiments; or such things as Titchener mentions when he says: "Other current usage identifies sentiment with what we have called passion (in the second sense), i. e., with such things as love of power, of fame, or economy, of cleanliness; hatred of injustice, of oppression, of affectation; devotion to science, or art or religion. It seems, however, more natural to speak of a passion for cleanliness, a passion for order, a passion for justice, a passion for old furniture, than to name these affective dispositions 'sentiments.'"

Feelings and action. The important thing in connection with all this is that the student in the course of his education does acquire those tendencies to desire, crave, need, whatever you would call it, the things that are desirable, and to act so as to obtain them. Feelings and action of the appropriate kind should go together. And they should continue to act together as permanent tendencies. The feeling should not habitually fritter off and nothing come of it. To have the feeling alone would only be a luxury, and perhaps, as Thorndike says, a vice.

From the practical point of view, we will lose nothing if we talk in the everyday forms of speech and imply that the feelings actually bring about actions. We can remember that they probably do not bring about the action, but that their 
presence indicates certain dispositions and that the casual links lie wholly in the nervous system.

The feelings dependent upon action. The actions are not so much the result of feelings, as the feelings are the result of actions. We accordingly find, granting the great influence of heredity, of course, that our actions settle for us our dispositions for this or that kind of activity. We act kindly, mercifully, justly, charitably, and we find the ideals of these things and the dispositions for them growing strong within us. We also find that these things satisfy us and the lack of them dissatisfies us. Not only has our living in a certain way developed our likes for this way of living, but it has also developed our dislikes for other ways, or ways that conflict with this. We have indicated here one of the fundamental things of which the educator must take advantage in developing the feeling habits of pupils. Get him to act so that he will have the right feelings. Do not merely arouse the feeling. What one feels may be enjoyed merely as so much pleasure. One may have a thrill and wait expectantly for the next thrill, and the enjoying of the thrill be the sum and substance of the matter. On the other hand what we do we come to like; what we do we tend to think of as our activity with the emphasis on 'our' and for that reason we are likely to defend it. Furthermore, the acting makes it a part of our nervous system.

Associations. The second great means of developing dispositions for things and activities lies in the associations that are or may be formed. Perhaps more than anything else, the reason that we like our native land, our own state, our own group, lies in the associations we have with them. You love one state and think of the sleigh rides, the skating, the canoeing, the friends, the weekend parties. I love another state and think of the same associations I have with that state. One man likes literature and you find that he has had pleasant associations with the literature that he has studied. Another dislikes literature and you may find that he had unpleasant associations with it. Yes, you say, but it may be an hereditary difference. One is born to like one kind of thing and another to like something quite different. Yes, that is so. But it is only part of the truth. One man tells that he disliked a certain subject until he had a certain teacher and forever after he enjoyed that subject. That is a matter of education and not of heredity. And it is a matter of associations. Even the disagreeable things of life conform to these laws. The busi- 
ness man may dislike his work but finally it becomes a necessity to his life. So the business man spends two weeks on a vacation and is glad to return again to his regular work. Many a man has retired from business and discovered that he was unhappy and discontented without the associations and activities to which he had through long years become accustomed.

The development of interests. It is likely that we consider our interests to be more intellectual than our passions. If a man has an interest in a subject, he is correctly supposed to desire to attend to and think about it, to indulge himself in it consciously, not merely to satisfy a craving. "The secret of education," wrote Adam Smith, "is to direct vanity to proper objects." (89). Radestock tells us: "The celebrated pedagogue, T. Ziller, studied the importance of interest very minutely, and declares that instruction must particularly awaken and develop a wide and many sided interest in the objects taught and the mental labor, while the separate particles received may occasionally, without harm, fall a prey to forgetfulness. It is this wide and various interest that distinguishes the truly educated and mentally active person; and the increased interest in separate subjects causes him to be saved from distraction, notwithstanding a generous education, and enables him to use his concentrated efforts in separate fields." (84).

I have often asked teachers which they would prefer their students to get from a course if they could get only one of two things, information on the one hand, or on the other, interest and a desire for more of the subject. The answer has always been interest and a desire for more. Fortunately one cannot teach a pupil anything so as to arouse an interest in it without also having information, be it ever so little, as part of the result. Part of the work of a teacher in any teaching is to inspire the pupil, to interest him, to arouse him, so that he will want more, so that he will have an abiding interest in the subject.

Making interests permanent. We have already (chapter 12) mentioned factors that may help to arouse interest and found a goodly number: appeal to instincts, pleasant introduction, pleasant activity in connection with the subject, competition, suggestion, arousal of feelings of value, or purpose, use of the definite and concrete, and the like. These may help temporarily. That is good. The greater work is that of which we have just spoken, that of making the interests per- 
manent; and this is to be done above all else by means of repetitions and associations. The introduction of the pupils to a subject or activity may be pleasant, interesting, and perhaps easy at the outset, but this is not enough if the pupil is to be developed to his highest power. He must go to effort which is not so pleasant. And the repetitions, the self activity, the many associations with hard work are the things which may be hoped to bring him through so that he will be a man of concentration and of sustained effort to long and arduous tasks.

The individual should also see so far as possible some returns for his labors or be made to realize that there will be returns of sufficient value. There is a much better attitude in work where the pupil realizes the value of the work to himself.

Other emotional tendencies. This right tilt, so to speak, given to the individual, and kept up, so that the desire, craving, whatever it becomes, be a permanent thing, is necessary for the many affective responses of life. That we have appreciation, sympathy, harmless enjoyment, the gentler emotions, all of those tendencies of which we can think, towards cleanliness, neatness, politeness, unselfishness, as well as those of a more courageous sort, self-control, diligence, endurance, and all of those finer feelings for the beautiful, for humor, awe, reverence, and the like, necessitates that the individual have an insight into them, have the feeling for them and continue to live in such a way that they become a part of his life and a necessary part of his life. That is, he should so live, feel, think, and do, that these responses are necessary to give him satisfaction; and the absence of them, or the opposite kind of things, give him dissatisfaction.

Imitation. Here, perhaps, more than anywhere else in the realm of education we have need for the best to imitate. Instinctive as it is for the child to imitate, it is one of the commonest things for him to imitate the likes and dislikes of those around him, or more accurately, to imitate their actions and thus to acquire certain likes and dislikes. The best actions, and objects, the acceptable models, should be the material for his imitation, and his feelings will grow through his imitation whether he is conscious or not. To have a finer appreciation of the best things in music, art, literature, the child must live in the presence of them. What he comes to like will be very largely that to which he has become accustomed. 
Moral education. The consideration of these permanent tendencies in the life of feeling leads us naturally to the problem of moral education. Out of all the thinking, feeling, and doing of the child should grow the ideals of right living, which themselves should be permanent possessions and should then find expression in the will of the moral individual.

Will in moral training. ". . . Will, taken in a psychological and not in a moral sense, is simply the general name for the sum total of tendencies, inherited and acquired, that determine our actions; and we distinguish different types of will, according as these tendencies are so deep-seated and persistent that he attains his end, or at any rate continues to strive towards it, however remote it may be and however numerous the counter-suggestions that oppose it; and the man of weak will is one whose tendencies are so instable that he is at the mercy of every fresh suggestion that comes. James remarks that, when the will is healthy, action follows, neither too slowly nor too rapidly, as the resultant of all the forces engaged; whereas, when it is unhealthy, action is either explosive or obstructed: the mercurial or daredevil, temperament shows an explosive will, 'discharging so promptly into movements that inhibitions get no time to arise'; and the limp characters, the failures, sentimentalists, drunkards, schemers, show the obstructed will, in which 'impulsion is insufficient or inhibition is in excess.'

The important thing in this connection is that our decisions and actions in accordance with the proper ideals becone habitual. The moral man is the one who habitually makes his decision in terms of his ideals of right, or who acts in accordance with those ideals without even having to think and make a decision.

Moral habits largely those of the second type. Moral habits are largely those of the second type, that is, those whose action is in terms of some general form of action, or in accordance with some ideal. Obviously in moral action there must of ten be considerable reflection in order to decide just what is right. just how one should act to be most just, etc. All of our general tendencies to be punctual, kind, merciful, helpful, involve or may involve some conscious direction. What the teacher desires is that the tendency to act in the appropriate way is present and ready to act promptly, surely, and effectively, no matter what the obstacles, and that the permanent tendency is so strong that all it needs is to be released and directed. 
This recalls what we have already said about habitude, or habitual attitude. (105).

Moral education in our schools. It has not been our purpose to go into the many and difficult problems of moral education, but rather to show how certain essential factors enter into the making of permanent affective and moral tendencies. Reference to a recent article as to the problem in connection with our public schools may perhaps appropriately conclude what we have to say on the subject in this connection. This article is by Professor Drake of Vassar College, who tells that moral development depends partly, to be sure, on physical heredity. Poor constitution, mental defects, pathological conditions, and the like, are unfavorable for high moral development. Eugenics may do much in helping to stop the reproduction of defectives in whom moral and, perhaps, all other kinds of development are limited. But the problem depends mostly upon social heredity or education. "Morality," he writes, "is something acquired by each generation, and not something transmitted by parents to offspring; we can greatly facilitate its acquisition. Morality is functional, not organic; it results from the way we use our powers and direct our instincts, not from their inherent nature. But we are not trying on any large and systematic scale to provide competent training in the art of life for our youth. We employ experts to teach them Latin and mathematics; we see to it that they know how to build bridges properly if they are to be engineers, or fill teeth properly, if they are to be dentists. But we leave the most important training of all, the training that shall show them how to guide their desires and instincts, how to avoid the snares and pitfalls of life, how to be steadily and honorably happy, to the haphazard attention of parents, who are for the most part themselves ill-trained and ignorant of how to live. We need not despair of the efficacy of moral training, for we have hardly begun to try it.

. Our educational system is fairly good on its informative side, and in the mental drill it provides. But in its moral training it is inexcusably deficient. What if our school superintendents and college presidents were to recognize that the prime function of education were to discuss concrete problems of conduct, and to quicken conscience, by the many methods known to skillful educators? It could then turn multitudes of boys and girls trained to a code, as knights were trained in former days to courage and chastity and the service 
of the weak. What if loyalty to school and college were to come to mean primarily loyalty to that code; so that for a Harvard man anywhere to be detected in lying would be shame to that college, or for a Yale man to use unfair methods in business would be to make his classmates blush and brand him as untrue to his alma mater? . . . . . In this moral education, rather than in eugenies, lies our real hope for the raising of the general standards of moral conduct." (22).

\section{QUESTIONS AND SUGGESTIONS FOR STUDY.}

1. Show how there are both instability and stability in the life of the feelings.

2. What has the teacher to do with the development of permanent cravings, needs, passions, appreciations, feeling or emotional dispositions?

3. How would you go about developing a passion for literature, or art, or science in yourself, and in a student?

4. What do you mean by the higher sentiments and what has the teacher to do in connection with them?

5. Compare the value of permanent acquisitions in the realm of the feelings and in the realm of the intellect.

6. What parts do thinking, feeling and doing have in the moral education of the individual?

7. What are the relative values of precept, examples, and practice in moral education?

8. Distinguish the idea of the will as some kind of a special power of the mind with the view given in this book.

9. What can you say about the need of and means of moral education in our schools?

\section{REFERENCES.}

1. Dewey, J. Moral Principles in Education. Boston, Houghton, Mimin Co, 1909.

2. PAYOT, J. The Education of the Will: The Theory and Practice of Self Culture. Tr. by S. E. Jelliffe. Funk and Wagnalls, 1909.

3. SNeAth, E. H. and Hodges, G. Moral Training in the School and Home. The Macmillan Co., 1913. Also other books in The Golden Rule Series, by the same authors and E. L. Stevens. 


\section{Chapter 15. \\ PHYSIOLOGICAL AND PHYSICAL CONDITIONS.}

Dependence of mind on body. We have come to realize that without ideals, purpose, determination, one is not likely to accomplish what he could with them. Or, again, without improvement in methods of doing things we cannot do them most economically. But, also bodily conditions and the influence of environment are so vital that we must see that they are the best possible.

We do not have far to go to find evidences of the dependence of mind on body. A blow on the head may make one unconscious; failing health often makes it impossible for one to do good mental work; one may notice his memory failing in sickness and returning to normal activity with the return to health; drugs often interfere with mental processes or may render one unconscious; adenoids and defects of the various senses all have their various effects on intellectual work.

The argument that great people have sometimes had marked physical defects, or that people have done great things even though they had serious bodily deficiencies does not in any wise prove that the defects made no difference and were unimportant. The defects very likely impeded the endeavors of these and other people who may have had them. On the other hand the defects may have had the effect of provoking them to greater effort.

The fact is that there appears to be a positive correlation between physical defects and failure of normal progress in our schools. It is reported that children in New York City schools who have had physical defects make 8.8 per cent. less progress than the normal children.

Special defects. Dr. W. S. Cornell, (18), in his Health and Medical Inspection of School Children, writes that except for poor nutrition, defective hearing in moderate degree is the most powerful retarding influence encountered by school children. The results of defective hearing induce defective scholarship in general (See Figs. 14 and 15) and defective speech in particular. Inullness, smaller head, and inferior 
strength of grip are said to be correlated with defective hearing.

A simple operation may remove wax or some foreign body from the ear and permit a child to hear who had not been able to hear before. The writer learned of a case recently where a girl by such a simple operation was able to hear distinctly for the first time, in at least a good many years. She informed her mother, "I can hear what the teacher says now; I can hear the clock tick." The disposition of the child changed noticeably also. She had been disagreeable and difficult to manage; after the operation this changed and she was very distinctly more agreeable and tractable and was much more willing to do what her parents asked;-perhaps, she knew for the first time with some degree of clearness just what they wanted. For a comparison of results of an experiment comparing hearing and deaf children, see Figs. 14 and 15.

Eye difficulties have interfered with study to an extremely large degree. It has been estimated that perhaps 60 per cent. of children who are studying need glasses. It is to be remembered that where one may not need glasses if he is not doing close work with the eyes, close work is just the thing that makes it necessary to give the eyes all possible aid. A study by F. J. Mann shows that hyperopia is five times more prevalent than myopia. One hundred and ninety-one cases were very carefully studied. Hyperopia is considered by Prof.

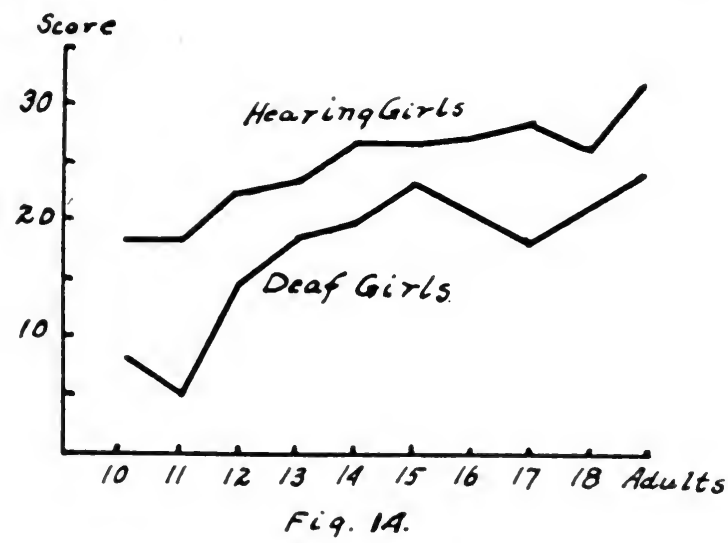

Fig. 14. Results for deaf and hearing girls in the digit-symbol test. (Pintner and Paterson, 82a). 
Mann as a much more serious cause of eyestrain and retardation in schools than myopia. (59).

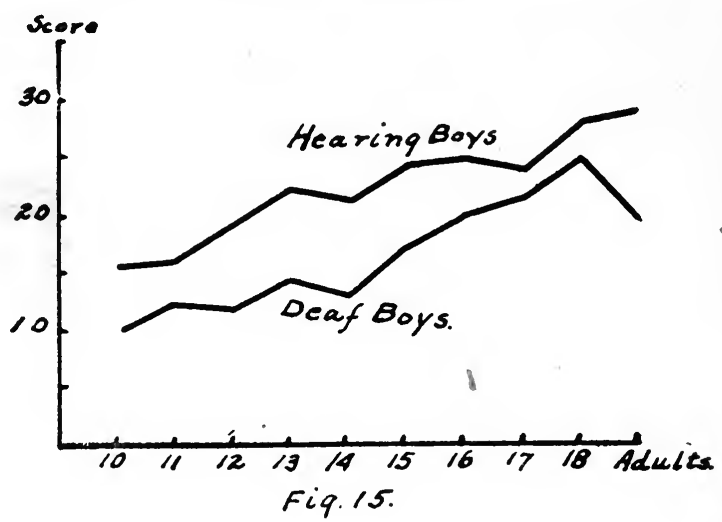

Fig. 15. Results for deaf and hearing boys in digit-symbol test. (Pintner and Paterson, 82a).

Nose and throat troubles and especially adenoids interfere with school work. Children who were thought to be subnormal and who had adenoids removed have been found to be of normal intelligence and fully able to keep up with normal children.

Although it has probably not been conclusively shown that poor teeth cause poorer mental work, there is no doubt that poor teeth, if they are not remedied, bring about serious physical conditions in adult life. Besides the statement that bad teeth lower scholarship, there is no doubt about the effects of bad teeth on lowered health, impaired digestion, and the greater danger of contagious diseases. There is found to be considerable correlation between bad teeth and rheumatism, and there is also evidence that not a few nervous diseases or at least disorders, may be traced to defective teeth and cured by the necessary treatment of the teeth.

Food. Lack of sufficient food, poorly prepared food, constipation, and resulting auto-intoxication, poor digestion, and lack of assimilation of food, lower the level of both physical and mental work. Forty-three per cent. of the New York City school children were at one time said to be underfed. The penny lunches appear to have been followed by better school 
work. In Minneapolis recently there was found a family in which the children had always done uniformly excellent school work. Suddenly the work of all deteriorated and on investigation it was found that because of business reverses and financial loss the family were unable to obtain sufficient food. Upon supplying sufficient, good, well cooked food again the children were found doing their customary excellent work.

$A$ balanced diet. People commonly pay too little attention to getting a balanced diet. Fisher and Fisk give a table by means of which one can roughly determine a properly balanced diet. See Table 1. (27).

\begin{tabular}{|c|c|c|c|}
\hline & $\begin{array}{l}\text { Poor in } \\
\text { fat. }\end{array}$ & $\begin{array}{l}\text { Rich in } \\
\text { fat. }\end{array}$ & $\begin{array}{c}\text { Very rich in } \\
\text { fat. }\end{array}$ \\
\hline $\begin{array}{c}\text { Very high } \\
\text { in } \\
\text { proteins }\end{array}$ & $\begin{array}{l}\text { White of eggs } \\
\text { Cod fish } \\
\text { Lean beef } \\
\text { Chicken } \\
\text { Veal }\end{array}$ & & \\
\hline $\begin{array}{l}\text { High in } \\
\text { protein }\end{array}$ & $\begin{array}{l}\text { Shell flsh } \\
\text { Skim milk } \\
\text { Lentils } \\
\text { Peas } \\
\text { Beans }\end{array}$ & $\begin{array}{l}\text { Most fish } \\
\text { Most meats } \\
\text { Most fowl } \\
\text { Whole egg } \\
\text { Cheese }\end{array}$ & \\
\hline $\begin{array}{c}\text { Moderate or } \\
\text { deficient } \\
\text { in } \\
\text { protein }\end{array}$ & $\begin{array}{l}\text { Most vegetables } \\
\text { Bread } \\
\text { Potatoes } \\
\text { Fruits } \\
\text { Sugar }\end{array}$ & $\begin{array}{l}\text { Peanuts } \\
\text { Milk } \\
\text { Cream soups } \\
\text { Most pies } \\
\text { Doughnuts }\end{array}$ & $\begin{array}{l}\text { Fat meats } \\
\text { Yolk of eggs } \\
\text { Most nuts } \\
\text { Cream } \\
\text { Butter }\end{array}$ \\
\hline
\end{tabular}

\section{TABLE 1.}

"The foods given in the uppermost compartment are those 'very high' in protein. . . . The compartment farthest to the right contains a list of those foods 'very' high in fat. .... The foods in the lower left compartment are rich in carbohydrates. Those in neighboring compartments are moderate and the others are poorest in carbohydrates."

"Thus practically the nearer the name of any food is to the upper left corner of this triangular table, the more protein that food contains; the nearer it is to the right hand corner, the more fat .... and the nearer to the remaining corner (lower left), the more carbohydrate (starch and sugar)."

"An ideal proportion of the three food elements is to be had only in the middle compartment of the lowest row. But it is by no means necessary or advisable to confine one's diet to the 
few foods which happen to fall in that compartment, provided foods chosen from other compartments balance each other. Thus, fruit and nuts balance each other, the one being at the left and the other at the right of the ideal compartment. In the same way, potatoes and cream balance each other, as do bread and butter. Instinctively these combinations have been chosen, especially bread and butter. This combination is, however, slightly too low in protein, and a better balance is obtained by adding a little from the compartment vertically above the ideal. In this way we obtain the familiar meat-, egg-, or cheese-sandwich, constituting of itself a fairly wellbalanced meal."

"In short, in order to maintain a diet correct as to protein, it is only necessary to make our main choices from the lowest row and, in case the foods so chosen are near the bottom, to supplement these by a moderate use from the row above and a still more sparing use of those in the top compartment." (27).

The importance of a correct diet cannot be overestimated and most of us could do better than we do in the matter. Other pages in the book just referred to are recommended to the reader.

Air. It was safe to say only a few years ago that people needed a certain amount of fresh air to breathe. Recent researches have suggested that perhaps all we need is to put old, much breathed air into motion. We at least are assured of the fact that air in motion can be breathed with perfect comfort and no physiological ill effects for a much longer period than can air which is not in motion. The unpleasant effects of air which has been breathed for some time can often be removed in this way.

Many systems of ventilation have been worked out and many studies of ventilation have been made. A good system of ventilation is invaluable. It has not been proved, that it is not wise to judiciously use window ventilation to supplement even the best systems of ventilation that have yet appeared.

Prof. Lee, (58), of Columbia University, in a recent report of the effects of atmospheric conditions in relation to physiological action, notes the current emphasis upon physical rather than upon chemical features. He writes: "The harmfulness of living in confined air is found in certain physical rather than chemical features - the air is too warm, too moist, and too still; and if it has not these physical features it is not harm- 
ful." It is perhaps too early to predict what the status of carbon dioxide will be in the future. We are not at present ready to have any percent at all of carbon dioxide in the air that we breathe and will probably remain a little critical of the statement that "the harmfulness of air is not due to its chemical components." There is no doubt about the need of keeping the physical conditions much better than has been done.

Temperature. Prof. Lee refers to the common experience of all when he writes in this same article, "We all have sat in crowded assemblies; we all have experienced the hot, humid, still days of an American summer; we all know the effects of such air on our sensations - the general bodily discomfort, the sleepiness, the flushed face, the headache, the disinclination to think or to act, the general debility, the longing for relief." Summing up the facts presented by Mr. Huntington, in his book, "Civilization and Climate," Prof. Lee continues: "All these data combine to demonstrate that the greatest physical efficiency of the individual is found not during the summer or the winter, but at intermediate seasons." That the same is true also of mental activity is shown by a study of the marks secured by the students at IVest Point and Annapolis in certain classes, especially mathematics. Of the various climatic features that might be responsible for these scasonal differences in achievement, temperature appears to be the most important. Both physical and mental activity seem to be greatest and most effective, not when extreme summer's heat or extreme winter's cold prevails, but when the body is subjected to an intermediate temperature. After a careful consideration of his many figures Huntington came to the conclusion that the optinum temperature of the outside air for the physical work of human beings is about 60 degrees $\mathrm{F}$. (15.5 degrees C.) and for mental work about 40 degrees $F$. (4.4 degrees C.) the greatest efficiency of the human body culminating at the intermediate point of 50 degrees $\mathrm{F}$. (10 degrees C.).

The studies we have all go to show that the customary temperature, 70 degrees $\mathrm{F}$. in which we are likely to keep our living rooms is too high. A temperature of 65 degrees to 68 degrees $\mathrm{F}$. (about 18 degrees to 20 degrees $\mathrm{C}$.) is probably best. It is likely also that the air is too quiet. And a third very important factor is the humidity.

Humidity. Professor Whipple has called our attention to the fact that the air in our dwellings sometimes exceeds in 
dryness that of the Desert of Sahara. The importance of humidity is so great that it would not be at all surprising if we should some day measure the humidity of our indoor air as carefully as we now measure the temperature. The hygrometer may some day be as common as the thermometer. The New York commission has recommended 50 per cent. relative humidity as most desirable. We are certainly not likely to do our best work, either physical or mental, if the air is either too dry or too moist.

Atmospheric conditions and mental work. Experiments as yet do not seem to clearly indicate the effects of atmospheric conditions on mental work. Further experiments on a fairly large scale are under way. Common experience and the observations already quoted above, however, indicate deleterious effects of extreme conditions. The fact is that extreme conditions are distractions, or at least tend to detract attention. More effort is therefore required on the part of the student and this constitutes a serious difficulty in the school room and in the case of any student who lacks the necessary motives, interest, or pressure to overcome the disturbing influences.

Uniformity of atmospheric conditions, that is, with little or no changes, is found to be dulling to both mind and body. Change is stimulating and if not too extreme or too often, is valuable. Clothing is important. Impeding the circulation of the blood by too tight clothing interferes also with the mental processes. To attempt to disregard these things, to overcome them by force of will, may be heroic, but is uneconomic and requires the paying of too big a price for diminishing returns. At the very outset the physical conditions should be made as nearly right as possible.

Regularity and Efficiency. Regularity of eating, sleeping, plenty of good nourishing food and of sleep, keeping the body in the best condition always, will do more for the intellectual welfare of the student than he realizes. Suppose that the student keep himself in this fine physical condition, and then push himself to his best efforts; that responsibilities and demands be made upon him; that he studies regularly and for long hours; he will be astonished to find what it is possible for him to accomplish. And, further, he will find that while he turns out more and better work, he can do it with perfect comfort. To use artificial stimulants to work leaves one in an abnormal condition; to use the right incentives, to concentrate effort, to develop interests and discover motives, to per- 
fect methods of study, to keep the body healthy for this purpose, reveals deeper levels of energy and develops a degree of efficiency of which the student may never have dreamed.

Change of work. To change from one kind of study or work to another kind of ten brings better results. One is not rested by doing this, but he feels rested. It removes weariness, the feelings of effort and boredom, and lets up on the strains that have started. Different parts of the brain may be called predominantly into action. And only predominantly, let it be said, for the brain works so much as a unit, that it is not true to say that youl use one part for one thing and another part for something else. Many parts of the brain are active whenever any of it is active. Different muscles may be exercised. If the eyes are used very much for one subject, a change to something requiring less eye work is advantageous.

Furthermore, the student should learn to do his hardest work, his best study, at the times when he is most rested, when he has the best supply of energy. It is certainly a mistake to think that one can do very good mental work when physically tired. It is much more economical to rest a while and then begin study. It is doubtful whether study should be done immediately after a meal; the blood should not be called immediately from the stomach to the brain by hard intellectual work. Such time might well be used for rest, recreation, or perhaps, for light, pleasant reading or conversation.

Fatigue. Fatigue is defined as the reduction in capacity for and pleasure in work. Mental fatigue is fatigue for mental work; bodily fatigue is fatigue for bodily work. Fatigue we have already distinguished from weariness or the feeling of fatigue. This feeling, we said, was no safe indication of the actual fatigue, that is for the actual lack of capacity for further work. Actual fatigue can be removed only by rest. Recreation, change of work or of subject matter, may remove the weariness but do not change the fatigue.

.It should also be remembered that one cannot fatigue himself for one kind of work, either mental or physical, and expect to be without the same fatigue for the other. He will be without the feeling of fatigue, perhaps, if the change of work brings renewed interest, relieves particular strains and unpleasantnesses, and brings pleasure through the change itself. Actual fatigue is not removed in this way.

The value of shorter periods of study and of work has appeared from various quarters. We have already referred to 
the value of comparatively short study periods. The fact that workmen can turn out more and better work in reasonably shorter than longer periods has found its expression in the shortened hours, for example, in the eight instead of the ten hour day. Just as much and perhaps more can be done in the shorter time and with no more or at least relatively no more, and perhaps even less fatigue considering the time expended.

Fatigue and school hours. The best progress in school requires careful elimination of fatigue whenever it appears, and careful administration of school affairs so that the minimum of fatigue results from the day's work. Taking the judgment of Offner, (72), which he made after an extensive study of the problem, we find the following statements. Sixty minutes is entirely too long for a class period and has no psychological reason for its justification. This applies to high school students. For older students a longer time is permissable, and eighty minutes is thought to be the longest which should be used for older students and then only for reviews. Forty-five minutes are recommended for the normal high school student. For lower grades thirty minutes are long enough. In coninection with this matter we may well consider the apparent success of many principals of high schools who have used thirty minute periods for their students and alternate the recitation with the study period. This, you remember, agrees with the results of experiment on the value of comparatively short study periods, $i$. e., twenty to thirty minutes.

Offner says that five periods a day are enough and that some authorities have decided that a return to four periods is wisest. The maximum for the week according to this writer should be twenty-four. As to pauses in the work; the pauses should be shorter early in the day and longer later in the day. It is very questionable as to the value of very strenuous exercise for those who are studying. A moderate degree of exercise is beneficial; much more than that may bring one too near to the point of fatigue and interfere more with mental work than it helps.

The rather extreme suggestion of two hours rest over the noon hour before one begins the afternoon's study will hardly meet with general approval. Yet this suggestion is found in the above mentioned author. The American would consider two hours rest in the middle of the day too much waste. The suggestion that informational instruction and class recitations be given up in the afternoon in order to keep students from 
studying during the noon hour is perhaps sufficiently well approximated in the plan which throws laboratory and shop work in the afternoon. Surely a rest after the noon meal, or at least, restraint, if happily it be restraint, is beneficial.

Sleep. Professor Whipple, (120), recommends the following hours of sleep for people of the ages given. The hours are averages from figures given by the six best authorities. See Table 2. For an admirable study of the sleep of school children one should read the study of Terman and Hocking. (108).

$\begin{array}{lllllllllllll}\text { Age: } & 6 & 7 & 8 & 9 & 10 & 11 & 12 & 13 & 14 & 15 & 16 & 17 \\ \text { Hours: } & 12.2 & 11.5 & 11.2 & 11 & 10.5 & 10.2 & 9.8 & 9.6 & 9.25 & 9.0 & 8.75 & 8.5 \\ & & & & & \text { TABLE } & 2 . & & & & & & \end{array}$

More sleep is necessary for more strenuous work or play, for younger people, and in winter than in summer. If sleep? does not fully restore the organism to complete capacity, that sleep was insufficient or the work of the day before too strenuous.

Short naps. Experiments and experience seem to show that short naps may be very useful in economizing time and energy. The rest and recuperation is greatest soon after going to sleep if one may reason from the soundness of sleep, and is less and less so in succeeding hours. See Fig. 16. It has been

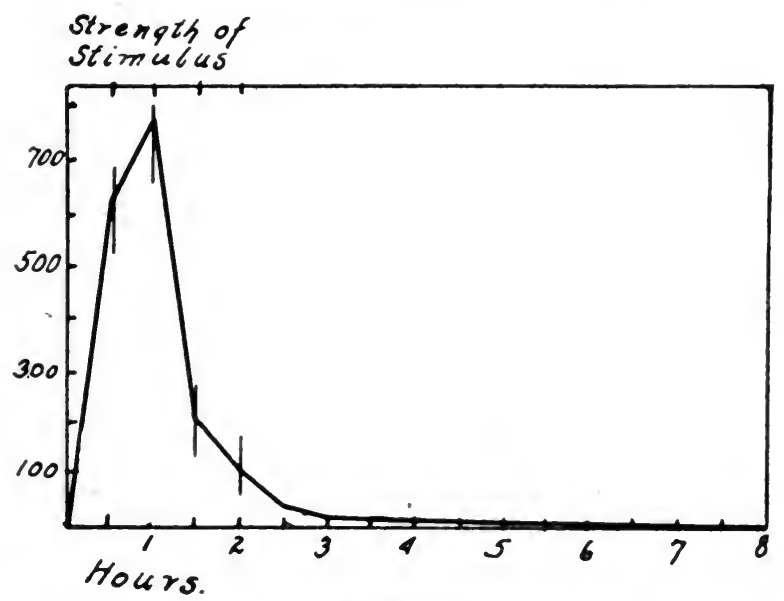

Fig. 16.

Fig. 16. "Curve illustrating strength of an auditory stimulus (a ball falling at half hour intervals). The curve indicates that the distance through which the ball required to be dropped increased during the first hour, and then diminished, at first very rapidly, then slowly. (Kolscheutter)." (I). 
said that a person can get the greatest amount of good from his hours of sleep if he cuts short the long night rest and takes a short nap in the middle of the day. He thus takes advantage of the greater rest to be gained from the earlier portions of two sleep periods.

"It appears that loss of sleep can be made up by fewer extra hours than the number lost though the explanation of this is not fully apparent." (2).

On this subject see also: Patrick and Gilbert (75). Also, C. E. Seashore, (88).

Social activities do more than hard work to bring on fatigue and in the cases of many of our students nervous breakdowns. Social intercourse is moderation is not only beneficial but necessary for the growth and development of normal life. But late hours and insufficient sleep with midnight suppers thrown in inevitably show in the lack of efficiency the next day, the extra energy required for the same work, the greater number of errors, and if kept up long enough in nervous breakdown. This may be fashionable, but the student will have to become more than ordinarily expert in statistics to prove that it is economical.

Study in evening school after a hard day's work cannot be expected to give the returns that study without any degree of fatigue would give. Economy for the students in evening classes would be found in using part of their available time in resting and then studying. The study time even though shorter would give better results. One must be careful not to sleep too long before the evening study, if he sleeps at all, for he must avoid the getting too drowsy to do any effective study later.

Raising the question whether or not it is permissible that pupils be fatigued, Offner answers, Yes. Fatigue is not dangerous if there is full recuperation every morning after the night's rest. A man needs training to meet the emergencies that demand work to the point of fatigue. Better development comes through reasonably hard work. " An easy school is a social crime."

\section{QUESTIONS AND SUGGESTIONS FOR STUDY.}

1. What facts have we that show the need for good physiological and physical conditions if we are to have good school work? 
2. What are the most important special physical defects of school children? What should be done about them?

3 . What is the relation of food to health and good mental work?

4. How would you work out a suitable diet from the table given in the text? What is meant by a balanced diet?

5. What three things are essential in connection with air? How far can and should they be controlled?

6. Discuss the problem of fatigue and its relation to school work.

7. What would you advise a student in regard to the right amount of sleep?

8. Distinguish between fatigue and the feeling of fatigue. What is the effect of recreation on, 1) fatigue, 2) the feeling of fatigue?

9. Discuss the problem of social activities in relation to school work.

10. What is the value of hard work and how is an easy school a social crime?

\section{REFERENCES.}

Cornell, W. S. Health and Medical Inspection of School Children. F. A. Davis. 1912 .

FISHER, I. AND Fisk, E. L. How to Live. Rules for healthful living based on modern science. Authorized and prepared in collaboration with hygiene reference board of the Life Extension Institute, Inc. Funk and Wagnalls Co. 3rd Ed. 1916.

OFFNER, M. Mental Fatigue, Tr. by G. M. Whipple. Warwick and York. 1911 . 
Chapter 16.

\section{THE DIRECTING OF LEARNING AND STUDY.}

Results of supervised study. No doubt seems to exist as to the need for supervised study. The amount of agreement that we should have it, is at least, out of proportion to the amount of directed study that has occurred, unless it be in the last few years. It appears that we might with profit hear less for a time about the very important matter of preparing the teacher to teach, and hear more about preparing the student to study, and the teacher to help him to study.

The justification of supervised study lies partly in the recognied need for it and partly in the fact that it has proved its worth where it has been tried and used. Study that is not supervised or properly directed is wasteful. Bad habits of study are thus formed. Supervised study has given results so far superior to the old wasteful ways of pupils, - they can hardly be called methods in many cases,-that no teacher who knows the facts can deny the economy of such supervision. The same lessons can be mastered in less time and bad habits of study avoided. Breslich is authority for the statement that supervised study may give results even two and one-half times superior to unsupervised study if we think of results in terms of time.

Moral value of home study habits. Nothwithstanding the recognized superiority of supervised study at school, there remains a very serious moral problem. It appears that in one place where home study was abolished, parents discovered that their children spent their evenings away from home instead of at home as they had done formerly. The problem is serious. The endeavor of educators today is to direct the activities of children for a larger number of hours out of every twenty-four. The street, the movie, all that influences children when they are not at lrome or in school is part of the educational problem. At these times they are forming habits, many of which may be exceedingly bad. The point is that a little home work may be of great value in getting pupils to form better habits of spending the evening hours. 
The pupil's failure in the application of advice for methods of study. Parker cites the case of a teacher who gave instructions to pupils as to methods of studying and found out later that one of these pupils knew nothing about studying the subject the teacher taught. The girl told her parents that she knew of no suggestions that the teacher had given about how to study the lesson. The parents inquired of the teacher and learned that such suggestions had been given. It is a question how frequent such cases are. From our general knowledge we may suppose that this case is by no means exceptional.

The only safe thing for the teacher is not only to give the instructions but to know that they are carried out. Supervised study in the school will give opportunity for the teacher to know this. It is also advisable that a part of the recitation be on the methods used in getting the lessons. Not only should children know the lesson, they should know how they learned it and be able to tell how they did it. The habits of study are some of the most important end results of education. Tests should include these habits formed as well as the habits that are commonly tested.

The teacher's inability to advise. As Judd has pointed out, teachers do not know what to tell students about how to study. He gives the example of a principal who arranged with his teachers for a separate period during which the teachers should direct students in the methods of getting their lessons efficiently and economically. "The program .... was arranged and the classes met the teachers. Then it was discovered that the teachers did not know what to say to the students. Teachers know about Latin and mathematics. They can ask questions in these subjects; but they do not know about students' minds in a way which makes it possible to tell students how to study."

Teachers fail to know the difficulties of students. They should know these difficulties and the particular difficulties of students in the subjects taught. Knowing these they should learn to apply the particular knowledge of method needed.

For the last four years the present writer has given suggestions for study to his students, especially to those students who were preparing to teach. The following suggestions were written out about three years ago and have been found very useful in his talks to teachers. They are here given in almost the same form as that in which they have been used for the last three years. They suggest many of the things that can be 
said to students in the attempt to improve their methods of study. Choice can be made from the list of suggestions which follow. Many of them will be of great value to students, especially if the teacher amplify upon the statements where necessary. The detailed facts found in the earlier chapters of this book will offer the necessary help for such amplification.

Suggestions for students. What you study is very important. How you study is more important. What you study you may forget in a short time. You will very likely forget a good deal of it. How you learn, the methods you use, become habits that are a very part of you. These habits stick through life. If you get good habits of study you can learn very much more quickly. And you will also be better able to learn things by yourself when there is no teacher to help you.

You have often heard about learning to use the hands. It is more important to learn to use the mind. Learning to use the mind correctly helps you to use the hands better. This makes the mental habits that are necessary for success in school and after you leave school. Whatever you think, feel, or do, develops in you the tendency for you to think, feel, and do the same later. That is, it makes your habits of thinking, feeling, and doing. If you form good habits they help you to succeed; if you form poor habits, they hinder you.

Remember that you must not simply listen to these suggestions and decide to use them sometime. You should use them now and all the time. You will have to use them until they become habits. You should realize that your old methods are probably not economical. If a new method seems harder to you it is probably simply because it is new to you. When you get used to it it will save you time and be easier.

Do not be prejudiced against these new methods. They have been worked out by people who have studied the best ways of doing things. These people are giving you these results after much study and many experiments. You are the one to be benefited if you will only use them. They studied these problems of study because the old ways wasted too much time.

Habit. Making a thing a habit permits you to do what you have learned in this way and to attend to the next new problem. Progress and mastery demand many useful habits, and, especially, as many as possible in one's chosen profession or vocation. 
Always learn correctly the first time; never learn incorrectly; things once learned can never be entirely unlearned.

Your habits will determine, for the most part, what you will be and do in the future; develop, therefore, the habits of thinking, feeling, and doing that will be helpful later.

Fully make your habits. Learn the things that will help you best to form difficult habits and make use of them.

Learn the things that interfere with the formation of habits in your case and do your best to avoid them, for example, laziness, not caring enough, too many engagements, not having time, and the like.

Remember that what you are getting out of your education are habits of some kind and that you want good habits rather than bad ones; habits that will save you time and effort, rather than habits that will waste your time and effort.

Fully formed habits are what give stability to character. One is expert only when one has many of these fully formed habits. Such habits are the only things that can be depended upon in the emergencies of life. That is what makes the trained soldier more valuable than the raw recruit. That is the reason that the football squad has to practice so long and so hard.

Habit formation involving study. Get a good start and start promptly. Don't waste time beginning. Half a minute is probably long enough to take to get started.

In the problems of life three things above everything else will be valuable to you: the ability to gather facts, the ability to get clear ideas, and the ability to make right judgments.

The more you know of a given subject, the more you can get from a lecture or from reading on that subject.

To be clear and to be accurate are the most important things in all study and in solving any of the problems of life.

Remember that thoroughness pays in the long run. Being thorough means fulfilling the requirements of the situation in which you are placed. One can be wisely thorough without being exhaustively thorough. Know what to do and where to stop.

Be true to the facts with which you are dealing. That is, don't think that the book says what you expect it to say. Find out exactly just what it does say.

Know exactly the aim of every study you go into. Adapt your method to that aim. Do exactly what you set out to do 
or know why you do something else and that it is right to change.

Imitate, and imitate only the best; add some thinking even then.

Mastery of material requires organization; if material is not well organized, organize it for yourself both for memory and for understanding.

Give good attention to the things you want to understand and remember.

Find the general subject or problem first; then find the first main thought, then the sub-topics under this main thought with the illustrations for each point; then the next main thought, the sub-topics and illustrations; repeat this until you have mastered your material.

Find a concrete example for everything you want to understand and remember.

Outline what you want to remember; then memorize the outline.

Follow through good reasoning of others; read books in which you find good reasoning.

Reason with others, and try to make your points so clear and forcible that the other man cannot fail to see them.

Reason out theories, and then test them to see where they are good and where bad.

Practise in picking out essential factors in situations. Learn how to pick out the most important ideas.

Learn to detect errors in reasoning and to avoid them.

Modes of thought. Discover the habits of thought that you have and that tend to lead you astray.

The trial and error method may sometimes save time; but thinking will save you more time and a great deal of waste effort.

Get all the facts you need before making a judgment.

Do not be prejudiced by what you want to think or to believe. Be prejudiced only to know clearly and accurately.

Know whether things happen by coincidence or by cause and effect.

Be definite in the use of words, and know exactly what others mean, either when they speak or write.

Remember that reasoning by analogy, that is by similarities, never proves anything and is one of the commonest ways in which people are led astray in their thinking. 
A person has to understand in terms of his own knowledge. But reading your thoughts and feelings into things may lead you far from the truth.

Be sure that an argument proves what it is supposed to prove and not something else.

Distinguish an appeal to the feelings from an appeal to the intellect.

Remember that a conclusion may be right even though the arguments are bad and fail to prove the conclusion.

Above everything else, be clear and be accurate.

Progress and improvability. Given the capacity, anyone, with proper methods, regular and persistent practice, can surpass the achievements of most people.

The best improvement is found to occur where one practices very definitely the thing in which the improvement is desired. Do not practise one thing and expect much or perhaps any improvement in other things.

Master all habits as you go along.

However, in thought material, go ahead often when you do not fully understand; you will get new light; reviewing the whole matter later will help you further in a full understanding.

Frequent reviews will give you the best results for the time you spend. Learn in the right order or in a very good order; use the best methods, and be regular in your application.

Understand the causes of "plateaus" in your case, and apply the reniedy needed.

Don't get the idea of studying just because a lesson is assigned. You are studying for your own advancement. Statistics show that it is possible for an educated person to rise higher and to do things impossible for an uneducated person.

Learn to help yourself just as much as possible.

Get your teachers to help you learn how to learn.

Learn to study and to do everything as nearly as possible in the way you will do them after you leave school.

Be a master of something.

Transfer of training. Training in one thing may help in other things; it may also hinder in other things. If you learn to do a thing correctly the methods may help you to do other things. If you learn a thing incorrectly, it is likely to hinder your doing it correctly later.

You improve most in the definite thing you study and practise. But if you try to apply, or if you have the ideal of the 
thing you are attempting, it may "carry over" to the doing of other things.

Try to see the value of things you are learning and make them help you in other things wherever possible.

Your methods of doing things transfer very of ten to doing other things. It is most important, therefore, how you do things.

Thorough intensive study may broaden one in a way he does not expect.

Memory and the permanence of acquisition. There is no general memory; there are many memories.

To remember better, have better conditions of study and have better methods of study.

Use all the things that make for better attention, attitude and purpose. Have the intention to remember.

Have many associations with the things you wish to remember.

Use your knowledge.

Take advantage of frequency of repetition, duration of the experience, vividness, recency, primacy, age and regularity.

Learn at your own best rate. Go over material more slowly at first, then at a faster rate. It is doubtful as to whether you should try to study very fast. It is valuable to be able to study and learn quickly, but speed often means inaccuracy. The more valuable thing is to be accurate.

Study the material at different times.

Study by wholes and not by parts. Learn what is the best amount of material to be studied as a whole.

Organize your material wherever you can and get the logical connections. Warm up to your work, and have two or three minutes at the end of the study for a hardening period. Do not allow any distractions at this time.

Avoid fatigue, and have the best physical conditions possible.

Do not depend upon mnemonics and mnemonic devices except where it is positively necessary.

Learn very thoroughly if you want to remember for a long time.

The mind is not to be stuffed. You should learn, assimilate and use.

The feelings and interest. One may become so absorbed in his work that there is no feeling connected with it, but interest 
is generally present in the best intellectual work. Other feelings are also desirable.

To help arouse the desirable feelings and attitude for study:

Choose the environment, people, situations, etc., which suggest the desired attitudes. Listen to, or better, participate in, discussions of the subject you are studying.

Recall facts, people, accomplishments of others and of yourself that arouse you to the desired attitude.

Compare your achievement with that of others and of your own earlier work.

Have a motive for your study.

Be wisely indignant over your failures, and direct the energy aroused to the study in hand. One may appeal to various instincts, the fighting instinct, for example, to develop the right aggressive attitude towards study. Decide that you have enough fight in you to conquer the difficulties in your lessons.

Act as if you had the desired feelings and they may come.

To arouse and develop interest:

Use suggestion of environment; choose places and people that make you want to do your work; that arouse your enthusiasm.

Attach or associate something pleasant with your subject.

Get as pleasant an introduction to it as possible; get as much pleasant knowledge about it as you can.

Take an attitude towards the subject; do something about it.

Find a use you can make of the knowledge or accomplishment; this may be to solve problems, to converse on this topic with educated people; to earn a living, to have a finer appreciation of something, or what not.

Find definite, concrete examples of the thoughts with which you are dealing.

Purpose and determination make for better results in every way.

Attention and sustained effort. The better the attention, the better all intellectual work.

A student should practise giving the best attention he can in all situations. He should develop the habit of concentration for any situation.

Some emotions help, for example, curiosity, interest, desire to achieve, and the like. Others hinder, for example, excitement, fluster and worry.

Changing from one phase of a topic to another helps. 
Having many thoughts on a topic and following them out to their logical conclusions will aid.

Competition with others and with one's own past record is likely to make for sustained attention.

Have a purpose, determination; care enough. If you care enough about a thing you are likely to succeed. Of course, you must have enough capacity to start with.

The suggestions of environment may help; the books, rooms, people, etc., which give the right influence.

Avoid the wrong suggestions : the easy chairs, the comfortable easy going people, luxurious and distracting surroundings.

To become relatively independent of distractions, try to study in any and all kinds of places, that is, where there is little and where there is much distraction. Persist, care enough about doing it, and hold to your purpose. This is the best way to form the habit of concentration. There is an easier way but it is not so good. That is to study at a certain time and in a certain place. This will form time and place habits. They will make it easy for you to study at the chosen time and in the chosen place. The reason that this is not so good is that it may make it difficult for you to study at other times and in other places.

To know definitely what you are looking for will help you to find it. If you have a very clear idea of what you expect to see you may think you see it when it is not there. So you must be careful. You may also overlook other important things.

Do not mistake the feeling of fatigue for actual fatigue; and do not fall into the habit of feeling tired and having to stop study in a very short time. That is just a bad habit.

Know clearly and exactly what you are to do; know clearly and exactly how to do it.

Have an ideal and live up to it. Many of our great men have become great because they had an ideal and lived up to that ideal.

Bodily conditions. The best bodily conditions are the necessary conditions for the best study.

Remove physical difficulties wherever possible.

Improve your mental work by improving your health.

Plenty of good, well-prepared food, good digestion and assimilation, good light, 'fresh air, right temperature, proper 
humidity, and enough sleep are essentials to efficiency of both mind and body.

Right physical conditions not only permit more and better work, but enable you to do it with comfort and enjoyment.

Artificial stimulants to work leave one in an abnormal condition.

Normal incentives call forth the best energy, and leave one better off for one's efforts.

Suggestions to be emphasized for all study:

Know exactly what you are to do.

Study with a definite purpose.

Adapt your method to the problem and to your type of mind.

Solve your problem; think it through to the finish.

What you know, know thoroughly.

Organize your knowledge.

Be clear and be accurate in all mental work.

Be wisely thorough; be selective rather than exhaustive.

Make the best use of time; divide your time well; learn at your own best speed.

Get the best physical conditions for study.

Choose the suggestive influences that will help you. Eliminate distractions.

Do not be disturbed by what you cannot do. Think about what you are doing and not about your feelings.

Forget yourself in your problem.

BE A MASTER OF SOMETHING.

The teacher's responsibility. The teacher's responsibility includes knowing how to direct study, giving the necessary instructions and seeing that they are carried out, that they become habits of study, and sceing that physical conditions for study are what they should be.

Directing study requires practice. No one can properly direct study without knowing just how to do it. There is not only the danger of giving insufficient or inadequate help; there is also the danger of giving too much help. A safe maxim would be: help the student to help himself.

The best way to see that pupils carry out instructions for study is undoubtedly in having stated study periods which are carefully supervised. This makes it possible to give instructions, to see that they are carried out, and children report that they are helped by a schedule which includes supervised study hours because it helps them to spend their time to better ad- 
vantage. Several advantages are apparent; it keeps children from the problem of what to do next; of wasting time getting started; of giving too much time to favorite subjects, and too little to other subjects; and of getting into the habit of putting things off till some other time. Many methods have been tried and a period devoted, half to recitation and half to study, has been very successful.

The supervision should include the seeing that chairs are of the right height for the pupils, that the desk is at the right angle; things that are not to be used should be put away so as not to be continually disturbing the work and the attention; and the like.

Pupil's study card and schedule. Some such card as that suggested by Reavis and modified by Parker will be found to be very useful. The following (Fig. 17), is taken from Parker's, Methods of Teaching in High Schools.

Obverse side of card.

\begin{tabular}{|c|c|c|}
\hline \multicolumn{3}{|c|}{ PUPIL'S STUDY PROGRAM. } \\
\hline \multicolumn{2}{|c|}{ Name. } & \\
\hline Hour & Study & Recite \\
\hline $9: 00$ & & \\
\hline $9: 45$ & & \\
\hline $10: 30$ & & \\
\hline $11: 10$ & & \\
\hline $1: 15$ & & \\
\hline $2: 00$ & & \\
\hline $2: 45$ & & \\
\hline $3: 20$ & & \\
\hline & & \\
\hline & & \\
\hline & & \\
\hline & & \\
\hline
\end{tabular}

Fig. 17. 
Reverse of card:

1. Follow your program regularly.

2. If possible, study your lesson immediately after the assignment is made.

3. Take brief notes and afterwards re-study by outline.

4. Use dictionary and reference books for points not clearly comprehended.

5. Concentrate your mind so that outside interests will not frequently disturb you.

6. Do not try to commit exact words until you understand their content.

7. Connect the important facts of the new lesson with facts previously learned.

8. Make comparisons and contrasts when possible.

9. Carefully review and think over the previous lesson before beginning the next.

10. The extra time spent on preparation pays the greatest intellectual dividends.

Going into details with the student. The suggestions given in this chapter for use with students are of a general nature and the teacher of each subject will find the necessity of making use of these general principles and of going farther with the individual student according to his particular needs and according to the particular needs of the special subject. (See suggestions for this in experiment given in chapter 17).

The one great problem for each student is to discover the particular combination of methods which is best for him.

The student who knows the laws of mind should also know what factors in the working of these laws are most important in his particular case. The following suggestions indicate some features of the individual problem.

The teacher, for example, will try to get the pupil to have a purpose in his work. But for each student there is the problem: What purpose will you have for your work? To learn this subject to help you in a certain profession; to study this subject or to read this book to answer certain questions; to study one subject thoroughly in order to be an authority on that subject; to study history in order to understand the great institutions of modern life; to study psychology in order to know the mind and to understand many of the facts of every day experience; to see a play in order to tell a friend about it. or, what will be your purpose? 
Organization is invaluable but how will you organize your knowledge so that it will best serve your purpose? Will you arrange all the facts topically with main heads and subheads, or, if you are studying history, will you place the facts in chronological order, and make a table with dates at the left and the facts for each date at the right? Or, if it be science, will you arrange the facts under chapter headings, so to speak, and put all facts in their appropriate places under each chapter head? Will you use large pages and keep them in some logical order, or use index cards and file them alphabetically?

Some students can study for long periods at a time, others find shorter periods more beneficial. How long can you study at a time and get good results? How long for this subject, and how long for that? Again what is the best time of day for you to do your studying, and at what time can you do your hardest work?

Rate and method of study. The student must learn his own best rate of study. The best speed for one individual is not the best speed for others. Most of us probably study too lazily or else we leave the task until the last minute and then rush through it too fast. The best rate of learning can be determined only after many trials. This can generally be done by increasing the rate of learning until the student finds that he is failing in clearness of thought and accuracy of detail, and in the ability to recall what he has studied. What is the best rate for you? What is the best rate in this subject and what in that? How fast should you go at first and how fast at later stages of progress?

It has long been supposed that the ear minded individual should be taught through the ear; and the eye minded child through the eye, etc. The truth seems to be that no matter how an individual is taught, he transforms what he learns into his own kind of memory. A person who is eye minded, may learn just as well by hearing, but he is likely to transform the sounds of the words into visual images and to remember them in that way. Most people, have not only one kind of predominant imagery with which they do most of their remembering; they are of mixed memory, so to speak, and use several types of images. There are exceptions to this, and there are exceptions to the fact that people can learn about as easily through one sense as through another. Younger people probably learn better through the ear.and older through the eye. But this is not always so and is not necessarily so. 
Exceptions to the general rules need to be understood by teachers. A child is reported by Meumann, for example, who could not remember the outline of Greece until he had traced it. Here neither seeing nor hearing sufficed, but learning through the tactual and muscular senses was necessary. Individuals can be found who do not remember well until they have articulated the matter to be learned. The first fact stands for most people, namely, that it does not matter so much through what sense a thing is learned, the learner transforms what he learns into his kind of imagery or memory. The second fact also stands, namely, that for some people a certain kind of learning is necessary in order that they may remember. One kind of memory may be much better than any other kind. The problem for the student remains: In what way can you study and get the best result? Should you see or hear or write out what you would remember or will any of those ways suffice in your case? Would it help to repeat audibly or semi-audibly? etc.

The size of units of study is to be determined. How great an amount should you take to go through at one time? How many pages of poetry, or prose, or of history?

Much failure in courses is because of insufficient preparation for the work. The student may not know enough to understand the advanced work; he may lack concrete facts on which to reason; preliminary work may be only partly mastered so that attention cannot be given wholly to the work in hand. In each case the individual must determine what is lacking and how to make up for his deficiency.

The final result. As a final problem the student should learn to make the results of his study work out into expression either of words or of deeds. One may have thoughts and be unable to express them; another may have great powers of expression but little or nothing to express. Work definitely for the two-fold resultant: the thought and its expression. This is the combination which is valuable in the work of the world. After graduation from school or college assume that you do not know very much and that you are not very skilled in expressing what you do know, and you will be well within the facts. You will also have the only safe attitude with which to begin a new line of work. Try hard in your new work to obey instructions, to follow them exactly, to do the kind of work demanded of you and you may find that you can soon 
do nearly as well as the man who has not had your education. Continue to work and to study and to solve your problems and you will find some day that your education will surely carry you beyond that which is possible for the man who is otherwise your equal but who has not had your education.

\section{QUESTIONS AND SUGGESTIONS FOR STUDY.}

1. What facts in your own experience point to the need for supervised study?

2. What is the greatest difficulty that is found when teachers are asked to teach children how to study?

3. Why is the giving of directions to pupils as to how to study only the first step in supervising study?

4. What could you say in your first talk to students on the subject of study? What would you try to accomplish in the first talk?

5. How would you plan later talks for your students?

6. What special preparation do you need for instructing students in methods of study?

7. What do you consider as the most important things for the student to understand thoroughly about study?

8. Discuss the value of a study card for the student?

9. How would you see that the desirable methods of study actually become habits of study?

10. How would you make allowance for individual differences among students?

11. Expand on the statements in the book as to the final result of study.

\section{REFERENCES.}

JUDd, C. H. Psychology of High School Subjects. Ginn and Co. 1915. Ch. 18.

MCMurry, F. M. How to Study and Teaching How to Study. Houghton, Mifflin Co. 1909.

PARKer, S. C. Methods of Teaching in High Schools. Ginn and Co. 1915. Ch. 16.

Swain, G. F. How to Study. McGraw-Hill Book Co., Inc., N. Y. 1917.

Whipple, G. M. How to Study Effectively. School and Home Education, Jan. 1916 and following numbers. Issued in book form by Public School Publishing Co., Bloomington, Ill. 1916. 
Chapter 17.

SUPERVISED STUDY AND THE SCHOOL CURRICULUM.

Methods outlined. Various arrangements have been made in schools for the purpose of fitting in supervised study. This is not adding a new study. If so, there would be good reason to doubt the advisability of making the attempt. The change consists in introducing better methods of doing work that is already demanded. Its justification lies in the better results that have already been obtained.

We may outline the methods that have been tried and those that may be worthy of trial under the varying conditions of different schools. In a general way we may say that the methods involve:

A. 1. The use of a regular teacher.

2. The use of a special teacher.

B. 1. Separate hours for instructions in study during school session.

2. Special times appointed by the principal .

3. The division of each regular school period.

4. The double period.

5. Conferences, during or after school, for individuals or groups of children.

6. Extra time during the regular session, or in summer.

7. The use of the general study hall.

The use of the regular teacher. Where supervised study has been tried, the regular teacher has commonly been called upon to do the supervising. If he supervises his own pupils in his own subjects there is the advantage that he knows exactly what is needed and understands better than a special teacher the particular difficulties and individual differences of his particular pupils. This requires no addition to the teaching staff, but it does require that the teachers learn how to direct study. It would likely be found that emphasis on supervised study would be only an extension and methodical administration of that which is now done by most teachers in a poor and haphazard, and therefore, in a much less effective way. 
The use of a special teacher. In many schools a special teacher who shall give his whole time to directing study has been found to be most beneficial. Such a teacher can be a specialist in the subject. Being a specialist, he can put more study, interest, and enthusiasm, into this work as the one great purpose of his teaching. This advantage does not hold where the special teacher is a student of a Normal School doing this work to finish the requirements for a diploma. If the special teacher is obliged to coach in all subjects, it is obvious that he cannot be as well acquainted with each subject as the regular teachers. Neither is he as well acquainted with the individual difficulties of each pupil.

Both methods valuable. Both methods have proved valuable and it is perhaps too early to say which is the better. What is better for one school may not be better for another school. As in other matters of administration, the problem. will need to be worked out for each school. This is true also in regard to the fitting of supervised study into the curriculum.

Separate times for instruction in study during the school session. One solution for the problem of how to find time for supervised study is to take the time in place of other work, either, by taking a whole period for this in place of other work, or, by shortening several periods, and using the time thus gained.

If the former method is used, different hours may be used on succeeding days. On the first day, the first period can be given to supervised study throughout the school; on the second day, the second period can be used, and so on, until each class has been instructed in methods of studying each subject. This can then be repeated.

The latter method is probably better for things that are not to be so regular as supervised study should be. This virtually means changing the schedule and rather than make a change like this permanent, some other more satisfactory plan should be found.

Special times appointed by the principal. Another method is that of having special periods set aside by the principal. this can be done so as to sandwich in the supervised study where there seems to be a good chance, or as a special feature. But this, again, does not give the uniformity needed, and is likely to be only a very inadequate way of solving the problem. This is better than nothing and where doubt exists as to the value of supervised study, a few trials well managed might 
prove its worth and show the value of regular, methodical, supervision.

The division of every period, part for supervised study. A method which has found favor with many teachers is the division of each period, so that part is given to the work as ordinarily carried on, and part given to teaching the pupils how to study the next lesson. A division of half and half has been successful in some schools. The first part of the time is given to recitation and discussion, the second half of the hour is used for giving directions to students as to how they are to go to work. The pupils are made definitely conscious of the particular problems they have to solve. Here each teacher has the opportunity to apply all the knowledge he has regarding the application of principles of study to his particular lesson. Making the assignment is a very definite part of this second half of the period. It is carefully prepared and made part of the teaching of the next lesson. Teaching the children how to work out this assignment follows. A little home study to finish lesson and for daily review is very desirable.

There is much to be said for this method. It has proved so successful in some schools, that more than half of the period is given to teaching how to study. The chief preparation of the teacher for this kind of lesson is preparation in the methods of study, and. needless to say, this work is very different from the giving of lessons in the old way. Contrary to expectation, it is found that there is plenty for the teacher to do and say in teaching pupils how to study the next lesson. The teacher finds that this is the most valuable part of the period. This method can be started without a single change in the curriculum.

The double period. Some schools have what is called the double period. For example, forty minutes are given to the recitation as now commonly carried on; the next forty minutes are given to directing the study of the new lesson. This has proved successful in not a few schools. One outcome is that there is more school study and less home study. The school study appears to be superior to the home study, and the same amount of time spent in directed study at school gives far better results than the home work.

Study conferences. Individuals or groups of pupils, who need special help, may by special appointment, meet with the regular teacher at a time when he has a vacant period. Or, if there is a special teacher, these pupils may be assigned to cer- 
tain hours when they shall meet the special teacher and receive the needed help. Such conferences may be used for both backward pupils who need help to keep up with their classes, or for bright pupils, who with special help may skip a grade. This latter plan is a good way of solving the problem of dealing with supernormal children in schools where there is no adequate provision for them. It is possible by means of such conferénces to work out many problems arising from the individual differences of pupils in large classes. Pupils at the lower end of the class may be helped not only to keep up with their class but encouraged to stay in school and do their best. Particular defects and difficulties may be discovered, which might not otherwise become known. A little help at the right time may save the individual pupil much loss of time. The most economical way to deal with repeaters is to prevent their ever becoming such.

Extra study periods. For cases in which the regular school periods do not seem adequate, extra time has been used with immensely valuable results. The simplest way is the taking of half an hour or so after the regular school session. Some schools have made use of Saturday morning for coaching backward pupils. A greater extension of this principle is found in special summer sessions for coaching not only backward pupils, but also supernormals. The backward pupils are helped so they can go on with their classes; the supernormals so that they can skip a grade.

Directing study in the general study hall. If there is a general assembly hall in which students not in attendance at a class or laboratory meet to do their studying, there is an opportunity to help them in their methods of study. The teacher in charge of such a room is likely to have too many other duties at this time. There are difficulties of many kinds arising in many subjects and the problem of discipline may interfere. At best, the use of this time for supervising study is but a makeshift and not systematic enough to give the best results. The teacher, unless he is a special coach, is not likely to be prepared to help pupils with all the difficulties that arise in the different subjects. In this limited time the teacher can give adequate help to only a few of all who are in need of it.

Essential factors in the administration of study supervision. Among the most essential factors in the planning of supervised study in the school are the following: The supervised study should have a regular place in the curriculum. It should not 
be left to chance or occasional use, but requires just as much place as any other work of the school. Each child should receive his share of help; the plan should not merely permit, but should require a certain amount of supervision for each child in each subject. This will help to eliminate the pupil's practice of having trouble for the purpose of getting special attention. The teacher, if not a special coach, should supervise his own subject, and should know the particular difficulties of the children and the inherent obstacles in the lessons. Attention should be given to the right methods, not to that which should not be done, except where necessary to break up an old bad habit. Correct methods should be made fully conscious to the pupil at first and then made completely formed habits. Informal, personal, encouraging help gives the best results. Marks should be given for methods of study as well as for the results of study. And, it should be remembered, just because time has been given to teach the pupil how to study, it is not to be expected that he will know how, or even know that he has been instructed in the matter. He must be instructed, and made explicitly conscious of method, and then tested in his knowledge of how to study.

An Experiment in Supervised Study in the Grade Schools and in the Normal Practice School, Athens, Ga. The remainder of this chapter gives an outline of an experiment (25) which is being made in the grade schools of Athens and in the Normal Practice School. Six typewritten pages of directions were made out and besides having conferences with teachers the writer has gone into the school room to try out some of them himself. The directions for the various subjects are given for the purpose of getting a start in the supervision of each subject in the school. The author offers them for the purpose of criticism and trial by the teachers who use them. He desires to know in what way they are useful and in what ways they should be modified to be made more valuable for school room work.

The statement of this experiment necessitates repetition of a small part of chapter 16 . Many of the statements are however, quite differently worded and the bringing together of a few selected directions used in talking to pupils is not without its advantages. A usable selection for young students is thus indicated and it is a concrete illustration of how selections may be made from earlier chapters for talks to students. The selection given below might well indicate the type of talk de- 
sirable for beginners. For older students other selections should be made and these fundamental principles reviewed.

The directions are as follows:

General suggestions for study. What you study is very important. How you study is more important. The way you study should always be the best way. This becomes habit and is a very part of you. If you get good habits of study you can learn very much more quickly. You will also be better able to study by yourself when there is no teacher present and after you leave school.

You have heard that it is important to know how to use the hands. It is more important to know how to use the mind.

You will be helped by these better methods only if you use them. To hear about them will do you no good unless you use them.

Getting started. 1. Always learn correctly the first time, never learn anything incorrectly. What is once learned cannot ever be entirely unlearned. Fully formed habits are the ones that make you expert. That is the reason the football squad has to practise so long and so hard.

2. Get a good start and start promptly. Do not waste time beginning. Probably half a minute is more than enough time to take to get started.

3. Always have ready the things you need with which to study.

4. Put everything else away.

5. Know exactly what you are to do, how to do it, and when to stop.

Study and thinking. 6 . To be clear and to be accurate are the most important things in all study and in solving the problems of life.

7. Know exactly the aim of every lesson. Adapt your method to that aim. Do exactly what you set out to do or know why you do something else and that it is right to change.

8. Understand what the lesson calls for. Know exactly what is given and what you have to get.

9. Imitate, but imitate only the best. Then think out a better way.

10. Reason out things for yourself and get into the habit of reasoning for yourself.

11. You are not to learn everything. You should be able to pick out the most important things and learn these thor. oughly. 
12. After selecting the most important things you should organize them in your mind or on paper.

13. It is very helpful to outline things on paper. The outline should be by topics and sub-topies.

14. All study should be by topies and sub-topies. That is the way you use your knowledge later.

15. Always give good attention to the things you want to understand and to remember.

16. Find a concrete example to help you understand and remember.

Making acquisition permanent. 17. To master anything you need to practise it. Drill, doing things again and again, using knowledge, is all important.

18. Try to find an application for everything you learn.

19. Frequent reviews will give you the best results for the time you spend.

20. Learn to help yourself just as much as possible. And do not get the idea you are studying just because the teacher gives you a lesson. You are studying to improve yourself and to get ahead.

21. To remember better get better methods of learning.

22. Have the intention to remember, the will to remember.

23. Learn at your own best rate. Go slower at first, then faster.

24. Twenty to thirty minutes are long enough to study new things at one time.

25. Study the same lesson at different times. Study a lesson as soon as possible after it is assigned; then review it before the next recitation.

26. Memorize by wholes not by parts. This whole method may not help you at first and you may think for a long time that the part method is better. You need to get used to the whole method.

27. If certain parts are very hard, begin with the whole method; then study the hardest parts by themselves; and finish with the whole method.

Interest, attitude and physical conditions. 28. Get interested. Find something pleasant in your lesson; compete with your past record; find a use you can make of what you are learning; make it a game and play the game.

29. Be glad to do hard and unpleasant study so as to become indifferent to unpleasant tasks. Don't let the difficulty throw you down. 
30. Learn things as though you were going to tell them to someone, and make them see them.

31. Have a purpose, a determination; care enough. If you care enough about a thing you are much more likely to succeed.

32. One of the greatest secrets of study is to be able to give good attention whenever you want to no matter what is going on around you. If you cannot do this learn to study at certain times and in a certain place. You will thus get time and place habits and these will make it easier to study, although though it may be harder to study at any other times and places. It is better to make yourself study in any place and with any kind of distraction if you can.

33. Keep well. Have plenty of good food and enough sleep. Eat sufficient but not too much. Have fresh air, right temperature (65 degrees to 68 degrees F.), right humidity (about 50 per cent.), and good light. Improve your study by improving your health. Remove any physical defects.

34. Do not try to do too much. Don't be disturbed by what you cannot do. Think about what you are doing and forget. your feelings.

35. BE A MASTER OF SOMETHING.

How to study reading. (Reading to get meaning is here distinguished from oral reading, the latter is important, the former is fundamental to all study).

1. You must be able to read accurately; this is necessary for studying other subjects.

2. Get the main subject or title.

3. Look for the leading thoughts.

4. Pick out the leading thoughts, then sub-topics, illustrations, reasons, etc.

5. Outline these in your mind or on paper.

6. Be sure to get the thought, the meaning, and be able to state it in your own words.

7. Write on paper all new words and look them up in your dictionary.

8. Also try to reason out meanings of new words from 1) their form, 2) their context.

How to study history. 1. Get the main subject.

2. Read through quickly to get a general idea of assignment.

3. Pick out the main topics, and the sub-topics.

4. Learn how to do this. 
5. Be sure that you understand them.

6. Thoroughly learn the facts you have selected.

7. Organize these facts in your mind.

8. Outline them on paper if you cannot master them without doing so.

9. Find examples in other history, especially, in modern history, to illustrate what you learn.

10. Make a list of things you do not understand and look them up or ask the teacher about them.

11. Helps: make charts, make maps, picture people and events to yourself, or make a little play to illustrate them.

How to study science. 1. Observe experiments carefully, or read carefully.

2. Note facts,- do not be led away from the facts by looking merely at the apparatus.

3 . See what the facts mean.

4. Do they teach any general law or principle? Try to find one.

5. Try to see applications of these facts, - of these laws. Try to make applications in, 1) the laboratory, 2) in the schoolroom, 3) at home, 4) to explain everyday things.

6. Outline the facts, laws and applications in your notebook.

7. Do these facts and laws make any difference in the way people do things or should they make a difference? How?

8. Distinguish between facts and laws, and the explanation of the facts and laws.

How to study mathematics. 1. Recall what you know that will help you.

2. Be sure you understand the signs, symbols, etc.

3 . Understand your problem. This requires the ability to read.

4. Find out what principle should be used. Know why.

5. Know how to apply the principle.

6. Know each step in doing the problem and how to do it.

7. Know how to verify and be sure to verify. Know how to verify when the answer is not given in the book.

8. Drill for quickness and accuracy; do examples for this.

9. Review principles whenever necessary.

10. How do you know when you are right? When you have proved anything?

11. If you use model examples be sure that you understand how and when to use them. 
English composition. 1. Have something you want very much to say.

2. Think it through clearly.

3. Get your thoughts arranged on paper in outline.

4. Think of your reader.

5. Try to make him see the thing as clearly as you do.

6. Do not hesitate; plunge in and try.

7. Notice the good language of speakers and writers.

8. Memorize good language of others; imitate only good language.

9. Try to improve your language; this helps you to think better.

10. Remember that good writing is one of the greatest and hardest accomplishments of the human mind. It is hard for others as well as you.

Manual Training and Domestic Science. 1. Have a clear idea of the thing to be done or to be made.

2. Understand the principles involved.

3. Do the thing correctly and practise doing it correctly.

4. Imitate from demonstration of the teacher; imitate only good models.

5. Try to do well rather than fast.

6. Criticize your own work.

Results. It is too soon to give any quantitative statement of results. It is possible however to state that many pupils have been helped. Some who were backward are now doing much better work. Some who were little interested have found a new interest in their study. Greater self-reliance has appeared in several cases. The writer wishes to emphasize again that these directions are only for making a beginning, that they must be worked over by the teachers themselves in the school room, but that so far they have improved the work of many pupils very appreciably. The author will consider it a favor if any one who may use them will send him any suggestions, criticisms; or statements of results. Every teacher must find his own way of approach in using them. The writer's experience in the school room indicates that it is most advisable to take a certain lesson, and while explaining how to study it, make the pupils go through the successive steps in a very thorough fashion. A few steps may be used for the first lesson, more steps another day, and so forth, until all the steps are completed. It will take longer at first to fol- 
low the methods indicated above. But the pupils will learn more, and later will work rapidly with these methods.

\section{QUESTIONS AND SUGGESTIONS FOR STUDY.}

1. Think of some particular school system with which you are familiar. What problems would arise in the attempt to put supervised study into the curriculum?

2. Pick out what you think are the most useful of the methods outlined in this chapter for putting supervised study into the curriculum and give your reasons.

3. What are the advantages and disadvantages of, 1) the special director of study, 2) the direction of study by the regular teacher.

4. What do you consider the essential factors that should be considered in any system of supervised study in a school? Name any that you can that are not mentioned in the text.

5. Try to outline directions for study for some subject for which the outline is not given in the report of the experiment mentioned in the text.

6. Could you suggest a plan for directing study so that pupils beginning in the fourth or fifth grade could be taught increasingly more in each succeeding grade on up through the high school? What would you do in each grade? With what subject or subjects would you begin? Could you arrange for increasingly more difficult problems for each grade?

\section{REFERENCES.}

Hall-Quest, A. L. Supervised Study. Macmillan. 1916. Chs. 5 and 6.

McMurry, F. M. How to Study and Teaching How to Study. Houghton, Mfflin Co. 1909.

PARKer, S. C. Methods of Teaching in High Schools. Ginn and Co. 1915. Ch. 16.

Swain, G. F. How to Stud!y. McGraw-Hill Book Co., Inc., N. Y. 1917.

Whipple, G. M. How to Study Effectively. School and Home Education, Jan. 1916 and following numbers. Also issued in book form: Public-School Pub. Co., Bloomington, Ill. 1916. 
Chapter 18.

\section{DEFINITENESS IN AIM AND IN METHOD.}

The need of definiteness. "It is true," writes Professor Snedden, "that the largest single problem to be solved on behalf of the high school of today is that of a clearer definition of the valid aims of secondary education." (90).

"The most impressive fact," writes Professor Judd, "which stands out in examining the results of a series of tests is the need in schools of more definite standards of work. Teachers are working in ignorance of what they ought to accomplish." (52) It is clear from a psychological point of view that if teachers are going to secure definite results, they must know what results they are to obtain. One may do traditional things and cover the traditional number of pages of a text book. But it is another matter to know definitely just what is to be accomplished and to be able to accomplish it. The psychologist hopes to be able to help the teacher obtain desired results by helping to improve method.

We have already shown that the habit theory is true to the multitude of facts that appear in connection with the educative process in the individual. It has, as has also been said, the advantage of definiteness. Warning must again be given against attempting to interpret anything so broad as education under too narrow a theory. But it must also be emphasized that this is not a narrow theory. For habit as we have defined it includes habitudes, interests, attitudes, all, indeed, that may be considered more or less permanent tendencies as the result of learning. It is at least worthy of consideration that we take habit in this sense as the great fundamental basis of educational practice and for the accomplishment of the great ends of education which may then be formulated in more general terms such as social efficiency and character. Again let us remember that habits are not so unmodifiable and that plasticity is not so easily lost as has been commonly thought. And further that progress in learning of any kind shows just this making and modification of habit. It is fitting that we look at this most important matter of definiteness a 
little closer and consider a few of the problems of the school in this connection.

Social values. The vagueness of aim and the varieties of aim are not denied. In fact they are admitted and emphasized from all sides. The psychologist can only add to the demand for greater cooperation for deciding what the legitimate aims should be. These, no doubt, must be decided in terms of social value. The examination of values of the various subjects to which the curriculum is being subjected today is inevitable and of great promise. No one more than the psychologist realizes the need for definiteness of aim. For it is only as he knows what is to be accomplished that he can render the service of working out the most efficient methods for obtaining those results.

The binding force of tradition. Students of education have been joined by the disappointed and questioning parents in considering the problem as to why certain subjects are taught in the schools. The answer has been in many respects that things are not of the value that had been supposed. And the reorganization of text books shows the elimination of many parts of subjects hitherto supposed to be necessary. Whole subjects have been dropped, for example, Greek, and Latin is perhaps the storm center of discussion at the present time. Latin and English afford typical illustration of certain facts and principles.

The case of Latin. It is interesting to trace the shifting defense of Latin in the schools. Latin has been considered essential to a liberal education. When Latin was introduced it was the road to a liberal education. It was necessary for one to know Latin in order to obtain a liberal education, if not any kind of an education, because the things that were to be learned were written only in Latin. This reason for learning Latin no longer exists, nor has it existed for a good many years. The case is clear. The conditions which demanded the study of Latin ceased to exist. The binding force of tradition has continued.

Latin and the professions. The foundations of the old argument having been carried away, the defense shifted. Latin was useful in the professions of law, theology, philology, history, etc. Any language may be useful to the historian or the philologist, but we are not all sufficiently interested in either of these subjects to make Latin necessary and few would ever make it useful to any appreciable extent. As for law, we have 
been told many times that the Latin used in law is not the classical Latin and that the classical student is obliged to learn the law Latin when he comes to it. As a jurist puts it, the Latin used in law is so different that even persons of good classical education cannot understand it. The theologian is. quite likely to study Greek, or Greek and Hebrew, in preference to Latin.

Roman literature. Again the defense shifted. One should study Latin in order to gain a knowledge of the rich treasures of Roman literature. In this also one may find recreation and pleasure after the day's toil. But it has been discovered that it takes many years of study of Latin to have the treasures of Roman literature opened up by that means. One must spend seven to ten years in the study in order to have any very great facility with the language. Those who maintain that this is too great a price to pay, especially inasmuch as this material can be had for the most part in English, have not been satisfactorily answered. Much may be lost in translations, and by the same token, much more is likely to be lost: by the poor translations of most students. It is yet to be provèd that a student can not get more by using a good translation than by making his own translations, to say nothing of the vast amount of difference in the expenditure of time. The argument for Latin as a recreation is negligible.

Latin for mental training. But another defense is added. Study Latin to train the mind. But psychologists are thoroughly persuaded that there is no such general transfer of training as was earlier thought and there is probably a small amount of improvement in one subject because of improvement in another; just what general improvement there is must be shown, but not by comparing classical students who have studied Latin four to seven or more years with scientific students who have studied one science one or two years. And also not by comparing the best taught subject in the curriculum, as Latin is known to be, with results of poorer teaching in other subjects.

But, at least, study Latin to improve your English. This sounds plausible as we know that English comes largely from the Latin. But competent observers tell us that in many cases, at least, it is very questionable whether or not the study of Latin contributes results of 'very much value to English. 'Indeed we are told that the majority of Latin students may be 
found to have their English actually impaired by the use of poor English in the making of translations.

Our conclusion is that the value of Latin under the present day conditions needs to be most seriously studied before we content ourselves with going on spending several millions of dollars a year in the teaching of Latin and requiring several years of our children's time in studying the subject. In considering the psychological fact that most improvement is in the thing practised, it is very pertinent to ask after all, is not the study and practice of English the best way to improve in English? Perhaps we shall think some day that it was curious we should ever have to ask that question.

The question of English. The study of English as a tool, and it has other objects, is of fundamental importance. No other subject is allowed so much time in the school and no other subject, we are told, shows such poor returns for the time and energy spent. What help can the psychologist give in connection with this problem?

One fact stands out with surprising clearness. That is that whereas the student may have practice with good English so far as his work for the English department goes, he is likely to practise poor English in his work for other departments. There is a very interesting and suggestive study of the transfer of spelling from English to Sociology themes that is pertinent. Professor A. R. Mead reports the following experiment.

With the help of four graduate students he collected thirty themes each from as many students who had written both in English and in Sociology. Each man's theme in English was compared with his theme in Sociology as regards the accuracy of spelling. The writer tells us :

"The problem accurately stated was, "To what extent do students use the accurate spelling vocabulary of their themes in English in themes in sociology?" "The results of the comparison of papers as made by the four graduate students are stated as follows: "There were then, approximately 160 per cent. more misspelled words in the sociology themes than in the English themes. In other words, there was a very geneal tendency to lower the standard of efficiency in spelling used in the sociology themes. In matters of punctuation and capitalization a beginning of a study was made. Here, too, a similar tendency was observed.

"The writer believes that this minor study shows a very prevalent tendency in the effectiveness of the teaching of Eng- 
lish in high schools and colleges, although the investigation made concerned college students only. As he interprets the situation, it represents a failure to secure habits which transfer, or ideals which are consciously generalized. As such, it suggests the following: 1) teachers of English should strive to secure such transfer;2) there should be a very much greater cooperation in the teaching of English. Had the instructor in sociology placed emphasis upon correct spelling, why should the students not have had a stronger tendency to spell correctly? 3) if such conditions exist as to spelling, the very content of one phase of the English language, what must be the conditions regarding the transfer of the more intangible elements of the mother tongue. It is probably easier to secure transfer of content than of some other elements. Hence, it is probable that many of the values of English are being realized only in a very minor degree." (60).

To state it differently, the student practises poor English more than he practises good English and has in his nervous system the results of his practice. It may seem a little hard on the school and college to say that they are fostering, nay more, that they are practically teaching poor English. Where other departments do not cooperate with the English teachers in the demand for good English the influence of that school or college is predominantly for poor English. This is the bare fact. And the English department alone with twice the time at its disposal than it now has could hardly be expected to counteract the tendencies that are allied against it.

A lesson from the French schools. The point,--that people learn to do as they practise,-is taken seriously in the French schools and we may well take a lesson from them in this respect. A quotation from the valuable study of Professor R. W. Brown will serve to emphasize further what I have been maintaining. Professor Brown tells us that "The value of the training the French boy receives in his courses in composition is increased materially by the character of the writing he is required to do in other subjects. It would be exaggeration, assuredly, to say that his writing in these other subjects is always done just as carefully as that which he submits to his teacher of composition; and it would be just as great an overstatement to say that every teacher of mathematics, botany, and history is as much interested in the character of his pupils' writing as he is in the subject he teaches. Nevertheless. the quality of this writing which is done as a part of the work in 
other classes receives a degree of attention from both pupil and teacher that in America may be found only in unusual instances.

"Teachers in France would protest against the assertion that they had attained an ideal condition in this respect; many of them feel, as we feel in America, that other departments too often neglect the quality of pupils' language. Yet when one compares the practices of the two countries, one cannot refrain from felicitating the teacher of the mother tongue in France upon the more conscientious, more intelligent support he receives from his colleagues in other fields of study. The result is not difficult to see. When the boy is obliged to write in his other courses, he sooner or later reaches the conclusion that all writing is important. He therefore not only gains from the thoughtful practice which he carries on in history, civics, and physics or botany, but he derives new profit from his instruction in composition. His teacher of the mother tongue ceases to be a person who is paid to talk about something that is unimportant except to himself, and becomes a person of consequence who can help one in doing what everybody seems to think is worth doing well.

"I was especially impressed by the neatness and accuracy with which the students in the normal school classes did all of their writing. I noticed, moreover, that many of the corrections on advanced papers had to do with the organization of the material and with smaller questions of clearness. .... In fact, whatever the prevailing faults of expression, there seemed to be no assurance for the pupil that the teacher would, by passing over them habitually, permit himself to undo the work of the teacher of composition and literature.

"The critical attitude toward all the pupils' written work is maintained also toward his speech. This fact was brought to my notice in a striking manner the first time I visited a class in science. . . . . If I had encountered no other cases, I might have thought this only the whim of an extremely sensitive teacher. But as I visited other classes in a variety of subjects, I came to see that most French teachers have a well developed conscience in respect to such matters. They do not drive a boy to abandon spontaneous speech, but they do insist that he make clear cut, straightforward answers, and that they be phrased in reasonably acceptable language."

Other facts in relation to English. Some of the difficulty in the teaching and learning of English may be seen also when 
one realizes the variety of problems which arise in dealing with the subject. The teacher desires to train the student in English composition, but attention to rhetoric is distracted by corrections of, and instruction in, grammar. The teacher wishes the student to acquire some appreciation of the great literary masterpieces, but enjoyment of the literary productions nust, seemingly, be interrupted by minute and generally uninteresting dissection of the English itself. At least two vastly different kinds of work appear to be thrown in unpsychological manner under one head: namely, the study of formal English and the study of English literature. These different kinds of work require different methods. The psychologist must advise; have some specific aim for one kind of work, and determine and use the particular methods calculated to attain this aim; for another kind of work choose and make use of the particular methods required for that.

Conditions of improvement in English. We are now ready to indicate some conclusions which may be drawn and to apply some of the facts and laws indicated in earlier chapters of this book. In the first place, most improvement is specific, that is to say, most improvement is in the thing practised. If, then, one is to improve in English, why not study English with this definite purpose? How much can one improve in English by studying another language? Is the price worth paying? In the opinion of the present writer these problems are still unsolved and need to be studied seriously. In the next place, and akin to the first point, it has been discovered in the laboratory that much of the greater improvement in laboratory experiments over the improvement outside of the laboratory is because of the specific nature of the practice on certain definite things. If, then, the student is to improve in English, why should not certain specific improvement be chosen and that improvement be worked for by the definite methods best calculated to bring the desired results? Again, it is known that improvement is greater where the learner knows his successes and failures. Is it not, therefore, advisable that the specific aim of any work be conscious to the student and that he know just what progress he is making towards the specified end?

The theory of specific training versus formal discipline. One other conclusion must be at least considered. If most improvement is in the thing practiced, if formal discipline or transfer of training is relatively small in amount, and, per- 
haps, limited in nature, should not the curriculum be made up on the theory of specific training instead of on the traditional theory of formal discipline? Think also of the vast amount of time spent, the large expenditures of money and the altogether questionable value of results, involved in following the disciplinary conception.

A quotation from Professor Snedden. The solution is stated in no uncertain terms by Professor Snedden, who says: "In teaching modern languages we must wholly discard the doctrine of formal discipline. As found in current defenses of modern language teaching, it is an unfortunate heritage from the factitious pedagogy of Latin. In view of current knowledge and uncertainties regarding mental training, the one safe assumption is this, 'Teach only those things, and to those degrees, and by those methods, that serve a demonstrably useful purpose in individual econony-useful, that is, as producing, in specific and tangible ways, the culture, the refinements, the sensibilities, the stored knowledges, the moral habits, the ethical ideals, the vocational powers that the world in its best judgment wants and approves. So teach towards the realization of these objects that the appropriate exercise of mental qualities is always involved, and the results of which will persist.' We know little today in favor of any theory of pure mental gymnastics. What experience everywhere teaches us, if we would but see it, is that valuable, and probably always the most valuable, mental training invariably accompanies the vigorous and systematic pursuit of intellectual objects in themselves worth while. The cumulative massing of the results of this by-product training in numerous and varied fields is what gives us, on the whole, the best mental training of which we have any knowledge."

A quotation from Professor Thorndike. "An impartial inventory of the facts in the ordinary pupil of ten to eighteen would find the general training from English composition greater than that from formal logie, the training from physics and chemistry greater than that from geometry, and the training from a year's study of the laws and institutions of the Romans greater than that from equal study of their language. The gramatical studies which have been considered the chief depositories of disciplinary magic would be found in general inferior to scientific treatments of human nature as a whole. The superiority for discipline of pure over applied science would be referred in large measure to the fact that pure 
science could be so widely applied. The disciplinary value of geometry would appear to be due, not to the simplicity of its conditions, but to the rigor of its proofs; the greatest disciplinary value of Latin would appear in the case, not of those who disliked it and found it hard, but of those to whom it was a charming game." (111).

The practical conclusion. What shall we say in the face of the facts known at the present time except that the only wise course is to accept the theory of specific instead of the theory of general improvement as the basis of our course of study? There is nothing then to prevent us from trying to get all the disciplinary value possible from what is taught. Shall we then teach more science instead of so much Latin? The objection rises immediately that science is not so well taught. This is undoubtedly true. But the course for educators is plain. Not to continue that which happens to be well taught now but to see that other subjects are as well taught.

Above all we must get away from the old incorrect notion that the mind is a collection of faculties whose 'general training' is possible. We must try to do that which is psychologically possible, practical and most valuable, not that which is dictated by the prejudice of tradition. The verdict of psychology is that we need to have a clear statement of aims, so that we may adapt definite methods for their accomplishment, and that the improvement above everything else, is, for the most part, in the thing practised, and as to the influence "carried over' into another field, it is little and may be either to improve or to impair.

The aim of the business man, of the scientist, of the manufacturer, is for definite results. The student and the educator must learn the lesson.

\section{QUESTIONS AND SUGGESTIONS FOR STUDY.}

1. Discuss the need for definiteness of aim in the work of the teacher.

2. Carefully define the aims for two or three subjects with which you are most familiar.

3. How must the binding force of tradition be wisely counter-balanced by consideration of social values?

4. What is the difference in the value of Latin as a school subject at the present time and at the time when it was put into the curriculum? 
5. Just what attitude should we take towards the teaching of a subject like Latin in the schools? Should we argue for or against it, or try to find exactly its social value, or try to compare it in social value with other subjects?

6. How may the influence of the schools and colleges actually be for poor English rather than for good English? Show in terms of the principle of habit formation.

7. How far can the principle of habit help us to the much needed definiteness in educational practice?

8. Discuss the possibility of making the aims and results of education comparable in definiteness with those of other kinds of big business. 


\section{SELECTED BIBLIOGRAPHY.}

\section{INTRODUCTION TO PSYCHOLOGY.}

1. H. Ebbinghaus. An Outline of Psychology. Tr. by Max Meyer. 1908. D. C. Heath and Co.

2. W. James. Psychology. Briefer Course. 1892. Henry Holt and Co.

3. W. James. Talks to Teachers. 1904. Henry Holt and Co.

4. E. B. Titchener. A Beginner's Psychology. 1916. The Macmillan Co.

\section{INTRODUCTION TO LEARNING AND STUDY.}

1. S. S. Colvin. The Learning Process. 1911. The Macmillan Co.

2. G. V. N. Dearborn. How to Learn Easily. 1916. Little, Brown and Co.

3. J. Dewey. How We Think. 1910. D. C. Heath and Co.

4. L. B. Earhart. Teaching Children to Study. 1909. Houghton, Mifflin Co.

5. A. L. Hall-Quest. Supervised Study. 1916. The Macmillan Co.

6. O. M. Jones. Teaching Children to Study: The Group System. Applied. 1910.

7. F. M. McMurny. How to Study and Teaching to Study. 1909. Houghton, Mifflin Co.

8. G. F. Swain. How to Study. 1917. McGraw-Hill Book Co., Inc. REFERENCES OF A TECHNICAL NATURE.

1. G. E. Jones. Training in Education. University of Pittsburg Bulletin. Vol. 12. No. 17. July 15, 1916.

2. E. Meumann. The Psychology of Learning. Tr. by J. W. Baird. 1913. D. Appleton and Co.

3. E. L. ThonNDIKE. The Psychology of Learning. Vol. 2 of his Educational Psychology. 1913. Teachers College, Columbia University. Or, his Educational Psychology, Briefer Course, 1915.

4. The Journal of Educational Psychology. Vols. 1 to present.

BIBLOGRAPHY OF REFERENCES USED IN TEXT.

1. American Textbook of Physiology. 2nd Ed. W. B. Saunders. 1901. Vol. 2, 294.

2. Same, 295.

3. ANGEll, J. R. Psychology. H. Holt and Co. 1908. 73-76.

4. Same. 66

5. Same. $159,196-7,206-7,220-1,224,287-8,294,361,365,410,414$, $419,430,433-7$.

6. Same. 436-7.

7. Same. 338-9.

8. Bagley, W. C. The Educative Process. The Macmillan Co. 1906. Ch. 14 .

9. Same. 212-13.

10. Book, W. F. The Psychology of Skill: with Special Reference to its Acquisition in Typewriting. University of Montana Publications in Psychology. Bulletin No. 53. Psychological Series No. 1. 178-9.

11. Breslich, E. R. Teaching High School Pupils How to Study. School Review. 20: 1912. 505-515. 
12. Brown, J. C. An Investigation of the Value of Drill Work in the Fundamental Operations of Arithmetic. Journal of Educational Psychology. 3: 1912. 485-492, 561-570.

13. Brown, R. W. How the French Boy Learns to Write. Harvard University Press. 1915. $86 \mathrm{ff}$.

13a. Bryan, W. L. and HARTer, N. Studies in the Physiolog! and Psychology of the Telegraphic Language. Psychological Review. 4: $1897,49$.

14. Carpenten, W. B. Mental Physiology. 1874. $339 \mathrm{ff}$. 70.

15. Colvin, S. S. The Learning Process. The Macmillan Co. 1911.

16. Same. $45 \mathrm{ff}$.

17. Conrad, H. E. and Arps, G. F. An Experimental Study of Economical Learning. American Journal of Psychology. 27: 1916. 507-529.

18. Connelu, W. S. Health and Medical Inspection of School Children. F. A. Davis. 1912.

19. Creighton, J. E. An Introductory Logic. The Macmillan Co. 1910. 203-204.

20. Dallenbach, K. M. The Effect of Practice Upon Visual Apprehension in School Children. Journal of Educational Psychology. 5: 1914 . 390 .

21. Dearbonn, W. F. Experiments in Learning. Journal of Educational Psychology. 1: 1910. 384-7.

22. Drake, D. The Acceleration of Moral Progress. The Science Monthly. June, 1916. 605-6.

23. Dumville, E. and Lewis, E. O. Silent and Concerted Learning. Journal of Educational Psychology. 4: 1913. 356-361.

24. EDwand, A. S. The Distribution of Time in Learning Small Amounts of Material. Studies in Psychology: Titchener Commemorative Volume. L. N. Wilson, Worcester, Mass. 1917. $209 \mathrm{ff}$.

25. Same. Directing Study in the School Room. High School Quarterly. April, 1917. $158 \mathrm{ff}$.

26. Ellwoon, C. A. Sociology and its Psychological Aspects. D. Appleton and Co. 1912. 78.

27. Fisher, I. and Fisk, E. L. How to Live. Funk and Wagnalls. 1916. 171-174.

28. Fosten, W. S. The Effect of Practice L'pon Visualizing, etc. Journal of Educational Psychology. 2: 1911. 11.

29. Hall, G. S. A Study of Anger. American Journal of Psychol. ogy. July, 1899. 10: 516-591.

30. Same. A Study of Fears. American Journal of Psychology. Jan. 1897. 8: 147-249.

31. Hethenington, C. W. The Demonstration Play School. University of California Publications. Vol. 5, No. 2. 1914. 241-288.

31a. Hollingwonth, H. L. Correlation of Abilities as Affected by Practice. Journal of Educational Psvchologv. 4: 1913. 405-414.

32. Hosic, J. F. Reorganization of English in Secondary Schools. Bull, 1917. No. 2. Bureau of Elucation, Washington, D. C.

33. James, W. Principles of Psychology. Henry Holt and Co. 1902. $1: 105-6$.

34. Same. 1: $110 \mathrm{ff}$.

35. Same. 1: 566 .

36. Same. 1: 589 .

37. Same. 1: 593-4.

38. Same. 1: 125-6.

39. Same. 1: 666-7.

40. James, W. Principles of Psychology. Henry Holt and Co. 1907. Briefer Course, 150. 
41. Same. Chapter on Habit.

42. Same. Talks to Teachers on Psychology. Henry Holt and Co. 1904. 64-66.

43. Same. 76 .

44. Same. Chapter on Interest.

45. Jevons, W. S. The Principles of Science. The Macmillan Co. 1907. 2 .

46. Same. 228, 9, 736-7.

47. Same. 745 ff.

48. Johnson, G. E. An Educational Experiment.'Pedagogical Seminary. Vol. 6. No. 4. 1899. 513-522.

49. Jones, G. E. Training in Education. University of Pittsburg Bulletin. Vol. 12. No. 17. July 15, 1916. 66-104.

50. Same. 66 .

51. JudD, C. H. The Psychology of High School Subjects. Ginn and Co. 1915. 412-414.

52. Same. Measuring the Work of the Public School. In the Cleveland Survey Series. W. F. Fell Co., Phila. 1916. 57.

53. KirkPATRICK, E. A. An Experiment in Memorizing versus Incidental Learning. Journal of Educational Psychology. 5: 1914. 405-6.

54. LADD and Woodworth. Elements of Physiological Psychology. 1900 .

55. Same. 566-72.

56. Lakenan, M. E. The Whole and Part Methods of Memorizing Poetry and Prose. Journal of Educational Psychology. 4: 1913. 189-98.

57. Same. 189-98.

58. LEE, F. S. Recent Progress in our Knowledge of the Physiological Action of Atmospheric Conditions. Science. New Series. Vol. XLIV. Aug. 11, 1916. 183-90.

59. MaNn, F. J. Eye Strain and Retardation in School Life. School and Society. Vol. 3, Jan. $1916.33-36$.

60. MEAD, A. R. Transfer of Spelling Vocabulary. Journal of Educational Psychology. 8: 1917. 41-44.

61. MEAD, C. D. Results in Silent versus Oral Reading. Journal of Educational Psychology. 8: 1917. $367 \mathrm{ff}$.

62. McDougall, W. An Introduction to Social Psychology. 9th Ed. 1915.116.

63. Same. 348.

64. Merriam, J. L. How well may Pupils be Prepared for High School Work without Studying Arithmetic, Grammar, etc., in the Grades? Journal of Educational Psychology. 6: 1915. 361-2. Or, Educational Review, April, 1909.

65. Meuman, E. The Psychology of Learning. Tr. by Baird. D. Appleton and Co. 1910. Chapter 1.

66. Same. Chapter 1.

67. Same. 267-9.

68. Same. 233 ff.

69. Same. $233 \mathrm{ff}$.

70. Mulhall, Miss. American Journal of Psychology. 26: 1915.

$219 \mathrm{ff}$. Murphy, H. H. Distribution of Practice Periods in Learning. Journal of Educational Psychology. 7: 1916. $150 \mathrm{ff}$.

72. OfFNer, M. Mental Fatigue. Tr. by Whipple. Warwick and York. 1911.

73. Parker, S. C. Methods of Teaching in High Schools. Ginn and Co. 1915. Chapter XIII.

74. Same. 403, 411. 
75: Patrick and Gilbert. Psychological Review. 1896. Vol. 3, No. 5.

76. Pearson, K. Grammar of Science. Part 1. 3rd Ed. 1911. 138. See also $130-34,136,150$.

77. Same. 7 footnote.

78. Peterson, J. Psychological Review. 23: No. 2 Mch. 1916. $153 \mathrm{ff}$.

79. Phillips, F. M. Value of Daily Drill in Arithmetic. Journal of Educational Psychology, 4: 1913. 159-163.

80. Pyle, W. H. Economical Training. Journal of Educational Psychology. 4: 1913. 148-158.

81 . Same. 5: 1914. 247-268.

82. Pintner, Kudolf and Gilliland, A. R. Oral and Silent Reading. Journal of Educational Psychology. 7: 1916. 210.

82a. Pintner, Rudolf and Paterson, Donald, G. A Class Test with Deaf Children. Journal of Educational Psychology, 6: 1915, 597.

83. Radestock, P. Habit and Education. Tr. by Caspari. D. C. Heath. 1914.

84. Same. 71-2.

85. Rapeer, L. W. The Problem of Formal Grammar in Elementary Education. Journal of Educational Psychology. 4: 1913. 125-37. 86. Reports of the Trustees of Independent Industrial Schools, Worcester, Mass. City Documents: No. 66, 1911; No. 67, 1912; No. 68, 1913.

87. Ross, E. A. Social Psychology. The Macmillan Co. Chapter on Custom and Imitation. Also, 94, 196, 274.

88. SeAshone, C. E. The Midday Nap. Journal of Educational Psychology. 1: 1910. 293.

89. SMiтн, A. Moral Sentiments. 6: 3.

90. Snedden, David. Problems of Secondary Education. Houghton, Mifllin and Co. 1916. 124 .

91. Same. 163-4.

92. Spencer, H. The Principles of Psycholog!. 1893. Vol. 1. 245.

92a. Starch, Daniel. Periods of Work in Learning. Journal of Educational Psychology. 3: 1912. 209-213.

93. Sumner, W. G. Folkways. 1913, iv. Also, Chapters 1 and 2. 94. Swift, E. J. Youth and the Race. Charles Scribner's. 1912. 95. Same. Studies in the Psycholog!y and Physiolog! of Learning. American Journal of Psychology. 14: 1903. $201 \mathrm{ff}$. 29.

96. Sully, JAmes. Outlines of Psycholog!y. D. Appleton. 1915,

97. Same. 120-1.

98. Same. 124 .

99. Same. 437-38.

100. Same. 473.

101. Same. 473.

102. Same. 483.

103. Same. 350-52.

104. Same. 369-70.

105. Same. 470-85.

106. TARDE, G. The Laws of Imitation. 1903. 7, 14, 137, 138, 366. footnote, 369 .

107. TAYLOR, A. E. Elements of Metaphysics. 1903. 238.

108. Terman, L. M., and Hocking, Adelaide. The Sleep of School

Children: Its Distribution, etc. Journal of Educational Psychology.

4: 1913 . $138-147 ; 199-208 ; 269-282$.

109. Thondike, E. L. Educational Psychology. Vol. 2. The 
Psychology of Learning. Teachers College, Columbia University, 1913, 199.

110. Same. 326-7.

111. Same. 424.

112. Same. Mental Fatigue. Journal of Educational Psychology. 2: 1911. 61-68.

112a. Same. Practice in the Case of Addition. American Journal of Psychology. 21: 1910. 483-486.

113. Titchener, E. B. A Beginner's Psychology. The Macmillan Co. 1916. 98-99.

114. Same. 170-71.

115. Same. $93 \mathrm{ff}$.

116. Same. A Primer of Psychology. The Macmillan Co. 1907, 79.

117. Same. 136-8.

118. Same. A Textbook of Psychology. The Macmillan Co. 1916. 274-5.

119. Same. 497.

120. Whipple, G. M. How to Study Effectively. School and Home

121. Woonnow, H. H. Practice and Transference in Normal and Feeble-minded Children. Journal of Educational Psychology. 8: Education. Jan., Mch., and Apr., 1916. Also same published in book form by Public School Publishing Co., Bloomington, Ill., 1916-7.

1917. Part 1: Practice, $85 \mathrm{ff}$; Part 2: Transference, $151 \mathrm{ff}$. 


\section{N D E X}

$\therefore$ ffective expansion, $\mathrm{I} 5 \mathrm{I}$.

Affective habits, Ch. I4 .

Agassiz, 78.

Age and learning, 7I.

Air, I88ff.

Analogy, 8o.

Angell, J. R., 27.

Appeal, means of for teacher, I44ff. case studies of successful appeals, I $47 \mathrm{ff}$.

"Apperception," 67.

Assignments, length of, I36f, and interest, $153 \mathrm{f}$.

Association Chs. Io and II; also II8, I 26, and feelings, 178 ; cramming, I $26 \mathrm{f}$ : interest, I52.

Attention, and sustained effort $\mathrm{Ch}$. I3: kinds of, I59; conditions of, I5), and distraction, I65; hindrances to, I65ff; case studies, I $67 \mathrm{ff}$ : direction of, $\mathrm{I} / \mathrm{I}$; and control of action, I7I.

Attitude of student, I36.

Auditory defects, I 84 f.

Bagley, IV. C., III.

Body and mind, 184 .

Preslich, E. R., 196.

Brown, R. W., 226.

Bryan and Harter, 99.

Classification of pupils, IOI.

Coincidences, $79 \mathrm{f}$.

Colvin, S. S., 36, 104.

Completeness of response, $94 \mathrm{f}$.

Conversion of arguments, 82.

Cornell, IV. S., I84.

Corson, H., 79.

Cramming, 126f.

Curriculum, 47; and supervised study, Ch. $1 \%$

Curve of learning, 97.

Dallenbach, K. M., 87f.

Definiteness, need for in education, Ch. 18.
Deafness, I $85 \mathrm{f}$.

Defects, I84.

Diet, balanced, I87f.

Distribution of repetitions, I2I.

Division of time, I22; and reviews, 122.

Drake, D., I82f.

Drill, 87, I 19: and use, 89.

Dumville and Lewis, I37.

Duration, II9.

Education: permanent results, 12; of the individual, 13 ; and heredity, I4: three principles of, 19; means of, I9: the educative process, 20: greatest needs of, 20; basis of, Ch. 2: and Neurology, Ch. 2; ideals the guiding influence, 45 ; the controlling principle of, 46 ; definition of, 49 ; moral, I8Iff; need for definiteness in aim and method, Ch. I8.

Early training, 53 .

Empathy, 77.

English, 225ff.

Evening school study, 194.

Fatigue, I24, I65; feeling of, I66; and school hours, I92ff.

Feelings, 93: and habit, Ch. It; and action, $17 \%$ : and associations, I 78 .

Flexibility, and variety of habits, 32 . Food, i86ff.

Forcing for improvement, 105.

Forgetting, Ifo.

Formal discipline, see Transfer of Acquisitions, Ch. 9.

French schools, a lesson from, 226.

Frequency of repetition, I19, I29.

Gencral impressions, 79.

Grammar, I39.

Habit: as used in this book, II, 15; vs. automatism, I2; fixes and releases, I2: importance of Habit 
Theory, I5ff ; comprehensiveness of 15 ff., 24., 27, 40; fundamental nature of, 22 ; and thinking, $28 \mathrm{ff}$., and originality 29 ; plasticity and fixity, 3off.; variety of response, 33 ; initiative, 34 ; types of, 35 ; as fundamental in education, Ch. 3 ; and higher stages of efficiency, 38 ; includes permanent desires and interests, 39; and character, $4 \mathrm{I}$; as basis for measurement, 42 ; kinds of, 48 ; and learning, $5 \mathrm{I}$; needs for, $5 \mathrm{I}$; results of, 5If.; principles of habit formation, $54 \mathrm{ff}$; ; hindrances to, $58 \mathrm{ff}$.; breaking old habits, 6off.; and feeling, Ch. I4; moral, I8I.

Hardening period, 124.

Heredity, and education, I4.

Henmon, V. A. C., I36.

Home study habits, 196.

Humidity, I 89 .

Ideas and habits, 44.

Ideals, 18 ; the guiding influence in education, 45; and achievement, 45 ; as permanent motives, 46 .

Imitation, 68, 78 .

Improvability, Ch. 8; limits of 105.

Improvement, avoidance of misleading tendencies, Ch. 6; progress and improvability, Ch. 7 ; universality of, 86 ; regularity and persistence, 87 ; drill, 87 ; use, 89 ; definite practice, 90 ; correct practice, $9 \mathrm{I}$; critical attitude, $9 \mathrm{I}$; of methods, 92; feelings, 93; physical and physiological conditions, 94 ; Ch. 15; completeness of response, 94 ; in subnormals, 95 ; at different stages of learning, I00; and individual differences, IOI; and plateaus, Io2ff.

Individual differences, IOI.

Inherited tendencies and capacities, I 44.

Institncts, selfish, I46.

Initiative, 34.

Interest, I5Iff ; and effort, 156, and Ch. I3; development of, I79ff.

James, W., I7ff., 25, 28f, 4I, 92.

Jevons, W. S., I5ff.

Jones, G. E., $47 f$.

Jost's law, I2I.

Judd, C. H., II2, I97, 222.

Jumping to conclusions, 80 .
Kirkpatrick, E. A., 89.

Lakenan, M. E., I34, I36.

Language difficulties, 84 ; and habit vs. grammar, 139.

Latin, 223ff.

Learning, through the senses, 64 : through reasoning, 69; and age, $7 \mathrm{Iff}$; trial and error, 68, 78; progress and improvability, (Ch. 7; plateaus, etc., Ch. 8; the curve of, 97 ; permanence of, Chs. IO and II; rate of, $127 \mathrm{f}$; order of, I 37 ; silent vs. aloud, I37; and supervised study, Chs. is and 17.

Lee, F. S., 189.

Leuba and Hyde, 130.

McDougall, W., 16.

Mead, A. R., and study in English, 225.

Mead, C D. I37.

Memories, Chs. Io and II; modern conception of, II7; conditions of, II8; primary and secondary laws of, II 8 ; cramming, $126 \mathrm{f}$.

Merrian, J. L., 47.

Methods, improvement in 92, 118 .

Meumann, E., I 19, 128, -133, 135 .

Mind and body, 184f.

Motivation, Chs. I2 and 13.

Mnemonics, I38f.

Murphy, H. H., 129.

Nature of material, I32.

Neurology and education, Ch. 2.

Note-taking, $68 \mathrm{f}$.

Offner, M., 192.

Opportunity classes, IoI.

Parker, S. C., 73, 197.

Pearson, K., I5, II 12.

Perception, 64ff.

Permanence and kind of learning, I4I; see Memories; and the feelings, Ch. I4.

Persistence, 87.

Physical and physiological conditions, Ch. I5.

Pintner and Gilliland, I37.

Pitfalls for the student, Ch. 6.

Plateaus, Ch. 8; causes of, rozff.

Practice, $87 \mathrm{ff}$.

Prejudice, 76.

Primacy, I2I. 
Principles, three, of education, 19.

Prooress, see Improvement.

Purpose, 173.

Radestock, P., I3.

Radossawljewitsch, P. R., I40.

Rate of learning, $127 \mathrm{f}$.

Reading, 73.

Reasoning, learning by, $69 \mathrm{ff}$.

Recency, I2I.

Regularity, 87, 129.

Repetition, IIgff, distribution of repetitions, I2I.

Response, completeness of, $94 \mathrm{f}$.

Retention, see memory; immediate and permanent, 126.

Reviews, I22.

Short periods, $124 \mathrm{ff}$.

Silent learning, 137.

Size of units, 135 .

Slcep, 193.

Snedden, Darid, 222, 229.

Social values, 223.

Spencer, H., 16.

Standards, I8.

Stimulus and release of energy, I43.

Study, observational, 64 ff.; by reasoning, 69ff.; supervised, Chs. 16 and 17 ; suggestions for student, to be used by teacher, I98ff.; the teacher's responsibility, 205; pupil's study card, 206; and the curriculum. 206f; maxims for study of school subjects, $218 \mathrm{ff}$.

Suggestion, I5I.

Sully, J., 25, 30, 43.
Supervised study, see Study.

Swift, E. J., 100, 146.

Teacher, the work of, $25,43,143$; means of appeal, case studies, I $47 \mathrm{ff}$, I $59 \mathrm{ff}$; suggestions for students, to be used by the teacher, I $98 \mathrm{ff}$; responsibility in teaching how to study, 205.

Temperature, I 89.

Thinking, common tendencies, Ch. 6 .

Thorndike, E. L., $98 \mathrm{ff} .$, I4If., $229 f$.

Titchener, E. B., 25, 37, 52, 177.

Topical study, I32.

Tradition, and the curriculum, 223.

Transfer of acquisitions, Ch. 9 ; factors that complicate the discussion, I08; extent of, 108 ; nature of, 109; factors in, IIo; conditions of, III; Maxims, II3; and choice of subjects and teachers, II 4 f.

Trial and error, 68, $78 \mathrm{f}$.

Use, vs. drill, 89.

Visual defects, I85.

Vividness, 119.

Warming up period, I23.

Whipple, G. M., I\&9f, I93.

Whole and part method, I33; modification of whole method, I35.

Will, in moral training, $\mathrm{I} 8 \mathrm{I}$.

Woodrow, H. H., 95f.

Woodworth and Thorndike, III.

Work, change of, 19I, and fatigue, 191. 



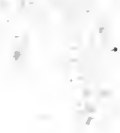





\section{DAY USE}

RETURN TO DESK FROM WHICH BORROWED

LOAN DEPT.

This book is due on the last date stamped below, or on the date to which renewed.

Renewed books are subject to immediate recall.

\begin{tabular}{|c|c|}
\hline $13 M 2 \cdot 58 w W$ & \\
\hline PrigD LD & \\
\hline HNG 1958 & \\
\hline 14Dec'58DF & \\
\hline RECD LD & \\
\hline UEt $3: y=0$ & \\
\hline 16 Nov'5 $\mathrm{S} J$ & \\
\hline REC'D LD & \\
\hline NOV 41959 & \\
\hline $9 N o \% 63 R V$ & \\
\hline REC'D LD & \\
\hline NOV 9'63-3PM & \\
\hline
\end{tabular}

LD $21 \mathrm{~A}-50 m-8, ' 57$

(C8481s10) 476B

General Library

University of California Berkeley 


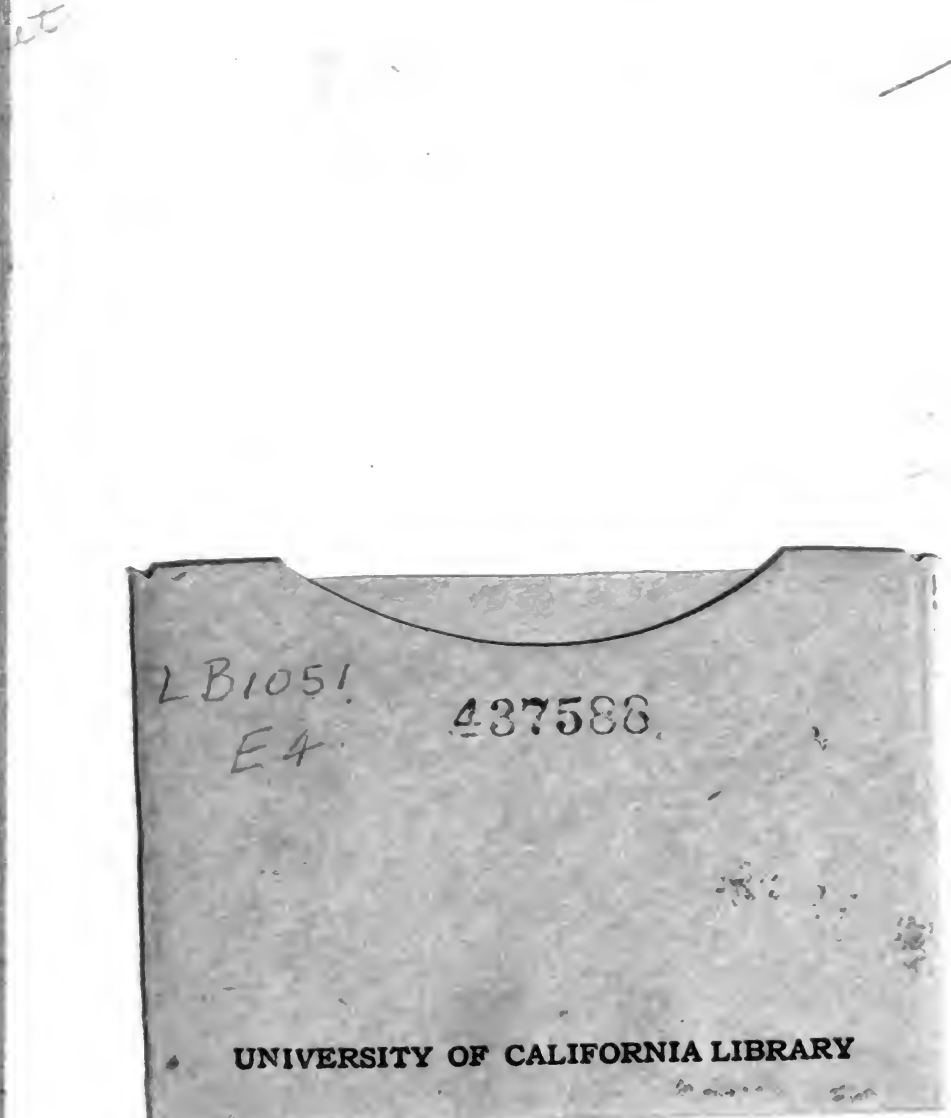




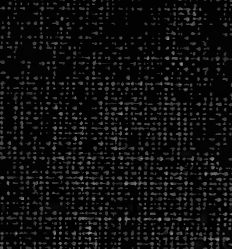

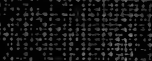

\%

(3)

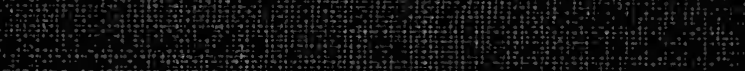

-

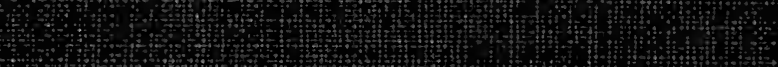

(M)

H.

(1)

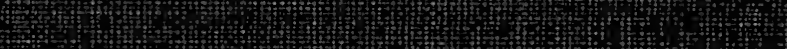

(1)

(1)

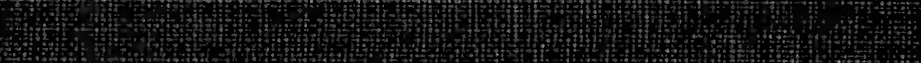
(3)

(1)

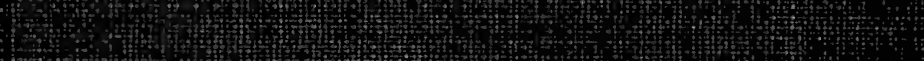

4.

(3)

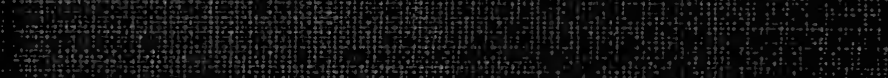

(3)

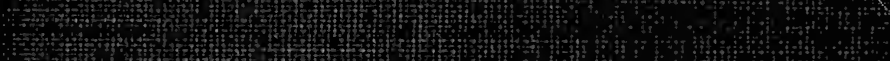

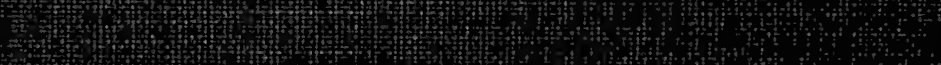

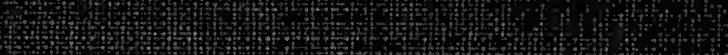

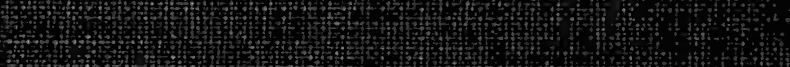

(3)

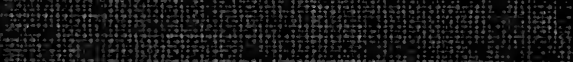

Som

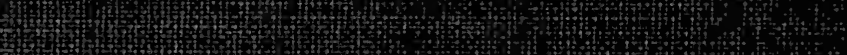

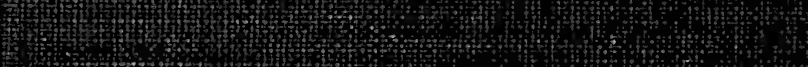

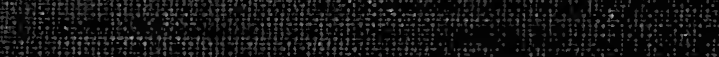

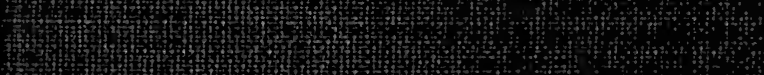

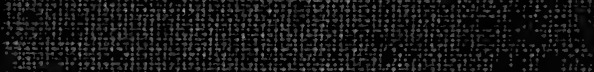

(3)

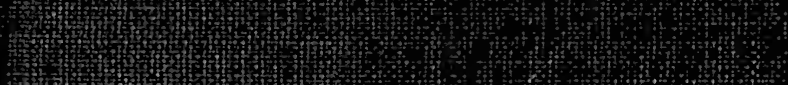

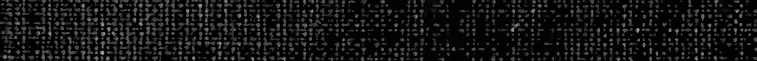

(3)

titis

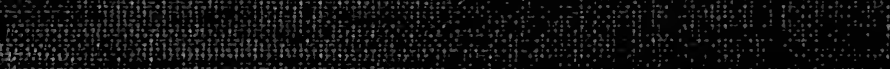

